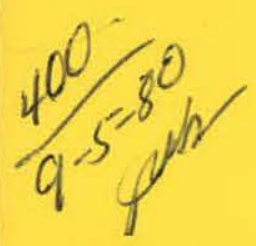

DR. 1702

ANL/OTEC-PS-6

\title{
OTEC-1 Power System Test Program: Test Plan for First Deployment
}

\section{MASTER}

DISTRIBUTION OF THIS DOCUMENT IS UALHAITE

\section{Ocean Thermal Energy Conversion \\ Program}

\section{Argonne National Laboratory}




\section{DISCLAIMER}

This report was prepared as an account of work sponsored by an agency of the United States Government. Neither the United States Government nor any agency Thereof, nor any of their employees, makes any warranty, express or implied, or assumes any legal liability or responsibility for the accuracy, completeness, or usefulness of any information, apparatus, product, or process disclosed, or represents that its use would not infringe privately owned rights. Reference herein to any specific commercial product, process, or service by trade name, trademark, manufacturer, or otherwise does not necessarily constitute or imply its endorsement, recommendation, or favoring by the United States Government or any agency thereof. The views and opinions of authors expressed herein do not necessarily state or reflect those of the United States Government or any agency thereof. 


\section{DISCLAIMER}

Portions of this document may be illegible in electronic image products. Images are produced from the best available original document. 
The facilities of Argonne National Laboratory are owned by the United States Government. Under the terms of a contract (W-31-109-Eng-38) among the U. S. Department of Energy, Argonne Universities Association and The University of Chicago, the University employs the staff and operates the Laboratory in accordance with policies and programs formulated, approved and reviewed by the Association.

\section{MEMBERS OF ARGONNE UNIVERSITIES ASSOCIATION}

The University of Arizona

Carnegie-Mellon University

Case Western Reserve University

The University of Chicago

University of Cincinnati

Illinois Institute of Technology

University of Illinois

Indiana University

The University of Iowa

Iowa State University
The University of Kansas

Kansas State University

Loyola University of Chicago

Marquette University

The University of Michigan

Michigan State University

University of Minnesota

University of Missouri

Northwestern University

University of Notre Dame
The Ohio State University

Ohio University

The Pennsylvania State University

Purdue University

Saint Louis University

Southern Illinois University

The University of Texas at Austin

Washington University

Wayne State University

The University of Wisconsin-Madison

NOTICE

This report was prepared as an account of work sponsored by an agency of the United States Government. Neither the United States Government or any agency thereof, nor any of their employees, make any warranty, express or implied, or assume any legal liability or responsibility for the accuracy, completeness, or usefulness of any information, apparatus, product, or process disclosed, or represent that its use would not infringe privately owned rights. Reference herein to any specific commercial product, process, or service by trade name, mark, manufacturer, or otherwise, does not necessarily constitute or imply its endorsement, recommendation, or favoring by the United States Government or any agency thereof. The views and opinions of authors expressed herein do not necessarily state or reflect those of the United States Government or any agency thereof.

Printed in the United States of America

Available from

National Technical Information Service

U. S. Department of Commerce

5285 Port Royal Road

Springfield, VA 22161

NTIS price codes

Printed copy: A08

Microfiche copy: A01 
ANL/OTEC-PS-6

ARGONNE NATIONAL LABORATORY

9700 South Cass Avenue

Argonne, Illinois 60439

OTEC-1 POWER SYSTEM

TEST PROGRAM:

TEST PLAN FOR FIRST DEPLOYMENT

\section{Prepared by}

Ocean Thermal Energy Conversion Program

Argonne National Laboratory

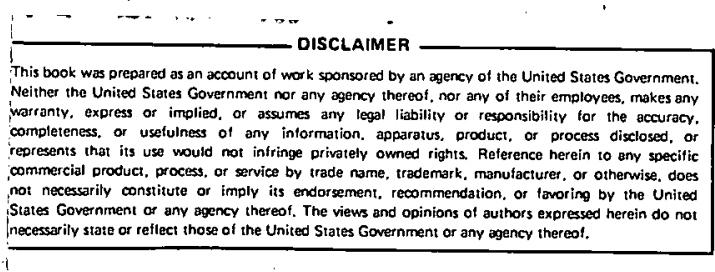

March 1980

The Argonne Ocean Thermal Energy Conversion Program

is a joint effort of the

Energy and Environmental Systems Division

and Components Technology Division

$$
\text { sponsored by }
$$

U.S. Department of Energy

Assistant Secretary for Energy Technology

Division of Central Solar Technology 
FOREWORD AND ACKNOWLEDGMENTS

Ocean Thermal Energy Conversion (OTEC) is a technology for producing electrical energy from the solar: energy collected and stored as heat in warm ocean water. Although OTEC has the potential of providing a considerable fraction of the U.S. power requirements in the coming decades, there are a number of: technical advances that must be made before OTEC becomes costcompetitive with conventional sources of electrical power. To this end, a "sizeable development program for OTEC power-plant components and systems is being undertaken by the U.S. Department of Energy. The cornerstone of this development program is currently the OTEC-1 test facility, which is to be deployed near Hawaii in the summer of 1980. 'This facility will be used for conducting performance tests of OTEC heat exchangers and biofouling countermeasures and for obtaining data on the environmental impacts associated with OTEC power-plant operation.

As part of its support of the Department's OTEC program, Argonne was asked in November of last year to prepare a plan for the first-deployment test program for the OTEC-1 facility. This document, the result of that request, is the work of the following persons from Argonne and other laboratories that participate in the OTEC-1 program:

Argonne National Laboratory

$\begin{array}{lll}\text { P. Benson } & \text { P. Gavin } & \text { D. McCown } \\ \text { F. Davis } & \text { D. Hillis } & \text { N. Sather } \\ \text { J. Ditmars } & \text { T. Kuzay } & \text { A. Thomas } \\ \text { J. Draley } & \text { J. Lorenz } & \text { D. Yung }\end{array}$

Energy Technology and Engineering Center.

F. Poucher

A. Klein

Lawrence Berkeley Laboratory

P. Wilde

In addition, the test plan had the benefit of written contributions from a number of persons who reviewed it prior to publication, most notably 
the following: $K$. Bell of Oklahoma State University, F. La Que (private consultant), R. Glumace of the Energy Technology and Engineering Center, R. Mitchell of Harvard University, and L. Toth of Alexander Systems Company. Others who reviewed the test plan were. K. Read of the U.S. Naval Academy; J. Michel of Oak Ridge National Laboratory; A. Lavi of ERDI, Inc.; R. Scotti of NOAA; Frank Herbaty. of the DOE Chicago Office; D. Neely, J. Hartman, and R. Salazar of the DOE San Francisco Office; and the staff of the DOE Ocean Energy Systems Division, including S. Gronich, L. Lewis, and E. Kinelski. Assistance in the preparation of the manuscript was provided by editors F. Bennett and $K$. Macal. The entire project was under the direction of N. Sather, Director of Solar Technology Programs at Argonne. 
ABSTRACT . . . . . . . . . . . . . . . . . . . . . .... 1

1 INTRODUCTION . . . . . . . . . . . . . . . . . . . . 1

1.1 Purpose of the Test Plan. . . . ................. . 1

1.2 Scope of the Test Plan. . . . . . . . . . . . . . . . . 2

1.3 Organization of the Test Plan ............... 2

2 GOALS AND PRIORITIES . . . . . . . . . . . . . . . . . . . . . 3

2.1 Test Program Objectives.................. 3

2.2 Essential Tests..................... 3

2.3 Other Tests........................ 5

3 DESCRIPTION OF THE OTEC-1 TEST FACILITY. . . . . . . . . . . . . . . 7

3. J. Platform and Cold Water Pipe. . . . . . . . . . . . . . . 7

3.2 Sea Water Systems . . . . . . . . . . . . . . ...... 10

3.31 MWe Evaporator and Condenser. . . . . . . . .. . . . . . . 13

3.4 The Ammonia System. . . . . . . . . . . . . . . . . . . . . . . 20

3.5 Biofouling Cleaning System. . . . . . . . . . . . . . . . 27

3.6 Biofouling and Corrosion Modules. . . . . . ... . . . . . . 30

3.7 Instrumentation, Data Acquisition, and Processing . . . . . . 35

3.8 Support Facilities. . . . . . . . . . . . . . . . 43

4 PROPOSED TESTS AND EXPERIMENTS . . . . . . . . . . . . . . . . 45

4.1 Evaporator and Condenser Tests............... . 45

4.2 Biofouling-Countermeasures-and-Corrosion Program. . . . . . . . 68

4.3 Environmental Measurements. . . . . . . . . . . . . . . . . 83

4.4 Ocean Engineering Tests . . . . . . . . . . . . . . . . . . . . 94

5 TEST SCHEDULE AND PLANS FOR UNSCHEDULED INTERRUPTIONS. . . . . . . . 97

5.1 Test Schedule... . . . . . . . . . . ........ . 97

5.2 Plans for Unscheduled Test Interruptions. . . . . . . . . . . 99

6 DIRECTION OF THE EXPERIMENTAL PROGRAM. . . . . . . . . . . . . . 109

6.1 Responsibilities. . . . . . . . . . ...... 109

6.2 Test Plan..... . ................... 112

6.3 The Data Flow Process . . . . . . . . . . . . . . . . 112

6.4 Test Status Evaluation. . . . . . . ........... . . 113

6.5 Deviations from the Test Plan . . . . . . ........ . 115

6.6 Summary . . . . . . . . . . . . . . . . . . 117

REFERENCES. . . . . . . . . . . . . . . . . . . . . . . . 119

APPENDIX A: ERROR ANALYSIS . . . . . . . . . . . . . . . . . . 121

APPENDIX B: DATA REDUCTION: EVAPORATOR AND. CONDENSER PERFORMANCE. • . 129 


\section{LIST OF FIGURES}

No.

3.1 Water Circuits. . . . . . .............. 11

3.2 Sampling Stations Schematic . . . . . . . . . . . . . 12

3.3 1-MWe Power Loop OTEC-1 Interfaces. . . . . . . . . . . . . . . . 15

3.4 Evaporator Design . . . . . . . . . . . . . . . . . . 17

3.5 Condenser Design. . . . . . . . . . . . . . . . . . . 19

3.6 Three Types of Water Test Loops . . . . . . . . . . . . . . 21

3.7 Test Loop Process Flows ... . . . . . . . . . . . . . 23

3.8 Evaporator Reflux Loop Pump Arrangement . . . . . . . . . . . 25

3.9. Condensate Return Pump Characteristics. . . . . . . . . . . . 26

3.10 Chlorine Generator Subsystem. . . . . . . . . . . . . . . 28

3.11. Amertap Subsystem . . . . . . . . . . . . . . . . 29

3.12 Biofouling and Corrosion Test Module. . . . . . . . . . . . . . 31

3.13 Heat-Transfer Monitor . . . . . . . . . . . . . . . 32

3.14 DAS Processing Block Diagram. . . . . . . . . . . . . . . . 36

4.1 Heat Exchanger Configurations . . . . . . . . . . . . . . . 47

4.2 Outlet Waterbox View of Instrumented Tube Locations.
in the Evaporator......... . . . . . . . . . . . . . . .

4.3. Outlet Waterbox View of Instrumented Tube Locations
in the Condenser. . . . . . . . . . . . . . . . 58

4.4 Proposed Stations during Hydrocruises . . . . . . . . . . . . . 90

5.1 OTEC-1 Test Schedule... . . . . . . . . . . . . . . . 98

6.1 Organization of the OTEC-1 Test Program . . . . . . . . . . 110

6.2 oteC-1 Data Flow Diagram.................... . . 114 


\section{LIST OF TABLES}

No:

Titlè

Page

3.1. Design Requirements of the Heat Exchangers . . . . . . . . . . . 14

3.2 Evaporator Characteristics . . . . . . . . . . . . . 16

3.3. Condenser Characteristics. . . . . . . . . . . . . . . . 18

3.4 System Design Parameters . . . . . . . . . . . . . . . 22

3.5 Biofouling and Corrosion Module. . . . . . . . . . . . . . . 34

3.6 Instrumentation Requirements ................... . . . . . 38

4.1. Nominal Test Conditions for the Evaporator and the Condenser . . . 48

4.2 Uncertainties in Calculated Quantities . . . . . . . . . . . :49

4.3 Predicted $U_{o}$ vs $R_{f}$ for Evaporator and Condenser. . . . . . . . . . 53

4.4 Reflux Ratio Tests ....................... . . . 61

4.5 Test Matrix for Biofouling and Corrosion Modules . . . . . . . . 70

4.6 OTEC Biofouling Countermeasures Test Matrix in Hawaiian Water, 1980. . . . . . . . . . . . . . . . 73

4.7 Sampling and Routine Water Characterization on OTEC-1. . . . . . . 81

5.1 Summary of Test Interruptions Due to Equipment Failures. . . . . 101 
OTEC-1 POWER SYSTEM TEST PROGRAM.

Test Plan for First Deployment

ABSTRACT

This report describes in detail ail tests planned for the first eight-month deployment of OTEC-1, a test facility constructed by the U.S. Department of Energy in order to test heat exchangers for closedcycle power plants using ocean thermal energy.

Tests to be performed during the first-deployment period are aimed primarily at determining (1) the effectiveness of countermeasures in preventing biofouling of the heat exchangers, (2) the extent of environmental impacts associated with operation of an OTEC facility, and (3) the performance of a 1-MWe, titanium she11-andtube evaporator and condenser pair. The condenser to be tested has plain tubes, and the evaporator employs the Linde High Flux surface on the working-fluid (ammonia) side to enhance the heat-transfer rate.

This plan provides a statement of the objectives and priorities of the test program, describes the test equipment, gives a detailed account of all tests to be performed and the test schedule, and discusses provisions for management of the test program.

\section{INTRODUCTION}

\subsection{PURPOSE OF THE TEST PLAN}

The purpose of this test plan is to describe comprehensively and in detail the power system test program for the first deployment of the OTEC-1 test facility. The plan will be used by those directing the week-to-week operation of the test program and by the on-board engineering staff conducting the day-to-day test activities. Because it is impossible to foresee all upsets to the test program from such problems as equipment malfunction or weather disturbances, the plan is intended as a guide rather than a rigid schedule. It emphasizes the goals and priorities of the test program so that, as unexpected problems arise, the best possible changes in the test program can be made with minimum loss of operating time. 
$\dot{A}$ great deal has already been written about the OTEC-1 test program. In particular, the OTEC-1 Test Request (dated October 15, 1979) prepared by the Energy Technology and Engineering Center (ETEC) contains considerable information about the OTEC-1 test objectives, schedules, and methods, as wel1 as the kinds of test results expected. The test plan described herein begins where the Test Request leaves off; translating the background material of the Test Request into a detailed and specific test plan appropriate to the needs of the Test Director Contractor (ETEC) and the Experimenter Group. ETEC is preparing manuals of the step-by-step procedures for conducting the tests. 'The test plan is intended to be the link between the Test Request and the procedures manuals.

\subsection{SCOPE OF THE TEST PLAN}

The test plan covers the power system tests to be conducted during the first deployment of OTEC-1, currently scheduled for the period August 1980 to April 1981. Thus, the plan covers only the heat exchanger tests with the 1-MWe titanium-tubed evaporator and condenser (provided under contract to TRW) and the biofouling countermeasures tests and environmental measurements planned for the first deployment. The tests planned for the second deployment of OTEC-1 will be described in a sequel. to this document to be issued in 1981 .

\subsection{ORGANIZATION OF THE TEST PLAN}

The general goals and priorities of the test program are described in Section 2 of the test plan. Section 3 summarizes the pertinent features of the OTEC-1 test facility, including the power system equipment onboard, the various experimental modules, the measurement instrumentation, and the data-handing system. The proposed tests for the first deployment of 0TEC-1 are described in detail in Section.4, as are the procedures to be used for calculating the heat transfer coefficients, biofouling resistances, and other measures of performance. The target schedule for the test program is laid out in Section 5, which also discusses contingency actions to be taken in the event of unscheduled test interruptions. Finally, Section 6 describes the arrangement for organizing the functions of the Test Director Contractor and the Experimenter Group into a management system to monitor and direct the day-to-day operation of the test program. 


\section{GOALS AND PRIORITIES}

\subsection{TEST PROGRAM OBJECTIVES}

The objectives of the power system tests during, the first deployment of OTEC-1 are:

- To evaluate the thermal-hydraulic performance of the 1-MWe shell-and-tube evaporator and condenser operated with sea water on an ocean-based plat form.

- To evaluate the short-term effectiveness of the Amertap system. in combination with intermittent chlorination for controlling microfouling of plain-tube OTEC heat exchangers and to assess intermittent chlorination for preventing macrofouling in the heat exchangers and adjacent sea water system components.

- To determine the impact of the OTEC-1 platform and the operation of the power system on the ambient ocean environment and to use this information to develop environmental guidelines for the planned OTEC pilot plant and other. future OTEC plants.

\subsection{ESSENTIAL TESTS}

It is necessary to distinguish between tests that are crucial to meeting the objectives of the test program and those that provide important, but not essential, additional information. In planning and carrying out the test program, the essential tests are assigned the highest priority, and the other tests are to be completed in order of decreasing priority as time permits. Under no circumstances should the first deployment test period be prolonged to complete nonessential tests; however, if the essential tests cannot be finished within the time allotted for the first deployment, extending the test period as necessary to allow their completion will be considered.

With reference to the general objectives of the first deployment test program listed above, the essential tests are as follows:

\section{Heat Exchanger Tests}

- Baseline thermal-hydraulic tests of the 1-MWe sprayedbundle evaporator and the 1-MWe condenser for the purpose of verifying performance predictions. 
- Variable ammonia feed rate tests on the evaporator to determine the optimum ammonia reflux ratio.

- Tests with the evaporator in a flooded-bundle configuration to obtain thermal performance data to compare with the performance of the evaporator operated as a sprayedbundle unit.

\section{Biofouling Countermeasures Tests}

- Tests to determine whether biofouling countermeasures that meet current EPA point-source emission guidelines are effective. These tests will involve operating each heat exchanger with a chlorine concentration in the sea water of $0.4 \mathrm{ppm}$ for a one-hour period each day and with a round-the-clock Amertap ball mean frequency of one ball every 15 minutes.

- Tests with special biofouling and corrosion modules using. different countermeasure levels for guidance in changing the heat exchanger countermeasures conditions, if necessary. Additional data from nearby tests at the Seacoast Test Facility and Mini-OTEC, when available, will be used for guidance in planning these changes.

- Tests to determine the character and quantities of macrofouling at selected locations in the sea water system for use in planning macrofouling control measures for future OTEC plants.

Environmental Impact Tests

- Sampling and analysis of the OTEC-1 effluents at the locations and frequencies required by the EPA operating permit.

- Monitoring currents and temperatures in the water column and surface waves from moored instruments in the vicinity of the OTEC-1 vessel and monitoring meteorological parameters from the ship deck. for use in both environmental and ocean engineering assessments.

- Sampling and analysis of important physical, chemical, and biological parameters in the ambient ocean at several stations in the region of influence of OTEC-1. These tests are to be conducted at two-to-four month intervals before, during, and after deployment. Locating and sampling the mixed-discharge effluent plume will be at tempted.

- Sampling and analysis of the raw sea water taken into the heat exchangers and found at the mixed discharge sump will be done concurrently with the preceding test. so that estimates of the effluent loadings to the ambient ocean can be made. 


\subsection{OTHER TESTS}

- Deactivation/reactivation tes.ts of the Linde High Flux tube surface of the evaporator in both the sprayed-bundle and flooded-bundle configurations:

- Water flow rangeability tests to diagnose causes of unexpected heat exchanger performance. This will entail determining the individual ammonia- and water-side heat transfer coefficients by the Wilson procedure.

- Tests to determine the effect of water in ammonia on the thermal performance of the sprayed-bundle evaporator.

- Contingency chlorination or Amertap tests, or both, at increased levels if necessary to prevent macrofouling and to control the microfouling thermal. resistance to the target level of $0.0002\left(\mathrm{Btu} / \mathrm{hr} \cdot \mathrm{ft}^{2} \cdot{ }^{\circ} \mathrm{F}\right)^{-1}$. 
THIS PAGE

\section{WAS INTENTIONALLY \\ LEFT BLANK}




\section{DESCRIPTION OF THE OTEC-1 TEST FACILITY}

\subsection{PLATFORM AND COLD WATER PIPE}

The U.S. Navy T2-SE-A1 turboelectric-driven tanker Chepachet (TAO-78) was obtained from the National Defense Reserve Fleet in Suisun Bay, California, for conversion to the OTEC-1 test platform. It was modified at Port1 and, Oregon.

Chepachet was built in 1943 at the Sun Shipbuilding and Dry Dock Company in Chester, Pennsylvania. It was designed for oil supply service to combat zones and naval bases, and was in service as a Military Supply Tanker Ship (MSTS) until deactivation in 1972 .

The rehabilitation and conversion of Chepachet followed the applicable regulations of the U.S. Coast Guard and the American Bureau of Ships (ABS). The ship is now classified as an oceanographic research vessel. It operates with a reduced draft of about $25 \mathrm{ft}$ at a displacement of about 18,500 tons. The freeboard has been established at approximately $16 \mathrm{ft}$ to provide a dry operating deck under all operating conditions. Ballasting ensures a stable and level working platform in the deployed mode, which includes the mooring load.

Because Chepachet has ample quarters, the entire midship house will be assigned to serve OTEC-1 test program personnel and operating functions.

All basic service and operating functions are served by existing vessel systems suitably modified to meet OTEC-1 requirements. The vessel is capable of independent operation on-station, and detachment and reattachment of the platform to the mooring system and to the cold water pipe. The initial laying of the mass anchor mooring and the initial deployment of the cold water pipe requires special tugs and barges.

Chepachet has been modified for the OTEC-1 plant and supporting auxiliary equipment with modest structural changes. Existing power and piping systems, accommodations, and other features have been adapted to satisfy all requirements for testing the 1 MWe plant.

All major OTEC-1 equipment containing ammonia is located in the 109.5 ft OTEC-1 compartment. This compartment, extending from Frame 62 to Frame 71 , 
is located between the wing bulkheads. The electrical classification is NEMA 7, Class 1, Grade D and Coast Guard Specification 46CFR111.8 for hazardous locations.

The OTEC-1 test evaporator, the condenser, and the balance of the test $100 \mathrm{p}$ are installed in an enclosed compartment in the forward portion of the ship. This area was created by removing bulkheads between centerline cargo tanks. All operating ammonia systems are confined to this compartment within a watertight boundary below the main deck. Ammonia storage and auxiliary systems equipment are located on the forward:main deck above the OTEC-1 compartment. The compartment is reached from the maln deck viu suitable bulkhead openings. Working platforms are provided for all plant operations and maintenarice.

The two test heat exchangers are positioned parallel to the ship's centerline at elevations within a. few yards of the operating waterline to minimize the effects of the ship's motions.

Controls and instrumentation for the OTEC-1 plant are. located in a self-contained, air-conditioned van. The van is on a. platform aft of the midship deckhouse for convenient access to OTEC-1 operating crew accommodations and the OTEC-1 compartment. Existing navigation spaces in the midship deckhouse serve both ship and OTEC operations.

A biofouling and corrosion laboratory van is located aft of the control van on the same platform.

Both vans are mounted on vibration-isolation mounts to provide a nearly vibration-free environment for control and laboratory equipment..

All electrical support equipment, including the motor control center, switchgear, and distribution panels, is located in Center Tank 9 and on the main deck under the midship deckhouse.

The ship operates with a fully refurbished and operational power plant and propulsion train. No steam plant modifications were required.

Using one boiler only of the two onboard, a total of approximately 3070 $\mathrm{kW}$ can be provided, which is enough to accommodate the thruster at full power when the thruster load is required. The electrical power for the operation of the water and ammonia systems is from the ship's propulsion turbogenerator operating as a stationary power plant. Emergency electrical power is supplied by two auxiliary turbogenerator sets. 
A passive mooring system will allow the vessel to rotate like a weathervane. A $1000 \mathrm{hp}$ rotatable thruster is located on the ship to permit ship control for avoiding interference between the cold water pipe (CWP) and the mooring lines. This thruster is mounted in a vertical tunnel outfitted with tracks so that the thruster can be raised or removed for ease of inspection and maintenance.

The mooring is configured for a water depth of about $4000 \mathrm{ft}$. A single-leg moor is attached to a mooring buoy; the ship is moored to the buoy. Once deployed; the ship can make up to (or depart from) the mooring buoy in a very short time under its own helm without disturbing the moor.

The mooring is anchored to a clump of surplus anchor chain (150 tons), which was required because available sedimentary material was not deep enough for an embedment anchor. The anchor 1 ine is tied to a subsurface buoy to. which the ship's mooring system is attached. A 1.3 mile radius watch circle. is anticipated with this design.

A center cargo tank, aft of the OTEC-1 compartment, approximately amidships, has been modified to create a cold water system sump, known as the moonpool. The specially designed structure supports the gimbal and the cold water pipe: Locating the center well in this area ensures minimum ship-induced dynamic motions to the gimbal and pipes. Cold water is pumped from the sump into the OTEC-1 compartment through the condenser and then into the discharge system.

The cold water supply is drawn in through a screen at a depth of about $2200 \mathrm{ft}$ and is conducted up through the pipe assembly to the moonpool.

The pipe assembly is made up of three 48 in $:$ diameter polyethylene pipe sections with upper and lower steel transition elements. At the upper end, the pipes merge into a single flow and attachment channel. A bottom weight supported, by cables within each pipe limits pipe motions. Special equipment for the deployment and recovery of the pipe after release is provided. The pipe assembly interfaces with the hull at the gimbal/diaphragm assembly, which structurally supports the pipe and isolates it from pitch and roll motions. The upper diaphragm element, which supports the gimbal and mates with the ship's moonpool structure, provides a sealed interface between cold water in the sump and adjacent warmer surface water at the bottom of the moonpool. 
The gimbal consists of an outer ring, an inner yoke socket, and four spherical bearings. The socket mates around the top end of the pipe assembly and connects through four attachment dogs that can be released hydraulically. The gimbal platform is a mechanical and hydraulic interface between the CWP and the ship. The platform itself consists of two fabricated steelring structures measuring approximately $14 \mathrm{ft}$ by $14 \mathrm{ft}$. This arrangement allows +30 degrees angular deflection in the roll and pitch directions.

Specialized deployment equipment will be utilized to tow out and upend the pipe assembly. It will consist of standard, marine-type handling gear that will be provided by a deployment contractor for the initial deployment.

The cold water pipe handing equipment, consisting of a deck-mounted moonpool crane structure, one overside crane structure, and a dual 50-ton winch, provides the capability. to recover, keelhaul, and mate the pipe assembly. This equipment can also lift the gimbal/diaphragm assembly up to deck level for maintenance.

\subsection{SEA WATER SYSTEMS}

$\dot{A}$ schematic diagram of the sea water circuits on oTEC-1 is shown in Fig. 3.1. Figure 3.2 is a schematic showing the water-sampling stations.

The cold water supply system can deliver up to 78,000 gpm cold. sea water to the condenser. The system consists of the CWP, a sump in the moonpool acting as a surge tank, a variable speed pump, the condenser, and the water discharge system.

The water is pumped from the moonpool (which serves as the sump) by the pump located there. When water is drawn from the moonpool, its level drops, inducing water to flow up the CWP to refill it.

From the moonpool, the water is pumped through the condenser into the port wing tank No. 5 ( $\mathrm{P} 5 \mathrm{~W}$ ), where it mixes with the warm water effluent from the evaporator.

The warm water system consists of water intakes, a sump, a pump, the evaporator, a discharge system, and associated piping. This system delivers up to $95,000 \mathrm{gpm}$ of warm sea water to the evaporator. 


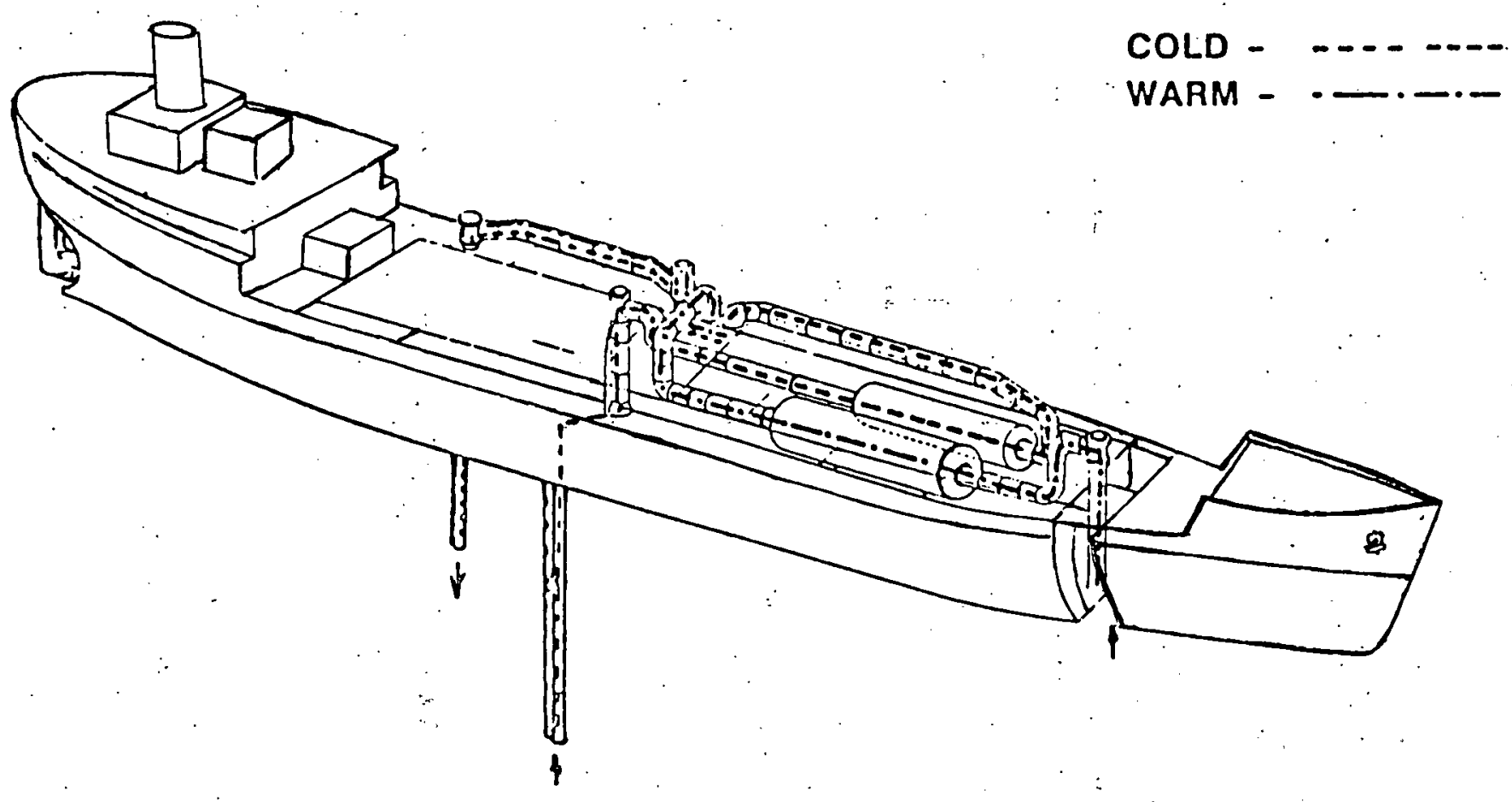

Fig. 3.1. Water Circuits 


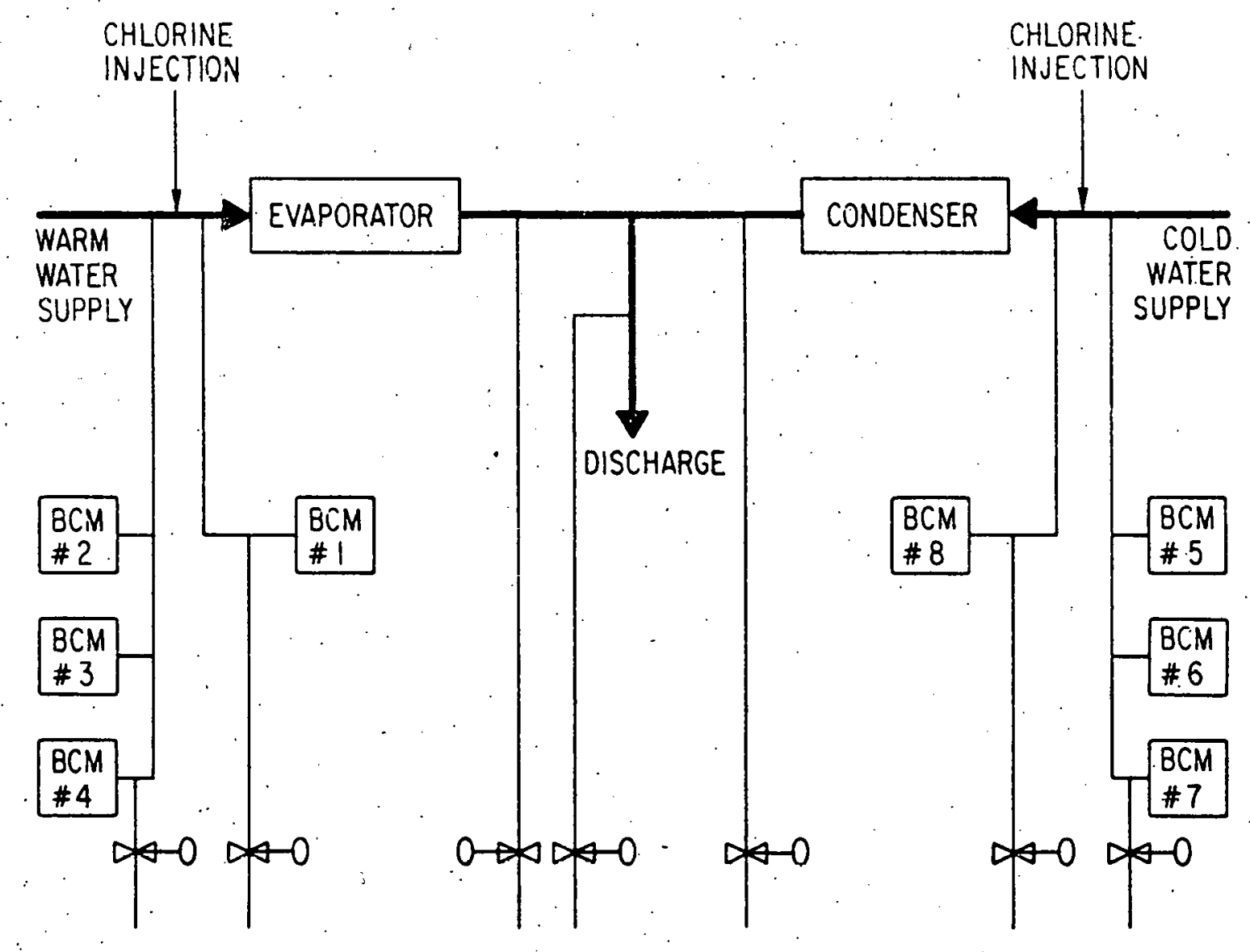

Fig. 3.2. Sampling Stations Schematic 
Warm sea water is drawn through a screened opening in the hull and into the. warm water sump. The inlet screen is self-cleaning and can easily be changed by a diver to permit the testing of various screen types.

The warm water pump has a variable-speed drive and delivers water from the sump through a pipe system that is $41 \mathrm{ft}$ in length and $5 \mathrm{ft}$ in diameter.

Water is pumped through the evaporator and then to port wing tank No: 5 ( $\mathrm{P} 5 \mathrm{~W}$ ), where it mixes with the condenser effluent. The mixed effluent is pumped through the discharge system into the ocean.

The discharge system consists of a pump, a tank (which acts as a conduit and is used for convenience only), the discharge pipe, and associated piping.

Condenser and evaporator effluents are routed through individual pipes to the effluent-water mixing tank ( $P 5 W$ ). The ends of the discharge pipes are submerged so that the pipes remain filled with water. The resulting siphon action aids the pumps. The mixed water sump has a valved access hole through the bottom shell to permit the water level of the sump to be controlled in various operating modes.

The discharge water is pumped from the P5W tank. through the port. wing tank No. 9 ( $P 9 W$ ) and is then expelled through a 6-ft diameter flexible nylon hose lined with rubber (Hypalon). The bottom of the discharge hose is closed. The discharge end section has holes in it, allowing the discharge water to flow out horizontally. Six 36- $\mathrm{ft}$ ' hose"sections will be used, so. that the discharge depth will be $240 \mathrm{ft}$.

\subsection{MWe EVAPORATOR AND CONDENSER}

Both the evaporator and condenser are horizontal shell-and-tube heat exchangers constructed of titanium and carbon steel with sea water on the 
Table 3:1. Design Requirements of the Heat Exchangers

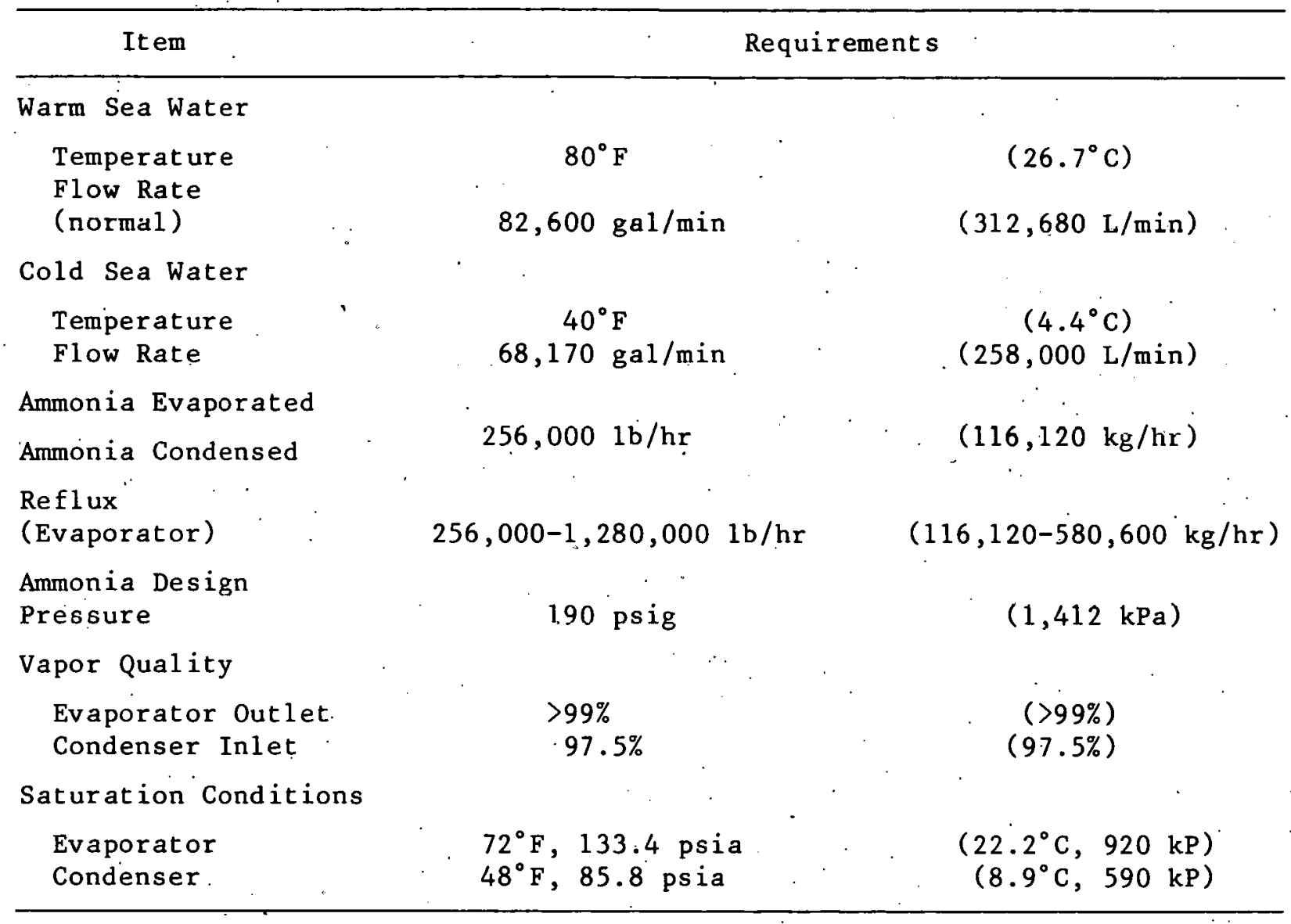

- inside of the tubes and ammonia on the shell side. These units have a thermal duty of approximately $40 \mathrm{MW}$, which is equivalent to an electrical output of 1 MWe for a typical OTEC operating efficiency of approximately $2.5 \%$. The design requirements of these units are shown in Table 3.1. Both exchangers are designed to comply with the ASME pressure vessel code for unfired boilers. Heat exchanger interfaces are shown in Fig. 3.3.

For the baseline evaporator design, liquid ammonia is sprayed over the top of the tube bundle and falls down over the tubes. Evaporation occurs at the surface of the ammonia liquid film covering each tube. The spray is directed onto the bundle from nozzles situated in two planes. One plane, consisting of two sets of spray nozzles, is located over the bundle; the other is midway between the top and bottom of the bundle. Any ammonia that does not evaporate drains into a drain tank below the main evaporator shell and is recirculated to the spray nozzles. 


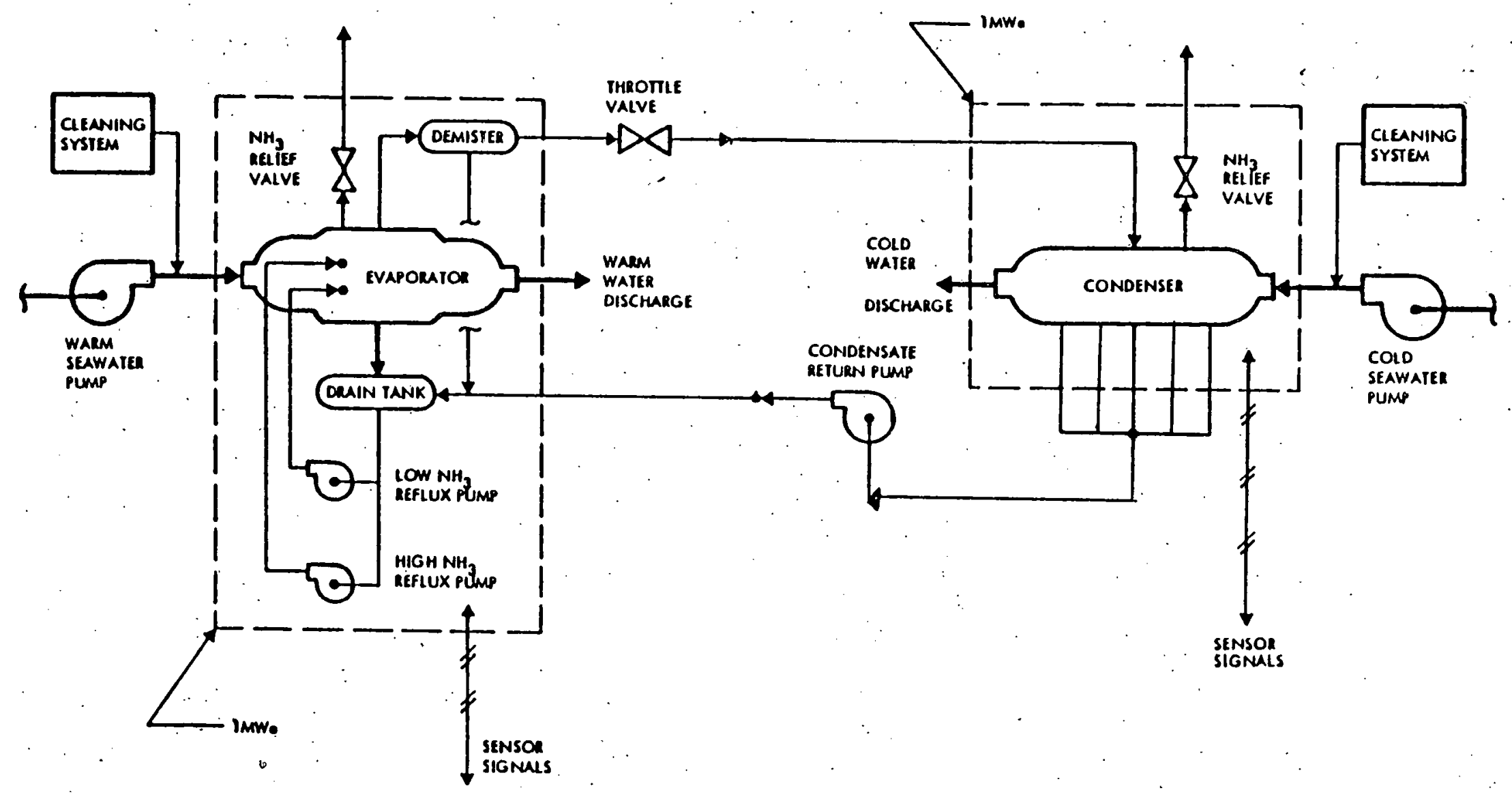

Fig. 3.3. . 1-MWe Power Loop OTEC-1 Interfaces 
The lower half of the tube bundle has a proprietary Linde enhanced surface that is intended to improve the heat transfer characteristics on the ammonia side. An ammonia feed supply is provided to permit independent evaluation of the upper or lower bundle performance: Other testing configurations are achieved by the installation of shroud plates, which enable various flow arrangements to be accomplished (see Fig: 4.1).

The evaporator bundle can be submerged in liquid ammonia for operation as a pool boiling exchanger. The primary mode of evaporation heat transfer is nucleate boiling -- vapor bubbles are formed at the tube surface, growing large enough. to break free and rise to the surface of the pool. Nucleate boiling can be improved by surface modification to increase the number of nucleation sites for vapor bubble formation.

An integral ammonia liquid separator is not provided in this design, but an external phase separator will enable the performance of the evaporator to be determined.

A schematic drawing of the evaporator is shown in Fig. 3.4, and its characteristics are given in Table.3.2.

Table 3:2. Evaporator Characteristics

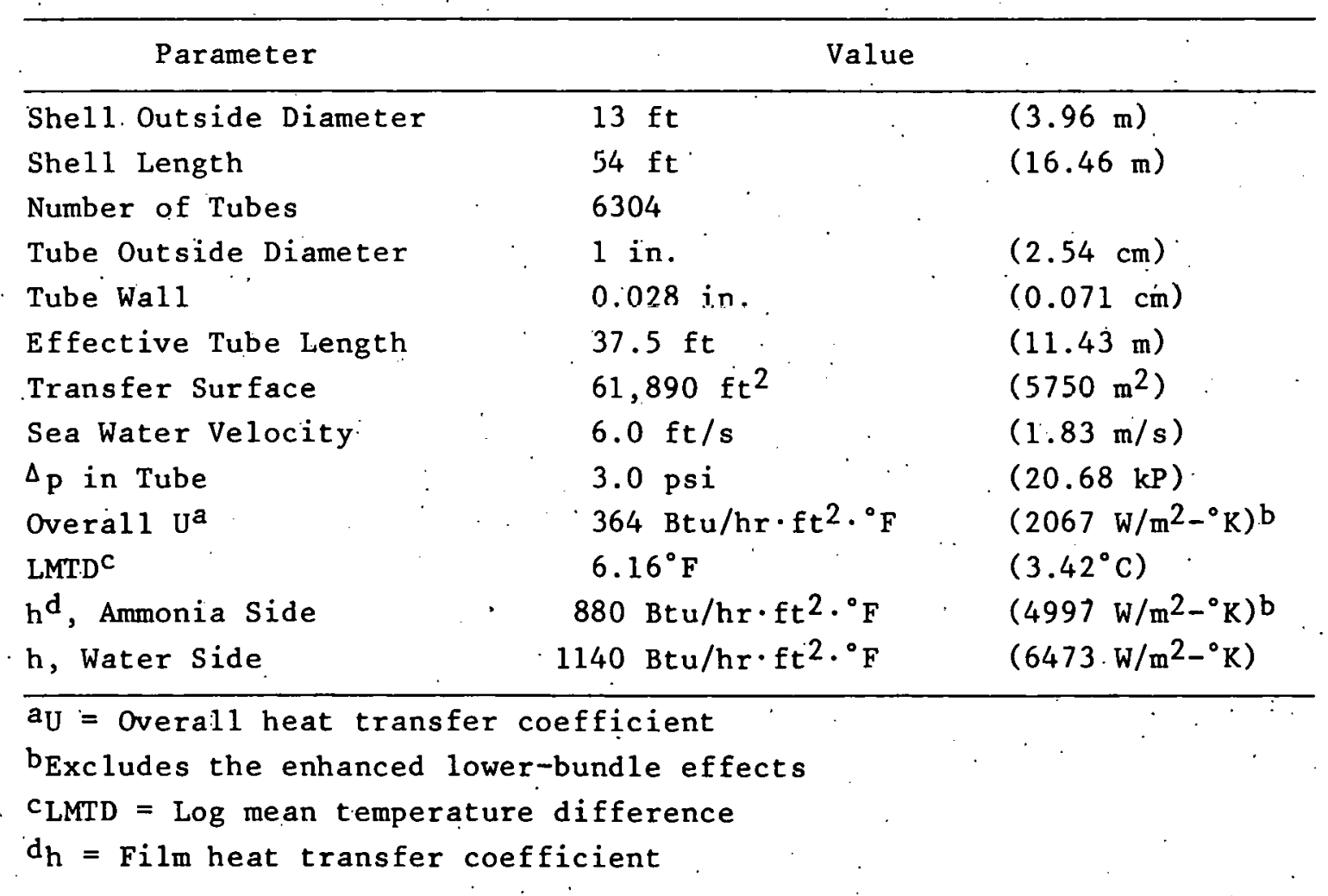




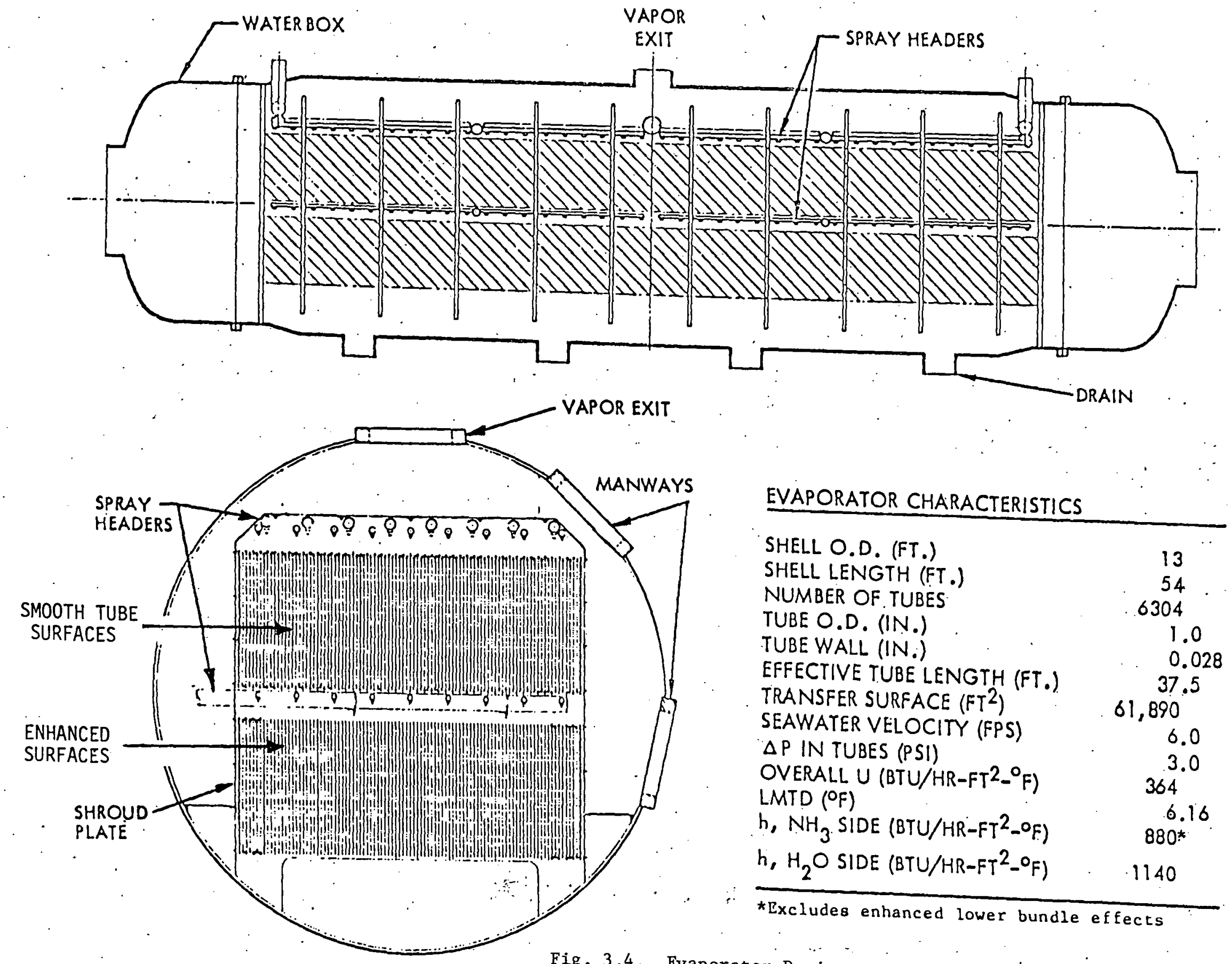

Fig. 3.4. Evaporator Design 
In the condenser ammonia vapor feeds from the top of the condenser and flows straight down through the tube bundle. The vapor transfers heat to the cold sea water flowing through the condenser tubes and condenses on the tube surfaces. The condensed ammonia drains to the integral condenser sumps.

Noncondensible gases will be present from start-up because nitrogen is used to blanket the vessels during shipping and to purge the system between tests. Other noncondensible gases will be generated continuously as impurities in the ammonia. Because even small amounts of noncondensible gases can reduce performance, they are removed via two vents located on each side of the condenser along the lower curve of the shell.

A schematic of the condenser is shown in.Fig. 3.5 and its characteristics are given in Table 3.3 .

In the heat exchangers, sea water temperature and pressure are measured at both the inlet and outlet water boxes. Water flow rates are measured by acoustic, flow meters. Ammonia vapor pressure differences are measured on the shell sides of both exchangers, but the instrumentation to measure ammonia flow and temperature is located elsewhere in the loop.

Table 3.3. Condenser Characteristics

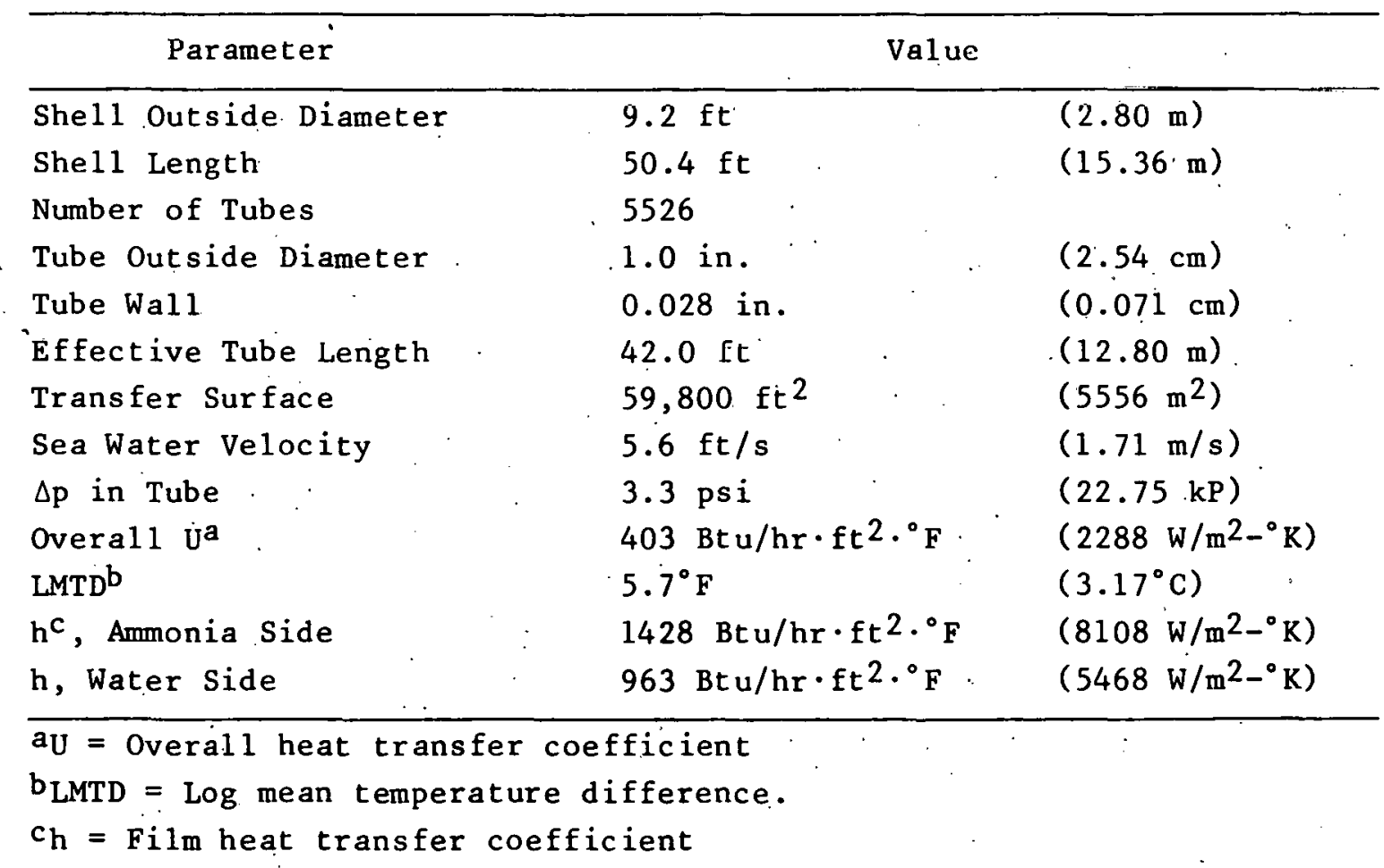



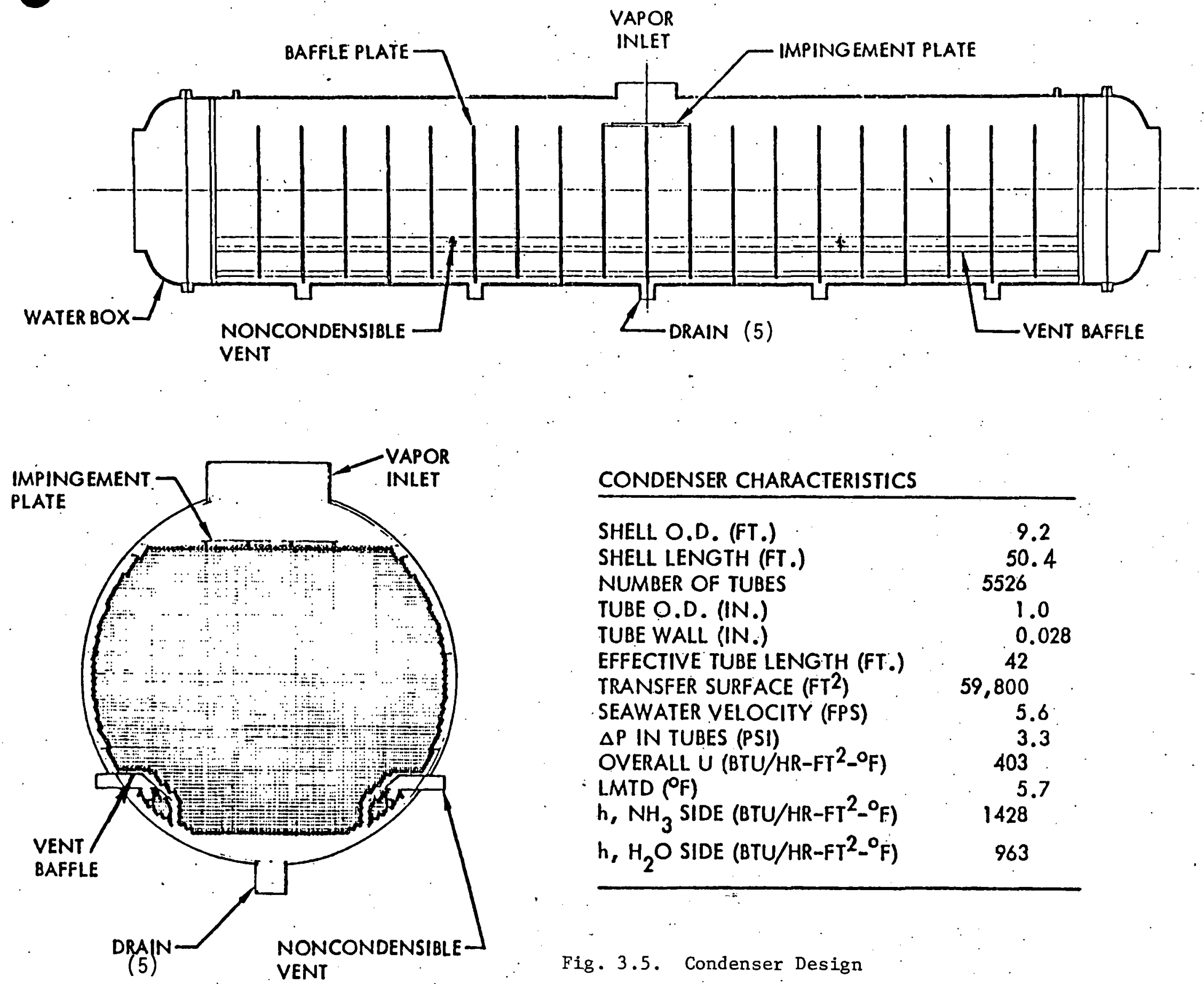

CONDENSER CHARACTERISTICS

SHELL O.D. (FT.)

SHELL LENGTH (FT.)

NUMBER OF TUBES

TUBE O.D. (IN.)

TUBE WALL (IN.)

EFFECTIVE TUBE LENGTH (FT.)

TRANSFER SURFACE (FT' ${ }^{2}$ )

SEAWATER VELOCITY (FPS)

$\triangle P$ IN TUBES (PSI)

OVERALL U (BTU/HR-FT ${ }^{2}{ }^{\circ} \mathrm{F}$ )

LMTD ( ${ }^{\circ}$ )

$h, \mathrm{NH}_{3}$ SIDE (BTU/HR-FT $\left.{ }^{2}-{ }^{\circ} \mathrm{F}\right)$

$h, \mathrm{H}_{2} \mathrm{O}$ SIDE (BTU/HR-FT $\left.{ }^{2}{ }^{\circ} \mathrm{F}\right)$
9.2

50.4

5526

1.0

0.028

42

59,800

5.6

3.3

403

5.7

1428

963

Fig. 3.5. Condenser Design 
Each heat exchanger is equipped with instrumented tubes as shown in Fig. 3.6. Six "clean" tubes carry recirculating water in separate loops. Four "dirty" tubes are equipped with diverters to prevent the entry of Amertap balls. Flow rates and inlet temperatures to the clean tubes can be controlled to reproduce the conditions at the sea water inlet to the tube bank. By comparing the measured heat transfer rates of the three types of instrumented tubes in a cluster, approximate rates of fouling and the specific effects of Amertap balls can be estimated. The differences in heat transfer coefficient at the different locations in the evaporator provide a measure of the variation in liquid loading with depth of the tubes in the bundle. In the condenser the performance of the local. instrumented tubes can be monitored for indications that, noncondensible gases are accumulating.

\subsection{THE AMMONIA SYSTEM}

The subsystems associated with the ammonia loop include the ammonia and nitrogen support subsystems. The system design parameters are given in Table 3.4 and a schematic of the system arrangement is shown in Fig. 3.7 .

The evaporator is designed to operate with an $80^{\circ} \mathrm{F}$ sea water supply. Liquid ammonia is introduced through sets of spray nozzles at the top of the evaporator'shell and also at the zone between the upper and lower bundle. Unevaporated 1 iquid ammonia falls to the bottom. of the evaporator and from there into the evaporator. drain tank. Ammonia vapor leaves the evaporator through a single nozzle at the top.

Ammonia vapor flow is piped out of the evaporator through a throttle valve and then to the condenser inlet nozzle. Condensate from the condenser is piped through equipment and piping to the evaporator drain tank, where it mixes with the excess liquid ammonia draining from the evaporator.' The mixture is recirculated or refluxed by the reflux system to the spray nozzles. The evaporator drain tank is sized to accommodate a volume of at least 600 $\mathrm{ft}^{3}$ of liquid ammonia for start-up. The operating level of 1 iquid is at 


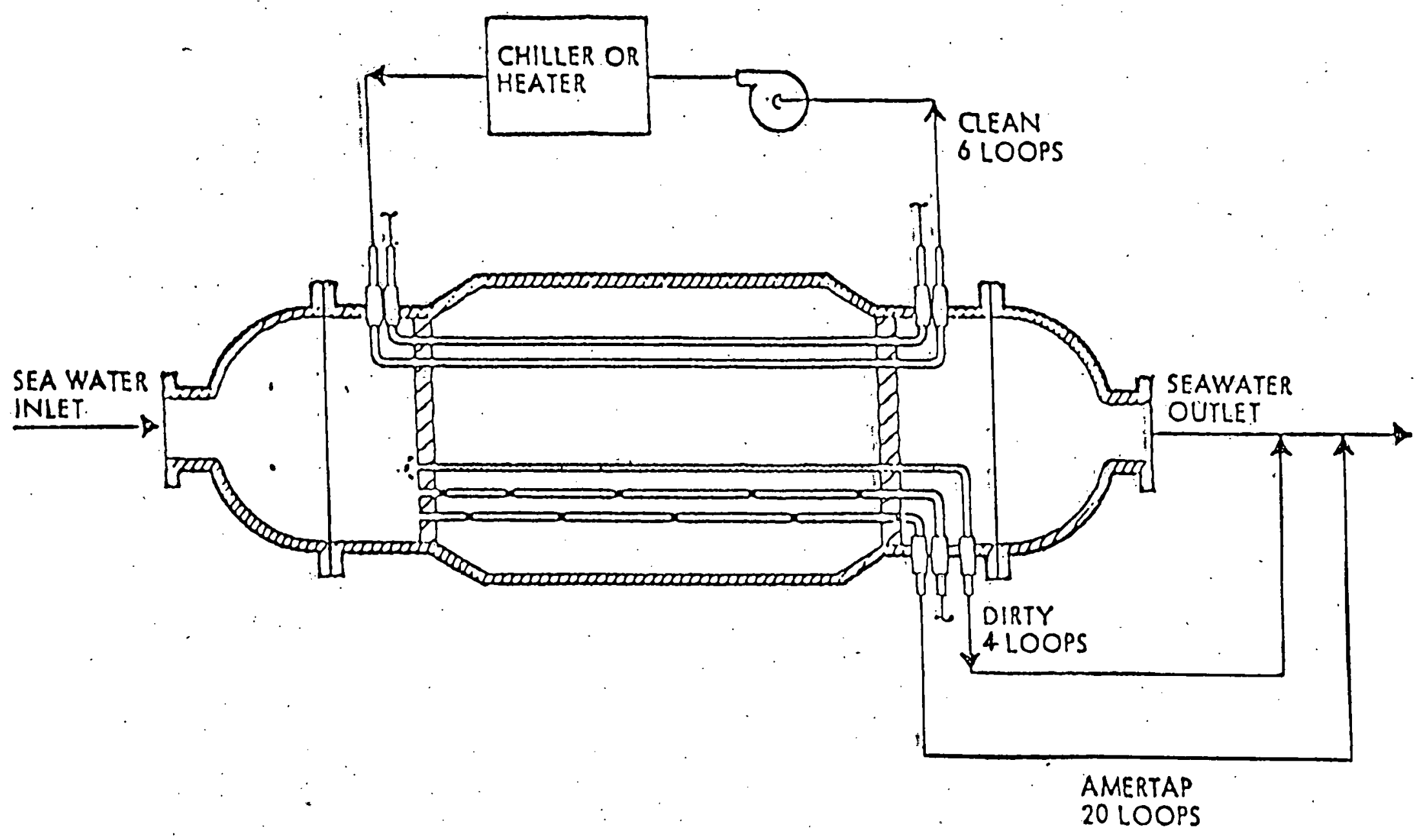


Table 3.4. System Design Parameters

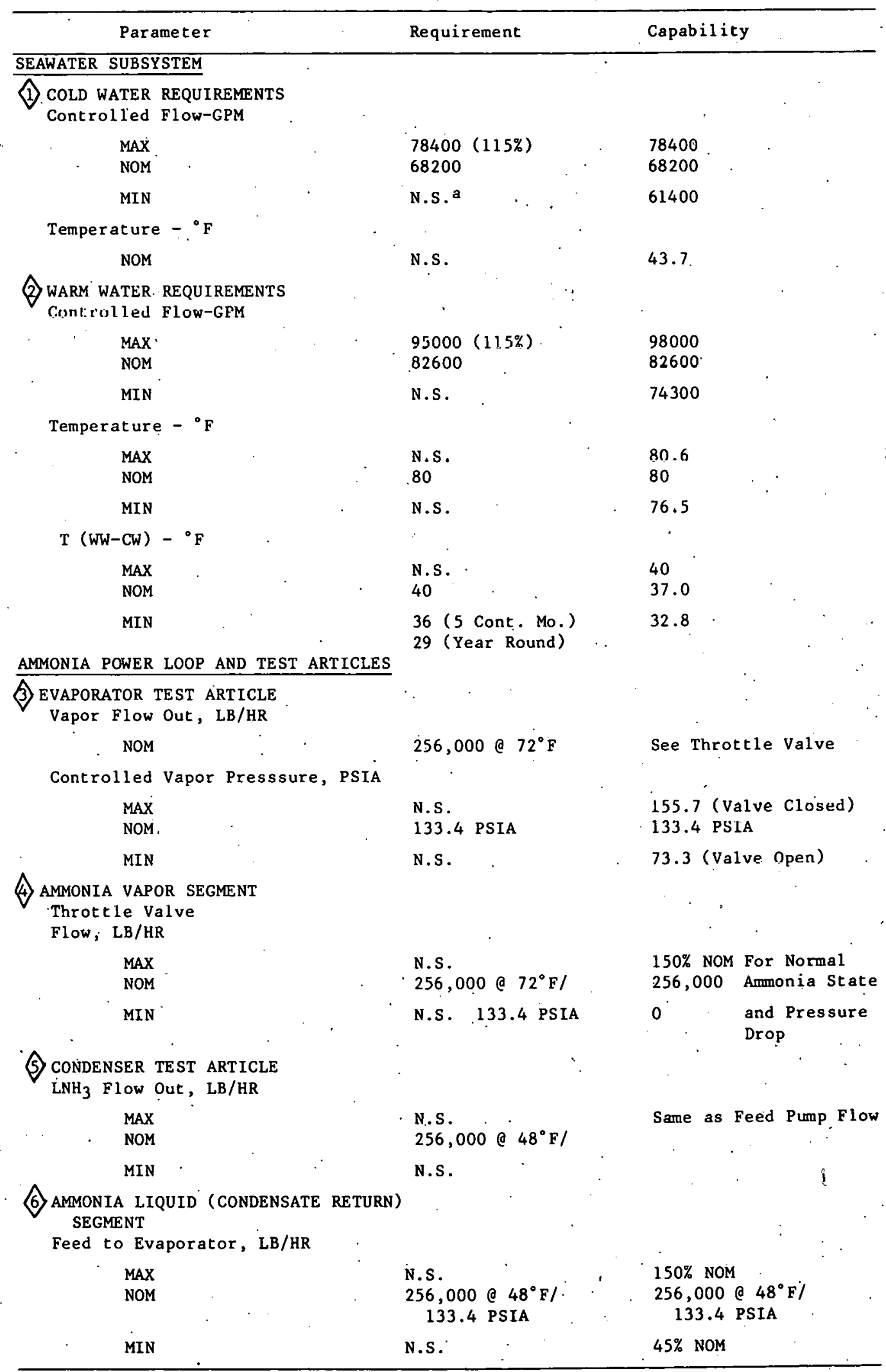

an.s. - Not Specified 


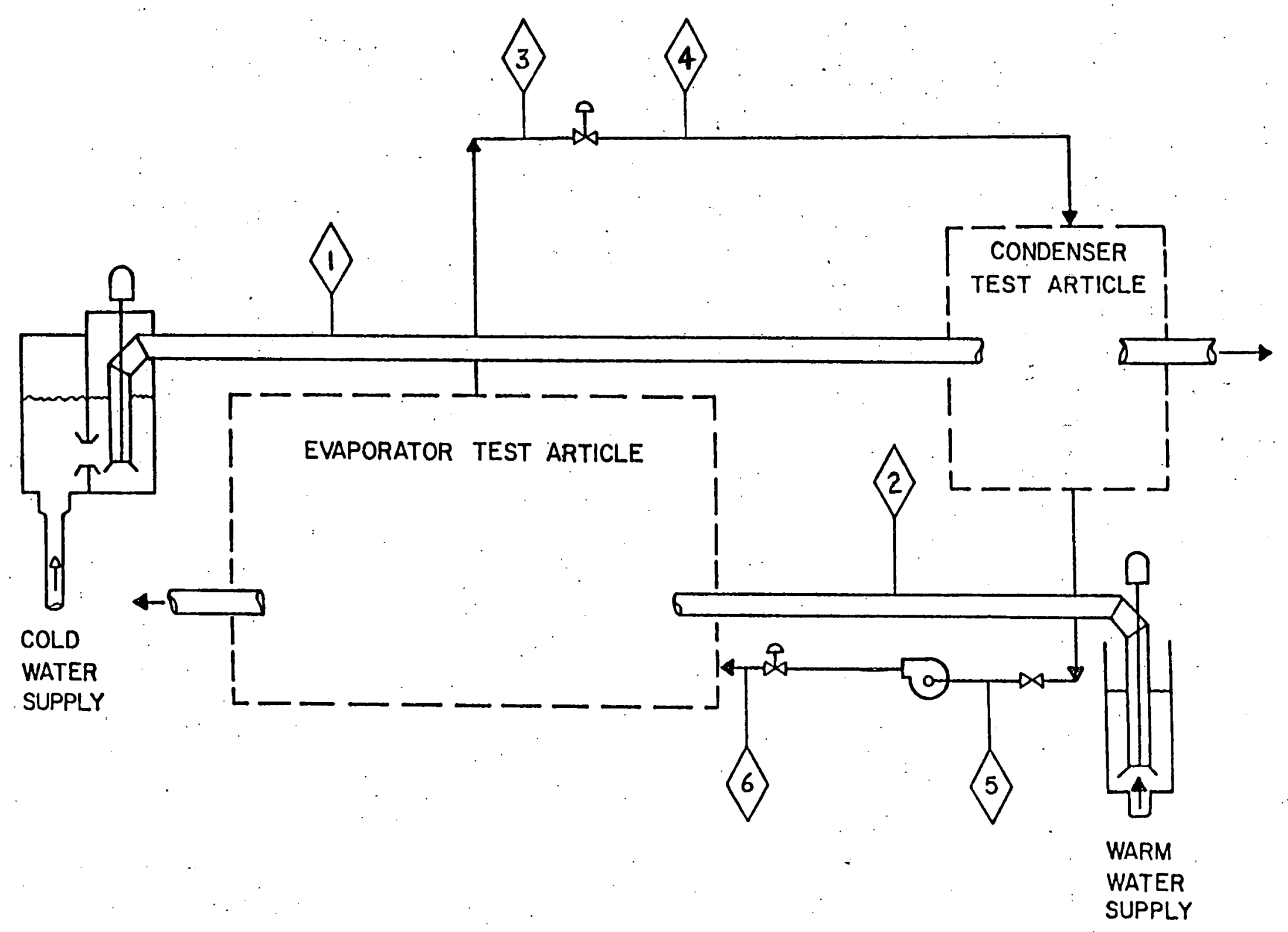

Fig. 3.7. Test Loop Process Flows (Tags refer to

test instrumentation listed in Table 3.4) 
the midpoint of the cylindrical drain tank. The tank contains a low level sensor with a transmitter for shutdown of the pumps. The liquid ammonia is pumped by one or both of the two variable speed pumps to the spray headers. Spray nozzles distribute the 1 iquid over the tube bundle. The baseline system is shown in Fig. 3.8.

The condenser is designed to operate with a $40^{\circ} \mathrm{F}$ sea water supply. The condenser is a crossfflow design with vapor introduced at the top. Condensation occurs on the outside tube surfaces. Condensate falls to the bottom of the condenser, which is divided into five sections. Each section has an individual drain nozzle and collection sump.

The ammonia pumping system transfers the condensate from the condenser to the evaporator sump. A valve at the feed pump outlet controls the flow to the evaporator sump. The piping will permit. $150 \%$ of nominal flow. Higher flows are possible with correspondingly higher line losses. The condensate feed pump and control valve are designed to provide a large flow range around the nominal. The range is determined by the performance characteristics of the constant-speed centrifugal pump, which is controlled by a downstream throttle valve. Closing the valve increases the head, thereby decreasing the flow. The characteristics for the pump selected are shown in Fig. 3.9.

The ammonia purity control consists of a detector that continuously. monitors water in the ammonia. The sample is taken from the evaporator ammonia sump. The ammonia purification system that was originally planned has been eliminated.

The nitrogen support subsystem supplies gaseous nitrogen for purging the power loop after shut-down and prior to start-up (if the closed power loop has been opened to ambient air). The concept of operation is to mix the gaseous nitrogen with the ammonia or air in the power loop and to exhaust the nitrogen/ammonia or nitrogen/air through a stack. The purge is continued until the residual air-to-ammonia ratio is diluted well below the explosive range. The total nitrogen storage capacity provides for a complete purge to be performed twice a month. 


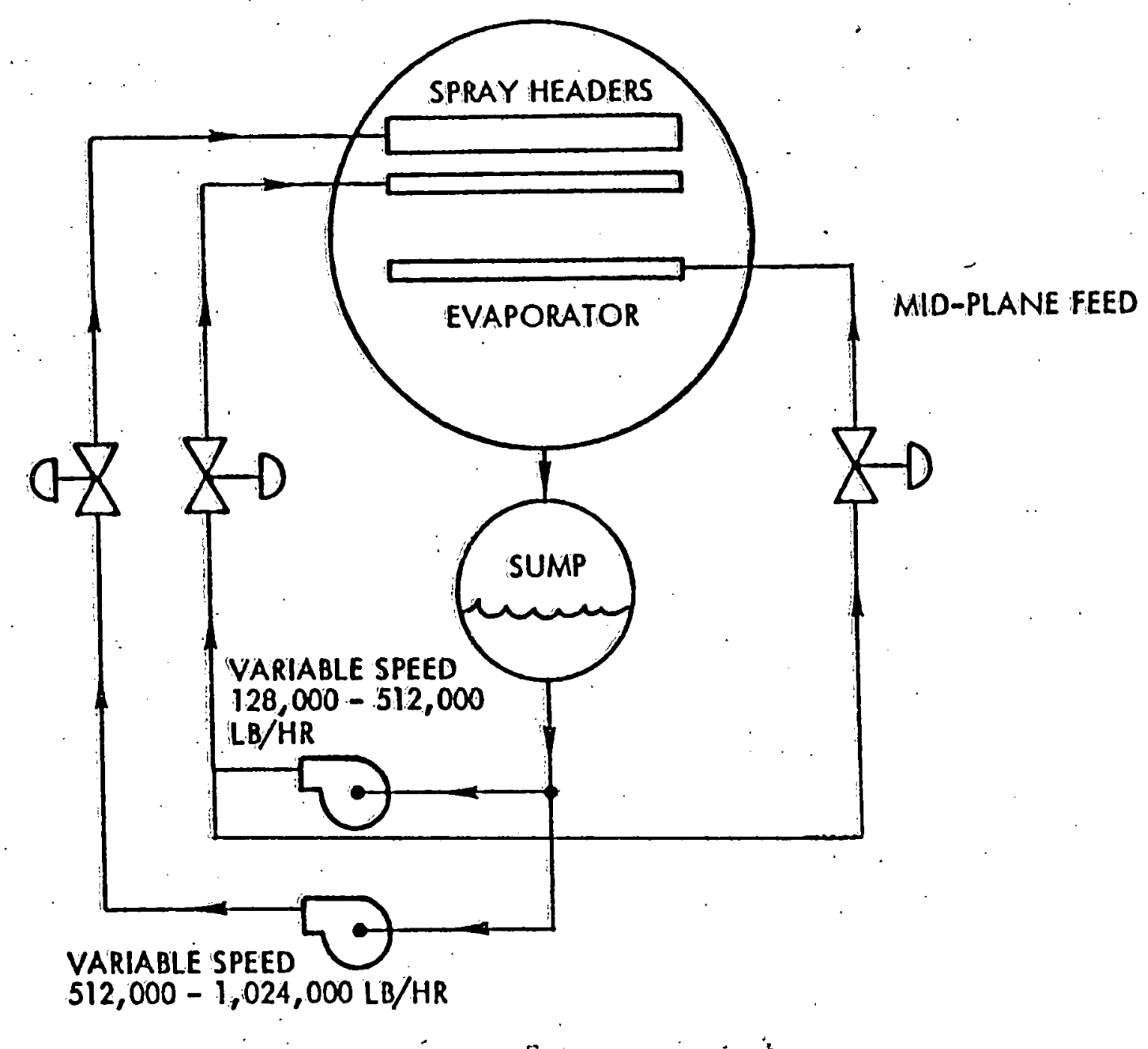

Fig. 3.8. Evaporator Reflux Loop Pump Arrangement 


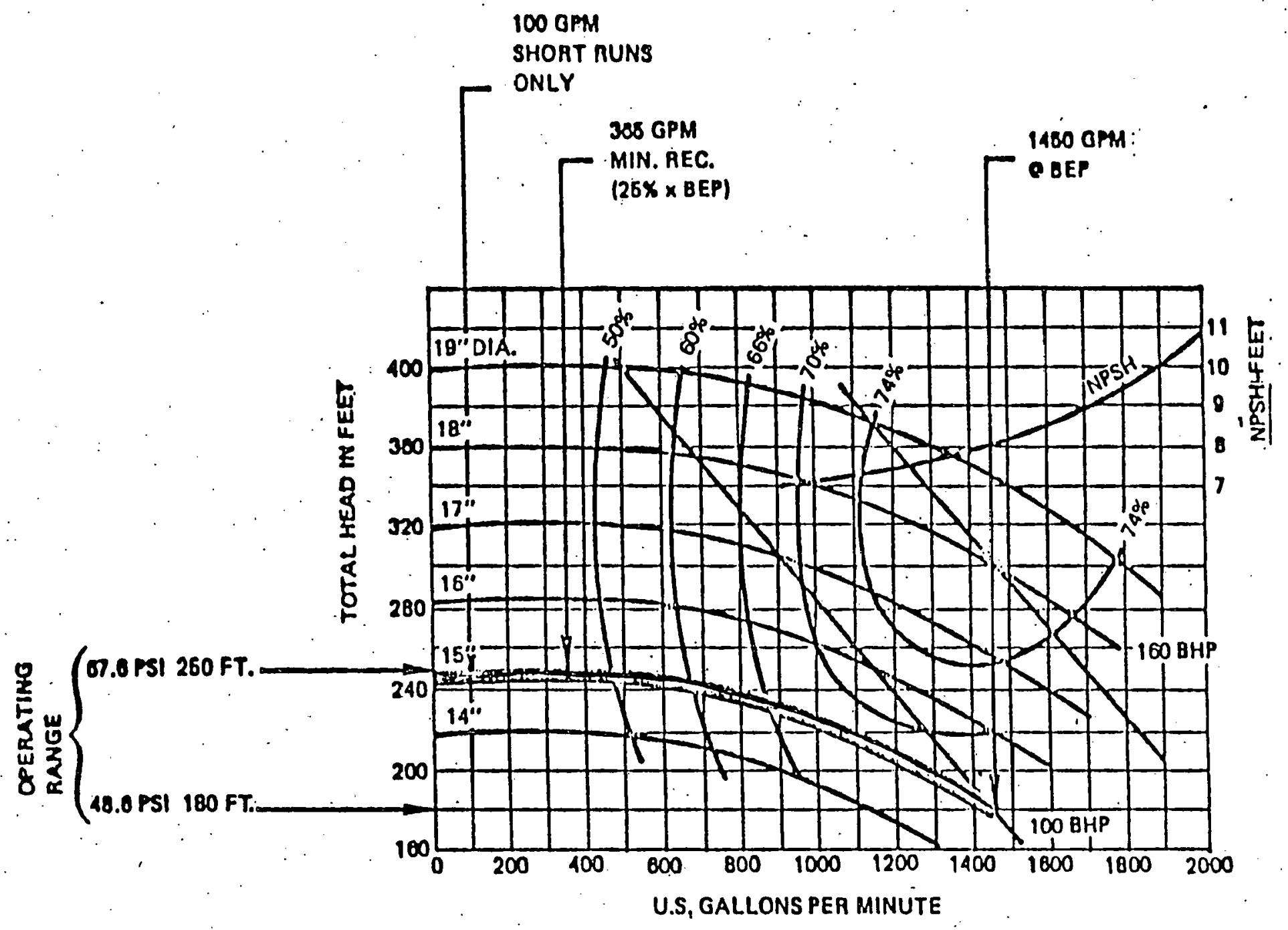

NOTES: 1. INGERSOLL RAND MODEL OX19A W/16" IMPELLER

2. H.P. SHOWN ARE FOR WATER

3. REFERENCE SPECIFICATION NO. CE12478

4. BEP - BEST EFFICIENCY POINT

Fig. 3.9. Condensate Return Pump Characteristics 


\subsection{BIOFOULING CLEANING SYSTEM}

A combination of two methods of biofouling control will be employed. These are:

- Intermittent chlorination to $0.4^{\circ} \mathrm{ppm}$ residual at the heat exchangers (see Sec. 4.2).

- Mechanical' cleaning of heat exchanger tubes by the Amertap system.

The OTEC-1 chlorination system to control biofouling is shown in Fig. 3.10. The chlorine generator is an electrolytic cell that produces sodium hypochlorite ( $\mathrm{NaOC} 1$ ) and hydrogen gas $\left(\mathrm{H}_{2}\right)$ from warm sea water. The maximum capacity of the generators is $801 \mathrm{~b} / \mathrm{hr}$ of equivalent chlorine. A control system will monitor chlorine concentrations and chlorine flow, backed up by periodic amperometric titrations.

The Amertap system shown in Fig. 3.11 is designed to remove microfouling by circulating sponge-rubber balls through the heat exchanger tubes. After the balls are injected into the sea water inlet streams, they flow through the tubes and are then collected for recirculation. The balls are randomly distributed to all the tubes in a given heat exchanger. The number of balls in circulation at any given time will be adjusted to provide an average tube-cleaning frequency of about once every 15 minutes. The number of balls can be changed, within limits, to provide any desired clean-. ing frequency.

The Amertap balls are natural, biodegradable sponge rubber. The diameter of the balls is slightly greater than the inside diameter of the heat exchanger tubes.

It is anticipated that with six hundred balls in circulation in each heat exchanger at one time, replacement of a minimum of 200 balls per week will be required. During the weekly Amertap shutdown for maintenance, all balls will be collected in the ball collector tank, removed, and graded for size. The replacement inventory will then be restocked to supply the original inventory quantity, and the system will be reactivated.

Abrasive, silicon carbide-coated, sponge-rubber cleaning balls will be used in place of the smooth balls when it is desired to scrub tube surfaces more thoroughly during the test. 


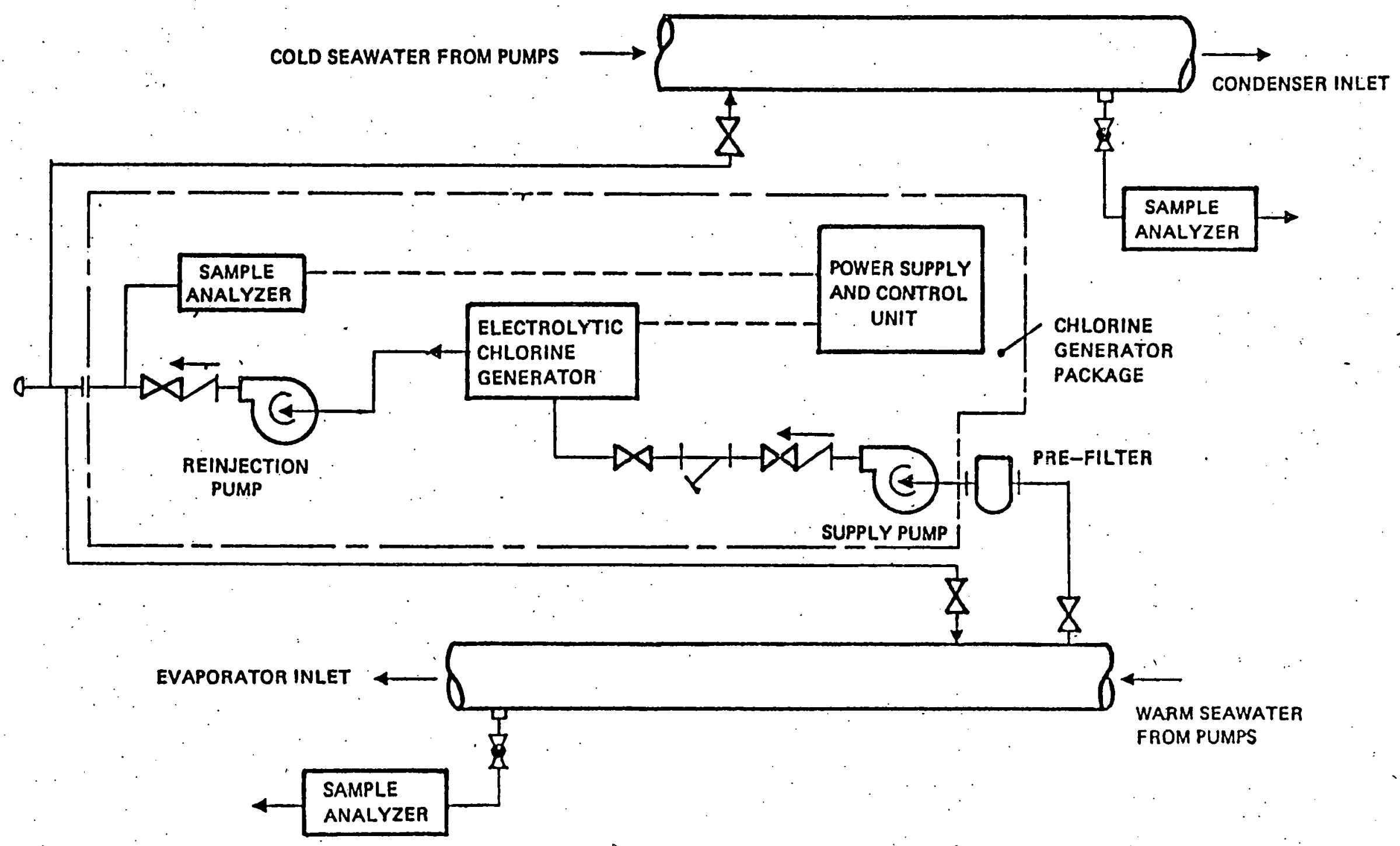

Fig. 3.10. Chlorine Generator Subsystem 


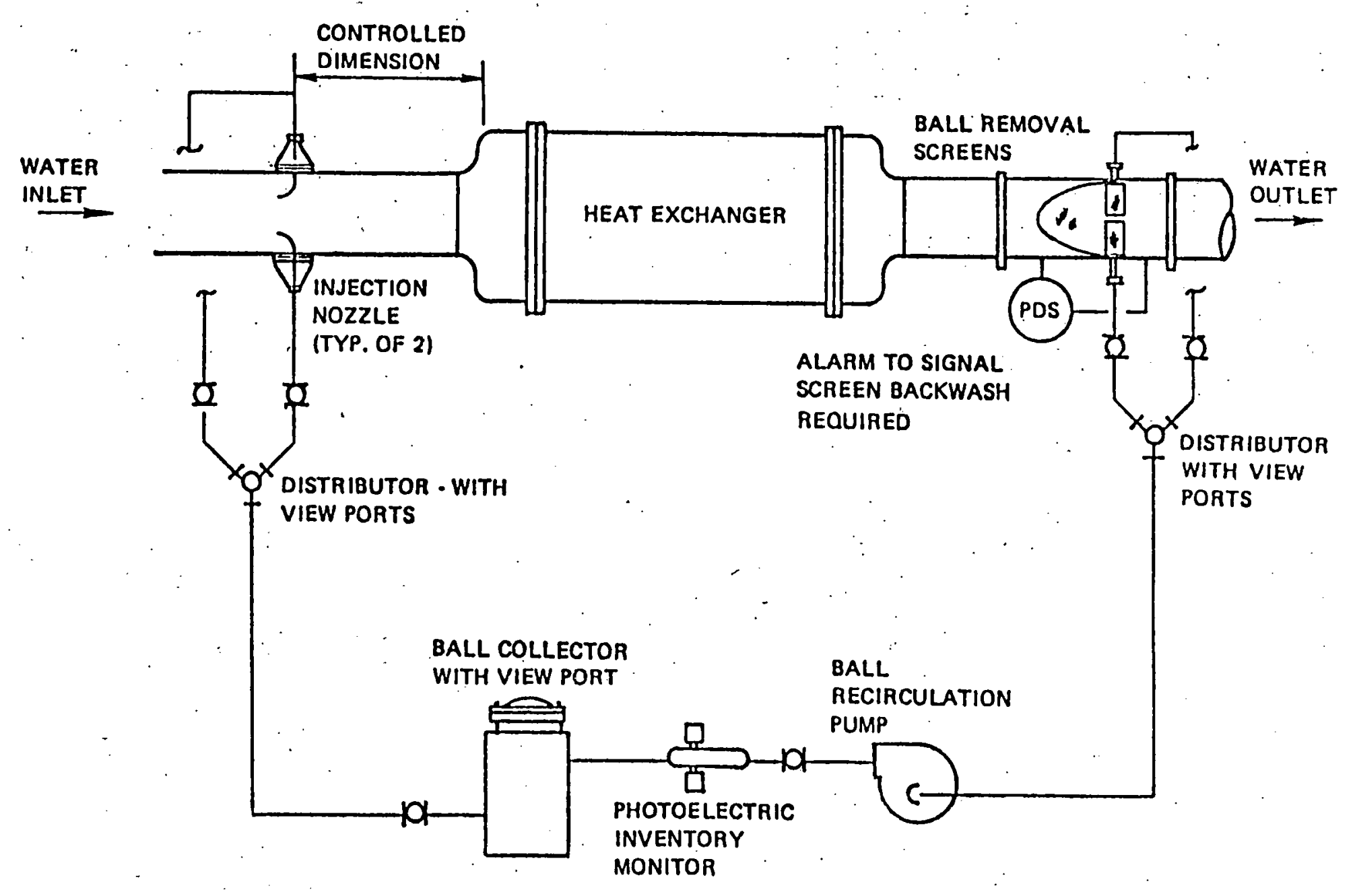

Fig. 3:11. Amertap Subsystem 


\subsection{BIOFOULING AND CORROSION MODULES}

Four ANL Biofouling and Corrosion Modules (B\&C modules) are asso-

ciated with each heat exchanger. The modules are designed to monitor changes in fouling film resistance in a typical heat exchanger tube and to provide specimens of tubes for physical examination of biological and corrosion films. The heat transfer monitors (HTM) are of the modified. Carnegie-Mellon type. They measure changes in the overall heat transfer coefficient that result from buildup of a biofouling film on the inside of the tube. Figure 3.12 illustrates the construction of the modules.

The HTM determines the heat transfer coefficient, $h$, by heating a segment of tube wall slightly above the water temperature and then observing its cooling rate after, the heat, input is removed. The cooling curve (temperature vs time) is exponential, according to Newton's law of cooling, with a time constant that is inversely proportional to $\mathrm{h}$. The necessary data and analysis are acquired by the on-board computers programmed to turn off the heater, to accumulate the flow rate and temperature decay data required, and to calculate the fouling resistance, $R_{f}$, for each $t$ ube on a set schedule.

As shown in Fig. 3.13, the HTM consists of a series of four cylindricạl copper blocks, 4 in. long by 1 in. inside diameter by $2-3 / 4$ in. outside diameter. The blocks are segmented and clamped to the outside of a heat exchanger tube with an outside diameter of 1 in. These blocks are covered on the outside.by Kaptan insulated, etched foil element "Thermofoil" heaters. The copper blocks, a thermopile for measuring the difference in temperature between the center heated block and reference. block, a water temperature thermistor, an air temperature thermistor, and a printed circuit board for signal conditioning are housed in a 5-in. PVC pipe enclosure.

Detailed parametric analysis and extensive analysis of data obtained with the Carnegie-Mellon device indicate that a sensitivity of $0.00002 \mathrm{hr}$. $\mathrm{ft}^{2}{ }^{\circ} \mathrm{F} / \mathrm{Btu}$ can be expected in $R_{f}$ measurements.

ANL has developed and provided to the Tést Director Contractor a complete computer program to control the units, to examine the data for signs of unsatisfactory operation (in which case data are not used and operator signals are provided), and to calculate results. 
1. HEAT TRANSFER MONITOR

2. BIOLOGICAL AND CORROSION SAMPLE TUBES

3. AMERTAP BALL SEPARATOR

4. BALL INJECTION VALVE

5. FLOWMETER TRANSDUCERS

6. EXPLOSION PROOF

INTERCONNECTION BOXES

7. CONNECTIONS FOR CABLING TO CENTRAL CONTROL AND. INSTRUMENT CABINET

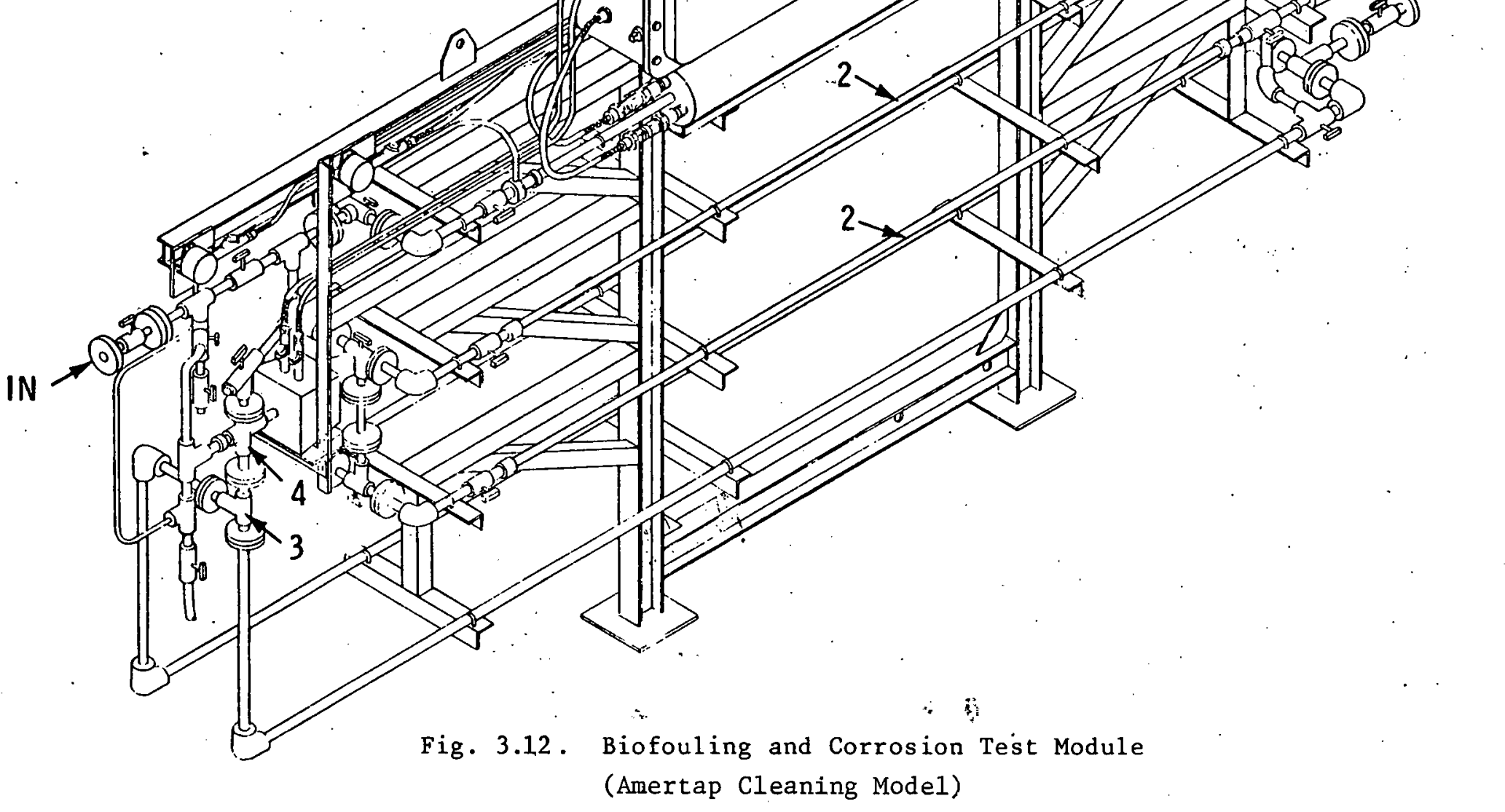




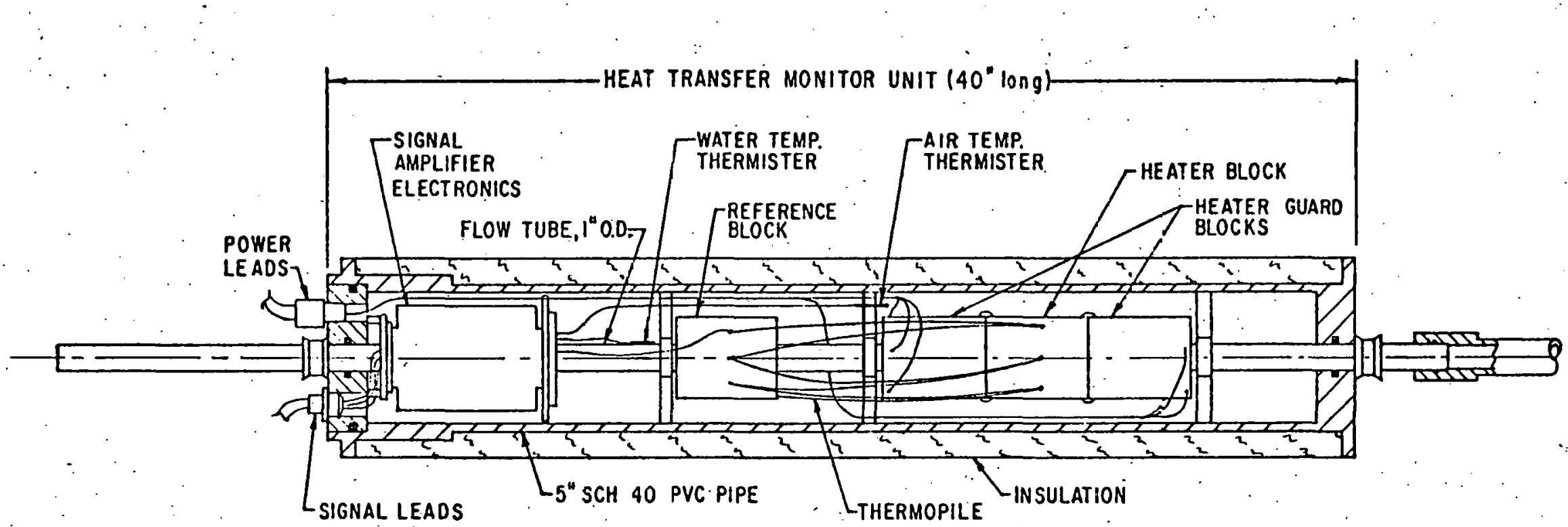


Tube sample sections ( $t$ wo on each module) consist of 10 precut sections of heat-exchanger tubing, each 9 in. long, held together by nylon fittings that allow quick removal of sample sections and replacement with dummy sections: In addition, some modules will contain 9-in. long sections consisting of precut, weighed tubular corrosion specimens of 5052 and Alclad 3003 aluminum. In order to 1 imit effects. of flow. stoppage on the HTM or B\&C module specimens; piping systems are provided to bypass the flow around the HTM or sample sections during times when samples are being removed or the HTM is out of service. All modules contain valving and piping required to circulate a single Amertap ball through the HTM and sample tubes and return it to the inlet end of the HTM at a predetermined interval.

Electronic and electric circuitry required to control the HTM heaters, the Amertap ball recirculation systems, and the independent chlorinator systems for the eight $B \& C$ modules are housed in the B\&C module interface rack. Interface connections to and from the computer are routed through the same rack.

As indicated in Table 3.5, one of the four HTMs associated with each heat exchanger ( $H X)$ is fed with water from the HX inlet 1 ine. Flow through this unit is controlled by the computer to follow the average flow rate in the $\mathrm{HX}$ tubes. The unit is fitted to recirculate Amertap balls of the same type and size and at the same average rate as those circulated in the HX. This unit is intended to provide sensitive online monitoring of changes in heat transfer efficiency in the $\mathrm{HX}$ to indicate trends that might go undetected by the less sensitive HX instrumented tubes and the gross heat balance calculations on the HX units.

The remaining three $B \& C$ modules, fed by an uninterrupted flow of untreated water from the $\mathrm{HX}$ inlet source, indicate the range over which the countermeasures employed can be varied to supply the biofouling control required to maintain acceptable $R_{f}$ values in the HX tubes employing the water available at the OTEC-1 site. One of these units operates on raw water from the $\mathrm{HX}$ feed source and serves as a control to indicate fouling potential of the raw water. This unit will be manually cleaned if the fouling resistance $\left(R_{f}\right)$ reaches a value of $0.0005 \mathrm{hr} \cdot \mathrm{ft}^{2} \cdot{ }^{\circ} \mathrm{F} / \mathrm{Btu}$.

The remaining two $B \& C$ modules are equipped to circulate Amertap balls and are capable of chlorinating the feed water independently of the system that chlorinates the main HX feed stream. 
Table 3.5. Biofouling and Corrosion Module

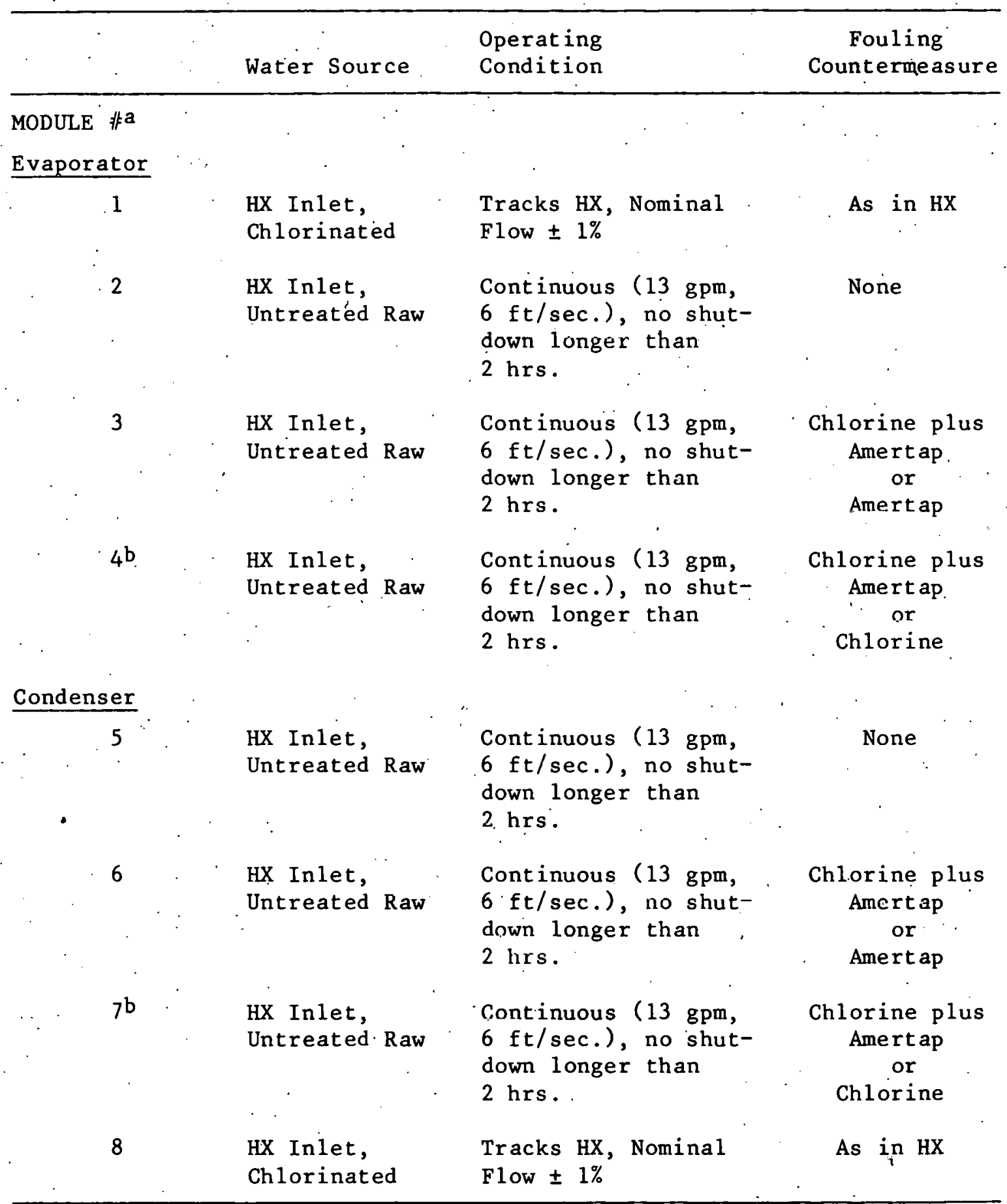

${ }^{a}$ All modules in parallel, per ANL design with ANL tube type HTM's. Tubes to be $\mathrm{Ti}$ from same lot as $\mathrm{HX}$ tubes.

${ }^{b} \mathrm{Chlorination} \mathrm{systems} \mathrm{for} \mathrm{modules} 4$ and 7 to be independent of the chlorination system for the main system. 
As installed on the OTEC-1 vessel, the modules will contain straight single pieces of stainless steel tubing in place of the HTMs and sample sections. The latter components are to be installed just prior to the time when the water circulating systems are to be tested. As part of the system check-out procedure, the operation of the flow meters, the ball circulating systems, the flow control systems, and the HTM heater will be checked out to verify proper operation and computer interfacing. Upon completion of these tests, the units will be drained and dried out to prevent contamination of interior tube surfaces enroute to the test site.

As soon as water from the test site is available and the pumps can be operated, flow meter calibrations and Wilson plots will be made on all units, after which the computer will be programmed to take cooling curves on a regular schedule: From this time on, flow is to be maintained at $6 \mathrm{ft} / \mathrm{sec}$ in the six units not tracking the HX conditions. The two HX tracking units will operate only when the water is circulated through the HXs.

\subsection{INSTRUMENTATION, DATA ACQUISITION, AND PROCESSING}

A mini-computer-based, digital data acquisition system (DAS) will be used to sample and record all test data. Personnel of the Test Director Contractor will identify test data and review them for discrepancies. Personnel will also maintain test reports and $\log$ sheets. Original data tapes will be duplicated, and the copy will be transported to a mainland facility to be corrected for instrument calibration and reduction to engineering units for detailed evaluation of system performance.

The DAS is a two-computer system configured as shown in Figure 3.14. CPU \#1 normally functions as the primary system computer and CPU 非 as the backup system computer. In this mode the data bus switch connects the test console, the data acquisition console, and the signal conditioners to the CPU \#1 data bus. A11 the real time displays and data acquisition functions are performed by this part of the system. CPU \#2 is available for off-line operations as well as for monitoring the on-line system for failure. If the primary system fails, the data bus switch connects the consoles and signal conditioners to the backup computer, which then performs the on-line system functions . 


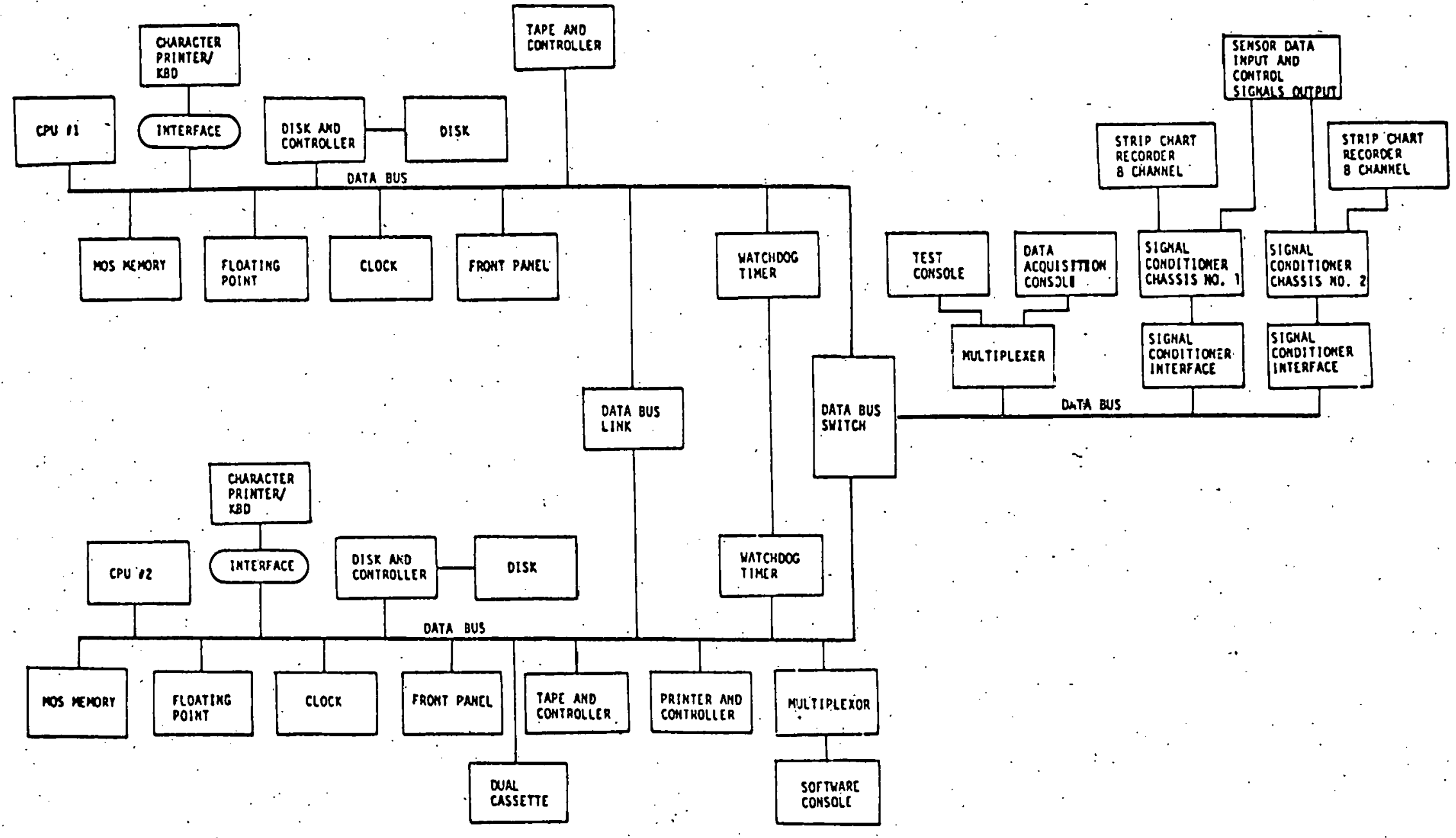

Fig. 3.14. DAS Processing Block Diagram 
Instrument sensor data from temperature transducers, pressure transducers, level transducers, load cells, and flow meters will be recorded during tests. The instrument 1 ist is given in Table 3.6 .

Data sampling and recording rates will be program controlled, and the operator will be able to change them. Data will be recorded on both tape and disc at independently selectable rates. Several different data groups may be required, with each group sampled and recorded at a different rate. Due to measurement characteristics, it may be necessary to sample some parameters several times and record averages. The system is capable of sampling and recording all channels-to-tape at a rate of up to five samples/sec each while recording all channels-to-disc at a rate of one sample/sec.

The DAS will provide support for both facility and test operations in the form of real time data displays. Preprogrammed and interactively selected data displays can be provided. Operator selection of the display frequency and display device will be necessary. Tabular output devices will: include the CRTs and the line printer. Graphical output can be provided by the CRT with hard-copy capability.

The interactive display programs allow the operator to select up to about 40 parameters. They will be tabulated at selected intervals on devices specified by the operator. Preprogrammed displays are required for the following subsystems: evaporator, condenser, ammonia plant, cold water pipe, biofouling and corrosion van, environmental, and stationkeeping.

It will be necessary to schedule several of these displays concurrent1y. The DAS is capable of selecting and scheduling these programs independently and displaying the output on devices selected by the operator.

The DAS can be used by the operator to set, or modify facility control system setpoints. In addition, the DAS will provide control functions for the eight ANL test modules. Setpoint changes can be logged on the system console with time and date.

Critical parameters can be monitored for out-of-1imits conditions. Tolerance and monitoring. intervals can be selectable. by the operator. Alarm trip indications $c$ an be displayed on the CRT and logged on the system console. The Test Director will determine what action must be taken in the event 
Table 3.6. Instrumentation Requirements

\begin{tabular}{|c|c|c|c|c|c|c|}
\hline Description (No. Sensors) & Location & & Range & $\begin{array}{l}\text { Instrument } \\
\text { System } \\
\text { Accuracy. }\end{array}$ & & $\begin{array}{l}\text { Tag } \\
\text { Number }\end{array}$ \\
\hline \multicolumn{7}{|l|}{ EVAPORATOR } \\
\hline Sea Water Temperature (2) & Inlet $\&$ Outlet Water & Lines* & - & - & & - \\
\hline Sea Water Temperature (4) & Inlet Water Box & & $65-90^{\circ} \mathrm{F}$ & $\pm 0.127^{\circ} \mathrm{F}$ & & $\mathrm{TE}-8$ \\
\hline Sea Water Temperature (14) & Outlet Water Box & & $65-90^{\circ} \mathrm{F}$ & $\pm 0.127^{\circ} \mathrm{F}$ & & $\mathrm{TE}-9$ \\
\hline Sea Water Pressure (4) & Inlet Water Box & & 5-20 psig & $\pm 0.051 \mathrm{psig}$ & & $\mathrm{PE}-7$ \\
\hline Sea Water Pressure (4) & Outlet Water Box & & 5-20 psig & $\pm 0.051 \mathrm{psig}$ & & $\mathrm{PE}-8$ \\
\hline Ammonia Temperature (10) & She11 Interior & & $65-80^{\circ} \mathrm{F}$ & $\pm 0.127^{\circ} \mathrm{F}$ & & $\mathrm{TE}-7$ \\
\hline Ammonia Temperature (1.) & Drain Tank & & $40-80^{\circ} \mathrm{F}$ & ${ }^{ \pm} 0.127^{\circ} \mathrm{F}$ & & $\mathrm{TE}-21$ \\
\hline Ammonia Vapor $\Delta P(1)$ & Upper Region & & $0-5$ in. $\mathrm{H}_{2} \mathrm{O}$ & $\pm 0.0027 \mathrm{in}$. & $\mathrm{H}_{2} \mathrm{O}$ & PDE -3 \\
\hline Ammonia Vapor $\Delta P(1)$ & Lower Region & & $0-5$ in. $\mathrm{H}_{2} \mathrm{O}$ & $\pm 0.0027 \mathrm{in}$. & $\mathrm{H}_{2} \mathrm{O}$ & $\mathrm{PDE}-4$ \\
\hline Water Temperature (1) & Closed Loop Inlet & & $65-90^{\circ} \mathrm{F}$ & $\pm 0.127^{\circ} \mathrm{F}$ & & $\mathrm{TE}-12$ \\
\hline Water Flow Rate (1) & Closed Loop Tubes & & $0-15 \mathrm{gpm}$ & $\pm 1.0 \%$ F.S. & & FT-31 \\
\hline Water Temperature (6) & Closed Loop Outlet & ${ }^{\circ}$ & $65-90^{\circ} \mathrm{F}$ & $\pm 0.127^{\circ} \mathrm{F}$ & & $\mathrm{TE}-10$ \\
\hline Sea Water Temperature (24) & Open Loop Outlet & & $65-90^{\circ} \mathrm{F}$ & $\pm 0.127^{\circ} \mathrm{F}$ & & $\mathrm{TE}-11$ \\
\hline Ammonia Reflux Flow Rate & Pump P-1 Discharge & & $1000-4000 \mathrm{gpm}$ & $\pm 1.0 \%$ & & FE-1. \\
\hline Ammonia Reflux Temperature. & Pump P-1 Discharge & & $40-80^{\circ} \mathrm{F}$ & $\pm 0.127^{\circ} \mathrm{F}$ & & $\mathrm{TE}-2$ \\
\hline Ammonia Reflux Flow Rate & Pump P-2 Discharge & & $0-2000 \mathrm{gpm}$ & $\pm 1 . .0 \%$ & . & $\mathrm{FE}-2$ \\
\hline Ammonia Reflux Temperature & Pump P-1 Discharge & & $40-80^{\circ} \mathrm{F}$ & $\pm 0.127^{\circ} \mathrm{F}$ & & $\mathrm{TE}-3$ \\
\hline Ammonia Reflux Flow Rate & Pump P-2 Discharge & . & $0-200 \mathrm{gpm}$ & $\pm 1.0 \%$ & & FE-3 \\
\hline Sea Water Flow Rate (1) & Open Loop Tube & & $0-15 \mathrm{gpm}$ & $\pm 1.0 \%$ & & FT -21 \\
\hline Ammonia Vapor Pressure (1) & Shell Interior & & $110-140^{\circ}$ psig & \pm 0.25 psig & & $\mathrm{PE}-1$ \\
\hline Ammonia Liquid Pressure (1) & Evaporator Sump & & $110-140$ psig & \pm 0.25 psig & & $\mathrm{PE}-2$ \\
\hline Ammonia Liquid Level (1) & Evaporator Sump & & $6-54$ in. $\mathrm{H}_{2} \mathrm{O}$ & \pm 0.501 in. & $\mathrm{H}_{2} \mathrm{O}$ & LE-1 \\
\hline
\end{tabular}

ॠProvisions for temporary measurement have been made. 
Table 3.6. (cont'd)

\begin{tabular}{|c|c|c|c|c|}
\hline Description (No. Sensors) & Location & Range & $\begin{array}{l}\text { Instrument } \\
\text { System } \\
\text { Accuracy }\end{array}$ & $\begin{array}{l}\text { Tag } \\
\text { Number }\end{array}$ \\
\hline \multicolumn{5}{|l|}{ CONDENSER } \\
\hline Sea Water Temperature (2) & Inlet \& Outlet Water Lines* & $-\quad \therefore$ & - & - \\
\hline Sea Water Temperature (4) & Inlet Water Box & $35-50^{\circ} \mathrm{F}$ & $\pm 0.127^{\circ} \mathrm{F}$ & $\mathrm{TE}-16$ \\
\hline Sea Water Temperature (14) & Outlet Water Box & $35-50^{\circ} \mathrm{F}$ & $\pm 0.127^{\circ} \mathrm{F}$ & TE-15 \\
\hline Sea Water Pressure (4) & Inlet Water Box & 5-20 psig & \pm 0.051 psig & $\mathrm{PE}-13$ \\
\hline Sea Water Pressure (4) & Outlet Water Box & 5-20 psig & $\pm 0.051 \mathrm{psig}$ & $\mathrm{PE}-12$ \\
\hline Ammonia Temperature (2) & She11 Interior & $40-80^{\circ} \mathrm{F}$ & $\pm 0.127^{\circ} \mathrm{F}$ & $\mathrm{TE}-14$ \\
\hline Ammonia Temperature (5) & Drain Pipes* & - & - & - \\
\hline Ammonia Vapor $\Delta \mathrm{P}(1)$ & Top-Bottom, Aft & $0-5$ in. $\mathrm{H}_{2} \mathrm{O}$ & \pm 0.0027 in. $\mathrm{H}_{2} \mathrm{O}$ & PDE-10 \\
\hline Ammonia Vapor $\Delta \mathrm{P}(1)$ & Top-Bottom, Fore & $0-5$ in. $\mathrm{H}_{2} \mathrm{O}$ & \pm 0.0027 in. $\mathrm{H}_{2} \mathrm{O}$ & PDE-11 \\
\hline Water Flow Rate (1) & Closed Loop Tubes & $9-15 \mathrm{gpm}$ & $\pm 1.0 \%$ & FT -51 \\
\hline Sea Water Flow Rate (1) & Open Loop Outlet & 9-15 gpm & $\pm 1.0 \%$ & FT-41 \\
\hline Water Temperature (1) & Closed Loop Inlet & $32-52^{\circ} \mathrm{F}$ & $\pm 0.127^{\circ} \mathrm{F}$ & $\mathrm{TE}-19$ \\
\hline Water Temperature (6) & Closed Loop Outlet & $35-50^{\circ} \mathrm{F}$ & $\pm 0.127^{\circ} \mathrm{F}$ & $\mathrm{TE}-17$ \\
\hline Sea Water Temperature (24) & Open Loop Outlet & $35-50^{\circ} \mathrm{F}$ & $\pm 0.127^{\circ} \mathrm{F}$ & $\mathrm{TE}-18$ \\
\hline Ammonia Flow Rate (5) & Drain Lines & $0-250 \mathrm{gpm}$ & $\pm 1.0 \%$ & FE -13 \\
\hline Ammonia Vapor Pressure (1) & She11, Central, Center & $58-75$ psig & $\pm 0.25 \mathrm{psig}$. & $\mathrm{PE}-9$ \\
\hline Ammonia Liquid Level (1) & Drain Pot & $0-14$ in. & $\pm 1.0 \%$ & LE 3-3 \\
\hline Vapor Temperature (4) & Noncondensibles Vent Lines* & - & - & - \\
\hline \multicolumn{5}{|l|}{ AMMONIA LOOP } \\
\hline Ammonia Flow Rate (1) & Downstream/Throttle Valve & $\begin{array}{l}4,777,200- \\
61,470,800 \mathrm{scfh}\end{array}$ & $\pm 0.255 \%$ & FT-106 \\
\hline Ammonia Temperature (2) & Upstream/Throttle Valve & $65-80^{\circ} \mathrm{F}$ & $\pm 0.127^{\circ} \mathrm{F}$ & $\mathrm{TE}-6$ \\
\hline
\end{tabular}

* Provision for temporary measurement has been made. 


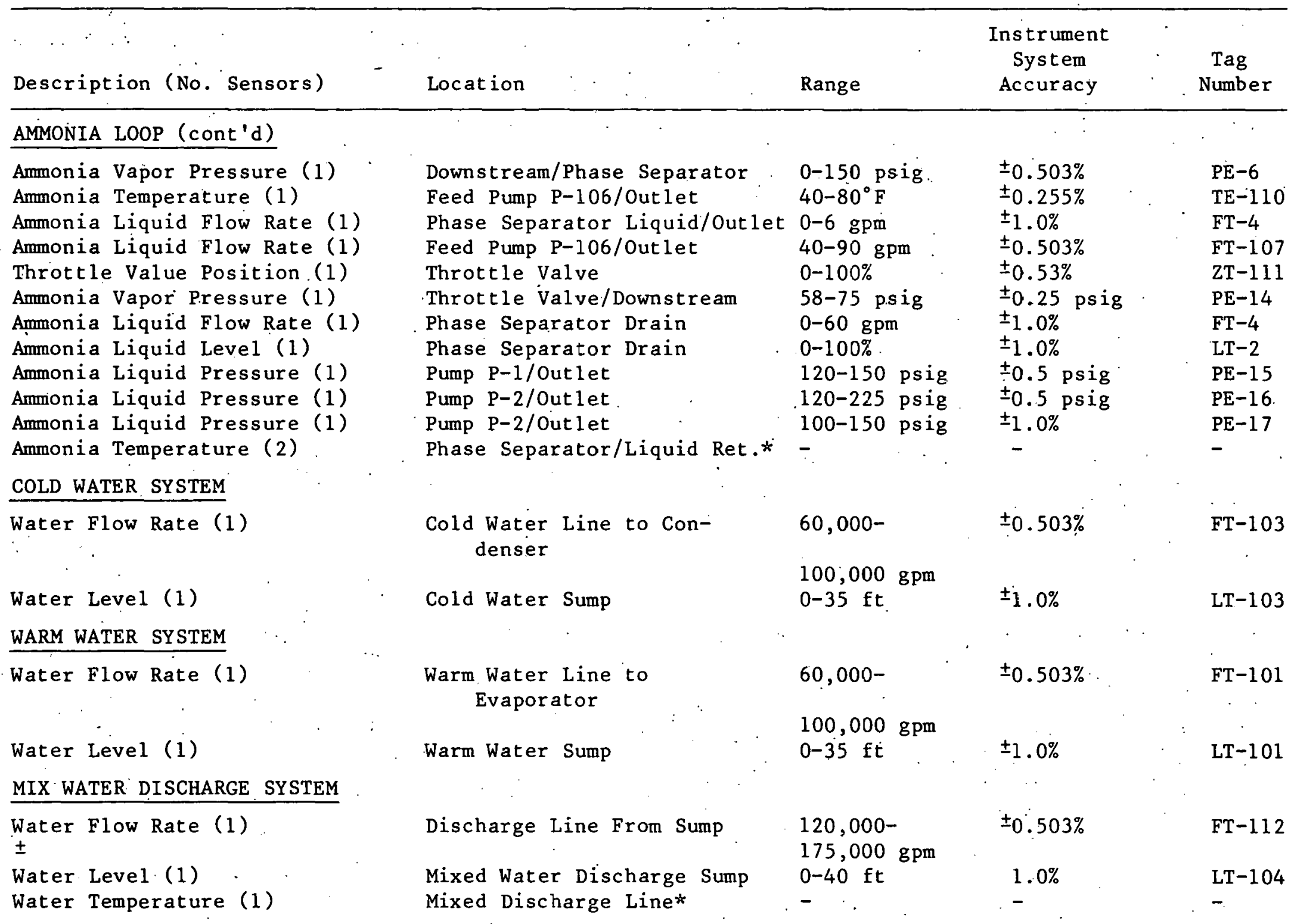

\#Provision for temporary measurement has been made 
Table 3.6. (cont'd)

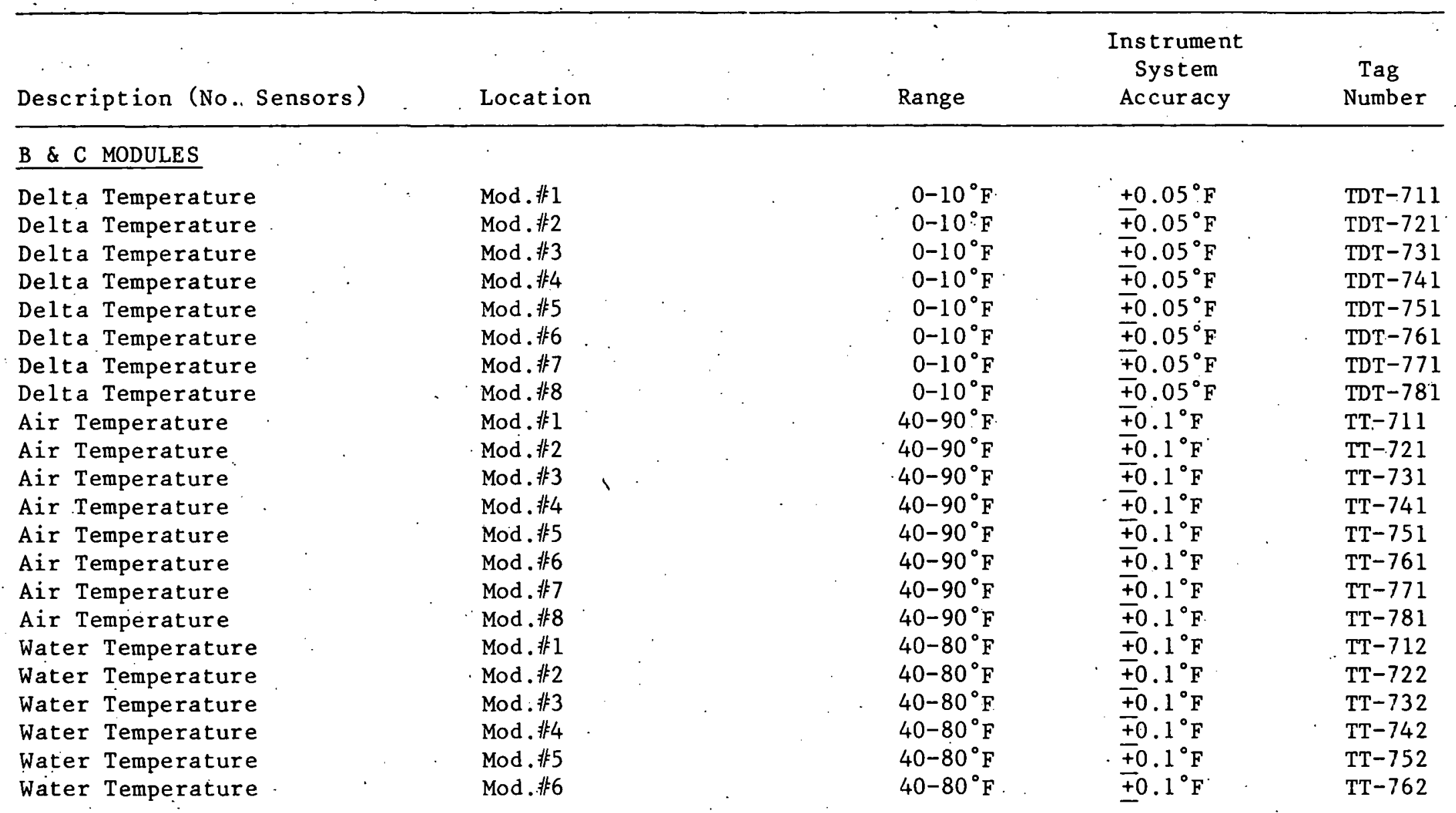

* Provision for temporary measurement has been made. 
Table·3.6. ( cont'd)

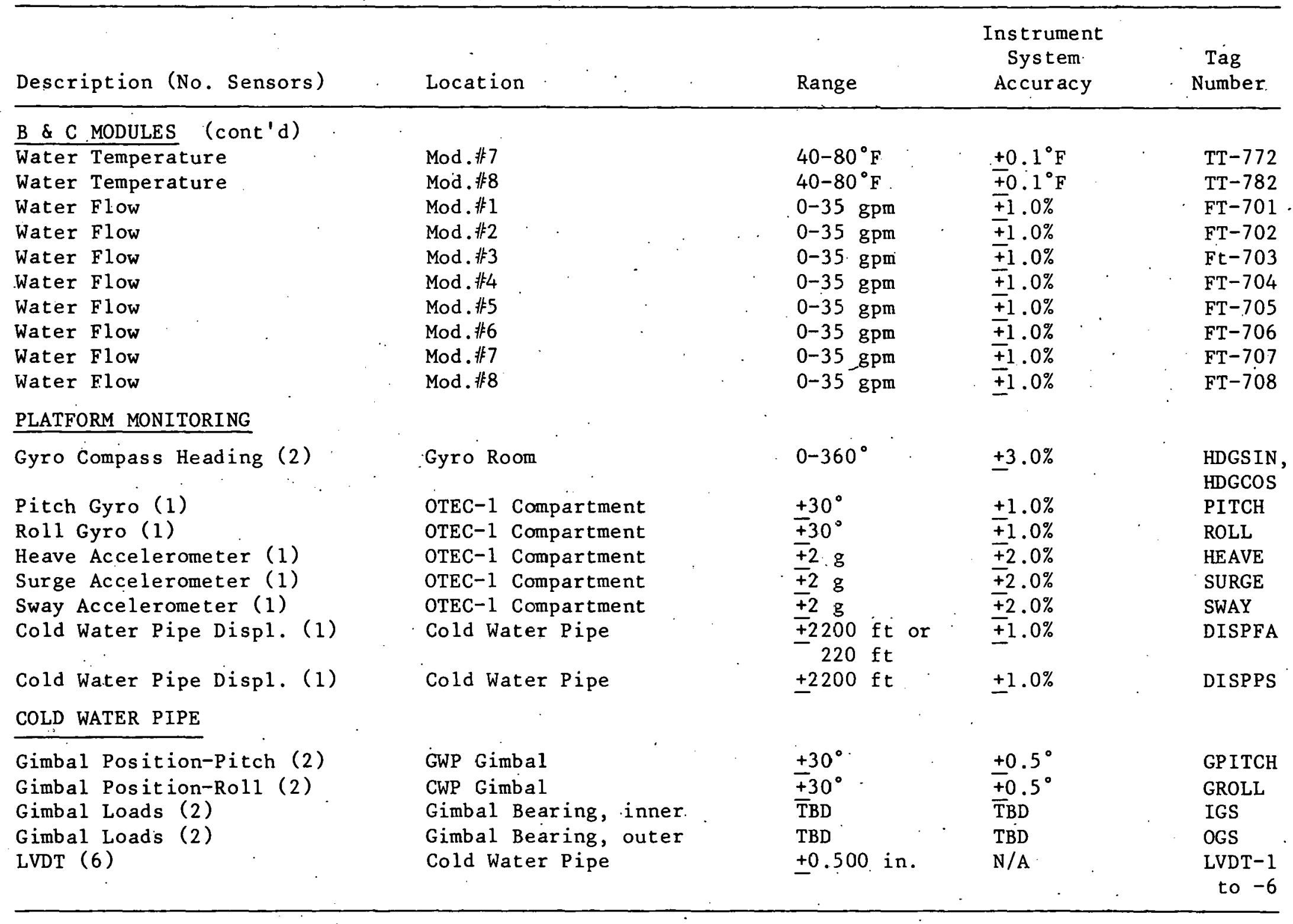

*Provision for temporary measurement has been made. 
of an alarm. Generally, the necessary actions will be identified in the detailed test procedures.

Recorder charts, test logs, test procedures, and raw data sheets.will be annotated, identified, and stored. Digital tapes. will record raw dâta and each record will contain the data sample time and an identification of the data channels contained in the record. Each tape will contain a parameter identification 1 ist and the instrument calibration data for converting each parameter to engineering units. Data tapes will be identified externally with a label and stored. for a minimum of five years after completion of the test program. Original tapes may be transported to shore after the duplicate has been received safely.

There is no uninterruptible power supply for the DAS. The system, however, is fail-safe in that recorded data will not be lost. The only lost signals will be. those that would have been recorded during the interval the power is off.

\subsection{SUPPORT FACILITIES}

On-board facilities will include shops for repair work, such as valve and pump maintenance, gasket and seal replacement, and instrument repair. Equipment and tools will be available for simple drilling, machining, and welding: A limited inventory of bolts, gaskets, seals, packings; and bearings will be maintained on board.

More extensive facilities are available on shore. These will be used initially as support for operations leading up to the initial deployment and will be available later to support:operations at sea as required. 
THIS PAGE

WAS INTENTIONALLY

LEFT BLANK 


\section{PROPOSED TESTS AND EXPERIMENTS}

\subsection{EVAPORATOR AND CONDENSER TESTS}

The primary objective. of the heat exchanger testing is to evaluate the thermal-hydraulic performance of the TRW 1-MWe shell-and-tube evaporator and condenser in an ocean environment. The following tests are planned:

- Baseline thermal-hydraulic tests with the 1-MWe evaporator and condenser to validate predicted performance.

- Tests using varying ammonia feed rates to determine the optimum reflux $r$ atio and to demonstrate the improvement in performance that $c$ an be attained with reduced liquid loading using mid-plane feed.

- 4-MWe ( $1 / 4$ section simulation) sprayed-bundle tests to determine the effect of vapor velocity and entrainment on heat exchanger performance.

- Flooded-bundle tests to obtain data for comparing with the performance of the sprayed-bundle evaporator.

The sequence of tests in order of decreasing priority is specified in the OTEC-1 target schedule given in Section 5. Highest priority is assigned to performance tests with the simulated 4-MWe configuration. Initial runs will be conducted at nominal conditions to establish a performance benchmark. Then, reflux ratio tests (with three different spray arrangements) will follow to determine the optimum ammonia feed rate. Runs at nominal conditions will be repeated periodically to detect any variations in performance that may arise because of changes in the Linde High Flux surface, biofouling resistance, or other uncontrollable factors.

In the next series of tests the 4 MWe-simulation shrouds will be removed to provide the reference 1-MWe baseline configuration. As with the simulated 4-MWe configuration, tests will be conducted first at nominal conditions and then over a range of ammonia reflux ratios. Following the sprayed-evaporator tests, shrouds will be installed to provide the 1-MWe flooded-bundle configuration, and tests will be conducted with both a fully flooded bundle and a partially flooded bundle (lower half only).

The essential heat exchanger testing will conclude with a run of the simulated 4-MWe configuration under nominal conditions. If time permits, miscellaneous tests will then be run--for example, activation/deactivation with the 4-MWe sprayed-bundle configuration and tests to determine the effects of water in ammonia. 
Section 4.1 is divided into four subsections: Baseline Tests (1-MWe configuration), Reflux Ratio Tests, Vapor Velocity Tests (4-MWe configuration), and Flooded-Bundle Tests. Each subsection provides a concise statement of the specific test objectives and a description of the tests. The first subsection, Baseline Tests, includes a discussion of required measurements, experimental uncertainties, and diagnostic tests, as well as a definition of steady state and the calculations required for performance evaluation. Because much of this material applies to the other tests as well, it is not repeated in the other subsections. The description of the OTEC-1 facility in Section 3 provides supplemental information on heat exchanger design features and is, therefore, a valuable adjunct to the present section.

\subsubsection{Baseline Tests}

The overall objective of the baseline tests is to evaluate baseline performance of the TRW 1-MWe evaporatior and condenser in an ocean environment. (See Configuration 1 of Fig. 4.1).

Description of Tests and Measurements

Nominal test conditions for the evaporator and condenser are given in Table 4.1. To measure the overall thermal-hydraulic performance of the evaporator and the condenser, the following quantities will be determined:

- $\Delta \mathrm{P}$ between waterboxes.

- Overall Uo and heat duty.

- $\mathrm{NH}_{3}$ side $\Delta \mathrm{P}$ and vapor flow rate.

- Exit quality and entrainment.

To ascertain local thermal-hydraulic performance, the following quantities will be determined:

- $\mathrm{U}_{\mathrm{O}}$ for individual instrumented tubes to examine tube-totube variations.

- Outlet waterbox temperature rake for crude assessment of "zonal" variations in $\mathrm{U}_{\mathrm{O}}$.

- Local shell-side temperature and pressure measurements. 


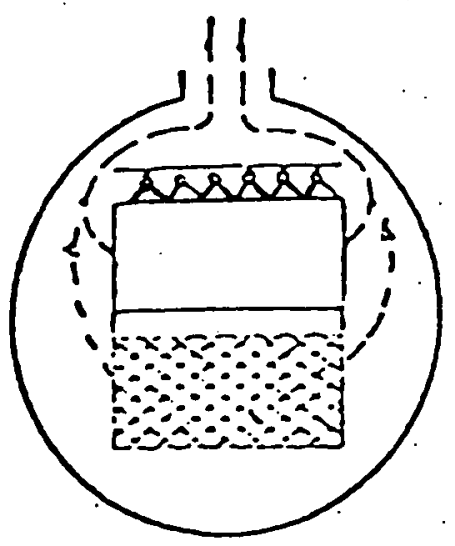

(A) TOP FEED ONLY

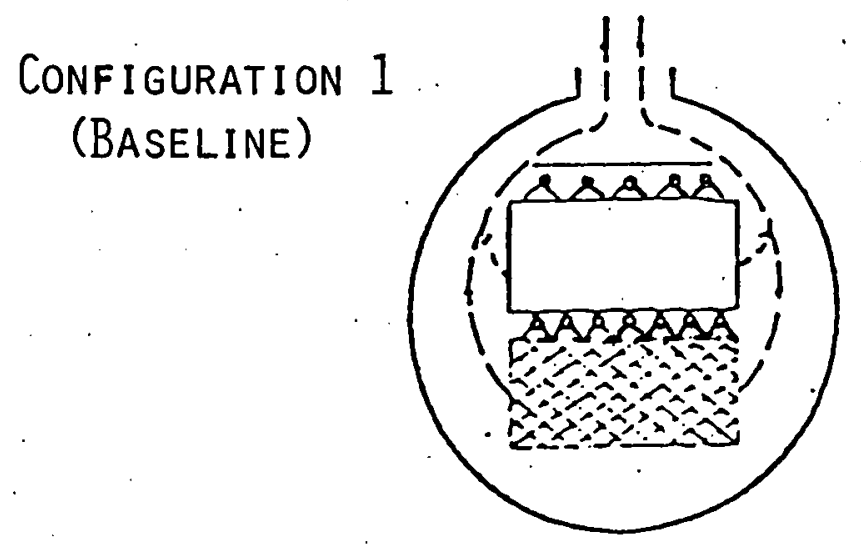

(B) MULT I-PLANE FEED
VAPOR EXIT

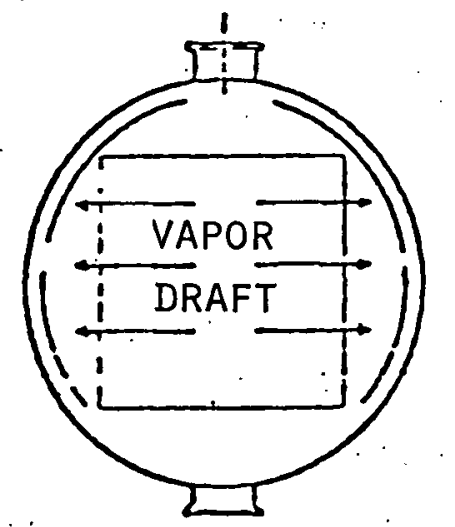

(A) UNSHROUDED FULL BUNDLE
Configuration 2

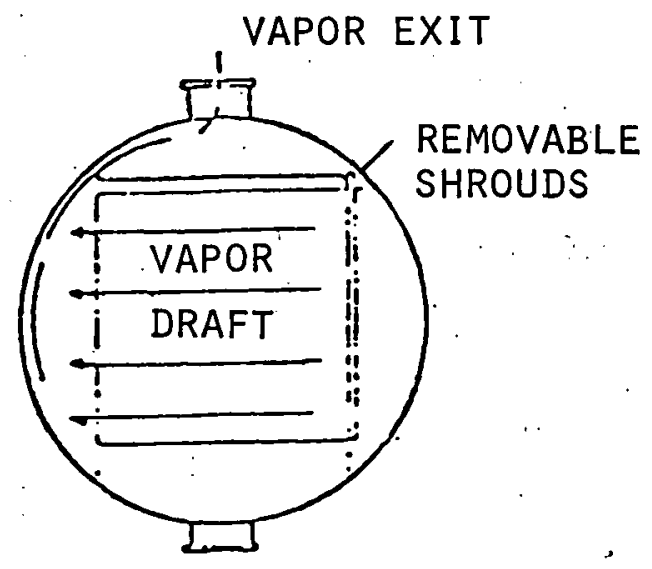

(B) SHROLDED FULL BUNDLE

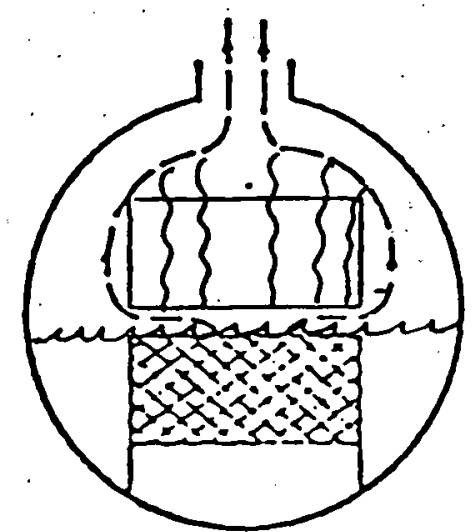

(A) FLOODED ENHANCED BUNDLE

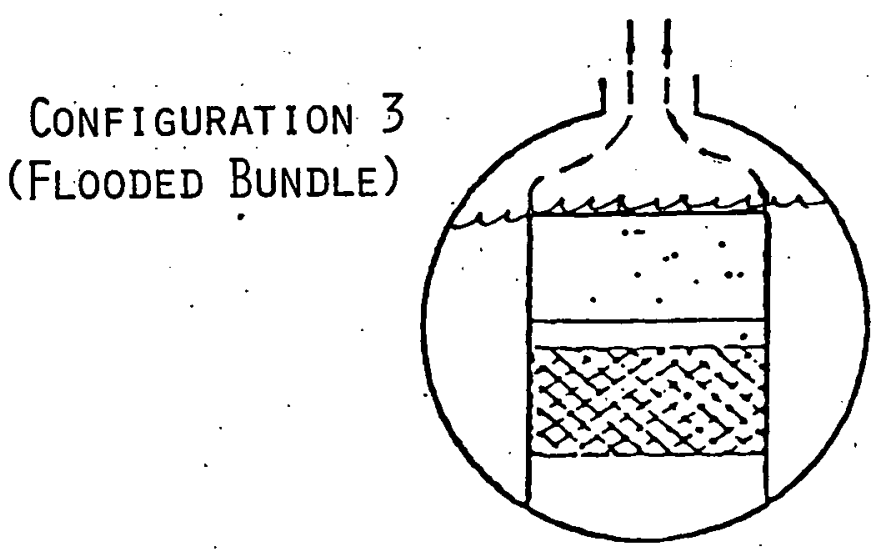

(в) FLOODED FULL BUNDLE

Fig. 4.1. Heat Exchanger Configurations 
Table 4.1. Nominal Test Conditions for the Evaporator and the Condenser

\begin{tabular}{|c|c|c|}
\hline . & Evaporator & Condenser \\
\hline Sea Water Flow Rate (gpm) & 82,600 & 68,170 \\
\hline Sea Water Velocity & & \\
\hline (in-tube, ft/sec) & 6.0 & 5.6 \\
\hline Sea Water Temperature $\left({ }^{\circ} \mathrm{F}\right)$ & 80 & 40 \\
\hline $\begin{array}{l}\text { Ammonia Feed Rate } \\
\text { (top nozzles, 1b/hr) } \\
\text { Ammonia Shell-side }\end{array}$ & 768,000 & - \\
\hline $\begin{array}{l}\text { Ammonia Shell-Side } \\
\text { Temperaturé/Pressure }\end{array}$ & $73.5^{\circ} \mathrm{F} / 136.9 \mathrm{psia}$ & $48^{\circ} \mathrm{F} / 85.8 \mathrm{psia}$ \\
\hline
\end{tabular}

${ }^{2}$ Estimated evaporator shel1-side temp/press to yield the nominal 1-MWe heat duty. Recall that the shell-side condition was $72{ }^{\circ} \mathrm{F} /$ 133.4 psia in the original TRW design with all smooth tubes. Operating under these conditions with the present evaporator would yield a heat duty in excess of 1-MWe and would overload the condenser.

To determine the effects of biofouling and biofouling control, the following measurements will be taken:

- $\mathrm{U}_{\mathrm{o}}$ for closed instrumented loops (clean water); and

- $U_{0}$ for open, instrumented Amertap and dirty loops (sea water).

These two quantities will be compared to assess biofouling $\left(R_{f}\right)$ and to check $\mathrm{K}_{\mathrm{f}}$ against biofouling monitors.

\section{Uncertainty in Calculated Quantities}

Table 4.2 contains a summary' of the uncertainties in the principal performance parameters calculated using the Kline-McClintock second-order approach. Details of these calculations are given in Appendix A. 
Table 4.2. Uncertainties in Calculated Quantities

\begin{tabular}{ll}
\hline \multicolumn{1}{c}{ Quantity } & Uncertainty \\
\hline P (between waterboxes) & $\pm 2 \%$ \\
Q: waterside heat balance & $\pm 5 \%$ \\
ammonia-side balance & $\pm 1 \%$ \\
$\mathrm{U}_{\mathrm{O}}:$ individual tubes $\quad$ & $\pm 6 \%$ \\
$\quad$ overalla & $\pm 3 \%$ \\
$1-\mathrm{X}_{\mathrm{e}}(1-$ exit quality) & $\pm 2 \%$ \\
$\mathrm{R}_{\mathrm{f}}$ (from instrumented 1oops) & $\pm 0.0001 \frac{\mathrm{hr} \cdot \mathrm{ft}{ }^{\circ} \mathrm{F}}{\mathrm{Btu}}$ \\
$\Delta \mathrm{h}_{\mathrm{NH}}$ (variation in $\mathrm{h}_{\mathrm{NH}}$ ) & $\pm 20 \%$ of reference $\mathrm{h}_{\mathrm{NH}_{3}}$ \\
$\quad$ unenhanced tubes \\
$\quad$ enhanced tubes
\end{tabular}

asee Appendix A for a detailed explanation.

Diagnostic Tests

A number of diagnostic tools are available to determine the cause of a variation between measured performance and predicted performance:

- $\mathrm{NH}_{3}$-side heat balance to check waterside heat balance.

- Instrumented loops to ascertain abnormal variations in $h_{N_{3}}$ throughout bundle resulting from nonuniform liquid feed, bundle-depth-related 1 iquid loading, and vapor shear.

- Comparison of $R_{f}$ from instrumented loops with $R_{f}$ from biofouling monitors.

- Instrumented tube in condenser to determine build-up of noncondensibles (e.g., near vents).

- View ports for flow visualization.

- Wilson plots and rangeability tests.

- Verification of Amertap ball rate and distribution by direct count in instrumented loops.

If the diagnostic tests reveal a serious functional problem (e.g., widespread plugging of spray nozzles), the Test Director and his technical advisors will decide on the appropriate course of action. 


\section{Definition of Steady state}

For all test measurements, the criterion for steady-state operation is defined as four hours (minimum) and six hours (preferable) of operation with no detectable change in heat duty, water flow rate, or ammonia feed rate outside the range of measurement uncertainty of the instruments used. During periods of steady, operation, the overall heat transfer coefficient should not vary by more than the uncertainty in its determination.

In tests at Argonne National Laboratory (ANL) with the Linde High Flux surface, it was found that approximately 100 hours were required to reach $a$. fully activated, steady state condition when the surface was initially deactivated (in contact with 1 iquid $\mathrm{NH}_{3}$ under nonboiling conditions). In the OTEC-1 baseline tests with the sprayed bundle, the lower enhanced portion of the bundle may indeed require 100 hours to attain steady state. Tests at ANL revealed that the approach to steady state could often be accelerated by rapid drying of the surfaces (by shutting off the ammonia feed for several hours) and then reestablishing nominal conditions. This drying procedure can be employed in the OTEC-1 testing if it is deemed necessary by the Test Director.

After initial start-up of the sea water pumps, no interruption of either the warm or cold sea water flow rate is planned. In the event of an unscheduled flow shutdown; the normal start-up procedure must be followed upon resumption of operation. To accelerate the attainment of steady state in the evaporator, it is recommended that the warm sea water flow be established before introducing the ammonia.

The real time behavior of certain "key" parameters will serve as a guide for the test operator to determine when steady state conditions.have. been attained in the heat exchangers. Based on test experience at ANL with $1-\mathrm{MW}_{\mathrm{t}}$ heat exchangers, the following are selected as key parameters:

- Overall U (evaporator)

- Ovérall Uo (condenser)

- Heat duty (evaporator)

- Heat duty (condenser)

Steady state conditions in the heat exchangers are assessed by monitoring these parameters as a function of time (on a digital plotter or strip chart 
recorder) and observing the approach to an asymptotic value. The following parameters should be monitored:

- Local U (evaporator, lower bundle)

- Shel1-side pressure (condenser)

These additional key parameters will serve as diagnostic tools rather than as indicators of steady state. The local $U_{j}$ of a tube in the lower enhanced portion of the evaporator will indicate the transient effects associated with activation of the Linde High Flux Surface. The condenser shell-side pressure will be monitored to determine the magnitude and frequency of pressure fluctuations. Based on ANL test experience, these she11-side pressure fluctuations are expected to be: substantial. Although a spectral analysis of the pressure signal is not planned, a visual inspection should be made to estimate the highest frequency component of the pressure spectrum; $f_{0}$. This maximum frequency. will be compared to the Nyquist frequency $1 / 2 \Delta$ to ensure that:

$$
1 / 2 \Delta>\mathrm{f}_{\mathrm{O}}
$$

where $\Delta$ is the time spacing of data sampled by the computer. The above inequality needs to be satisfied to prevent aliasing and to ensure an unbiased time average of the pressure signal. This is important because the average shell-side pressure is used to calculate the average shell-side saturation temperature, which in turn is used to calculate the overall $U_{0}$ of the condenser.

In conducting the OTEC-1 heat exchanger tests, the test operator will utilize not only real time input from the key parameters, but also less frequent printouts of all heat exchanger performance parameters.

\section{Calculations for Performance Evaluation}

This section summarizes the basic calculations required to evaluate performance. The detailed data reduction scheme is given in Appendix. $B$. 
1. Overall thermal-hydraulic performance of the evaporator and the condenser

- $\triangle \mathrm{P}$ between water boxes to verify design calculations and relate to pumping power requirements for the evapor ator and condenser:

$\Delta P=\bar{P}_{\mathbf{i}} \cdot-\overline{\mathrm{P}}_{\mathrm{O}}$

where:

$\bar{P}_{i}=$ average static pressure in the inlet waterbox, and

$\overline{\mathrm{P}}_{\mathrm{O}}=$ average static pressure in the outlet waterbox.

- $\mathrm{U}_{\mathrm{o}}$ and heat duty for comparison with predicted performance (see Table 4.3).

$Q=\dot{m} c_{p}\left(\bar{T}_{i}-\bar{T}_{o}\right)$

$\Delta T l_{m}=\frac{\left(\bar{T}_{i}-\bar{T}_{o}\right)}{\ln \left(\frac{\bar{T}_{i}-\bar{T} !}{\bar{T}_{0}-\bar{T} !}\right)}$

$\mathrm{U}_{0}=\frac{\mathrm{Q}}{\mathrm{A}_{\mathrm{O}} \Delta \mathrm{T}_{\ell \mathrm{m}}}$

or

$\mathrm{U}_{\mathrm{o}}=\frac{\dot{\mathrm{m}} c_{\mathrm{p}}}{\mathrm{A}_{\mathrm{o}}} \ln \left(\frac{\overline{\mathrm{T}}_{\mathrm{i}}-\overline{\mathrm{T}}^{\prime}}{\overline{\mathrm{T}}_{\mathrm{O}}-\overline{\mathrm{T}}^{\prime}}\right)$

where:

$$
\begin{aligned}
Q & =\text { heat duty, } \\
\Delta \mathrm{T}_{\ell \mathrm{m}} & =\text { log-mean temperature difference, } \\
\dot{\mathrm{m}} & =\text { water flow rate, } \\
\overline{\mathrm{T}}_{\mathbf{i}} & =\text { average } \mathrm{H}_{2} \mathrm{O} \text { inlet temperature (inlet waterbox), } \\
\overline{\mathrm{T}}_{\mathrm{O}} & =\text { average } \mathrm{H}_{2} \mathrm{O} \text { outlet temperature (outlet waterbox); and } \\
\overline{\mathrm{T}}^{\prime} & =\left\{\begin{array}{l}
\text { evaporator } \mathrm{NH}_{3} \text { saturation temperature from shell-side RTDs. } \\
\text { condenser } \mathrm{NH}_{3} \text { saturation temperature at condenser pressure. }
\end{array}\right.
\end{aligned}
$$


Table 4:3. Predicted $U_{0}$ vs $R_{f}$ for Evaporator and Condenser

\begin{tabular}{lllll}
\hline & & \multicolumn{4}{c}{$\mathrm{U}_{\mathrm{o}}\left(\mathrm{Btu} / \mathrm{hr} \cdot \mathrm{ft}^{\left.2 \cdot{ }^{\circ} \mathrm{F}\right)}\right.$} \\
\cline { 3 - 5 }$\left(\mathrm{hr} \cdot \mathrm{ft}^{2} \cdot{ }^{\circ} \mathrm{F} / \mathrm{Btu}\right)$ & Smooth & Enhanced & Overalla & Condenser \\
\cline { 2 - 5 } & & \multicolumn{3}{c}{ Evaporator } \\
\hline 0.00053 & 370 & 520 & 445 & 389 \\
0.0004 & 390 & 561 & 476 & 411 \\
0.0003 & 407 & 596 & 502 & 430 \\
0.0002 & 426 & 636 & 531 & 450 \\
0.0001 & 446 & 682 & 564 & 473 \\
0 & 468 & 735 & 602 & 498
\end{tabular}

approximated by the average of smooth and enhanced

In Table 4.3, $\mathrm{U}_{\mathrm{O}}$ is defined as follows:

$$
\frac{1}{\mathrm{U}_{\mathrm{o}}}=\frac{1}{\mathrm{~h}_{\mathrm{o}}}+\frac{1}{\mathrm{~h}_{\mathrm{i}}} \frac{\mathrm{A}_{\mathrm{o}}}{\mathrm{A}_{\mathrm{i}}}+\frac{1}{\mathrm{~h}_{\mathrm{w}}} \frac{\mathrm{A}_{\mathrm{o}}}{\mathrm{A}_{\mathrm{w}}}+\mathrm{R}_{\mathrm{f}} \frac{\mathrm{A}_{\mathrm{o}}}{\mathrm{A}_{\mathrm{i}}}
$$

where: $h_{w}=4926 \mathrm{Btu} / \mathrm{hr}^{\circ} \cdot \mathrm{ft}^{2}{ }^{\circ} \mathrm{F}$,

$$
\begin{aligned}
& \mathrm{A}_{\mathrm{o}} / \mathrm{A}_{\mathrm{i}}=1.059, \text { and } \\
& \mathrm{A}_{\mathrm{O}} / \mathrm{A}_{\mathrm{W}}=1.029
\end{aligned}
$$

where $h_{0}$ and $h_{i}$ are given below:

\begin{tabular}{ccc} 
& Condenser & \multicolumn{1}{c}{ Evaporator } \\
\hline $\mathrm{h}_{\mathrm{O}}$ & 1428 & 1000 (Unenhanced) - Lockheed Data \\
$\left(\mathrm{Btu} / \mathrm{hr} \cdot \mathrm{ft}_{2}{ }^{\circ}{ }^{\circ} \mathrm{F}\right)$ & & 4500 (Enhanced) - ANL Data \\
$\mathrm{h}_{\mathrm{i}}$ & $963^{*}$ & $1140^{*}$
\end{tabular}

*TRW design value from Braun correlation 
Equations 2, 3; and 4 apply to both the evaporator and the condenser. Moreover, since the evaporator is a hybrid unit (i.e., it has a smooth upper bundle and an enhanced lower bundle), the performance of each portion can be evaluated separately. A splitter plate in the waterbox of the evaporator outlet isolates the upper and lower bundles. In evaluating Eqs. 2, 3, and 4 for each bundle, $T_{0}$ is based on the average of the resistance temperature devices (RTDs) in the respective portions of the outlet waterbox. Also, a $50 / 50$ water flow split is assumed. Predicted $U_{0}$. values are given in Table 4.3.

- Exit quality and entrainment

Mixture quality, $x_{e}$, is defined as follows:

$$
\mathrm{x}_{\mathrm{e}}=\frac{\dot{\mathrm{m}}_{\mathrm{v}}}{\dot{\mathrm{m}}_{\mathrm{v}}+\dot{\mathrm{m}}_{\ell}}
$$

where:

$$
\begin{aligned}
& \dot{\mathrm{m}}_{\mathrm{v}}=\text { vapor flow rate, and } \\
& \dot{\mathrm{m}}_{\ell}=1 \text { iquid flow rate. }
\end{aligned}
$$

In the present case, the liquid flow rate represents the entrainment rate. For the overall evaporator, Eq. 5 is readily evaluated from (1) the measured ammonia vapor flow after the phase separator and (2) the measured ammonia liquid flow in the drain line of the phase separator. There is no provision for separate measurements of the entrainment rates in either the upper or the lower bundle. This can be determined only from a detailed entrainment analysis.

Based on calculations using a vapor/liquid interaction and entrainment model developed by ANL, 1 iquid entrainment is expected to be relatively small.

- $\mathrm{NH}_{3}$ side heat balance to check heat duty calculated from waterside measurements

EVAPORATOR:

$$
Q=\dot{\mathrm{m}}_{f}\left[\frac{1}{(1+\sigma)} \mathrm{h}_{\mathrm{fg}}+\mathrm{c}_{\mathrm{p}}\left(\mathrm{T}_{\mathrm{o}}-\mathrm{T}_{\mathrm{i}}\right)\right]
$$


where:

$$
\begin{aligned}
\sigma & =\frac{\dot{\mathrm{m}}_{\mathrm{f}}-\dot{\mathrm{m}}_{\mathrm{v}}}{\dot{\mathrm{m}}_{\mathrm{v}}} \\
\sigma & =\text { reflux ratio, } \\
\dot{\mathrm{m}}_{\mathbf{v}} & =\mathrm{NH}_{3} \text { vapor flow from phase separator, } \\
\dot{\mathrm{m}}_{\mathbf{f}} & =\mathrm{NH}_{3} \text { feed flow to evaporator, } \\
\mathrm{T}_{\mathbf{i}} & =\mathrm{NH}_{3} \text { liquid inlet to evaporator (subcooled), and } \\
\mathrm{T}_{\mathrm{o}} & =\mathrm{NH}_{3} \text { saturation temperature at exit. }
\end{aligned}
$$

CONDENSER :

$$
\dot{Q}=\ddot{\mathrm{m}}_{\mathrm{v}}\left[\mathrm{h}_{\mathrm{fg}}+\mathrm{c}_{\mathrm{pv}}\left(\mathrm{T}_{\mathrm{i}}-\mathrm{T}_{\mathrm{s}}\right)+\mathrm{c}_{\mathrm{pl}}\left(\mathrm{T}_{\mathrm{S}}-\mathrm{T}_{\mathrm{o}}\right)\right]
$$

where:

$$
\begin{aligned}
& \dot{\mathrm{m}}_{\mathrm{v}}=\mathrm{NH}_{3} \text { vapor flow from phase separator to condenser, } \\
& \mathrm{T}_{\mathrm{i}}=\mathrm{NH}_{3} \text { inlet temperature to condenser (superheated), } \\
& \mathrm{T}_{0}=\mathrm{NH}_{3} \text { liquid from condenser (subcooled), and } \\
& \mathrm{T}_{\mathbf{S}}=\mathrm{NH}_{3} \text { saturation temperature at condenser pressure. }
\end{aligned}
$$

2. Local thermal-hydraulic performance to validate design calculations and for diagnostic purposes

- $\mathrm{U}_{\mathrm{o}}$ for instrumented tubes (Refer to Figs. 4.2 and 4.3 for specific tube locations.)

$$
\mathrm{U}_{\mathrm{o}}=\frac{\dot{\mathrm{m}} \mathrm{c}_{\mathrm{p}}}{\mathrm{A}_{\mathrm{o}}} \ln \left(\frac{\overline{\mathrm{T}}_{\mathrm{i}}-\overline{\mathrm{T}^{\prime}}}{\overline{\mathrm{T}}_{\mathrm{o}}-\overline{\mathrm{T}}^{\prime}}\right)
$$

where:

$$
\begin{aligned}
& \dot{\mathrm{m}}=\text { individual tube flow rate from orifice flow meter, } \\
& \overline{\mathrm{T}}_{\mathrm{i}}= \begin{cases}\text { open loops: } & \text { average } \mathrm{H}_{2} \mathrm{O} \text { temperature in inlet waterbox } \\
\text { closed loop: } & \text { single temperature measurement after }\end{cases} \\
& \text { conditioning unit, } \\
& \overline{\mathrm{T}}^{\prime}=\text { average } \mathrm{NH}_{3} \text { shell-side temperature, and } \\
& \mathrm{T}_{\mathrm{O}}=\mathrm{H}_{2} \mathrm{O} \text { outlet temperature (measured individually for each } \\
& \text { tube). }
\end{aligned}
$$


- Spatial variation in $h_{0}$

In the evaporator and condenser, variations in $h_{0}$ can result from vapor shear and liquid loading. Accumulation of noncondensibles in the condenser is another factor. For any given tube, the following can be written:

$$
\frac{1}{U_{o}}=\frac{1}{h_{o}}+\frac{1}{h_{i}} \frac{A_{o}}{A_{i}}+\frac{1}{h_{w}} \frac{A_{o}}{A_{m}}+R_{f} \frac{A_{o}}{A_{i}}
$$

where:

$$
\begin{aligned}
& h_{0}=\text { ammonia-side heat transfer coeffictent, } \\
& h_{i}=\text { water-side heat transfer coefficient, } \\
& h_{w}=\text { tube wall conductance, and } \\
& \mathrm{h}_{\mathrm{f}}=\text { fouling resistance (or fouling factor). }
\end{aligned}
$$

By comparing-instrumented loops at two different locations, the spatial variation in $h_{0}$ can be determined as follows:

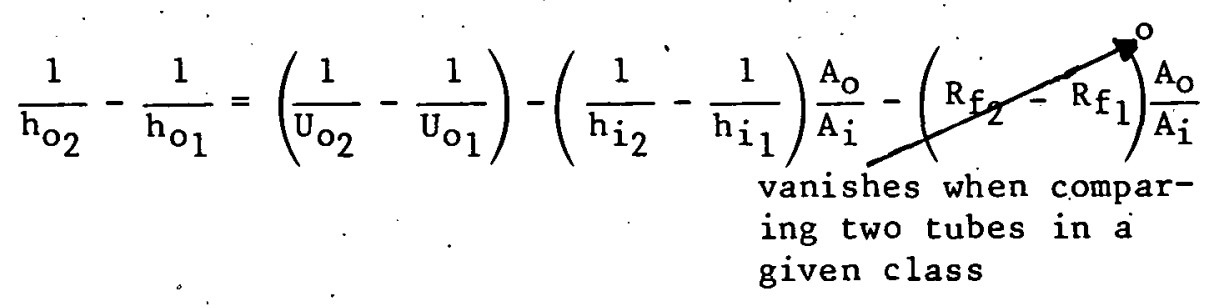

The subscripts " 1 " and "2" refer to the two tube locations under consideration. Note that the terms involving $h_{w}$ cancel because the tube wall conductance is the same for all tubes. Also, the terms involving $R_{f}$ cancel when two tubes in a given class are compared (i.e., clean. loop, Amertap loop, or dirty loop). Although $R_{f}$ values for the Amertap loops are probably different from $R_{f}$ values for the dirty loops, it is reasonable to expect that the $R_{f}$ values in any one class are nearly equal: For the clean loops, which employ deionized water, $R_{f}$ is taken to be zero.

The terms involving $h_{i}$ will not necessarily be equal, because there are slight variations in the mass flow rates of the individual tubes. Since m is measured for each tube, the variation can be accounted for using the Dittus-Boelter correlation:

$$
\frac{h_{i} d_{i}}{k}=0.023 \operatorname{Re}^{0.8} \operatorname{Pr}^{0.4}
$$




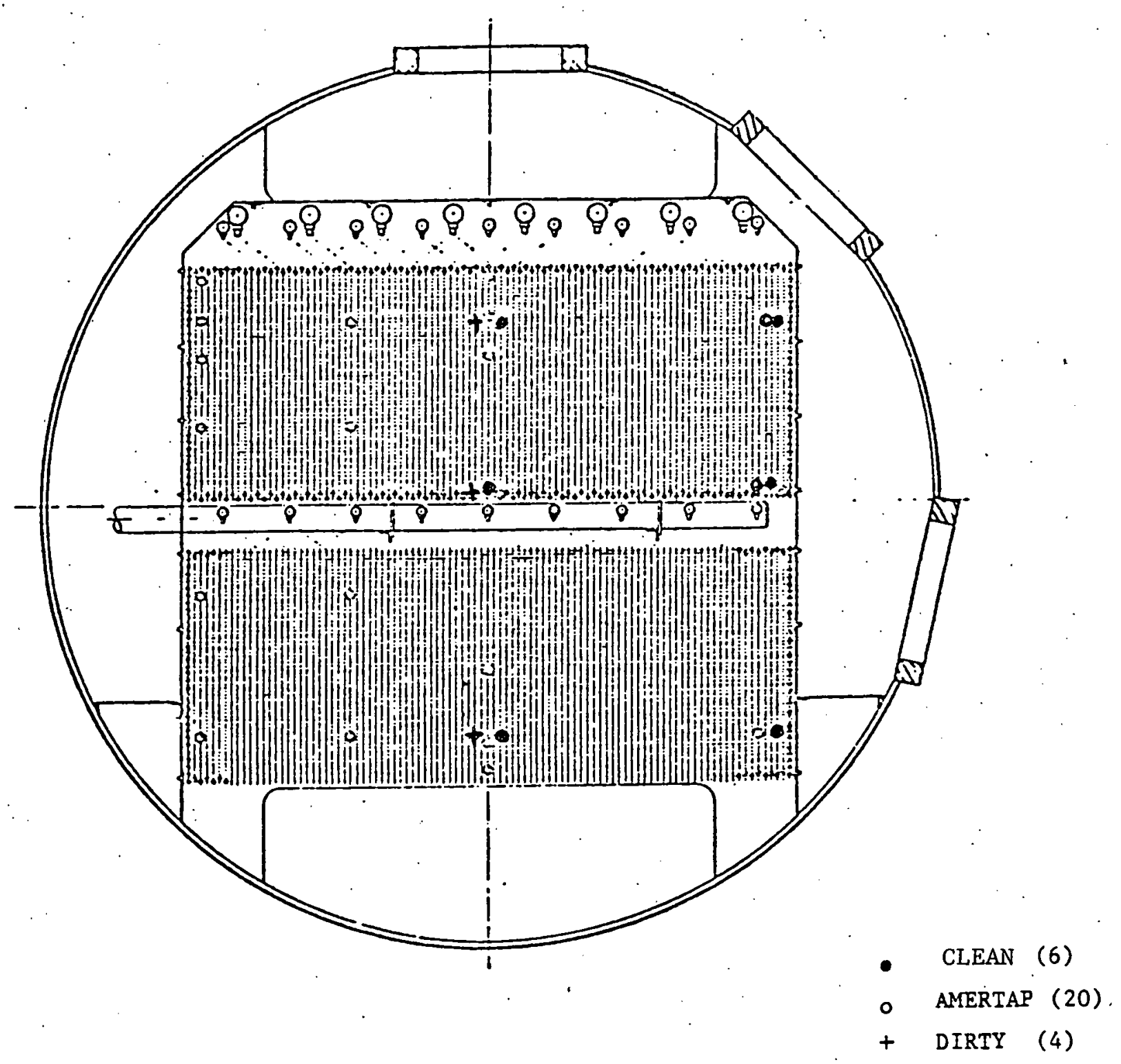

Fig. 4.2. Outlet Waterbox View of Instrumented Tube Locations in the Evaporator 


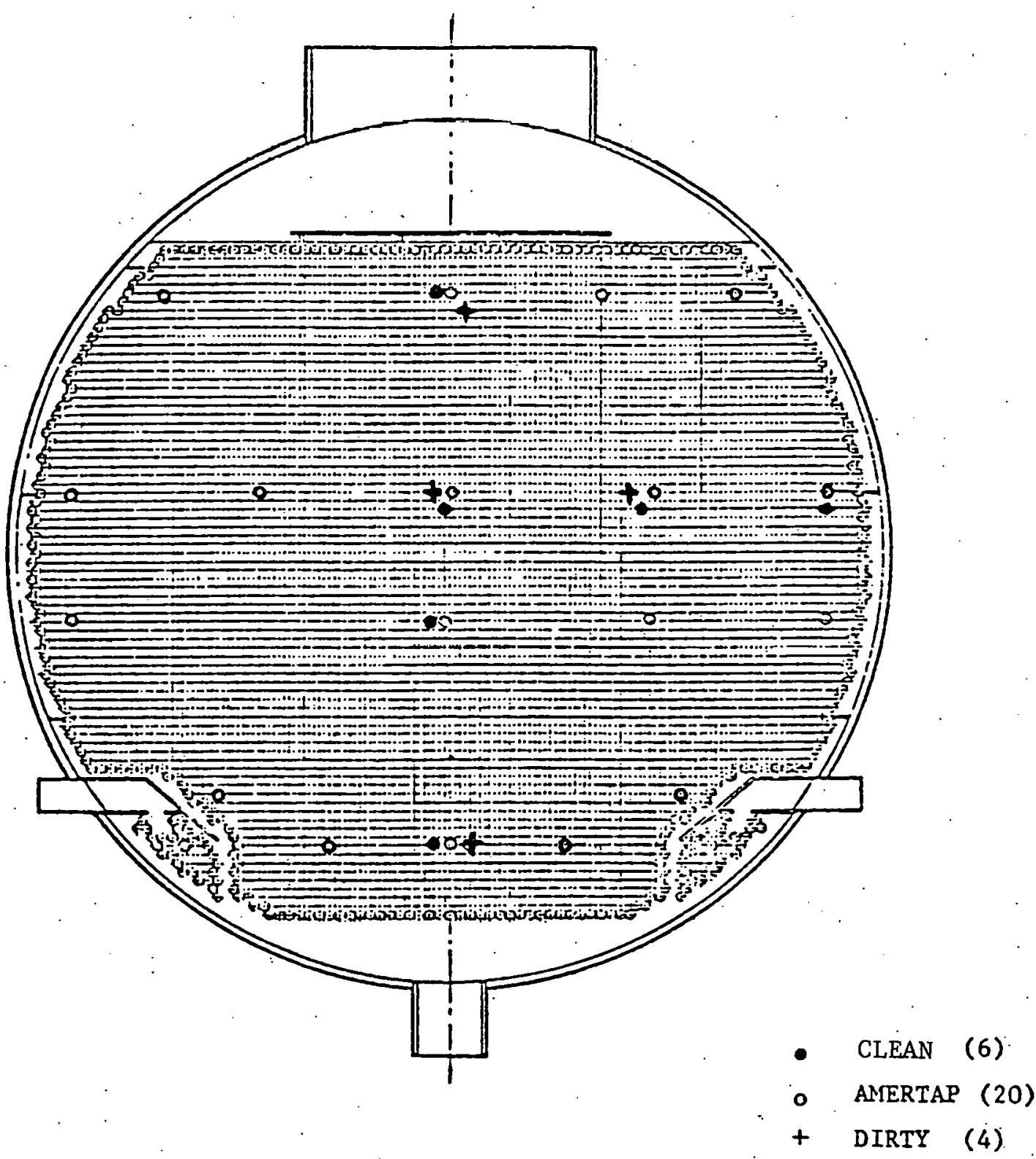

Fig. 4.3. Outlet Waterbox View of Instrumented Tube Locations in the Condenser 
- Zone-by-zone variations

For both the evaporator and condenser, resistance temperature devices (RTD) in the outlet waterbox will permit a further (but somewhat crude) assessment of variations in $h_{0}$. The calculation is similar to that for the instrumented tubes, except that $h_{0}$ and $U_{0}$ apply to a zone of tubes rather: than a specific tube. At each RTD location, a zonal value of $U_{0}$ can be calculated using Eq. 8, and the variation in $h_{0}$ from one zone to the next can be calculated using Eq. 10. "Since $\dot{m}$ is not measured for each zone, the flow rates in any two zones will be assumed to'be equal.

\section{Biofouling}

The instrumented loops are strategically grouped to evaluate biofouling. (See Figs. 4.2 and 4.3.) At each of the six clean-loop locations, there is a neighboring Amertap loop, and at four of those locations, there is also a neighboring dirty loop (i.e., a loop with no Amertap cleaning). The $R_{f}$ for both the Amertap loop and the dirty loop can be calculated as follows:

$$
\mathrm{R}_{\mathrm{f}_{2}}-\mathrm{R} \mathrm{A}_{1}^{\mathrm{P}}=\left(\frac{1}{\mathrm{U}_{\mathrm{o}_{2}}}-\frac{1}{\mathrm{U}_{\mathrm{o}_{1}}}\right) \frac{\mathrm{A}_{\mathrm{i}}}{\mathrm{A}_{\mathrm{o}}}-\left(\frac{1}{\mathrm{~h}_{\mathrm{O}_{2}}}-\frac{\mathrm{L}_{\mathrm{o}_{1}}}{\mathrm{~A}_{\mathrm{o}}}\right) \frac{\mathrm{A}_{\mathrm{i}}}{\mathrm{A}_{\mathrm{o}}}-\left(\frac{1}{\mathrm{~h}_{\mathrm{i}_{2}}}-\frac{1}{\mathrm{~h}_{\mathrm{i}_{1}}}\right) \frac{\mathrm{A}_{\mathrm{i}}}{\mathrm{A}_{\mathrm{o}}}
$$

The subscript "1" refers to a clean loop, and the subscript "2," to an adjacent Amertap or dirty loop. The terms involving $h_{0}$ vanish because the tubes are close enough for the ammonia-side coefficients to be the same. The $R_{f}$ values calculated from Eq. 12 can be compared with the $R_{f}$ values. from the special biofouling monitors.

\subsubsection{Reflux Ratio Tests}

The purposes of the reflux ratio tests are (1) to demonstrate the improvement in performance that can be obtained with reduced liquid loading via mid-plane feed and (2) to determine the optimum reflux ratio. (See Configuration 1 of Fig. 4.1.)

\section{Test Sequence}

Table 4.4 shows the sequence of tests for evaluating evaporator performance over a range of reflux ratios, $\sigma$. The full range of reflux ratios 
(maximum to zero) will be covered, for the overall bundle and for each half bundle. From plots of $U_{O}$ versus $\sigma$, the optimum reflux ratios can be identified. Following each sequence of tests with a given spray configuration, the reference baseline conditions will be re-established to examine any changes.

\section{Top Nozzles}

The system controls will be adjusted to provide the maximum feed of $1,280,0001 \mathrm{bm} / \mathrm{hr}$ of ammonia through the top nozzles only, and a sequence of runs will be conducted at progressively lower feed rates (see Table 4.4). The system will be allowed to stabilize at each condition as determined from the attainment of asymptotic values of $U_{0}$ for the upper and lower bundles.

In Table 4.4, it can be seen that the reflux ratio for the overall bundle ranges from 4:1 to 0 , while the individual reflux ratios for the upper and lower halves range from $11: 1$ to $1.4: 1$ and $7: 1$ to 0 , respectively. In conducting these tests, the effective feed to the lower bundle must never be reduced below the point at which zero reflux is first measured. This is to avoid drying out the enhanced tubes, because they may require a long time to reach steady state upon subsequent rewetting. Referring to Table 4.4, it is evident that this constraint presents a problem in attaining a reflux ratio below 1.4:1 for the upper bundle. Fortunately the mid-plane feed can. eliminate the problem.

\section{Top Plus Mid-Plane Nozzles}

When the top feed is reduced below $256,0001 \mathrm{bm} / \mathrm{hr}$, the mid-plane feed system will be activated and set at some constant feed rate (assumed to be $148,0001 \mathrm{bm} / \mathrm{hr}$ in Table 4.4) to keep the lower enhanced bundle wetted. The feed to the top nozzles will be reduced stepwise until zero reflux is measured for the upper bundle.

The mid-plane feed will also demonstrate that overall evaporator performance is improved by reducing the liquid loading on the upper bundle.

\section{Mid-Plane Nozzles}

The feed to the top nozzles will be shut off and the ammonia feed through the mid-plane nozzles set to the maximum possible value. According to 
Table 4.4. Reflux Ratio Tests

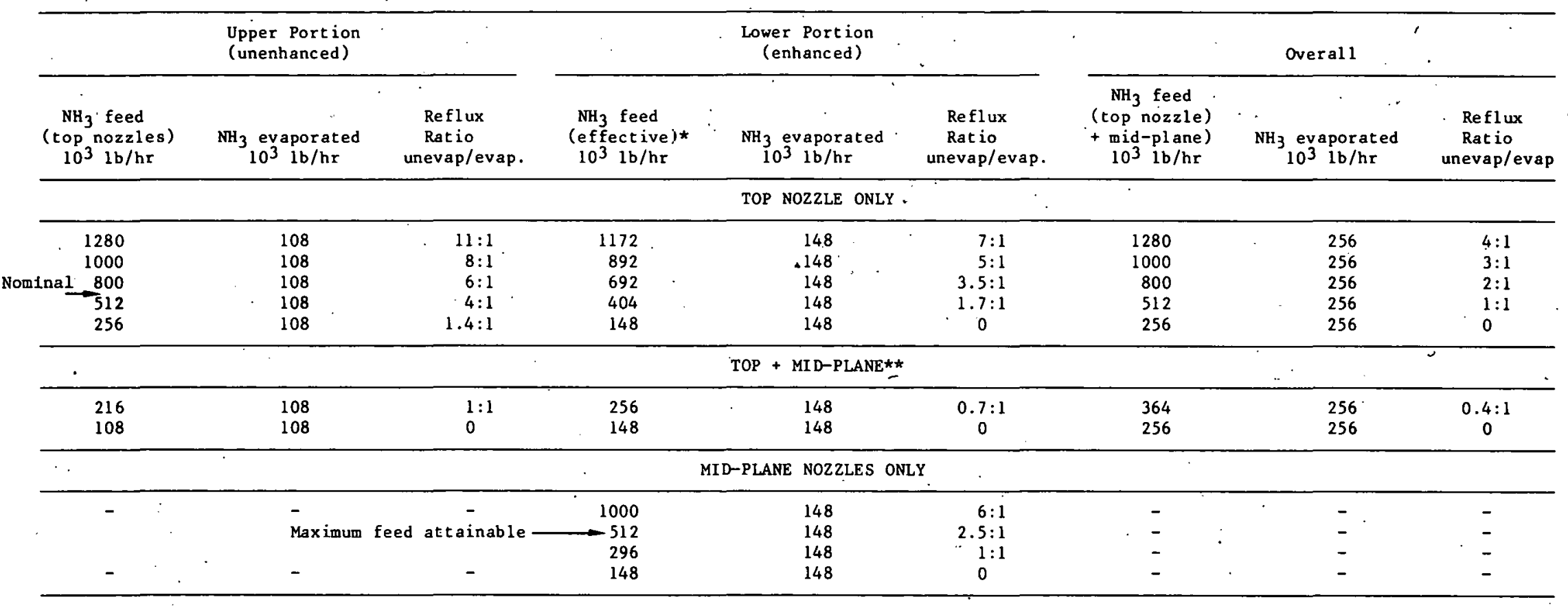

* See Eqs. (16) \& (18) for definition of effective feed to lover bundle

$\star_{\text {mid }}$-plane feed $=148,000 \mathrm{lbm} / \mathrm{hr}$ for both runs 
TRW, the mid-plane spray system can handle a maximum feed of only about $512,000 \mathrm{lbm} / \mathrm{hr}$. Beyond this feed rate, operating problems may be encountered, due to high velocities in the feed 1 ines. As shown in Table 4.4, a sequence of tests will be conducted with reflux ratios ranging from $2.5: 1$ to 0 .

The entire range of reflux ratios obtained with the mid-plane feed was previously covered with the top nozzles only. Therefore, a comparison can be made between enhanced bundle performance with a direct mid-plane feed and performance with an indirect (or effective) feed from the upper bundle.

\section{Opt imum Reflux Ratio}

Enhanced Bundle. In tests at ANL with an enhanced sprayed bundle, it was found that $U_{0}$ remains constant as $\sigma$ is reduced to some critical value. Below this point, $U_{0}$ decreases abruptly because the lower tubes dry out.

In the present case, a similar but possibly less abrupt drop in $\mathrm{U}_{\mathrm{O}}$ is expected to occur as $\sigma$ is progressively reduced below some minimum value. Tentatively, the minimum recirculation rate will be defined as the value of at which $U_{0}$ has decreased by a statistically significant percentage below the reference $U_{o}$ value. The percentage is statistically significant if it is on the order of the measurement uncertainty $(6 \%)$.

Unenhanced Bundle. The shape of the $U_{0}$ versus $\sigma$ curve for the unenhanced bundle will be different from that of the enhanced bundle. In the unenhanced bundle, the dominant heat transfer mode is thin film evaporation rather than nucleate boiling. An optimum is expected to occur in the $U_{0}$ vs $\sigma^{\circ}$ curve as the recirculation ratio is decreased and the film becomes thinner (i.e., less resistance to heat transfer). However, when is reduced further, the $\mathrm{U}_{\mathrm{o}}$ value will drop as film breakdown occurs and the bottom tubes begin to dry out. From the plot of $U_{0} \cdot v s$, an attempt will be made to identify the optimum reflux ratio. However, it is unlikely that the true optimum will be observed, because only a limited number of data points can be obtained.

Overall Bundle. The performance of the overall bundle is essentially a: summation of the performance of the upper and lower bundles. 
Calculation of Reflux Ratio

Reflux ratio, $\sigma$, is defined as the ratio of unevaporated $\mathrm{NH}_{3}$ to evaporated $\mathrm{NH}_{3}$ :

$$
\sigma=\frac{\dot{\mathrm{m}}_{\mathrm{f}}-\dot{\mathrm{m}}_{\mathbf{v}}}{\dot{\mathrm{m}}_{\mathbf{v}}}
$$

where:

$$
\begin{aligned}
& \dot{\mathrm{m}}_{\mathrm{f}}=\text { the ammonia feed rate, and } . \\
& \dot{\mathrm{m}}_{\mathrm{v}}=\text { the evaporation rate. }
\end{aligned}
$$

The evaluation of terms in Eq. 13 depends on the particular reflux ratio being considered (i.e., overall bundle, upper bundle, or lower bundle).

Reflux Ratio for the Overall Bundle. "The calculation of the reflux ratio for the overall bundle is straightforward. Equation 13 is evaluated using the measured overall vapor flow rate (after the phase separator) and the measured ammonia liquid feed (top plus mid-plane). to the evaporator.

Reflux Ratio for Upper Bundle. The vapor generation rate is calculated. from a heat balance on the upper bundle, yielding:

$$
\dot{\mathrm{m}}_{\mathrm{v}}=\frac{\mathrm{Q}-\mathrm{m}_{\mathrm{f}} \mathrm{c}_{\mathrm{p}} \Delta \mathrm{T}}{\mathrm{h}_{\mathrm{f}_{\mathrm{g}}}}
$$

where:

$Q$ is determined from a water side heat balance on the upper portion,

$\dot{\mathrm{m}}_{\mathrm{f}}=$ the ammonia feed to the top nozzles, and

$\Delta \mathrm{T}=$ the ammonia inlet subcooling.

The value of $\dot{m}_{f}$ for use in. Eq. 13 is simply the ammonia feed to the top : nozzles.

Reflux Ratio for Lower Bundle, Top Nozzles Only. The vaporization rate is calculated from a heat balance on the lower bundle:

$$
\dot{m}_{v}=\frac{Q}{h_{f_{g}}}
$$


$Q$ is determined from a waterside heat balance on the lower bundle. Note that there is no subcooling term, because the ammonia liquid is preheated to saturation in the upper bundle.

The effective feed flow, $\dot{m}_{f}^{*}$, to the lower bundle is equal.to the unevaporated liquid from the upper portion, with a correction for entrainment:

$$
\dot{\mathrm{m}}_{\mathrm{f}}^{*}=\left(\dot{\mathrm{m}}_{\mathrm{f}}-\dot{\mathrm{m}}_{\mathrm{v}}-\dot{\mathrm{m}}_{\mathrm{ent}}\right)_{\mathrm{upper}}
$$

where $\mathrm{m}_{\mathrm{ent}}$ is the rate of entrainment in the upper bundle. This, rate of entrainment is assumed to be half of the total entrainment for the entire bundle as determined from the phase-separator liquid flow.

Reflux Ratio for Lower Bundle, Top Plus Mid-Plane Nozzle. The evaporation rate is:

$\dot{\mathrm{m}}_{\mathrm{v}}=\frac{\mathrm{Q}-\dot{\mathrm{m}}_{\mathrm{f}} \mathrm{c}_{\mathrm{p}} \Delta \mathrm{T}}{\mathrm{h}_{\mathrm{f}_{\mathrm{g}}}}$

where:

$Q$ is measured from a waterside heat balance on the lower bundle,

$\dot{\mathrm{m}}_{\mathrm{f}}=$ ammonia feed to the mid-plane nozzles, and

$\Delta \mathrm{T}=$ subcooling.

The effective feed to the lower bundle is:

$\dot{\mathrm{m}}_{\mathrm{f}}^{*}=\left(\dot{\mathrm{m}}_{\mathrm{f}}-\dot{\mathrm{m}}_{\mathrm{v}}-\dot{\mathrm{m}}_{\mathrm{en} t \mathrm{t}}\right)_{\mathrm{upper}}+\dot{\mathrm{m}}_{\mathrm{f}}(\mathrm{mid}-\mathrm{plane})$

Reflux Ratio for Lower Bundle, Mid-Plane Nozzle Only. The evaporation rate is given by Eq. 17, and the effective feed flow in this case is simply the 1 iquid feed through the mid-plane nozzles. In tests where ammonia is fed only through the mid-plane nozzles, the upper bundle can transfer heat to the vapor (plus entrained 1iquid) generated in the lower enhanced bundle. The evaporator exit quality, $x_{e}$, determined from the external phase separator will be slightly different from the actual quality for the lower bunde alone. The latter $c$ an be estimated by accounting for heat transfer from the upper bundle, yielding:

$$
\mathrm{x}_{\text {actual }}=\mathrm{x}_{\mathrm{e}}-\frac{\dot{Q}}{\left(\dot{\mathrm{m}}_{\mathrm{v}}+\dot{\mathrm{m}}_{\ell}\right) \mathrm{h}_{f_{g}}}
$$


where:

$$
\begin{aligned}
\mathbf{x}_{e} & =\frac{\dot{\mathrm{m}}_{\mathrm{v}}}{\dot{\mathrm{m}}_{\mathrm{v}}+\dot{\mathrm{m}}_{\ell}} \\
\dot{\mathrm{m}}_{\mathrm{v}} & =\text { vapor flow from phase separator, } \\
\dot{\mathrm{m}}_{\ell}= & \text { liquid flow from phase separator, and } \\
\mathrm{Q} & =\text { heat transferred in upper bundle from water side } \\
& \text { heat balance. }
\end{aligned}
$$

Equation 19 provides only a crude estimate of the actual quality, because the water-side temperature difference will be too small to measure accurately.

In the event that the vapor is superheated as a result of heat transfer from the upper bundle, the following equation applies:

$$
x_{\text {actual }}=1+\frac{c_{p} \Delta T}{h_{f_{g}}}-\frac{Q}{\dot{m}_{v} h_{f_{g}}}
$$

where:

$$
\begin{aligned}
& \Delta \mathrm{T}=\text { the measured superheat of the vapor, } \\
& \dot{\mathrm{m}}_{\mathrm{v}}=\text { vapor flow rate after the phase separator, and } \\
& Q \text { is the heat transferred in the upper bundle as calcu- } \\
& \text { lated from a water-side heat balance. }
\end{aligned}
$$

When calculating Uo for the lower enhanced bundle, the vapor temper: ature should be based on the average of the shell-side resistance temperature devices located in the lower portion only. The upper shell-side resistance temperature devices are not averaged in, because the vapor may be slightly superheated. As an alternative to employing the lower shel1-side RTDs, the shel1-side pressure of the evaporator can be used to calculate the appropriate ammonia saturation temperature.

\subsubsection{Vapor Velocity Tests}

The objective of the vapor velocity tests is to determine the effect of vapor velocity on heat transfer and entrainment in a bundle simulating a quarter section of a 4-MWe unit. (See Configuration 2 of Fig. 4.1). 


\section{Description of Tests}

The test sequence and operating conditions for the vapor velocity tests are identical to those for Configuration 1 of Fig. 4.1 (that is, a reference baseline test followed by the series of reflux ratio tests in Table 4.4). A comparison of the results for Configurations 1 and 2 will yield a direct assessment of the effect of vapor velocity on entrainment, heat transfer, and she11-side pressure drop. The effect of vapor velocity on, reflux ratio.will also be examined.

\section{Diagnostics}

With Configuration 2, vapor velocity may indeed influence evaporator performance. But before any effect can be attributed solely to vapor velocity, other factors must be properly ruled out (e.g., biofouling or a malfunctioning spray system). All of the basic diagnostic tools will be used to assess vapor velocity. Of particular value will be instrumented tubes located at the same vertical level but in different radial positions. Considering tubes at the same level ensures that differences are attributable to vapor velocity, which varies almost linearly with radial position, rather.than liquid loading.

\subsubsection{Flooded-Bundle Tests}

A flooded bundle has certain advantages over a sprayed bundle--no elaborate feed system is required, and complete wetting of the tubes is essentially guaranteed. A major disadvantage is the hydrostatic head penalty.

The objective of the flooded-bundle tests is to obtain data that enable one to compare the performance of a flooded bundle and a sprayed bundle having the same configuration. (See Configuration 3 of Fig. 4.1).

\section{Flooded Enhanced Bundle}

Highest priority will be given to testing Configuration $3 a$, in which only the lower enhanced bundle is flooded. Results of this test will be compared with performance data for the enhanced sprayed bundle.

As in the sprayed-bundle tests with the mid-plane nozzles, the exiting vapor may be slightly superheated due to heat transfer from the upper bundle. 
Therefore, the shell-side pressure of the evaporator (measured near the exit) will be used to determine the saturation temperature for calculating $U_{0}$. Determining the saturation temperature in this manner incorporates the static head penalty into the definition of $U_{0}$. On the other hand, if the saturation temperature were based on the static pressure at the mid-plane bundle, the static head penalty would be factored out. Either method of calculating $U_{0}$ is acceptable, but the former is more suitable for a direct comparison with the sprayed-bundle results. Perfórmance. of the flooded bundle is expected to approach that of the sprayed bundle.

\section{Flooded Full Bundle}

In the test of Configuration $3 b$, both the upper. and lower bundles will be flooded. This test will demonstrate heat transfer augmentation in the upper bundle resulting from convection induced by bubbles generated below in. the enhanced bundle. The mode of heat transfer in the upper bundle is analogous to forced-convective vaporization in annular, two-phase flow in tubes. Overall performance is expected to be somewhat inferior to that of the comparable sprayed bundle.

\section{Deactivation/Reactivation}

In tests at ANL, it was found that deactivation of the high flux. surface occurred, when the warm water flow was shut down and nonboiling liquid ammonia remained in contact with the surface.

To study deactivation on OTEC-1, the warm water pump will have to be shut off for an extended period of time ( $24 \mathrm{hr})$, but biofouling considerations make: such an action undesirable. However, deactivation can be simulated by cliosing the ammonia valve in the vapor line to the condenser. This causes pressure in the evaporator to increase, thereby suppressing boiling. When the valve is reopened, the heat transfer recovery can be tracked as reactivation occurs.

Although the foregoing procedure does not truly simulate deactivation caused by the shutdown of a warm water flow, it should nevertheless provide a clue to the deactivation/reactivation phenomena. 
To ensure complete coverage of the bundle by liquid ammonia, the level detactor should be set to hold the vapor/liquid interface about six inches above the top row of tubes. This should be verified by direct visual observation through the view ports.

\subsection{BIOFOULING-COUNTERMEASURES-AND-CORROSION PROGRAM}

The biofouling-countermeasures-and-corrosion program for the first deployment of OTEC-1 has three primary objectives. The first objective is to establish the effectiveness of intermittent chlorination (at $0.4-0.5 \mathrm{ppm}$ ) and Amertap balls (circulating at an average rate of one every $15 \mathrm{~min}$ ) in maintaining acceptably low fouling-film resistance in the heat exchanger tubes. The present EPA guidelines for a point discharge allow $0.2 \mathrm{ppm}$ free chlorine for a period not to exceed two hours per day.

The second objective of the program is to determine how effectively the chlorination schedules employed for the heat exchangers control macrofouling in adjacent components of the sea-water system. Specimens will be examined, and the degree of macrofouling will be correlated with the chlorine treatment for both cold- and warm-water systems.

The third objective is to gather information about the corrosion behavior of aluminum alloys that are being considered for use in the second deployment of OTEC-1 and in subsequent OTEC systems.

The remainder of this section provides detailed information regarding countermeasures to be utilized, operation of the instrumented tubes and the heat-transfer monitors, and descriptions of microfouling and macrofouling experiments. The section also lists the water-analysis measurements that are required to establish the water conditions to which the surfaces of the system are exposed.

\subsubsection{Biofouling Countermeasures}

Chlorine at 0.4-0.5 ppm will be provided each day for one hour to the condenser, followed immediately by one hour of chlorine at the same concentration to the evaporator. The exact chlorine injection rate will be such that the mixed discharge contains $0.2 \mathrm{ppm}$ chlorine (excluding the amount lost by chemical reaction) for two hours per day. In conjunction. with the chlorine treatment, Amertap balls will be circulated through the heatexchanger tubes at an average rate of one ball per tube every $15 \mathrm{~min}$. 
A combination chlorine-Amertap countermeasures system has proven effective in the OTEC experiments at the Naval Coastal Systems Center, Panama city, florida. There, in a test of several months duration, the addition of 4 or $5 \mathrm{ppm}$ chlorine to produce a residual concentration of 1 ppm for 15 min/day has prevented almost entirely the fouling of a titanium surface and consequent loss in heat-transfer efficiency. In other experiments at the same location, Amertap balls at intervals of 15 min have controlled the buildup of fouling less perfectly, with $R_{f}$ increasing by $(0.3-1) \times 10^{-4} \mathrm{Btu}^{-1}$. $\mathrm{hr} \cdot{ }^{\circ} \mathrm{F} \cdot \mathrm{ft}^{2}$ per month in a titanium pipe. Lower fouling rates in the open ocean could lead to more successful cleaning.

For the most part, the chlorine-Amertap countermeasures are directed at the prevention of fouling-film buildup within the heat exchangers; that is, these measures address the problem of microfouling. Additional countermeasures may be required to prevent and reverse the fouling of equipment by larger-scale marine organisms (i.e., macrofouling). One technique for the cleaning of OTEC equipment subject to macrofouling is the Cavijet system, in which crew members using high-pressure water-jet apparatus scour the larger organisms off the equipment.

\subsubsection{Countermeasures Testing Strategy}

A set of eight. B\&C modules (four associated with the warm-water portion of the system and four with the cold-water portion) will be used to determine the effectiveness of the countermeasures employed to limit and prevent biofouling and corrosion of the heat-exchanger components. The strategic placement of these modules will permit the test crew not only to monitor actual heat-exchanger performance, but also to predict the potential effectiveness of measures other than those in use, both more rigorous and less rigorous.

These B\&C modules will monitor conditions in both the warm- and cold-water systems during two consecutive four-month periods. During the first four months, the modules associated with each heat exchanger will monitor performance under the following conditions (see Table 4.5): 
Table 4.5. Test Matrix for Biofouling and Corrosion Modules

Test Periods and Levels

\begin{tabular}{|c|c|c|c|c|}
\hline \multirow[b]{2}{*}{ Unit } & \multirow[b]{2}{*}{ First Four Months } & \multicolumn{3}{|c|}{ Second Four Months } \\
\hline & & Level $1(++)$ & Level $2(+)$ & Level $3(-)$ \\
\hline Evaporator ${ }^{a}$ & $\begin{array}{l}\text { Chlorination: } 0.4 \text { ppm for } \\
1 \text { hr per day } \\
\text { Amertap: } 1 \text { ball per } 15 \\
\text { min }\end{array}$ & $\begin{array}{l}\text { Chlorination: } \\
0.1 \text { ppm con- } \\
\text { tinuously } \\
\text { Amertap: } 1 \text { ball } \\
\text { per } 15 \text { min }\end{array}$ & $\begin{array}{l}\text { Chlorination: } \\
1.0 \text { ppm for } 24 \\
\text { min per day } \\
\text { Amertap: } 1 \text { ball } \\
\text { per } 15 \text { min }\end{array}$ & $\begin{array}{l}\text { Chlorination: } \\
0.4 \text { ppm for. } 1 \\
\text { hr per day } \\
\text { Amertap: } 1 \text { ball } \\
\text { per hr }\end{array}$ \\
\hline \multicolumn{5}{|l|}{$B \& C$ modules $^{b}$} \\
\hline \#1 (8) & $\begin{array}{l}\text { Same as in evaporator (con- } \\
\text { denser) }\end{array}$ & & & \\
\hline 非（5） & $\begin{array}{l}\text { Chlorination: None } \\
\text { Amertap: None } \\
\left(\text { If } R_{f} \text { reaches } 0.0005\right. \\
\mathrm{ft}^{2} \cdot \mathrm{hr} \cdot{ }^{\circ} \mathrm{F} / \mathrm{Btu}, \mathrm{clean} \\
\text { by manual brushing.) }\end{array}$ & $\cdot$ & & . \\
\hline \#3（6） & $\begin{array}{l}\text { Chlorination: } 1.0 \text { ppm for } \\
24 \text { min per day } \\
\text { Amertap: } 1 \text { ball per } 15 \text { min }\end{array}$ & $\begin{array}{l}\text { Continue as in } \\
\text { first four } \\
\text { months, without } \\
\text { initial manual } \\
\text { cleaning }\end{array}$ & $\begin{array}{l}\text { Continue as in } \\
\text { first four } \\
\text { months, without } \\
\text { initial manual } \\
\text { cleaning }\end{array}$ & $\begin{array}{l}\text { Chlorination: } \\
\text { None } \\
\text { Amertap: } 1 \text { ball } \\
\text { per } 15 \text { min. }\end{array}$ \\
\hline 非（7） & $\begin{array}{l}\text { Chlorination: } 0.1 \text { ppm con- } \\
\text { tinuously } \\
\text { Amertap: } 1 \text { bali per } 15 \text { min }\end{array}$ & $\begin{array}{l}\text { Continue as in } \\
\text { first four } \\
\text { months, with- } \\
\text { out initial } \\
\text { manual cleaning }\end{array}$ & $\begin{array}{l}\text { Continue as in } \\
\text { first four } \\
\text { months, with- } \\
\text { out initial } \\
\text { manual cleaning }\end{array}$ & $\begin{array}{l}\text { Chlorination: } \\
0.4 \text { ppm for } \\
1 \text { hr per day } \\
\text { Amertap: None }\end{array}$ \\
\hline
\end{tabular}

all specifications under "Test Periods and Levels". are the same for the condenser.

bodule numbers in parentheses are the corresponding ones for the condenser. 
- Control conditions -- No countermeasures (except manual brushing, if required) are to be employed in these modules ( 2 and 5 ).

- Tracking conditions -- Countermeasures used in these modules are to be the same as those employed in the heat exchangers (modules 1 and 8 ).

- More rigorous countermeasures -- Modules 3 and 6 will monitor the effects of intermittent chlorination at a higher level than that used in the heat exchangers, with Amertap; modules 4 and 7 will monitor the effects of continuous chlorination at a lower level than in the heat exchangers, also with Amertap.

At the end of the first test period, the effectiveness of the various $B \& C$ countermeasure levels will be evaluated and a decision made on the regimen to be followed in the heat exchangers during the next four months. On the basis of data obtained from the B\&C modeules, the main-system countermeasures will be made more rigorous (at one of two levels, "++" or "+," as defined in Table 4.5) if biofouling is not sufficiently inhibited to maintain acceptable performance. If countermeasures used in the tracking and/or less rigorous modules proved adequate, shifting to a less rigorous regimen is contemplated (the "-" level in Table 4.5). In selecting the new countermeasures level, the "predictive" nature of data taken by modules under the more rigorous/less rigorous conditions should prove particularly helpful.

Prior to starting a new regimen, the heat exchangers and their tracking modules will be cleaned with abrasive balls until the tracking modules' surfaces are clean (defined as $R_{f}=0$ and specimens free of deposits). Then either a more rigorous or a less rigorous cleaning procedure will be instituted for the heat exchangers. The new cleaning regimen will be selected on the basis of $R_{f}$ measurements and examination of specimens from the B\&C modules*, and the nearby Mini-OTEC and Seacoast Test Facility. Both facilities will employ modules operating with the original OTEC-1 cleaning regimen and with regimens that are both more and less rigorous. Table 4.6

*The criteria for determining inadequate cleaning are (1) a definite positive slope in the $R_{f}$-versus-time curve (at such time the value of $R_{f}$ might be about $0.0002 \mathrm{Btu}-\mathrm{l} \bullet \mathrm{hr} \cdot{ }^{\circ} \mathrm{F} \cdot \mathrm{ft}^{2}$ ) and (2) significant biological deposits on specimens removed from the module. The determination of inadequacy in cleaning will be made by the biofouling-and-corrosion experimenter. 
gives the salient features of the tests conducted on Mini-OTEC and the Seacoast Test Facility.

After the countermeasures in the heat exchangers have been adjusted, the test will run another four months with the modules reset as follows (see Table 4.5): Control modules, no change; tracking modules, matched to new countermeasure conditions in the heat exchangers; less rigorous and more rigorous modules, adjusted to employ countermeasure levels that are either less rigorous or more rigorous, respectively, than the new heat-exchanger regimen.

The water-side heat-transfer coefficient in the cleaned condenser will perhaps not change, because the temperature is low and possibly because there are fewer organisms in the supply water. If no fouling is observed in the condenser tracking module, a decision will be made whether to reduce or eliminate the countermeasures, utilizing data from the cold-water B\&C modules and (if available) from Mini-OTEC and the Seacoast Test Facility. The decision will be made at the times marked in the schedule chart. (Fig. 5.1), at one-third and two-thirds of the way through the eight-month test. It will be the responsibility of the biofouling-and-corrosion experimenter to decide on the details of any change that is to be made.

By this iterative, "bracketing" operation, it is hoped that countermeasure levels can be determined that have minimum potential for adverse environmental effects and, at the same time, effectively control biofouling so as to maintain heat-exchanger performance.

\subsubsection{Countermeasure-Effectiveness Monitoring Equipment}

In order to establish the effectiveness of the specified countermeasures, both the $\mathrm{B} \& \mathrm{C}$ modules and instrumented tubes of the heat exchanger will be utilized to monitor changes in the heat-transfer efficiency of the heat-exchanger tubes resulting from microfouling.

\subsubsection{Instrumented HX Tubes}

It is anticipated that the instrumented tubes in the heat exchanger will indicate changes in $R_{f}$ greater than about $0.0002 \mathrm{hr} \cdot \mathrm{ft}^{2} \cdot{ }^{\circ} \mathrm{F} / \mathrm{Btu}$ as functions of the location of the tubes and the circulation of Amertap balls. Insofar as their sensitivity will allow, these tubes will provide the primary information needed in order to evaluate the effectiveness of the 
Table 4.6. OTEC Biofouling Countermeasures Test

Matrix in Hawaiian Water, 1980

\begin{tabular}{|c|c|c|c|c|c|}
\hline : & \multicolumn{2}{|c|}{$\begin{array}{c}\text { OTEC-1. } \\
\text { First Deployment }\end{array}$} & \multicolumn{2}{|c|}{$\begin{array}{l}\text { Proposed for } \\
\text { Mini-OTEC } \\
\text { Second Deployment }\end{array}$} & $\begin{array}{cl}\text { Seacoast } & \text { Test } \\
\text { Facility; } & \text { Stage } 1\end{array}$ \\
\hline Purpose & \multicolumn{2}{|c|}{$\begin{array}{l}\text { Evaluate heat ex- } \\
\text { changer performance, } \\
\text { provide data for } \\
\text { alternative. } \\
\text { operation. }\end{array}$} & \multicolumn{2}{|c|}{$\begin{array}{l}\text { Evaluate counter- } \\
\text { measures, with } \\
\text { emphasis on cold } \\
\text { water and long } \\
\text { times (including } \\
\text { polymer layer). }\end{array}$} & $\begin{array}{l}\text { Evaluate counter- } \\
\text { measures, warm water } \\
\text { only; emphasis on } \\
\text { long times (includ- } \\
\text { ing polymer layer). }\end{array}$ \\
\hline $\begin{array}{l}\text { Initial No. } \\
\text { of Modules }\end{array}$ & \multicolumn{2}{|r|}{8} & \multicolumn{2}{|c|}{12} & 18 \\
\hline $\begin{array}{l}\text { Initial Use } \\
\text { of Modules }\end{array}$ & $\begin{array}{l}\text { Warm } \\
\text { Water }\end{array}$ & $\begin{array}{l}\text { Cold } \\
\text { Water }\end{array}$ & $\begin{array}{l}\text { Warmi } \\
\text { Water }\end{array}$ & $\begin{array}{l}\text { Cold } \\
\text { Water }\end{array}$ & · \\
\hline Free Fouling & 1 & 1 & 1 & $2^{a}$ & $3^{a}$ \\
\hline Chlorine & 1 & 1 & $2^{a}$ & $3^{a}$ & $4^{a}$ \\
\hline Amertap & 0 & 0 & 1 & $2^{a}$ & $3^{a}$ \\
\hline $\mathrm{Am}+\mathrm{Cl}$ & 2 & 2 & 0 & 1 & $3^{a}$ \\
\hline
\end{tabular}

a Includes one aluminum HTM

microfouling countermeasures employed in the heat exchangers. Clean tubes in each heat exchanger. serve as controls for the dirty. and Amertap tubes and reveal variations in the local ammonia-side heat-transfer coefficient.

The instrumented tubes of the heat exchanger monitor changes in heat-transfer efficiency due to fouling on the water side. By pairing results from clean tubes with those from adjacent Amertap tubes at $s$ ix locations in each heat exchanger, information will be obtained on the distribution of microfouling at different locations. The data obtained from the four dirty tubes will be of assistance in evaluating the effectiveness of Amertap balls as an adjunct to chlorination in maintaining low fouling rates. The uncertainty in the $R_{f}$ values determined from these tubes has been calculated to be $0.0001 \mathrm{hr} \cdot \mathrm{ft}^{2}{ }^{\circ} \mathrm{F} / \mathrm{Btu}$ (see Sec. 4.1). On this basis, the distribution of fouling and the effectiveness of Amertap balls in controlling the rate of change in $R_{f} c a n$ probably. be observed only if the effects in $R_{f}$ are about $0.0002 \mathrm{hr} \cdot \mathrm{ft}^{2} \cdot{ }^{\circ} \mathrm{F} / \mathrm{Btu}$ or greater. 
Temperature, sensed by the resistance temperature detectors (RTDs) at the inlet and outlet of each instrumented tube, will be logged by. the computer every 15 minutes. The computer will also monitor daily the output of each of the four differential-pressure transmitters (two for each heat exchanger, one for the clean-water tubes, and one for the Amertap and dirtywater tubes). These transmitters will sense pressure drop across the orifice plates located in the effluent stream from each tube. Readings of pressure drop across each orifice will be taken by manully valving the sensing lines from the pressure taps on the orifices to the transmitters. This procedure will require a means of recording on the computer the identity of the tube for which flow is being sensed. The heat-transfer coefficient and fouling resistance for each tube can be calculated from the temperature change and flow determined from the recorded data. Monitoring of these values will indicate major changes in the heat-transfer efficiency of the tubes.

Since the external piping that enables flow to be measured in these tubes results in a nontypical flow path, flow rates will be individually adjusted to the average flow in the heat-exchanger tubes. Thus, a flow in the instrumented tubes will not be representative of that in the uninstrumented tubes in a particular section of the heat exchanger. Also, since flow rate may be a factor in fouling, the buildup in these instrumented tubes will not necessarily indicate buildup in the surrounding tubes. For the same reason, a degree of uncertainty will exist in determining the distribution of Amertap balls by counting the number that passes through selected normal instrumented tubes in a given time. Consequently, these measurements will be made in the $B \& C$ modules, as discussed in the next subsection.

\subsubsection{Biofouling and Corrosion Modules}

The $B \& C$ modules will indicate changes in fouling rates that are not detectable by the instrumented heat-exchanger tubes or by gross heat balances on the heat exchangers. The modules will also provide specimens from the interior surfaces of the tubes. These specimens will be used to characterize the biofouling films in: relation to changes in the rate of fouling. Since the buildup of biofouling layers in open ocean waters is expected to be a slow process, the more sensitive measurements obtained with the modules will provide important input into decisions regarding possible adjustments in the countermeasures being employed. 
The B\&C modules will provide more accurate measurements of changes in heat-transfer efficiency. They will also indicate trends that may not be discernible by gross heat-transfer balances on the heat exchangers or by measurements with the instrumented tubes. The uncertainty in $R_{f}$ values determined by the Carnegie-Mellon-type heat-transfer monitors has been calculated to be $0.00002 \mathrm{hr} \cdot \mathrm{ft}^{2} \cdot{ }^{\circ} \mathrm{F} / \mathrm{Btu}$.

The modules that track the heat exchangers will reproduce the $R_{f}$ value from the normal instrumented tubes only if fouling is sufficient to provide measurable trends there. Otherwise, only the values from the heat-transfer monitors will be useful. The fouling potential of the raw water will be monitored by the two heat-transfer monitors operated with a continuous supply of raw water. The remaining modules, which also operate independently of the heat-exchanger conditions, allow countermeasures that. are outside the range of those being employed in the main heat exchangers to be evaluated. These modules will provide information about the levels to be instituted in the event the heat-exchanger cleaning regimen needs to be changed, as discussed above in Sec. 4.2.2.

The B\&C modules will be installed on the OTEC-1 vessel with stainlesssteel tubes in place of the HTMs and sample sections. Prior to the scheduled wet tests of the ship's circulating systems in Puget Sound, HTMs and specimens will be mounted on the modules, and the complete system, including computer operation, will be checked in accordance with detailed procedures provided by ANL. When these tests are complete, the modules will be drained and dried to prevent contamination of the inside surfaces of the tubes during transport to the test site.

As soon as water from the ocean is available to the modules, the flow meters will be calibrated and Wilson plots will be run for each HTM. From this time on, the water flow rate through each of the six modules not tracking the heat exchangers will be maintained at $13 \mathrm{gpm}(6.0 \mathrm{ft} / \mathrm{sec})$ with stoppages held to a minimum (no stoppage to be longer than two hours). The HTMs and sample sections will be kept full of water at all times.

Flow to the two modules that will track the flow and countermeasure conditions in the heat exchangers will begin when the water is introduced into the heat exchangers, and flow through these units will be adjusted, by the computer to be equal to the average flow through a single tube in the 
heat exchangers. Tracking modules will be drained when heat exchangers are drained.

\subsubsection{Equipment Maintenance and Cleaning}

If there has been no prior inspection of the heat-exchanger water boxes, the evaporator and condenser will be shut down and opened for inspection at the five-month point (or at another period, to be selected), while heat-transfer measurements are not being carried out (see Fig. 5.1). Any fouling will be examined as indicated in subsection 4.2.6. If necessary; tube sheets and perhaps other surfaces.will be cleaned using commercial equipment manufactured for that purpose. This equipment will be made available on the ship before the heat-exchanger water boxes are inspected.

If the flow of water to a heat exchanger stops unexpectedly, and if such stoppage lasts longer than two hours, the heat exchanger and as much of its associated piping as possible will be drained to prevent the growth of fouling organisms. Only when it is feasible to restart operation will the system be refilled with sea water. Time permitting, macrofouling in the heat-exchanger water boxes and other accessible areas will be examined. Upon restart, biofouling specimens from the tracking module will be removed for examination. An alternative procedure, to be selected if circumstances iustify its use, is to fill the shut-down heat exchanger with chlorinated sea water. At normal pumping speed for one heat exchanger only, the 80-1b/hr chlorination system would provide at least 2 ppm initial concentration of chlorine in the water during shutdown. Before restart, decay in chlorine concentration would be confirmed by analysis to assure that the discharge to the ocean would not exceed the $0.2 \mathrm{ppm}$ allowed in the EPA permit (Ref. 1).

If the heat exchangers and the $B \& C$ modules have not been cleaned with abrasive balls at seven months; they will be cleaned if there is evidence of a biological film. As evidence, measured values of $R_{f}$ will be determined, and specimens that have been removed will be examined in the laboratory. The abrasive balls will be employed for the last ten days of the test. Rf values will be calculated, and removable specimens will be examined carefully to determine the effectiveness of the cleaning. 


\subsubsection{Biological Analyses of Specimens}

Provision has been made in each $B \& C$ module for 20 sample sections of 9 in. each. Following the detailed procedures in the operating manual, the test crew will periodically remove sample sections and prepare them for shipping to an analytical laboratory designated by ANL. Specimens, which are to be removed on a regular monthly basis (more often if additional data are needed because of unusual events or upcoming decisions), will be analyzed according to the following routine set of OTEC analyses:

(1) Organic film components

(a) Biomass estimates -- total organic carbon (TOC) and/or carbon-hydrogen-nitrogen ( $\mathrm{CHN}$ ) analysis, adenosine triphosphate (ATP), and total protein

(b) Scanning electron microscopy

(2) Film thickness -- light microscopy, ultrasonics

(3) Film density

(4) Inorganic film constituents

(a) Corrosion products

(b) Scale formation

(c) Scanning electron microscopy/energy-dispersive $x$-ray spectrometry (EDAX)

The following, more extensive sets of analyses will be performed when a major shift in $R_{f}$ is indicated or when a cleaning method fails to remove film totally. Primarily designed to evaluate the effectiveness of fouling countermeasures, these analyses will measure biomass, physiological status, population structure, and exopolymer in the microbial film, as follows:

(1) Microbial biomass
(a) Total adenosine nucleotides (ATP, ADP, and AMP ) and energy charge
(b) Total lipid phosphate
(c) Total lipid glycerol
(d) Epifluorescence 
(2) Physiological status

(a) Energy charge

(b) Analysis

(3) Population structure

(a) Lipid analyses

(b) Steroid proportions and composition

(c) Primary-amine composition

(d) Fatty-acid composition

-(4) Exopolymer
(a) Carbohydrates
(b) Muramic acid
(c) Inositol
(d) Glucosamine
(e) Uronic acid
(f) Sulfur

(5) Scanning electron microscopy

\section{2:5 Corrosion of Aluminum}

The B\&C modules that track the heat exchangers (modules 1 and 8 ) and those in which intermittent chlorination at a different concentration level than in the heat exchangers is employed for the first four months (modules 3 and 6 ) will also be loaded at the beginning of the test with aluminum specimens. Modules 1 and 8 will contain ten specimens through which Amertap balls will pass and ten specimens that will not see Amertap balls. Five of the ten in each case will be of Alloy 5052 and five of Alclad Alloy 3003. Molules 3 and 6 will contain ten specimens, five of Alloy 5052 and five of Alclad Alloy 3003.

The specimens will be weighed before loading and will be mounted between plastic couplings. They will be removed on a prescribed schedule, and an ANL subcontractor will weigh them, examine them microscopically, and then clean them, weigh them, and examine them again. Numbers and sizes of pits will be determined, as well as corrosion weight losses and the weights of film as-received. 
The two alloys whose performance will be tested are being considered currently for use in heat exchangers. The tests will show the effects on the corrosion of these alloys of (1) the countermeasures employed in the heat exchangers and (2) the Amertap balls used at a constant water-flow rate.

\subsubsection{Macrofouling Characterization}

Although it is doubtful that a climax macrofouling community will develop during the limited deployment period of OTEC-1, short-term macrofouling investigations will be conducted in the plant by a specialist designated by ANL. Results will be compared with the results of Aufwuchs investigations by environmental scientists in the field. Detailed procedures for sample acquisition and processing will be provided.

Regular macrofouling investigations will be made at least monthly. They will also be undertaken when circumstances permit access to points within the warm- and cold-sea-water systems that are not generally accessible. Investigations will consist of physical examinations (quantitative and qualitative observations) and fouling-plate studies.

\subsubsection{Physical Examination}

Observations will be made throughout the entire cold- and warm-water systems, including intakes, screens, sumps, and piping. These observations may require the services of divers. Diver observations will also be made regularly on the platform hull, mooring lines, and the exteriors of intake and discharge pipes.

The following will be determined by observation: Fouling species, their abundance, their spatial distribution, their size, and (within random but defined areas) their biomass. Each observation site will be photographed, and scrapings will be made periodically for rough estimates of biomass.

\subsubsection{Fouling-Plate Studies}

A series of fouling plates will be immersed at the cold- and warmwater intakes (preferably in sumps or other accessible areas). The plates 
will be replicated to establish variability, and a control series will be maintained throughout all tests. Plates will be removed on a monthiy basis during a test period and photographed. They.will then either be examined immediately according to accepted laboratory practices or be preserved for direct microscopic examination later. From random areas of known dimension, data on fouling species and their sizes, abundance, and spatial distribution will be recorded. Larval recruitment will also be emphasized. During each. examination, the preweighed plates will be weighed and total fouling biomass estimated. These data will be analyzed using standard statistical methods whenever applicable.

\subsubsection{Further Considerations in Macrofouling Investigation}

Because many of the macrofouling observations must be made when the opportunity arises, close coordination and communication between the Test Director and the macrofouling specialist will be required. The Test Director will be responsible for informing the macrofouling specialist whenever the sea-water system becomes accessible to observation. With adequate training, the ship's crew will be able to retrieve and process plate samples for onshore laboratory analysis.

At the end of the scheduled experiments, when the modules are cleaned by abrasive Amertap balls, a final macrofouling inspection will be made of heat exchangers and other available components according to ANL-approved procedures.

\subsection{7: Biofouling Sea-Water-Analysis Requirements}

Because both micro- and macrofouling can be affected profoundly. by physical and chemical parameters, a sea-water-analys is program is proposed in conjunction with the routine analyses performed during environmental studies (see Table 4.7). Daily chlorine demand and ammonia level will be monitored in raw untreated sea water (taps at modules 2 and 5): In addition, the ammonia level of the mixed heat-exchanger discharge will be monitored as part of the environmental studies. These measurements will be compared with daily measurements of total residual chlorine (oxidant) and ammonia taken at heat-exchanger inlets. (taps at modules 1 and 8 ) and at outlet taps to be provided to assess heat-exchanger chlorination periods. Any pronounced 
Table 4.7. Sampling and Routine Water Characterization on OTEC-1

\begin{tabular}{|c|c|c|c|c|c|c|c|c|}
\hline \multirow[b]{2}{*}{ Parameter } & \multicolumn{5}{|c|}{ Environmental Studies } & \multicolumn{3}{|c|}{ BCM Studies } \\
\hline & $\begin{array}{l}\text { Evaporator Kaw } \\
\text { Water intake }\end{array}$ & \multicolumn{2}{|c|}{$\begin{array}{l}\text { Condenser Raw } \\
\text { Water intake }\end{array}$} & \multicolumn{2}{|c|}{$\begin{array}{l}\text { Mixed Discharge } \\
\text { Effluent }\end{array}$} & $\begin{array}{l}\text { Evap/Cond } \\
\text { Inflowd }\end{array}$ & $\mathrm{Hx}$ & $\begin{array}{c}\text { Evap/Cond Hx } \\
\text { Discharge } e^{e}\end{array}$ \\
\hline Chlorine Demand & Daily & & Daily & & - & - & & - \\
\hline Total Residual Oxidant & - & & - & & Dailyf & Daily & & Daily \\
\hline Ammonia & Daily & . & Daily & & Daily $f$ & Daily & & Daily \\
\hline Suspended Solids & Weekly & & Weekly & & Weekly f & - & & - \\
\hline Nitrateg & ii & & $"$. & & "f & - & & - \\
\hline Total Nitrogen & $"$ & & $"$ & & $"$ & Weekly ${ }^{i}$ & & Weekly ${ }^{i}$ \\
\hline Phosphateg & $"$ & & $"$ & $\cdot$ & " f & - & & - \\
\hline Total Phosphorus & $"$ & & $"$ & & $"$ & Week $1 y^{i}$ & & Weekly i \\
\hline Silicates & $"$ & & $"$ & & " $\mathrm{f}$ & " $\mathrm{i}$ & & " $\mathbf{i}$ \\
\hline $\mathrm{pH}$ & $"$ & & $"$ & ' & $"$ & $"$ & i & i \\
\hline Salinity & "(Dailyh) & & "(Dai) & & $"\left(\right.$ Daily $\left.y^{h}\right)$ & $"$ & i & $"$ \\
\hline Alkalinity & $" \cdot$ & & $"$ & & $: "$ & $"$ & i & $"$ \\
\hline Dissolved Oxygen & $"($ Dailyh) & & $"$ (Dai) & & $"($ Dailyh) & $"$ & i & $"$ \\
\hline $\mathrm{BOD}_{5}^{\mathrm{j}}$ & "(Daily $y^{h}$ & & " (Dai) & & $"($ Dailyh) & - & & $\cdot-$ \\
\hline Titanium & Monthly & & Monthly & & Monthlyf & Monthlyi & & Monthlyi \\
\hline Iron & " & & $"$ & & "f & " $i$ & & " $\mathrm{i}$ \\
\hline Aluminum & $"$ & ' & $"$ & & " $\mathrm{f}$ & " $\mathrm{i}$ & i & $"$ \\
\hline Cadini um & $" \mathrm{~h}$ & . & $" h$ & & ". h & - & & - \\
\hline Copper & $"$ & & $"$ & & $"$ & Monthly $i$ & & Monthlyi \\
\hline Zinc & $" \mathrm{~h}$ & & $" \mathrm{~h}$ & & $" \mathrm{~h}$ & " $\mathbf{i}$ & i. & " $\mathrm{i}$ \\
\hline Nickel & $"$ & & $"$ & & $"$ & $" \mathrm{i}$ & i & $"$ \\
\hline Dis. Org. Carbon & $"$ & & $"$ & & $"$ & $" i$ & i & $" \quad i$ \\
\hline Part. Org. Carbon & $"$ & & $"$ & . & $"$ & . " $\mathrm{i}$ & i & \\
\hline EMC Biol/Chem Analy. ${ }^{k}$ & Monthly & & Monthly & & Monthly & Monthly & & Monthly \\
\hline 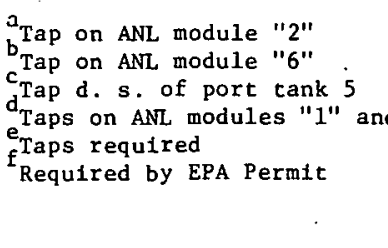 & nd "8" & & $\begin{array}{l}g_{\mathrm{EP}} \\
\mathrm{h}_{\mathrm{Se}} \\
\mathrm{i}_{\mathrm{Se}} \\
\mathrm{j}_{\mathrm{Bi}} \\
\mathrm{fi} \\
\mathrm{k}_{\mathrm{Al}} \\
\mathrm{sar} \\
\text { (t) }\end{array}$ & $\begin{array}{l}\text { Peru } \\
\text { ond-p } \\
\text { ond-p } \\
\text { ogic } \\
\text {-day } \\
\text { enat } \\
\text { ana } \\
\text { ird p }\end{array}$ & $\begin{array}{l}\text { says nitrate } \\
\text { iority environm } \\
\text { fority BCM para } \\
1 \text { oxygen demand } \\
\text { period } \\
\text { ve to listed mo } \\
\text { yses as done on } \\
\text { iority). }\end{array}$ & $\begin{array}{l}\text { and phospha } \\
\text { nental param } \\
\text { ameters } \\
\text { 1, averaged } \\
\text { nthly param } \\
\text { n cruises, } \mathrm{S} \\
\text {. }\end{array}$ & $\begin{array}{l}\text { ate. } \\
\text { meter: } \\
\text { over } \\
\text { meter: } \\
\text { Sec. }\end{array}$ & $\begin{array}{l}\text { s is the } \\
4.3 .6\end{array}$ \\
\hline
\end{tabular}


differences between analytical results from the condenser and the evaporator will indicate differences in heat-exchanger behavior. All chlorine measurements will be made amperometrically (in accordance with accepted methods) as close to the sample tap as is feasible. Chlorine should also be measured periodically at the discharges of $B \& C$ modules 4 and 7 . Here, as in the heat exchangers, chlorine levels should be monitored continuously while the chlorine-generating system is being adjusted.

In accordance with the environmental studies, sampling taps on modules 2 and 5 will be used to monitor heat-exchanger-intake nutrients and hydrographic features on a weekly basis, as outlined in Table 4.7. Similarly; taps will be provided on the heat-exchanger discharges to monitor these parameters weekly; in order to assess $\mathrm{HX}$ effects and to disclose any potential differences between the condenser and the evaporator. Also, in accordance with the environmental studies and for comparative purposes, taps on the heat-exchanger discharges will be monitored monthly for the heavy metals and organic-carbon types listed.in Table 4.7.

To ensure consistent results, sampling should be conducted as nearly as possible at the same time at all points on the test platform and in the sea nearby. An analytical laboratory, using standard sea-water methods and consistent instrumentation, should perform the analyses.

\section{2:8 Data Handling and Systems Control}

All data acquisition and reduction and systems control will be performed by the shipboard computer, which will be programmed to operate the neat-transfer-monitor (HTM) heaters, to acquire the required data automatically, to screen the data to exclude invalid.values, and to perform the computations required to display $R_{f}$ values on a near-real-time basis.

The computer will take one complete set of data from each HTM every day. A data set is defined as ten valid cooling curves (see Sec. 3.6). Data

- are to be provided to the ANL experimenter every two days and will be within two days of being current. 


\subsection{ENVIRONMENTAL MEASUREMENTS}

\subsubsection{General Scope of Environmental Measurements}

Environmental experiments involve the monitoring of effluents from the OTEC-1 platform (principally the power-system discharges) and the monitoring and sampling of the ocean in the vicinity of the platform. The measurements will be used to characterize and quantify the loadings from the plant to the ocean environment, to record the variability of the ocean conditions, and to investigate the impact of the plant on the ocean environment.

The environmental experiments themselves provide little in terms of specific direction for the heat-exchanger, biofouling-and-materials, and ocean-engineering experiments. Constancy of the mixed evaporator and condenser discharge flows is preferred. Fixed deep discharge of the mixed power-systems effluent is preferred over discharge from the hull or at an intermediate depth. The larger OTEC deployments of the future are expected to require deep discharge to preclude recirculation and degradation of the thermal resource. To formulate environmental guidelines for large deployments, data must be acquired on the impact of deep chlorinated discharges during OTEC-1 deployment. Therefore, the depth of the mixed discharge will be $73 \mathrm{~m}(240 \mathrm{ft})$.

The environmental tests include measurements of water streams on board the test platform, measurements of the ocean and the atmosphere from the test platform, and measurements in the ambient ocean from other vessels and moored instruments. Measurements will begin prior to the deployment of OTEC-1 and will continue throughout periods of the early test-article and Power System Development (PSD) studies and periods of the platform's absence from the site. Responsibilities for the various tests are divided between the Test Director Contractor (TDC) and its Environmental. Monitoring Contractor (EMC).

The following subsections describe the environmental studies to be conducted, the schedules for the studies; the party responsible for the study and data analyses, and, where appropriate, the relationship of the study to other studies in the test plan. 
4.3.2 Plant-Effluent Sampling, Analys is, and Disclosure of

Results in Accord with the EPA Permit Requirements.

The Environmental Protection Agency, Region IX, has issued a draft operating permit for OTEC-1 requiring that most effluents from the platform be monitored on a regular basis. The responsibility for monitoring the effluents and reporting the results to the EPA belongs to the San Francisco Operations Office (SAN) of DOE or its designated subcontractor, the TDC. The monitoring is not a test per se, but it is an integral part of the total water quality measurement activity for OTEC-1 and thus is included here.

The locations for sampling effluents, the parameters to be analyzed, and the frequency of sampling are indicated in the draft permit document (Ref. 1). Some 21 effluent streams are identified for sampling, including the mixed discharge from the power system heat exchangers. Sampling frequencies vary from continuous monitoring of a few parameters to once-amonth sampling at a number of locations. For example, the mixed power system discharge effluent (EPA designation 001) is to be monitored continuously with respect to flow rate and temperature, once a day for total residual chlorine (total residual oxidant) and ammonia, and once a week for nutrients. Other effluents, such as deck drainage, will be sampled once a month, and flow rates will have to be estimated. Some of the analyses can be performed aboard OTEC-1. Others will have to be done at a shore-based laboratory -the acquisition of multiple samples, the preservation of samples, or both may be required.

The relationship between the sampling and analyses required for the EPA permit and other sampling and analysis activities for environmental experiments and biofouling, corrosion, and materials experiments is discussed in section 4.3.7. The specific sampling for the EPA permit is a legal requirement and, consequently, of first priority among the environmental studies.

\subsubsection{Regular Characterization of Intake and Discharge Flows Beyond the Requirements of the EPA Permit}

In addition to the specific sampling and analysis requirements of the EPA permit and the intensive sampling to be done during the environmental monitoring cruises (Section 4.3.6), regular characterization of the 
flows to and from the power system will be needed to estimate effluent loadings to the ocean environment and to provide data on the variability of the influent and effluent streams. The responsibility for these measurements is that of the Test Director Contractor. or its Environmental Monitoring Contractor.

While the EPA permit calls for daily sampling of the total residual oxidant (chlorine-induced) at the mixed discharge, it is necessary to have additional data related to the chlorination operation. The chlorine demands of the raw intake waters to the evaporator and condenser should be determined daily. The rates at which chlorine ( $\mathrm{NaOC} 1)$ is injected into the raw intake waters of the evaporator and condenser heat exchangers should be monitored and recorded. Total residual oxidant values should be determined by the same amperometric titration procedure used in the biofouling studies and the environmental monitoring cruises. Since ammonia in the mixed discharge is determined daily, it is appropriate to determine ammonia concentrations" in the intake waters as well to facilitate the estimation of power system additions .

The EPA permit calls for once-a-week sampling of suspended solids, nitrates, phosphates, and silicates in the mixed discharge effluents. 'Concurrent sampling of the $r$ aw intake waters (evaporator and condenser) and analyses for the same nutrient parameters should be carried out to establish the magnitude of plant effects on intake water quality. In addition to the parameters listed above, the analyses of weekly samples of both the. inflows. (evaporator and condenser) and the mixed discharge should be supplemented to include $\mathrm{pH}$, salinity, alkalinity, dissolved oxygen, and $\mathrm{BOD}_{5}$. Of secondary priority are daily measurements of dissolved oxygen, BOD 5 , and salinity.

The EPA permit requires once-a-month sampling of the mixed discharge for titanium, iron, and aluminum. As in the case of the weekly samples, the inflows to the evaporator and condenser should be sampled for titanium, iron, and aluminum on a monthly basis as well. A more nearly comprehensive set of chemical analyses for samples drawn from the raw water intakes and mixed discharge on a monthly basis is required. Additions to the EPA permit requiremetts include analyses for other metals, such as copper and nickel, and for dissolved organic carbon and particulate organic carbon. 
The monthly samples described above represent a minimum, first-priority requirement. Lower-order priority is assigned to analyses for. cadmium and zinc, and even lesser priority is given to the chemical and biological analyses proposed for ocean water samples during the environmental monitoring cruises (Section 4.3.6). Such comprehensive monthly sampling will provide time-series data on the variability of inflow and discharge water characteristics that will fill the gaps between the data gathered during cruises (Section 4.3.6) scheduled to occur at two-month and longer intervals. While additional analyses will be required for the more comprehensive characterization, water sampling activities will not increase, because samples can, be taken monthly with those required for the EPA permit requirements.

The relationship between the water sampling and analysis described above and other analyses required for the environmental studies and biofouling, corrosion, and materials studies is discussed in section 4.3.7.

\subsubsection{Environmental Measurements on the OTEC-1 Plat form}

Meteorological measurements will be made continuously aboard the OTEC-1 platform. They. will be employed in the environmental studies for the interpretation of site transport characteristics and sea temperatures and in the ocean engineering studies with regard to near-surface currents, surface waves, and platform motions. The instrumentation for these measurements will be provided by the Environmental Monitoring Contractor and maintained by the EMC or the crew (EMC proposal, Ref. 2). The instruments include an anemometer for wind speed and direction, a barometric pressure transducer, an air temperature and dew point system, and a spectral pyrometer (for measuring insolation). It should be noted that the wind direction sensor records wind direction from a fixed orientation relative to the OTEC-1 platform and that synchronous, continuous recording of the platform's gyro compass heading is required to determine absolute wind direction.

The hull. scrapings program planned by the EMC will include sampling of the hull by divers at 3-month intervals. Areas to be sampled will be chosen by a random stratified sampling design, and the areas will be photographed and scraped. About five areas will be sampled, each about $0.5 \mathrm{~m}^{2}$ in area. Graphs indicating rates and patterns of colonization will be prepared by the EMC. 
An impingement monitoring program planned by the EMC is centered on the collection of $\mathrm{fish}$ and other nekton on the warm-water intake screen. or. in its vicinity. Samples will be taken weekly over a 24-hour period to indicate diurnal impingement patterns. All fish and nekton will be identified and enumerated by species, and a total weight by species will be taken.

Hydroacoustic monitoring to provide estimates of fish abundance. will be accomplished by a precision fish-finding sonar system on the OTEC-1 platform. Although the specific system has not been chosen, it is expected. that it can be operated by a crew. member and will provide continuous stripchart or digital output. The EMC will analyze the data to provide relative. fish abundance in sectors around the platform on diurnal, daily, weekly, and. monthly bases. Diver observations will be employed to support the hydroacoustical data.

\subsubsection{Measurements from Moored Instruments}

Time-series records of ocean currents, water temperatures, and surface waves in the site area are necessary to establish the transport pathways of effluents away from the plant and to analyze the station-keeping/mooring and coldwater pipe motions. The deployment and retrieval of the moorings and instruments and the processing of data are the responsibility of the Environmental Monitoring Contractor.

Current measurements should begin prior to deployment, because they wil1. provide the insight into transport pathways necessary to choose'sampling stations for subsequent water sampling after deployment and prior to plant operation. Present EMC plans call for deployment of one mooring with current meters in the site area three months prior to OTEC-1 deployment, followed by the installation of two more moorings upon the OTEC-1 platform deployment at the site (see section 5.1).

The moorings are to be arranged at the vertices of a triangle about seven miles on a side, centered about the OTEC-1 platform. Present plans (Ref. 2) call for each mooring to be instrumented with Aanderaa RCM-4 current meters with temperature and pressure sensors. These meters can record data at 15-minute sampling intervals for 150 days before retrieval and servicing. The option chosen by the EMC calls for three moorings. One mooring will have meters at $40,70,100,350$, and $700 \mathrm{~m}$ below the surface. 
The other two moorings will have meters at depths of 50 and $150 \mathrm{~m}$ and will have thermistor chains with 11 thermistors each between depths of 60 and $140 \mathrm{~m}$. Waverider buoys will be attached to the tops of two of the moorings when they are deployed. These buoys transmit signals proportional to vertical water surface displacement. The receiver will have to be placed on board OTEC-1 or on shore in a line-of-sight location. In addition, aufwuchs coupons ( $37 \times 37 \mathrm{~cm}$ asbestos plates) will be secured to the moorings at each instrument and subsurface float level at deployment and recovered at mooring retrieval. The details of the moorings, instruments, and sampling rates are given in Ref. 2 .

If data obtained indicate that the moorings are too close to each other to describe the circulation in the vicinity of the plant adequately, an alternative arrangement will be instituted, placing the three moorings in a triangle with larger sides ( 12 miles). One mooring will remain in the site area outside the drift circle, and the other two.will be in shallower water to the southeast ( $300 \mathrm{~m} \mathrm{depth}$ ) and east-northeast (500 $\mathrm{m}$ depth) of the site. If the alternative mooring scheme is followed, the deep mooring near the OTEC-1 site will have current meters at $40,70,100,200,350,500$, and $700 \mathrm{~m}$ depths, a thermistor chain in the top $100 \mathrm{~m}$, and a Waverider buoy. The 300-m mooring (SE) will have current meters at 40 and $100 \mathrm{~m}$ and a thermistor chain in the top $100 \mathrm{~m}$. The 500-m mooring (ENE) will have current meters at 40 and $100 \mathrm{~m}$ and a Waverider buoy.

\subsubsection{Environmental Monitoring Cruises}

Environmental monitoring cruises are planned to sample and characterize the ambient ocean environment in the site area at regular intervals prior to, during, and after the deployment of OTEC-1 in order to assess any impacts on the environment. A secondary objective is to attempt to locate and characterize the mixed-discharge effluent plume from OTEC- 1 .

The environmental monitoring cruises will be carried out by the EMC. The EMC Effort is divided into six phases:

Phase I - prior to the arrival of the test platform on site

Phase II. - after test platform arrives, but prior to testing

Phase III - testing of 1 MWe test article

Phase IV - after test platform has left the site 


\section{Phase V - testing of PSD articles \\ Phase VI - after test platform has left the site.}

Cruises will occur during Phases II-VI and will be conducted bimonthly during the biologically productive periods (spring through fall) and less frequently during winter. Cruises will be conducted during Phases IV and VI regardless of the season. A total of 16 cruises is planned.

The details of the environmental monitoring cruise activities are discussed in Ref. 2. A summary of the cruise activities and necessary related studies is given below.

Sampling from the Survey Vesse1. A sampling grid of 12 stations (Fig. 4.4) will be established, based on interpreting data on mean currents gathered from the current meter during Phase I (Sect.4.3.5). Five of the stations are high-priority stations. They will be sampled first to ensure minimum data return. Normal cruise plans call for the occupation of " 17 stations. This will give some repetition to gain a synoptic view. At each station, twelve-liter, Niskin-bottle samples will be taken at 11 depths between the surface and $350 \mathrm{~m}$ (light variable sampling depths during the day). At two stations, samples will be taken at $800 \mathrm{~m}$ depth. Profiles will be made at each station with a CTD, transmissometer, and irradiance meter. Current profiles in the upper $200 \mathrm{~m}$ will be measured from the survey vesse 1 , and standard meteorological observations will be made at 6- and 4-hour intervals, respectively. Plankton tows along different transects during the day and night will be made. One oblique tow will be made in the deep scattering layer and two in the mixed layer, and a vertical tow from the bottom of the mixed layer to the surface will be made. The water samples collected will be analyzed for:

\begin{tabular}{|c|c|c|}
\hline $\begin{array}{l}\mathrm{pH} \\
\text { dissolved } \\
\text { alkalinity }\end{array}$ & oxygen & \\
\hline $\begin{array}{l}\text { luminum } \\
\text { admium }\end{array}$ & ( & $\left({ }^{p a r t}.\right)$ \\
\hline balt & ( " & $"$ \\
\hline romium & ( " & $"$ \\
\hline pper & ( ". & $"$ \\
\hline on & ( " & $"$ \\
\hline nganese & ( " & $"$ \\
\hline kel & ( " & $"$ \\
\hline tanium & (" & $"$. \\
\hline
\end{tabular}

zinc (dis. \& part.)

nitrite-nitrate

ammonia

or thophosphate

total phosphorus

total nitrogen

silicates

residual oxidants

dissolved organic carbon

particulate organic carbon

soluble petrochemicals.

bromoforms 


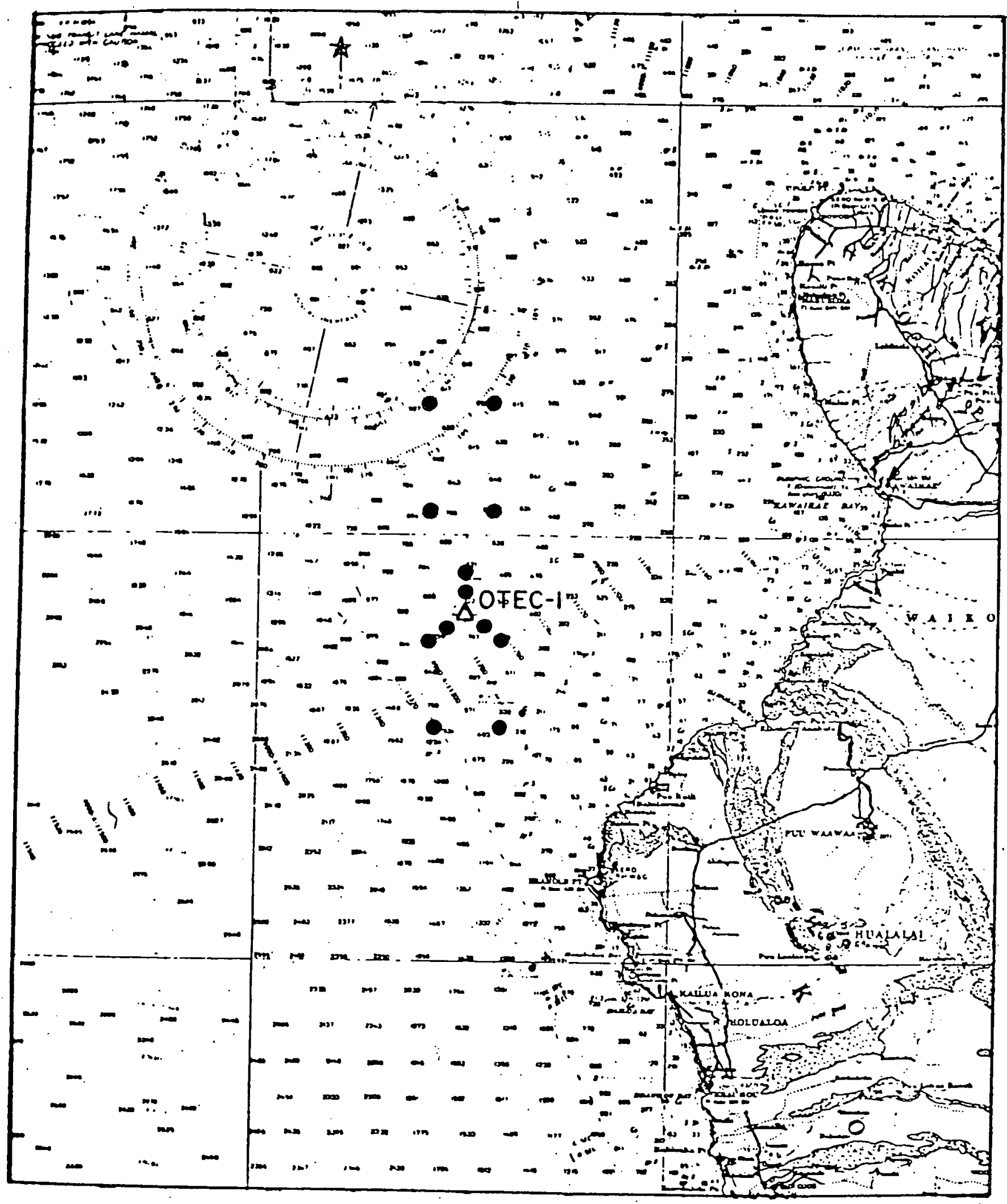

Fig. 4.4. Proposed Stations during Hydrocruises. (Station spacing and orientation relative to the OTEC-1 platform will be determined based on mean current patterns.) (from Ref. 2) 
In addition, analyses related to primary productivity will be conducted with carbon-14 tracers for chlorophyl1-a, phaeopigment, and ATP. Plankton samples will be quantified and identified. During at least one cruise, water samples from the surface, from $350 \mathrm{~m}$, and from $800 \mathrm{~m}$ should be analyzed for total $\mathrm{CO}_{2}$ and dissolved gas constituents.

Sampling from OTEC-1. Although not specified in the activities of the environmental monitoring cruise, water samples should be taken on board OTEC- 1 at the evaporator and condenser raw water intakes and particularly at the mixed discharge ( $t$ ap downstream of port tank 5 ) during the cruise. These samples should be taken just prior to and at the end of the monitoring cruise and should be subjected to the same analyses as water samples collected at the ambient ocean stations to provide a measure of what the plant contributes to the ocean environment near the plant. Moreover, plant intakes and discharges should be monitored at least twice daily during cruise activities for total residual oxidant, ammonia, salinity, $\mathrm{pH}$, and dissolved oxygen.

Effluent Plume Measurements. The EMC will attempt to locate and sample the'mixed discharge effluent plume as part of the environmental monitoring cruises during Phases III and $V$. The effluent plume is expected to be narrow, thin (a few meters thick in the vicinity of the plant), and difficult to locate. To facilitate detection of the plume (it will have a very small temperature/salinity signal), dye will be injected into the discharge for several hours. It will probably have to be injected onboard the platform in port tank 5 or port tank 9. An in-situ fluorometer and CTD will be used to attempt to sense the plume in the near vicinity of the platform. If the plume is found, two plankton tows will be made and three water samples will be collected within: the plume. These samples will be analyzed in the same manner as other environmental monitoring cruise samples discussed above. Additionally, analyses for organohalide compounds within the water and plankton will be made.

\subsubsection{Relationships Among the Required Water Samples and Analyses}

To satisfy EPA permit requirements, water samples and analyses are required for the regular characterization of inflow and effluent waters and for the environmental monitoring cruise operations. Biofouling, corrosion, 
and materials studies (BCM) also require some of the same samples and analyses (Section 4.2). Table 4.7 summarizes the locations of samples, the frequency of sampling, and parameters for which analyses (onboard or shoreside) will be performed. Required analyses and those that are particularly useful but of lower priority are noted. The important sampling locations for s the environmental studies are at the raw water streams for the evaporator and condenser and at the mixed discharge stream. BCM studies require daily samples at the inflows (after chlorination) and discharges of the evaporator and condenser for total residual oxidant and ammonia. More detailed analyses on either side of the heat exchangers are of lower priority.

The routine chlorination schedule of the heat exchangers is intermittent (Section 4.2.1). The condenser inflow is chlorinated for one hour; followed immediately by chlorination of the evaporator inflow for one hour, once each day. Thus, the daily samples for chlorine demand and total residual oxidant must be obtained in a manner consistent with the chlorination schedule. Raw intakes should be sampled for chlorine demand just prior to or during chlorination, and evaporator and condenser inflows (past the point of chlorination) and discharges should be sampled for total residual oxidant about midway into the chlorination cycle of the appropriate heat exchanger (after about 30 minutes). The mixed discharge should be sampled for total residual oxidant twice during the chlorination cycle: First, about midway into the condenser chlorination, then again midway into the evaporator chlorination (after about one hour). Of course, samples of the mixed discharge for total residual oxidant should be taken during the release of chlorinated sea water following any unplanned cessation of water flow to the heat exchangers that might result in chlorination (Section 4.2).

It is particularly important that consistent procedures and standardized techniques be employed in the collection and analysis of the data. clearly, the same amperometric titration procedure (and instrument) should be used to provide the total residual oxidant data daily for both the environmental and BCM studies. Onboard procedures should be consistent with those employed by the EMC with regard to the environmental cruise samples from the ambient ocean.

The weekly samples of both the intake and effluent flows are necessary, not only to meet EPA requirements, but also to have some grosis measure of the variability of ambient water quality and of the plant effects on water 
quality. Such data are important for assessing any marked changes in biofouling as we11. An alternative to the listed monthly analyses is the performance of the biological and chemical analyses that the EMC will carry out at two-to-four-month intervals in relation to the environmental monitoring cruises (Section 4.3.6). Such a comprehensive analysis on a monthly basis would provide a time series against which to compare ambient ocean survey data, but it is listed as low in prinrity.

\subsubsection{Analyses and Evaluation of Environmental Data}

In contrast to the heat exchanger and biofouling tests, the environmental studies do not, for the most part, involve detailed analyses or evaluations to be made in real time for adjustment or modification of test conditions. Exceptions to this statement are the adjustments to experimental plans during the environmental monitoring cruises (Section 4.3.6) on the basis of field measurements and the adjustments to operation and/or chlorination procedures necessary to comply with EPA requirements. The conditions for these adjustments are described in Refs. 1 and 2. After collection of the data, the analyses and evaluation of the environmental measurements involve several groups within the OTEC program. However, the Lawrence Berkeley Laboratory is responsible for the final environmental assessments. For the most part, the preliminary analysis of data has been assigned to the Environmental Monitoring Contractor (EMC), supported by personnel and subcontractors of the Test Director Contractor (TDC). As suggested in Section 4.3.7, coordination of analysis techniques and procedures among those performing chemical analyses is particularly important. A summary of the flow of data for analyses and evaluation is given below.

\section{Water Quality Data Collected On Board OTEC-1}

The water quality data collected on board OTEC-1 have been summarized in Section 4.3.7. The daily chlorine demand, total residual oxidant, and ammonia data must be analyzed on board and be available for the BCM experimenters. The weekly and monthly samples of water streams sampled on board will be analyzed either on board or at the shoreside laboratory by the TDC. Results should be made available to SAN (for those parameters that must be reported monthly to the Region IX EPA as described in the EPA permit), to the Lawrence Berkeley Laboratory environmental group, and to the Argonne National Laboratory BCM program. 


\section{Environmental Monitoring Cruise Data}

The responsibility for the analyses of data collected during these activities is that of the EMC. The Lawrence Berkeley Laboratory may have personnel on board the environmental monitoring cruise vessel during the sampling, and the Argonne environmental group during plume measurements, but the preliminary analysis of data rests with the EMC. Data reports from the EMC to SAN will also be sent to the Lawrence Berkeley Laboratory for evalwation of environmental modification. Data related to plume studies will be provided to ANL for evaluation and comparison with model predictions. It is the responsibility of SAN to transmit to the EPA the environmental monitoring cruise data as required by the EPA permit.

\section{Physical Oceanographic and Meteorological Data}

The processing and preliminary evaluation of the physical oceanographic and meteorological data is the responsibility of the EMC. The results of these analyses are to be provided to the NOAA Office of Ocean Engineering OTEC group, the Lawrence Berkeley Laboratory, and the Argonne environmental group, as well as to SAN, which has responsibility for transmitting these results to the EPA. The NOAA group will employ those data and plant data to evaluate the sea water system performance, and the Lawrence Berkeley Laboratory and Argonne groups will use the information to interpret the environmental-impact data, plume analyses, and circulation models. The Argonne and LBL groups will, in accordance with permit requirements, provide the EPA with any reports concerning the above environmental-impact data, plume analyses, and circulation models.

\subsection{OCEAN ENGINEERING TESTS}

\subsubsection{Cold Water Pipe Studies}

Cold water pipe studies for OTEC-1 are focused on the behavior and safety of the cold water pipe system (CWP). No studies are specifically directed toward the validation of CWP codes under development by NOAA for larger OTEC deployments, because the OTEC-1 CWP system is unique and unlikely to be duplicated in the future. 
The measurements required for study of the OTEC-1 CWP behavior are the responsibility of the Test Director Contractor and SAN. These studies are more closely related to the operation of the platform than they are to a specific experiment, and they are not discussed in détail here. The measurements required are given in detail in the OTEC Test Request N-070EA01-TS003 draft, dated January 7, 1979.

\subsubsection{Sea Water Systems Experiment}

The objective of the sea water systems experiment is to collect data for the validation of $a$ : sea water systems (SWS) model by the NOAA Office of Ocean Engineering. This experiment is completely passive with regard to OTEC-1 operations and power systems, biofouling, environmental, and other ocean engineering experiments. It simply requires the utilization of OTEC-1 systems data collected for other purposes.

The sea water system (SWS) of OTEC-1 is composed of the hydraulic loop interconnecting the following subsystems supported by the platform: the cold water inlet and pipe; warm water inlet; sea water pumps; sumps; holding tanks, valves, and piping; heat exchangers; and cold and warm water discharge pipes. A model of a generic OTEC SWS is under development at NOAA. This model will be applied to the OTEC-1 SWS for analysis of the transient and steady-state operations. The OTEC-1 SWS component specifications and theoretical operating characteristics will be programmed into the NOAA analytical model, and operational data will be used for the validation and demonstration of the model.

The data required for validation and demonstration include synoptic data sets for temperatures, pressures, and flows throughout the OTEC-1 SWS; measurements of platform motions; measurements of CWP behavior; and environmental measurements (meteorological parameters, currents, and waves). Initially, such data sets will be used for validation of the model. Later data sets will be employed for demonstration. That is, platform motion and gross SWS operating characteristics (e.g., seawater pump speeds, inlet water temperature, and surface-wave characteristics) will be put into the model for the prediction of temperatures and pressures throughou' the OTEC-1 SWS. 
The data sets required for model validation and demonstration are among those planned for acquisition for platform operation, heat exchanger tests, and environmental studies. They need only be supplied to the NOAA group after preliminary shoreside processing. 


\section{TEST SCHEDULE AND PLANS FOR UNSCHEDULED INTERRUPTIONS}

\subsection{TEST SCHEDULE}

The first deployment of OTEC-1 is planned to run for nine months -a one-month period at the beginning for checkout of the mooring, stationkeeping; and seawater systems and an eight-month test period. Figure 5.1 shows the test schedule, including both the sequence and the duration of the individual tests according to the priorities discussed in sections 2 and 4 . The following features of the test schedule should be noted:

1. The biofouling countermeasures tests will begin as soon as the sea water flow is started, approximately two weeks after the ship arrives at the test site. Once the sea water flows are established, they will not be inter-. rupted unless equipment failures require the sea water pump to be shut down. The chlorine treatment and the Amertap ball rate must be maintained at the planned levels, unless these prove to be inadequate. If changes in either of these levels are required, they will be made between the test periods for the different evaporator configurations (i.e., during the scheduled periods for changing the evaporator shrouds).

2. The heat exchanger tests will begin at the conclusion of the shakedown tests of the ammonia transfer and circulating system (chosen as the reference time zero in Fig. 5.1). The first sequence of tests will be for the evaporator in the simulated 4-MWe, sprayed-bundle configuration, and the goal is to obtain performance information within two months after start of the tests. The evaporator in the 1-MWe, sprayed-bundle configuration will be tested next, followed by the 1-MWe, floodedbundle tests and a return to the baseline 1-MWe, sprayed-burdle configuration.

3. The tests of the evaporator include performance measurements at different reflux ratios with the three different spray systems and, in the case of the flooded-bundle configuration, measurements both with the upper and lower tube bundles and with the lower bundle only. For each of the three basic evaporator configurations, measurements at baseline design configurations will be made first in order to establish a performance benchmark. These baseline tests will be repeated periodically throughout the test sequence to track the onset of any changes in performance that may arise because of changes in the High Flux surface, the biofouling resistance, or other uncontrollable factors. 


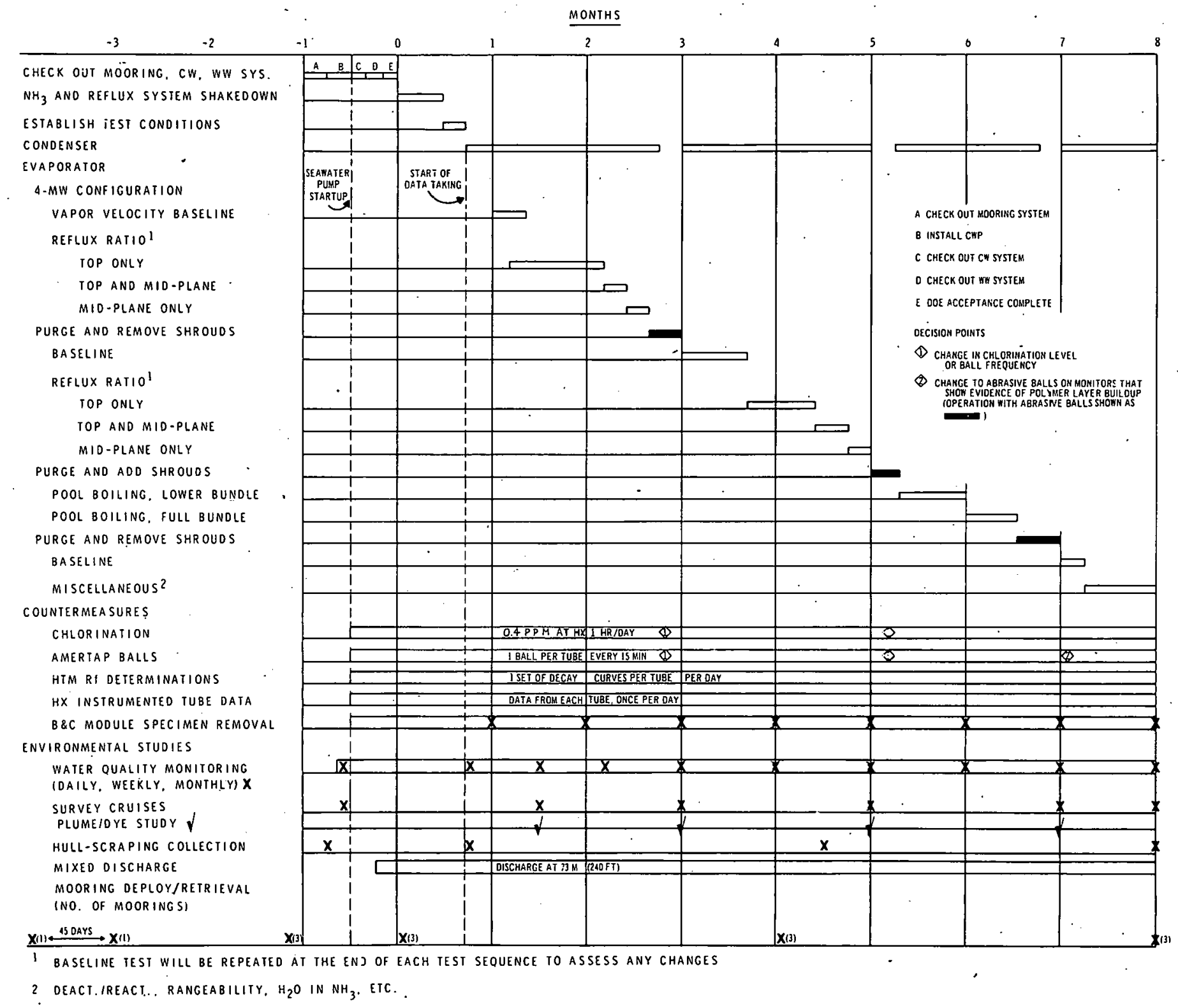

Fig. 5.1. OTEC-1 Test Schedule 
4. Second-priority tests of the heat exchangers will be deferred until all of the tests in (3) above are completed satisfactorily. In descending order of priority, these second-order tests are: (a) High $F$ lux , surface deactivation/reactivation tests in the flooded-bundle evaporator configuration, (b) deactivation/reactivation tests in the sprayed-bundle evaporator configuration, and (c) tests to determine the effect of water in the ammonia on the performance of the sprayed-bundle evaporator.

5. Data from the biofouling heat transfer monitors and the instrumented tubes are to be taken daily during. the entire time that the sea water pumps are operating.

6. The environmental monitoring tests will begin 3-1/2 months before the ship arrives at the test site and continue until the sea water pumps are shut down.

\subsection{PLANS FOR UNSCHEDULED TEST INTERRUPTIONS}

Unscheduled interruptions in the tests can occur due to ship system malfunctions, test equipment failure, and severe weather. Detailed operating procedures to protect the safety of the crew and the integrity of equipment will be worked out by the System Integration Contractor and the Test Director Contractor. The experimenters are fully aware that the protection of the crew and equipment is of overriding priority.

The summary of actions in the event of test interruptions in Table 5.1 is compiled from the point of view of (a) exploiting equipment malfunctions as opportunities for obtaining useful information, (b) preserving experimental conditions as far as practicable, and (c) preserving the continuity of test data. The Test Director Contractor will need to refer to this summary while preparing detciled operating procedures, in order to accommodate the experimenters' requirements. Conflicts arising between the experimenters' needs and the equipment operating capabilities will be resolved in detailed discussions between the experimenters and the Test Director Contractor during the preparation of operating procedures.

The summary is divided into seven categories:

I Evaporator System,

II Condensing System,

III Fresh Water System,

IV Ammoniá Power System, 


\section{Biofouling, \\ VI Instrumentation and Analysis, and \\ VII Environmental Considerations.}

Under each category except the last one, there are five headings that describe the fault; the possible causes of the fault, the probable effects on the experiments, the action required, and the changes in the data acquisition procedure during the interruption. Category VII, Environmental Considerations, is a brief statement of the spirit of the EPA permit and the philosophy that should be. followed with respect to effluents and discharges, particularly unplanned ones. 
Table 5.1. Summary of Test Interruptions Due to Equipment Failures

I Evaporator System

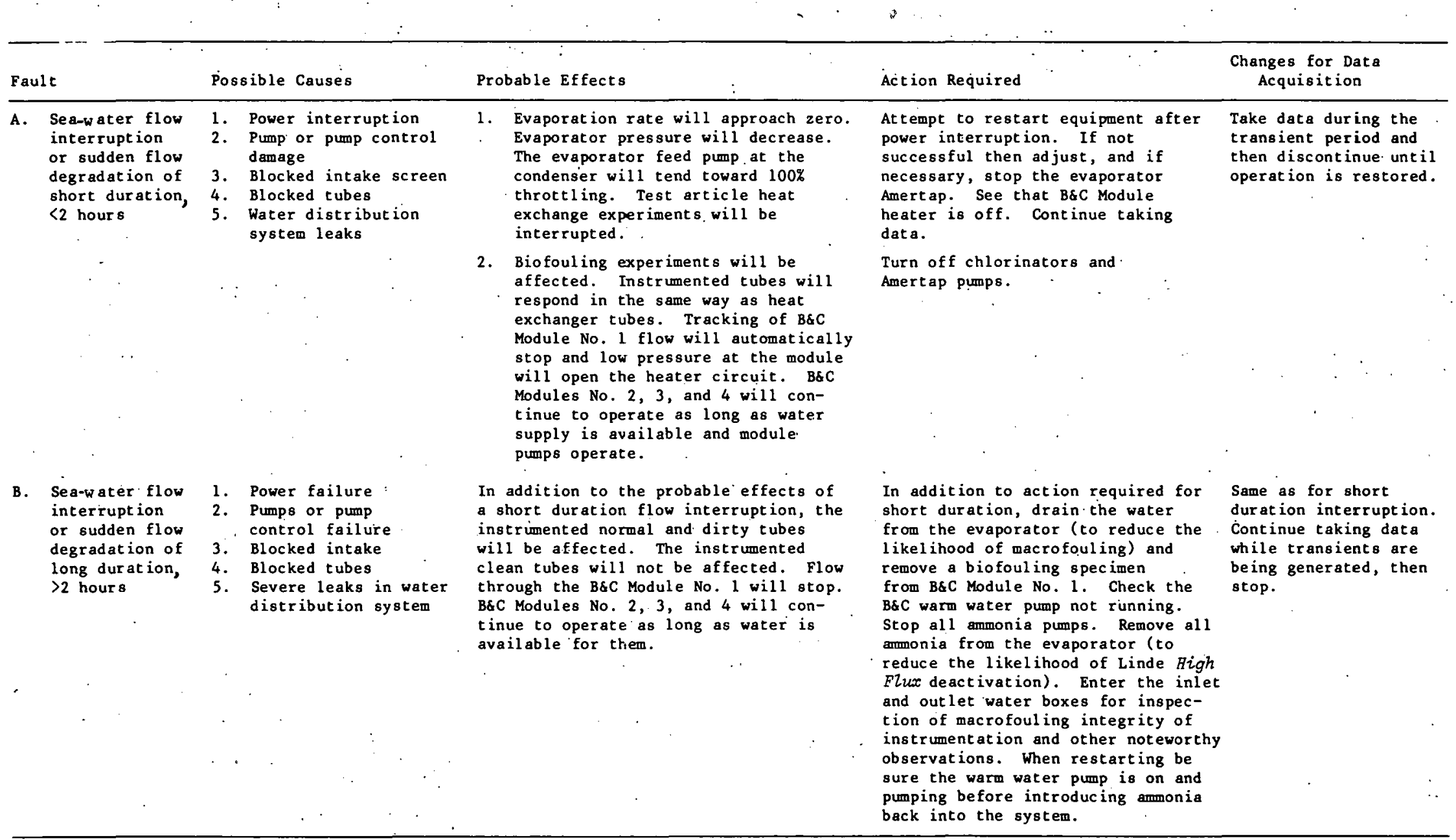


Table 5.1. (Cont'd)

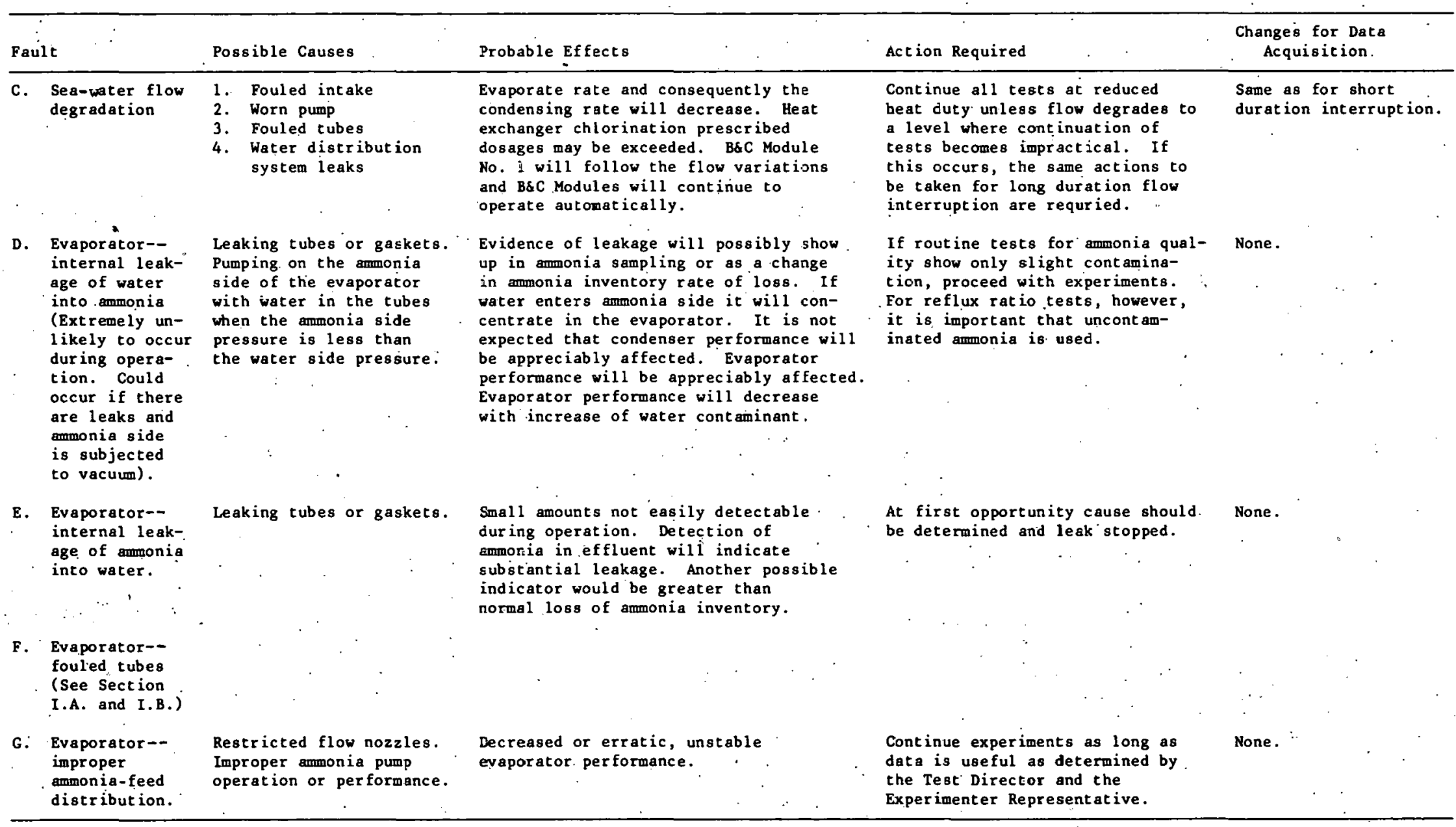


Table 5.1. (Cont'd)

II Condensing System

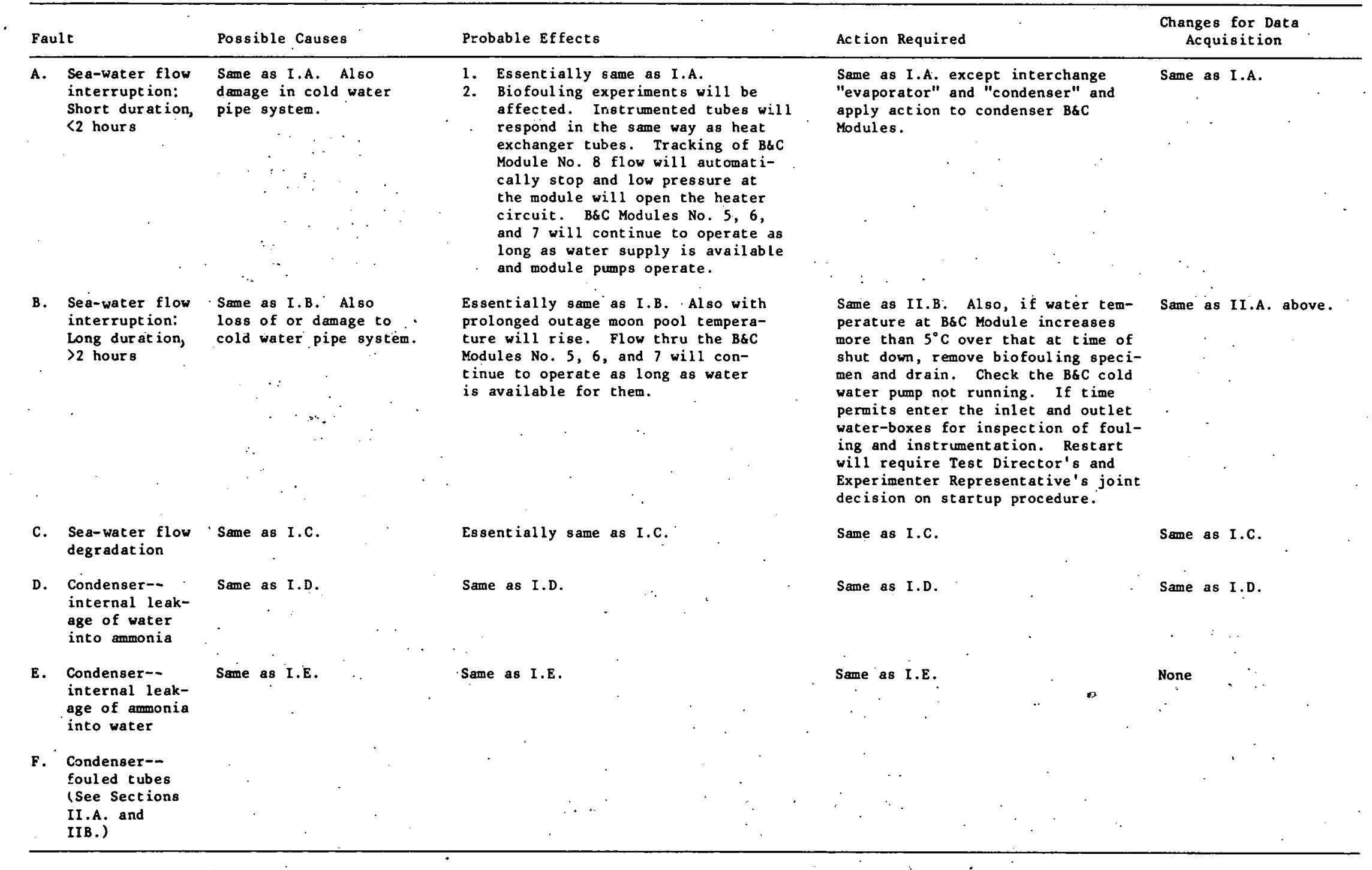


Table 5.1. (Cont'd)

III Fresh Water. System

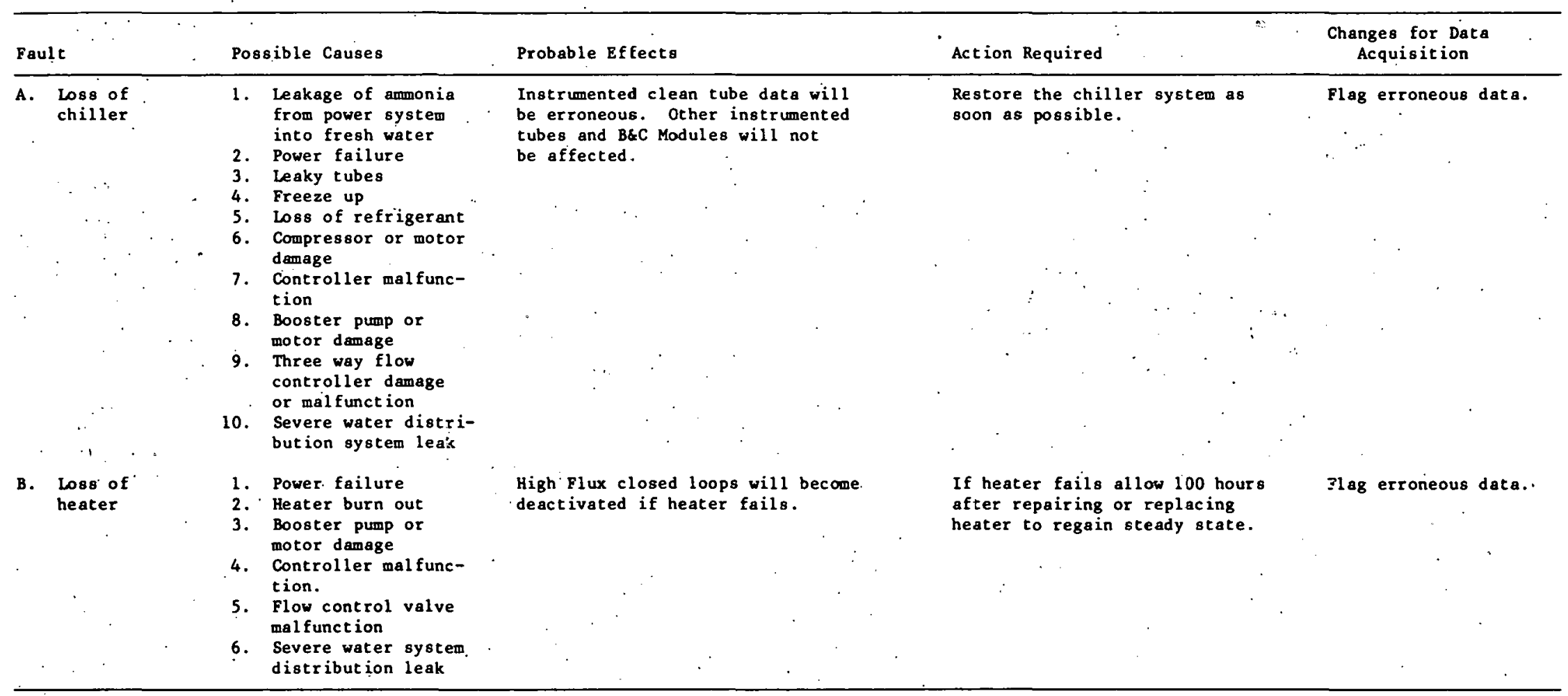


Table 5.1. (Cont'd)

IV Ammonia Power System

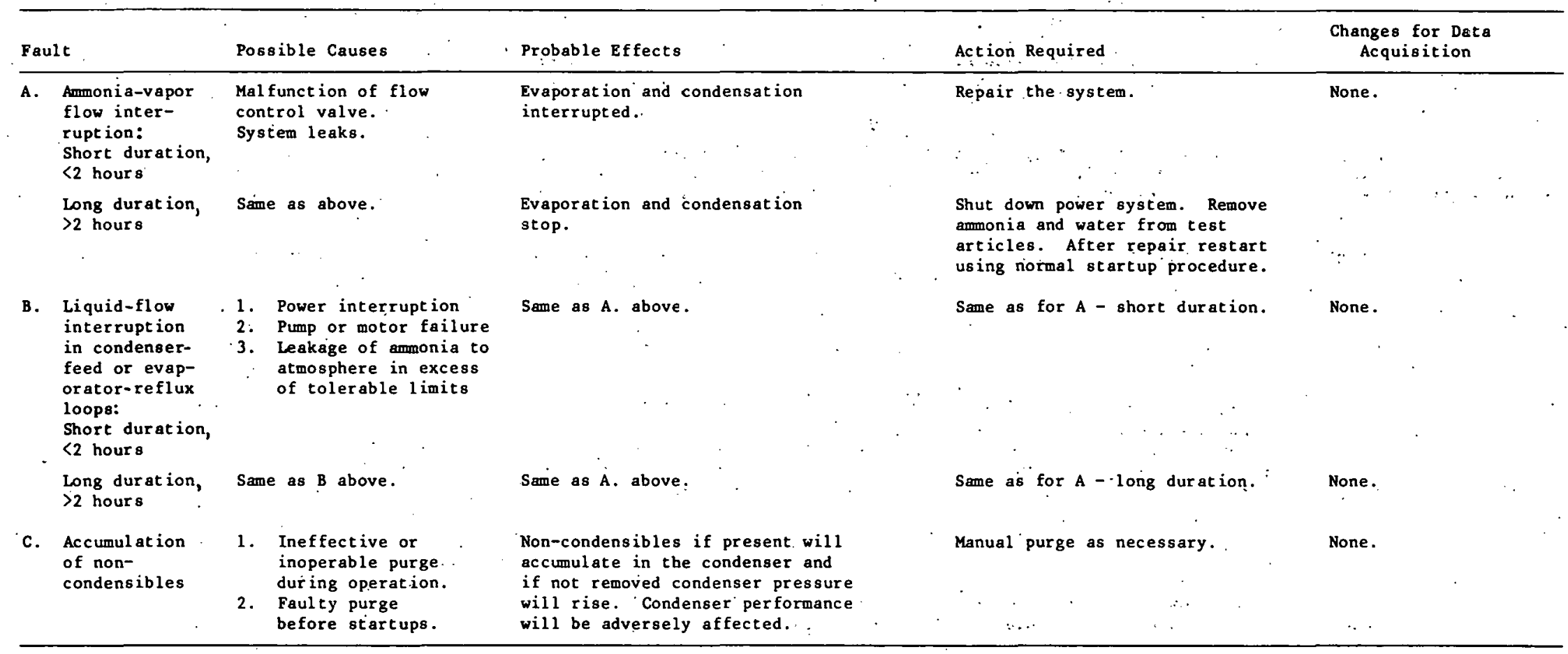


Table 5.1. (Cont'd)

$v$ Biofoul ing

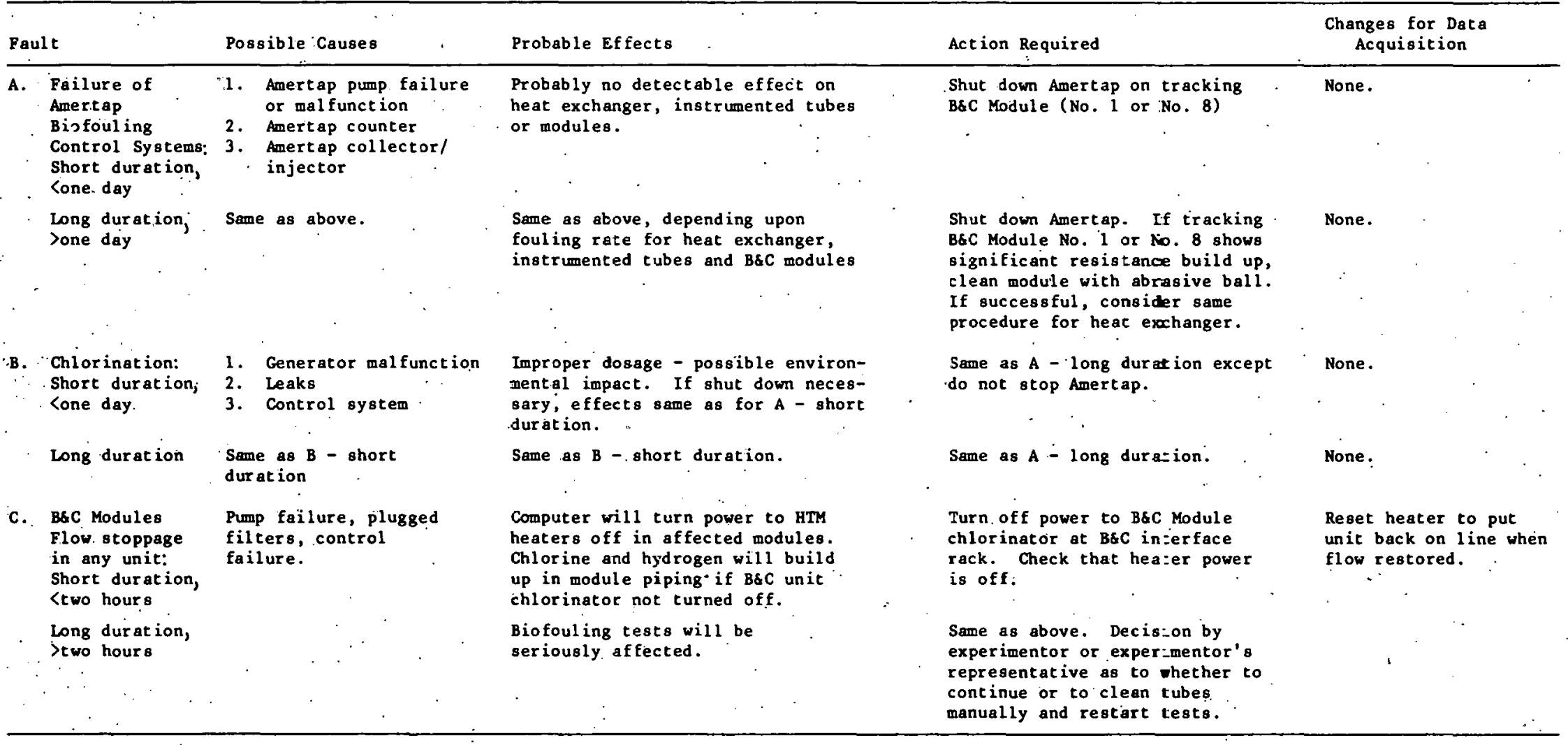


Table 5.1. (Cont'd)

VI Instrumentation and Analysis

\begin{tabular}{|c|c|c|c|c|c|c|}
\hline Faul & $1 t$ & Possible Causes & Probable Effects & Action Required & $\begin{array}{l}\text { Changes for Data } \\
\text { Acquisition }\end{array}$ & \\
\hline A. & $\begin{array}{l}\text { Interruption } \\
\text { or loss of } \\
\text { data-acquisi- } \\
\text { tion capability }\end{array}$ & $\begin{array}{l}\text { Computer or other } \\
\text { system faults. }\end{array}$ & Loss of continuity in detail data. & $\begin{array}{l}\text { Continue taking data manually } \\
\text { while correcting fault. }\end{array}$ & Manual recording. & \\
\hline B. & $\begin{array}{l}\text { Loss or } \\
\text { partial loss } \\
\text { of acquired } \\
\text { data }\end{array}$ & $\begin{array}{l}\text { Loss of tapes or } \\
\text { computer memory. }\end{array}$ & Loss of experimental data. & $\begin{array}{l}\text { May require repeating of } \\
\text { some experiments. }\end{array}$ & & • \\
\hline c. & $\begin{array}{l}\text { Loss of } \\
\text { chemical or } \\
\text { other analy- } \\
\text { tical ability }\end{array}$ & $\begin{array}{l}\text { Van systems out of } \\
\text { service. }\end{array}$ & $\begin{array}{l}\text { Possible loss of plume tracking, } \\
\text { and environmental data. }\end{array}$ & $\begin{array}{l}\text { Continue taking other data. Take } \\
\text { data manually and continue to } \\
\text { analyze, if possible. }\end{array}$ & $\cdot$ & . \\
\hline
\end{tabular}

VII Environmental Considerations

The operation of OTEC-1 is expected to be environmentally benign. Environmental monitoring activities and experiments are planned to provide evidence to support those expectations. However, untoward permit violations or environmental upsets could possibly interrupt the test schedule.

The draft permit from U. S. EPA Region IX for the operation of OTEC-1 has some specific effluent limitations. The most important limitation is that the daily average for the discharge of residual chlorine from the mixed discharge shall be 0.1 mg/L. The maximum residual chlorine discharge is specified as $0.2 \mathrm{mg} / \mathrm{L}$ for two hours, but if that level is used no chlorine may be discharged for the remaining 22 hours in the day. The other 1 imitations are that free ofl and float1ng solids shall not result from the 21 specified effluent streams and that no ammonia shall be in the bilge water discharged from the OTEC compartment. The final permit may be similar or may specify additional effluent limitations.

Should an experimental or facility systems fault result in noncompliance, the operator of the plat form is required not only to attempt to bring the system into compliance, but also to "minimize any adverse impact to receiving waters ... including such accelerated or additional monitoring as necessary to determine the nature and impact of the noncomplying discharge." Thus, should noncompliance be obvious or made apparent during required sampling; the environmental experimenters' representative should be notified to determine whether additional monitoring activities are necessary.

Although no environmental upsets are expected to occur due to the operation of OTEC-1, it is conceivable that some event (such as fish kill or severe discoloration of the water by plankton) could occur in the vicinity of the platform due to natural processes or platform operation. Although all $\mathrm{plat}$ form effluents might be in compliance with the permit limitations during such an event, it is important that the environmental experimenters be notified. If possible and warranted, monitoring will be undertaken to determine the nature and cause of the event.

Should it become necessary because of any system or component failure to discharge to the sea any substance such as contaminated ammonia, a qualitative analysis and a record of the amount of overboard discharge should be made. 
THIS PAGE

\section{WAS INTENTIONALLY \\ LEFT BLANK}




\section{DIRECTION OF THE EXPERIMENTAL PROGRAM}

\subsection{RESPONSIBILITIES}

The tests to be conducted on the OTEC-1 ship are intended to provide data for several research groups. The remoteness of the test facility from the final users of data, the high costs of operation at s̀ea, and the likelihood of operational problems make it necessary to establish clear procedures for the control and direction of the experimental program. Since the entire OTEC-1 undertaking, involves several parties (i.e., experimenters, the Test Director Contractor, and the Department-of Energy), a meaningful discussion of direction requires a definition of the respective responsibilities of each. The management organization is shown in Fig. 6.1.

\section{1:1 The Test Planning and Evaluation. Working Group}

DOE will form and chair the Test Planning and Evaluation Working Group (TPEWG). The TPEWG is to have representatives from the experimenters (Argonne National Laboratory and Lawrence Berkeley Laboratory), the Test Director Contractor (ETEC), and other experts invited by the chairman on an ad hoc basis. The TPEWG is concerned with the scope, the goals, and the long range schedules of the test program. The group will provide input to the test plan, will give it final approval, and will review all requests for subsequent amendments to the plan. All decisions relating to the direction of the experimental program will be communicated by the DOE Chicago Operations Office to the chairman of the Joint Test Group (formed by the experimenters). All contractual matters will be transmitted by the San Francisco. Operations office to the Test Director Contractor.

\subsubsection{The Experimenters}

Argonne National Laboratory and Lawrence Berkeley Laboratory have been charged with the job of specifying the tests, evaluating the data, and publishing the results obtained from the first deployment of OTEC-1. Experimenters from these laboratories will direct the OTEC-1 program in the three major areas of technical interest: heat exchangers; biofouling, corrosion, and materials; and environmental impacts. The experimenters will be free to 
- - - - -

Interfacing
TEST PLANNING AND EVALUATION WORKING GROUP (TPEWG)

- Approves test plan and amendments

- Provides direction for generation of test plan

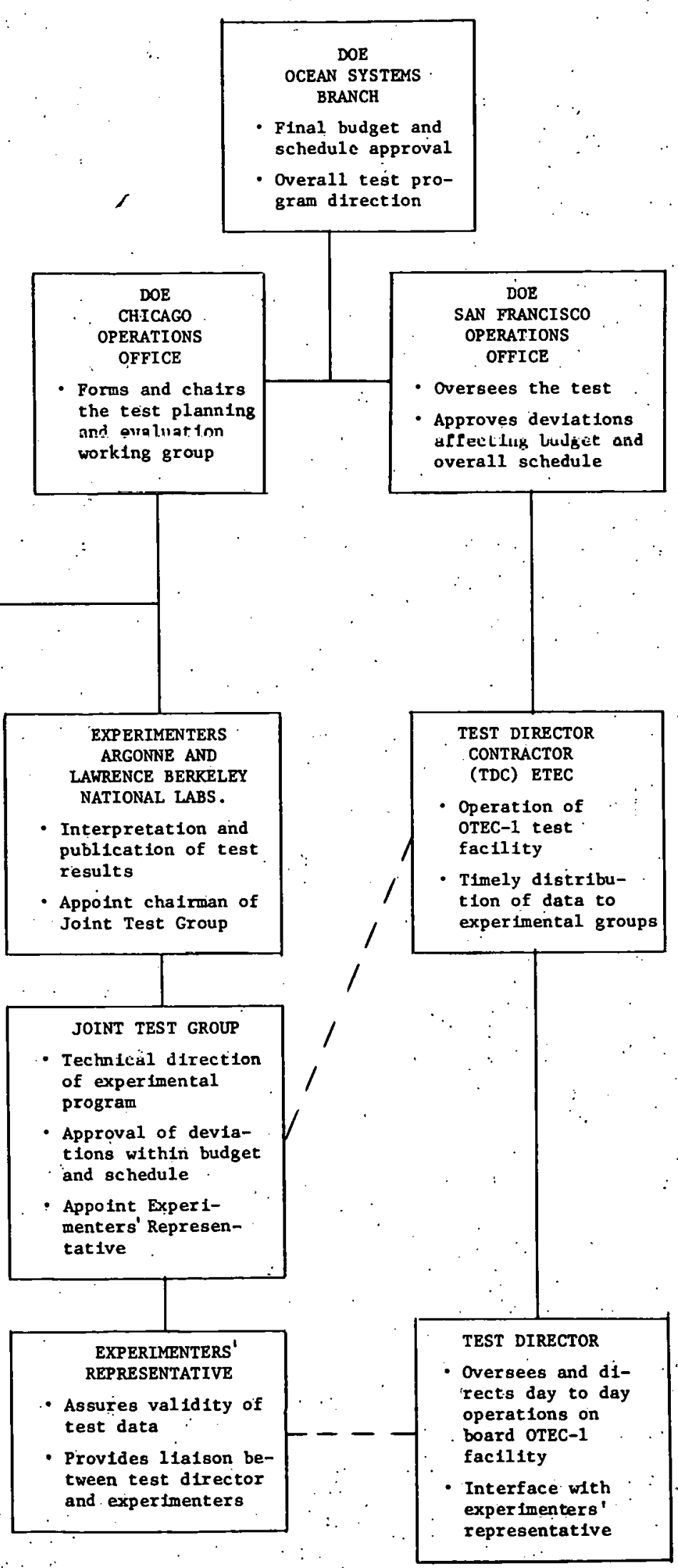

Fig.6.1. Organization of the OTEC-1 Test Program 
consult with other experts as needed. For example, TRW, the manufacturer of the heat exchangers, may be consulted on specific technical matters.

\section{1 .3 Joint Test Group (JTG)}

In order to direct the experimental program, the experimenters will form the Joint Test Group (JTG), which will issue short- and long-range scheduling priorities to the Test Director Contractor. The JTG will meet at least weekly, and more often if necessary. The Test Director Contractor will be represented on the JTG. The chairman of the JTG will have the authority to approve changes in priorities and sequences of tests provided that they do not alter overall goals or cause budget and schedule overruns. The chairman will be responsible for transmitting the decisions and recommendations made at each JTG meeting to the DOE San Francisco Operations office. Any amendments to the test. plan must be reviewed by the TPEWG and approved by DOE (see Section 6.5 .3 ).

\subsubsection{Experimenters' Representative (ER)}

An Experimenters' Representative (ER) will be appointed by the chairman of the JTG. The responsibility of the ER will be to assure the JTG that its recommendations are being followed in the daily test operations on board OTEC-1 and that the test data are valid and are collected under properly controlled conditions. The $E R$ will have access to sufficient on-line data aboard OTEC-1 to ascertain the progress of the tests. The ER will be responsible for having the experimenters review the detailed operating procedures prepared by the Test Director Contractor and for signing off completed test sequences. The ER will spend several weeks on board OTEC-1 at the beginning of the first deployment in order to become thoroughly familiar with the test equipment and operating procedures. Since the ER will be the first-line contact between the Test Director and the experimenters, this person will have to be experienced in large-scale test operations and be well-versed in heat transfer and the other technical areas that underlie the OTEC-1 test program.

\subsubsection{Test Director Contractor (TDC)}

The Test Director Contractor will be responsible for the safe and proper operation of the test apparatus. The test apparatus consists of the 
data acquisition system, the 1-MWe heat exchangers, the biofouling modules, the environmental test hardware, the cold water pipe, and the seawater and ammonia systems. The responsibilities of the TDC.include the preparation of detailed operating procedures and work instructions, the resolution of operational problems; and the preliminary screening and dissemination of the test results to the experimenters. The TDC is contractually responsible to the DOE San Francisco Operations Office:

\section{1 .6 Test Director (TD)}

The TDC.will select a Test Director to oversee and direct the day-today operation of the test apparatus aboard OTEC-1. This is a key position. The individual must be an experienced facility operator able to exercise good judgment in handling any operating problems that might arise with the apparatus. Furthermore, he must be thoroughly knowledgeable about test plan requirements and be able to evaluate the impact of his decisions on the tests in progress. The Test Director interacts with and supports the Experimenters' Representative on a daily basis.

\subsection{TEST PLAN}

The test plan serves as the common focal point for all involved in the experimental program. It specifies the test objectives and priorities of the tests, the details of the tests, and the preferred sequence in which they should be performed. The test plan is generated jointly by the experimenters and the Test Director Contractor, with appropriate guidance from the TPEWG. Once accepted, this document becomes the guide and reference for all parties involved in the OTEC-1 test program and serves as a basis for the generation of detailed test procedures by the Test Director. Deviations from the test plan can be made only according to the procedures described below in Section 6.5 .

\subsection{THE DATA FLOW PROCESS}

\subsubsection{Levels of Activity}

At least three distinct levels of activity in the acquisition, use, and reduction of data can be identified in the hierarchy of the OTEC-1 test 
program. Level 1 involves the work of the experimenters, who are ultimately responsible for the publication and dissemination of technical design data to the OTEC community. Level 2 involves the work of the Test Director Contractor, who is responsible for collecting the data specified in the test plan and supporting the experimenters' needs. Level 3 involves the work of the Test Director and the operating crew, who operate the OTEC-1 facility and form the initial link in the chain of data acquisition and transmission.

\section{3:2 The Organization of the Data Flow}

The conceptual organization of the data flow process is shown in Fig. 6.2. Making use of the information in the test plan, the experimenters, working with the Test Director Contractor, generate requirements for the data acquisition system. The specifications state the quantities to be monitored, the desired accuracies, the sampling rates, and the number of sensors.

Under normal test conditions, the Test Director (Level 3) refers to the test plan and issues detailed instructions to the operating crew. The Test Director makes use of the data displays aboard ship for operating the systems and for keeping apprised of the test progress. The Test Director is responsible for the preliminary review of the test results. The initial screening includes checks for obvious errors and inaccuracies as well as comparison with the criteria in the test. plan (steady state, overall heat balances, etc:). The final approval of a completed test sequence must be signed off by the Experimenters' Representative.

The Test Director Contractor (Level 2) forwards the test data to the experimenters weekly or upon formal request. The TDC maintains dupíicates of all test data. Both the experimenters and the Test Director Contractor submit monthly progress reports to DOE summarizing the highlights of the experimental program. The OTEC community is informed of the test results by reports of the experimenters and by presentations at OTEC conferences and meetings.

\subsection{TEST STATUS EVALUATION}

The test status evaluation is intimately related.to the data flow process. It is essential that all three levels of data handling have adequate and timely data to evaluate the status and the progress of the tests. 


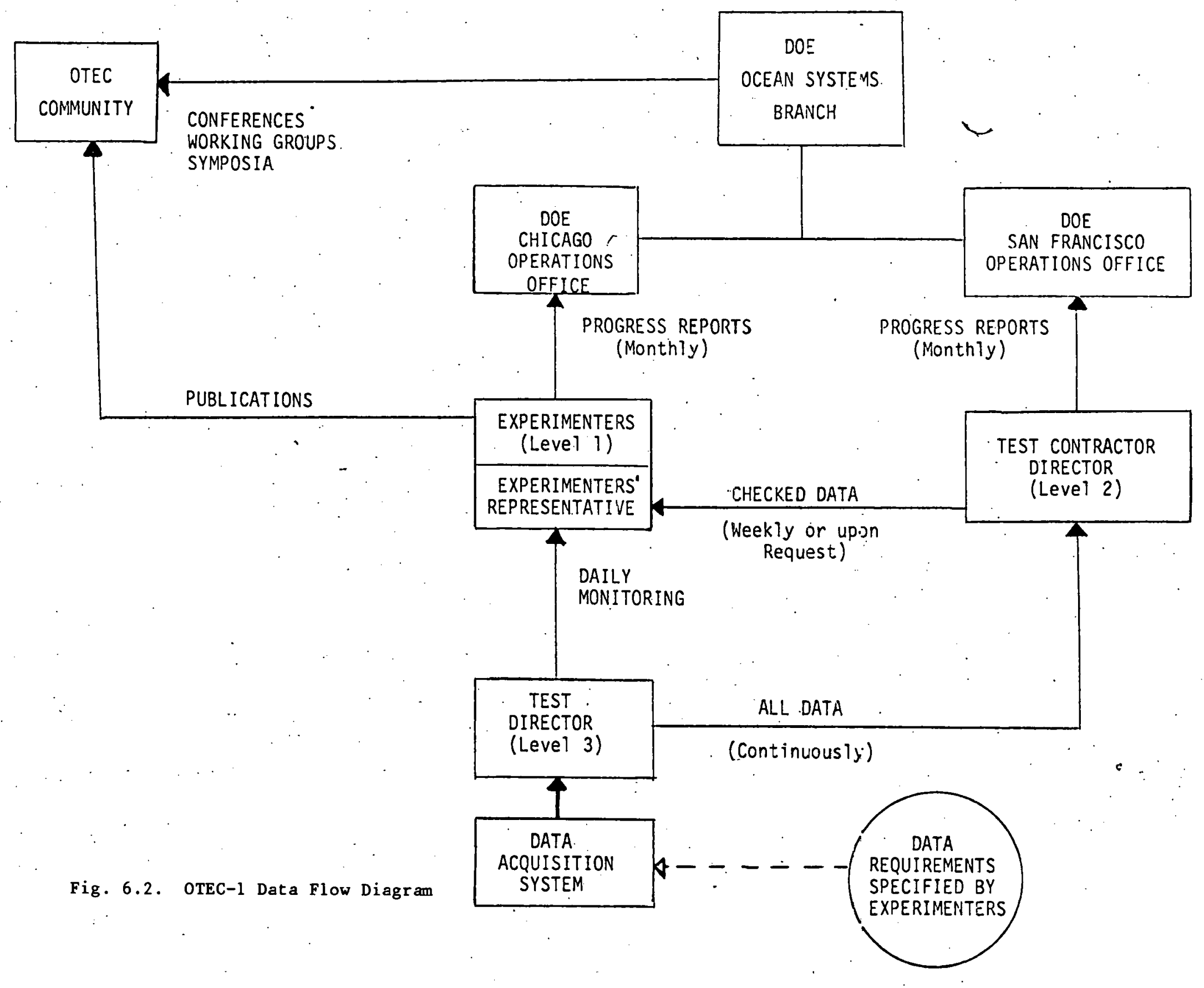


The experimenters (Level 1). must have free access to the Test Director (Level 3) to clarify specific questions of progress and detailed experimental procedures. The Test Director (Level 3) needs feedback from the experimenters as to the quality of the results. The experimenters (Level 1) and the Test Director Contractor (Level 2) must interact in order to assess the progress of the test program and to evaluate it against schedule requirements and budget limitations. Clearly, there is a need for at least two different modes of communication characterized by different time scales and formats.

The first is a continuous or very frequent interaction between the Experimenters' Representative (Level 1) and the Test Director (Level 3 ).

The second mode of test status evaluation involves the Joint Test Group. The JTG receives information from three sources: from the Experimenters'. Representative, from the Test Director Contractor, and from each individual experiment. The JTG evaluates this information on a weekly basis, determines the status of the needs of the individual experiments, and provides up-to-date direction to the Test Director Contractor on how to proceed with the program. The chairman of the JTG submits copies of minutes of JTG meetings and operations schedules to the DOE San Francisco Operations office and all other interested parties. The representative of the Test Director Con- . tractor on the JTG is responsible for providing needed information on all matters related to the test hardware capabilities, limitations, modifications, repair, and operating procedures.

\subsection{DEVIATIONS FROM THE TEST PLAN}

It is to be expected that various operational problems and difficulties will arise during the course of the test operation. It is also very likely that, as a consequence of the test results, the experimenters will request changes and deviations from the original test plan. It is essential to recognize this need for flexibility as an essential element of the program and to provide for it in advance. Basically, three different sets of circumstances $c$ an be foreseen that might require deviations from the original test plan.

\subsubsection{Operational Adjustments}

The first and most basic deviation, is likely to occur in day-to-day operations. Adverse weather conditions, equipment difficulties, and other 
unpredictable problems will require minor adjustments in the test sequence. Such deviations are anticipated in the test plan and are to be accomodated by choosing between alternatives described in the test plan. These decisions belong to the-Test Director (Level 3), who will make them in consultation with the Experimenters' Representative (Level 1). These decisions will be recorded in the experimental log book.

\subsubsection{Deviations with No Budget or Overal1 Schedule Impact}

\section{Planned Deviarions}

Requests from experimenters to alter either the immediate priorities or the short-term schedule and requests from the Test Director. to change the course of tests outside. the range of options authorized by the test plan because of apparatus or operating problems constitute the second type of test plan deviation. Deviations in this category cannot result in ultimate schedule or budget overruns. Requests for such deviations. will be submitted to the chairman of the Joint Test Group in writing. Approval by the Joint Test Group will be sufficient. DOE San Francisco Operations Office will be informed but will not be involved in the approval. All approved deviations will be documented by the chairman of the JTG.

\section{Unplanned Deviations}

In cases of operational problems requiring unplanned deviations from the test plan, the Test Director will contact the Test Director Contractor and the Experimenters' Representative. With the full support of the Test Director Contractor, the Test. Director will assess the nature of the operational problem or equipment failure and the recommended remedies. These findings will be reported by the Test Director Contractor to the Joint Test Group. The JTG will comment and approve the proposed deviation. It is understood that the approval by the Joint Test Group will not relieve the Test Director Contractor of his responsibility for the protection of the experimental hardware. In extremely urgent situations requiring immediate action, telephone consultation between the Test Director, the chairman of the Joint Test Group, and the Test Director Contractor will be sufficient basis for action by the Test Director. The Test Director will document such deviations 
within 48 hours and submit copies of such documentation to the DOE San Francisco Operations office.

\subsubsection{Amendments to the Test Pian}

Operational problems due to major equipment malfunction or failure and experimenters' requests resulting in major changes in priorities or scope of the tests constitute the third type of deviation. These deviations require a formal amendment to the test plan. Amendments will be generated jointly by the experimenters and the Test Director Contractor and recommended to the Test Planning and Evaluation Working Group for review. The implementation of such amendments will generally involve cost and schedule overruns. Amendments reviewed by the TPEWG will be transmitted in writing to DOE for consideration. Approval and authorization of any required additional funding by DOE is required before any proposed test.plan. amendment can take effect :

\subsection{SUMMARY}

The key elements to be recognized in this plan for test program direction are as follows:

(1) The experimenters will. be responsible for the final analysis, interpretation, and publication of the test results.

(2) The Test Director Contractor will be responsible for the operation of the experimental apparatus and the timely distribution of data to the appropriate members of the Experimenter Group.

(3) The Test Plan will be the basic document defining the scope and extent of the experiments. It will be generated with the full participation of DOE, the experimenters, and the Test Director through their participation in the Test Planning and Evaluation Working Group.

(4) The scope or schedule of tests will be altered only by following the procedure for deviation from or amendment to the test plan.

(5) The experimenters will form a Joint Test Group. The charge of this group will be to oversee the status and progress. of the experimental program on a weekly basis and to provide technical direction to the Test Director Contractor. 
(6) The chairman of the Joint Test Group will appoint an Experimenters' Representative whose responsibility will be to assure that the data being collected on OTEC-1 are valid and meaningful. The Experimenters' Representative will interact on a daily basis with the Test Director aboard OTEC-1.

(7) The Test Director will be the interface between the experimenters and the test facility. The person in this position must be an experienced enginecr capable of exercising good judgment in deciding on contingencies and must be able to interact effectively with the Experimenters' Representative.

(8) In the interest of saving time and money, unplanned deviations from the test plan will be agreed to by telephone conversation between the Test Director and the chairman of the Joint Test Group. This will be sufficient grounds for action by the Test Director; however, the Test Director will be responsible for documenting and justifying any such agreements to the Test Director Contractor and the Joint Test Group. 
REFERENCES

1. "Draft NPDES Permit No. HI0110272," U. S. Environmental Protection Agency, Region IX (dated Oct. 4, 1979).

2. "Environmental Monitoring Contractor Proposal," EG\&G (Sept. 19, 1979; amended Oct. 4, 1979) (Not final--contract not yet negotiated). 
THIS PAGE

\section{WAS INTENTIONALLY LEFT BLANK}


APPENDIX A

ERROR ANALYSIS 
APPENDIX A

ERROR ANALYSIS

The Kline-McClintock "second order". equation is employed to find the probable error in a quantify, $f$, which is calculated from independent measurements $x_{1}, x_{2}, x_{3}, \ldots, x_{n}$.

$$
\begin{aligned}
& f=f\left(x_{1}, \ldots, x_{n}\right) \\
& \delta f=\left[\left(\frac{\partial f}{\partial x_{1}} \delta x_{1}\right)^{2}+\left(\frac{\partial f}{\partial x_{2}} \delta x_{2}\right)^{2}+\ldots+\left(\frac{\partial f}{\partial x_{n}} \delta x_{n}\right)^{2}\right]^{1 / 2}
\end{aligned}
$$

The probable errors in heat exchanger performance parameters (summarized in Table 4.2 of the text) were calculated using Eq. A.2, assuming the following measurement accuracies:

$$
\begin{array}{ll}
\text { flowrate (vapor or liquid) : } \frac{\delta \dot{m}}{\dot{m}}= \pm 0.01 \\
\text { temperature (RTD's) } & : \delta \mathrm{T}= \pm 0.125^{\circ} \mathrm{F} \\
\text { pressure (static) } & : \delta \mathrm{P}= \pm 0.05 \mathrm{psi}
\end{array}
$$

The error analysis is somewhat conservative in that no credit is taken for multiple instrumentation (i.e., the error in the average is assumed to be equal to the individual accuracy). Also, in certain instances no credit is taken for the reduction in error when differences, rather than absolutes, are calculated.

- Pressure drop

$$
\begin{aligned}
& \Delta \mathrm{P}=\mathrm{P}_{\mathrm{i}}-\mathrm{P}_{\mathrm{o}} \\
& \frac{\delta \Delta \mathrm{P}}{\Delta \mathrm{P}}=\left[\left(\frac{\delta \mathrm{P}_{i}}{\Delta \mathrm{P}}\right)^{2}+\left(\frac{\delta \mathrm{P}_{\mathrm{o}}}{\Delta \mathrm{P}}\right)^{2}\right]^{1 / 2}
\end{aligned}
$$

For nominal baseline conditions, the error was estimated to be $\frac{\delta \Delta P}{\Delta P} \simeq \pm 0.02$ 
- Heat Duty

- Waterside heat balance

$$
\begin{aligned}
& Q=m c_{p}\left(T_{i}-T_{0}\right) \\
& \frac{\delta Q}{Q}=\left[\left(\frac{\delta \dot{m}}{\dot{m}}\right)^{2}+\left(\frac{\delta T_{0}}{\left(T_{i}-T_{o}\right)}\right)^{2}+\left(\frac{\delta T_{i}}{\left(T_{i}-T_{0}\right)}\right)^{2}\right]^{1 / 2} .
\end{aligned}
$$

From Eq. A.4 the error was calculated to be $\frac{\delta Q}{Q} \simeq \pm 0.05$.

- Ammonia-side heat balance

Evaporator heat balance:

$$
Q=\dot{m}_{v} h_{f g}+\dot{m}_{f} C_{p}\left(T_{o}-T_{i}\right)
$$

$$
\begin{aligned}
\frac{\delta Q}{Q} & =\frac{1}{\left(1+\frac{(1+\sigma) C_{p} \Delta T}{h_{f g}}\right)}\left[\left(\frac{\delta \dot{\mathrm{m}}_{\mathrm{v}}}{\dot{\mathrm{m}}_{\mathrm{v}}}\right)^{2}+\left(\frac{(1+\sigma) \mathrm{C}_{\mathrm{p}} \mathrm{T}}{\mathrm{h}_{\mathrm{fg}}}\right)^{2} \cdot\left(\frac{\delta \dot{\mathrm{m}}_{\mathrm{f}}}{\dot{\mathrm{m}}_{\mathrm{f}}}\right)^{2}\right. \\
& \left.+\left(\frac{\delta \mathrm{T}_{\mathrm{o}}}{\Delta \mathrm{T}}\right)^{2}+\left(\frac{\delta \mathrm{T}_{\mathrm{i}}}{\Delta \mathrm{T}}\right)^{2}\right]
\end{aligned}
$$

where $\Delta \mathrm{T}=\left(\mathrm{T}_{\mathrm{O}}-\mathrm{T}_{\mathbf{i}}\right)$

$\mathrm{T}_{\mathrm{O}}=\mathrm{NH}_{3}$ exit temperature (saturated)

$\mathrm{T}_{\mathbf{i}}=\mathrm{NH}_{3}$ inlet 'temperature (subcooled)

The $\mathrm{NH}_{3}$ inlet temperature $\mathrm{T}_{i}$ can be calculated from a heat balance on the evaporator sump. Assuming that the liquid returning from the evapo$r$ ator is at the condenser saturation temperature, $\mathrm{T}_{\mathrm{oc}}$, it $\mathrm{c}$ an be shown that:

$$
\Delta T \cong \frac{\left(\mathrm{T}_{0}-\mathrm{T}_{O C}\right)}{1+\sigma}=\frac{24}{(1+\sigma)}
$$


where $\sigma$ is the reflux ratio. The approximation sign is used in Eq.: A.6 because the ammonia returning from the condenser may be slightly subcooled and the reflux from the evaporator slightly superheated. Substituting Eq. A.6 into Eq. A. 5 yields:

$$
\begin{aligned}
\frac{\delta Q}{Q}= & \frac{1}{\left(1+\frac{24 C_{p}}{h_{f g}}\right.}\left[\left(\frac{\delta \dot{\mathrm{m}}_{\mathrm{V}}}{\dot{\mathrm{m}}_{\mathrm{v}}}\right)^{2}+\left(\frac{24 \mathrm{C}_{\mathrm{p}}}{\mathrm{h}_{\mathrm{fg}}}\right)^{2}:\left(\frac{\delta \dot{\mathrm{m}}_{\mathrm{f}}}{\dot{\mathrm{m}}_{\mathrm{f}}}\right)^{2}\right. \\
& \left.+\left(\frac{\delta \mathrm{T}_{\mathrm{o}}}{\Delta \mathrm{T}}\right)^{2}+\left(\frac{\delta \mathrm{T}_{\mathrm{i}}}{\Delta \mathrm{T}}\right)^{2}\right]
\end{aligned}
$$

For a. reflux ratio of $\sigma=1.5$, Eq. A.7 yields $\delta Q / Q \simeq 0.01$, which is considerably better than the accuracy of $\delta Q / Q \simeq 0.05$ from the waterside heat balance, Eq. A.4. Since the dominant contribution to the heat duty is the first term in Eq. $6, \dot{\mathrm{m}}_{\mathrm{v}} \mathrm{h}_{\mathrm{fg}}$, the error in $Q$ is essentially equal to the error in $\dot{\mathrm{m}}_{\mathrm{v}}$; or $\delta Q / Q \simeq \delta \dot{\mathrm{m}}_{\mathrm{v}} / \dot{\mathrm{m}}_{\mathrm{v}} \simeq 0.01$.

Condenser heat balance:

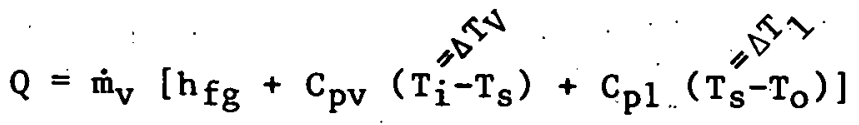

$$
\begin{aligned}
& \frac{\delta Q}{Q}=\frac{1}{\left(1+\frac{C_{p v} \Delta \mathrm{T}_{\mathrm{v}}}{\mathrm{h}_{\mathrm{fg}}}+\frac{\mathrm{C}_{\mathrm{p} 1} \Delta \mathrm{T}_{1}}{\mathrm{~h}_{\mathrm{fg}}}\right)}\left[\left(\frac{\delta \dot{\mathrm{m}}_{\mathrm{v}}}{\dot{\mathrm{m}}_{\mathrm{v}}}\right)^{2}\left(1+\frac{\mathrm{C}_{\mathrm{pv}} \Delta \mathrm{T}_{\mathrm{v}}}{\mathrm{h}_{\mathrm{fg}}}+\frac{\mathrm{C}_{\mathrm{p} 1} \Delta \mathrm{T}_{1}}{\mathrm{~h}_{\mathrm{fg}}}\right)^{2}\right. \\
& \left.+\left(\frac{\mathrm{C}_{\mathrm{pv}}}{\mathrm{h}_{\mathrm{fg}}}\right)^{2} \delta \mathrm{T}_{\mathrm{i}}^{2}+\left(\frac{\mathrm{C}_{\mathrm{pl}}}{\mathrm{h}_{\mathrm{fg}}}\right)^{2} \delta \mathrm{T}_{\mathrm{o}}{ }^{2} \cdot\left(\frac{\mathrm{C}_{\mathrm{pl}}}{\mathrm{h}_{\mathrm{fg}}}-\frac{\mathrm{C}_{\mathrm{pv}}}{\mathrm{h}_{\mathrm{fg}}}\right)^{2} \delta \mathrm{T}_{\mathrm{s}}\right]^{1 / 2}
\end{aligned}
$$

As with the evaporator, the dominant contribution to the heat duty is $\dot{\mathrm{m}}_{\mathrm{v}} \mathrm{h}_{\mathrm{fg}}$, and Eq. A.8 essentially reduces to $\delta Q / Q \simeq \delta \dot{\mathrm{m}}_{\dot{\mathrm{v}}} / \dot{\mathrm{m}}_{\mathrm{v}} \simeq 0.01$.

- Heat transfer coefficient

- $\mathrm{U}_{0}$ from waterside Q

$$
\mathrm{U}_{\mathrm{o}}=\frac{\dot{\mathrm{m}} \mathrm{C}_{\mathrm{p}}}{\mathrm{A}_{\mathrm{O}}} \ln \left(\frac{\mathrm{T}_{\mathrm{i}}-\mathrm{T}^{\prime}}{\mathrm{T}_{\mathrm{o}}^{\prime}-\mathrm{T}^{\prime}}\right)
$$




$$
\frac{\delta U_{0}}{U_{0}}=\left[\left(\frac{\delta \dot{m}}{\dot{m}}\right)^{2}+\left(\frac{\delta T_{i}}{n\left(T_{i}-T^{\prime}\right)}\right)^{2}+\left(\frac{\delta T_{0}}{n\left(T_{0}-T^{\prime}\right)}\right)^{2}+\left(\frac{\left(T_{i}-T_{0}\right) \delta T^{\prime}}{n\left(T_{0}-T^{\prime}\right)\left(T_{i}-T^{\prime}\right)}\right)^{2}\right]^{1 / 2}
$$

where $\eta=\ln \left(\frac{T_{i}-T^{\prime}}{T_{o}-T^{\prime}}\right)$

From Eq. A.9 the error in $\mathrm{U}_{0}$ was estimated to be $\frac{\delta \mathrm{U}_{Q}}{\mathrm{U}_{0}}=0.06$

-U from ammonia-side Q

$$
\begin{aligned}
\mathrm{U}_{0} & =\frac{\mathrm{Q}}{\mathrm{A}_{\mathrm{O}} \Delta \mathrm{T}_{1 \mathrm{~m}}} \\
\frac{\delta \mathrm{U}_{0}}{\mathrm{U}_{\mathrm{O}}} & =\left[\left(\frac{\delta \mathrm{Q}}{\mathrm{Q}}\right)^{2}+\left(\frac{1}{n\left(\mathrm{~T}_{\mathrm{i}}-\mathrm{T}^{\prime}\right)}-\frac{1}{\left(\mathrm{~T}_{\mathrm{i}}-\mathrm{T}_{\mathrm{o}}\right)}\right)^{2} \delta \mathrm{T}_{\mathrm{i}}{ }^{2}\right. \\
& \left.+\left(\frac{1}{n\left(\mathrm{~T}_{\mathrm{o}}-\mathrm{T}^{\prime}\right)}-\frac{1}{\left(\mathrm{~T}_{\mathrm{i}}-\mathrm{T}_{\mathrm{o}}\right)}\right)^{2} \delta \mathrm{T}_{\mathrm{o}}^{2}+\left(\frac{\left(\mathrm{T}_{\mathrm{i}}-\mathrm{T}_{\mathrm{O}}\right) \delta \mathrm{T}}{n\left(\mathrm{~T}_{\mathrm{o}}-\mathrm{T}^{\prime}\right)\left(\mathrm{T}_{\mathrm{i}}-\mathrm{T}^{\prime}\right)}\right)^{2}\right]^{1 / 2}
\end{aligned}
$$

where $\delta Q / Q$ is determined from Eq. A.7 for the evaporator and Eq. A.8 for the condenser. From Eq. A.10 the error in $U_{0}$ was calculated to be $\frac{\delta U_{0}}{U_{0}} \simeq$ 0.03 , which can be compared with an error of $\delta \mathrm{U}_{0} / \mathrm{U}_{0} \simeq 0.06$ from a waterside balance, Eq. A.9.

Unfortunately, the ammonia-side heat balance can only be employed in. determining the overal1. $\mathrm{U}_{\mathrm{O}}$. The waterside heat balance must be used when calculating $U_{o}$ for both halves of the evaporator and for the instrumented tubes.

- Fouling factor

$$
\begin{aligned}
& \mathrm{R}_{\mathrm{f}_{2}}=\left(\frac{1}{\mathrm{U}_{\mathrm{O}_{2}}}-\frac{1}{\mathrm{U}_{1}}\right) \frac{\mathrm{A}_{\mathrm{i}}}{\mathrm{A}_{\mathrm{o}}}-\left(\frac{1}{\mathrm{~h}_{\mathrm{i}_{2}}}-\frac{1}{\mathrm{~h}_{\mathrm{i}_{1}}}\right) \frac{\mathrm{A}_{\mathrm{i}}}{\mathrm{A}_{\mathrm{o}}} \\
& \delta \mathrm{R}_{\mathrm{f}_{2}}=\frac{A \mathrm{~A}}{\mathrm{~A}_{\mathrm{O}}}\left[\left(\frac{\delta \mathrm{U}_{\mathrm{O}_{2}}}{\mathrm{U}_{\mathrm{O}_{2}}^{2}}\right)^{2}+\left(\frac{\delta \mathrm{U}_{\mathrm{o}_{1}}}{\mathrm{U}_{\mathrm{o}_{1}}^{2}}\right)^{2}+\left(\frac{\delta \mathrm{h}_{\mathrm{i}_{2}}}{\mathrm{~h}_{\mathrm{i}_{2}}^{2}}\right)^{2}+\left(\frac{\delta \mathrm{h}_{\mathrm{i}_{1}}}{\mathrm{~h}_{\mathrm{i}_{1}}^{2}}\right)^{2}\right]^{1 / 2}
\end{aligned}
$$

Since $h_{i} \sim \dot{\mathrm{m}} 0.8$ (i.e., Dittus-Boelter), it can be shown that

$$
\frac{\delta \mathrm{h}_{i}}{\mathrm{~h}_{\mathrm{i}}}=0.8 \frac{\delta \dot{\mathrm{m}}}{\dot{\mathrm{m}}}
$$


Substituting Eq. A.11 into Eq. A.10 yields

$$
\delta \mathrm{R}_{\mathrm{f}_{2}}=\frac{\mathrm{A}_{\mathrm{i}}}{\mathrm{A}_{\mathrm{O}}}\left[\left(\frac{\delta \mathrm{U}_{\mathrm{o}_{2}}}{\mathrm{U}_{\mathrm{o}_{2}}^{2}}\right)^{2}+\left(\frac{\delta \mathrm{U}_{\mathrm{o}_{1}}}{\mathrm{U}_{\mathrm{o}_{1}}^{2}}\right)^{2}+\left(\frac{0.8}{\mathrm{~h}_{\mathrm{i}_{2}}} \frac{\delta \dot{\mathrm{m}}_{2}}{\dot{\mathrm{m}}_{2}}\right)^{2}+\left(\frac{0.8}{\mathrm{~h}_{\mathrm{i}_{1}}} \frac{\delta \dot{\mathrm{m}}_{1}}{\dot{\mathrm{m}}_{1}}\right)^{2}\right]_{(\mathrm{A} .12}^{1 / 2}
$$

where $\frac{\delta \mathrm{U}_{0}}{\mathrm{U}_{0}}$ is calculated from Eq. A.9. Rather arbitrarily, it was decided to present Eq. A.12 as an absolute error $\left(\delta R_{f}\right)$ rather than a fractional uncertainty $\left(\frac{\delta R f}{R}\right)$. From Eq. A.12 the error in the fouling factor is $\delta R_{f} \simeq$ $\pm 0.0001 \frac{\mathrm{hr} \cdot \mathrm{ft}^{2} \cdot{ }^{\circ} \mathrm{F}}{\mathrm{Btu}}$.

- Spacial variation in $h_{0}$

$$
\frac{1}{\mathrm{~h}_{\mathrm{O}_{1}}}-\frac{1}{\mathrm{~h}_{\mathrm{O}_{2}}}=\left(\frac{1}{\mathrm{U}_{\mathrm{O}_{1}}}-\frac{1}{\mathrm{U}_{\mathrm{O}_{2}}}\right)-\left(\frac{1}{\mathrm{~h}_{\mathrm{i}_{1}}}-\frac{1}{\mathrm{~h}_{\mathrm{i}_{2}}}\right) \frac{\mathrm{A}_{0}}{\mathrm{~A}_{\mathrm{i}}}
$$

Rearranging Eq. 10 and defining $\Delta h=h_{\mathrm{o}_{2}}-h_{\mathrm{o}_{1}}$ yields:

$$
\begin{aligned}
& \Delta \mathrm{h}=\mathrm{h}_{\mathrm{O}_{1}}\left(\mathrm{~h}_{\mathrm{O}_{1}}+\Delta \mathrm{h}\right)\left[\left(\frac{1}{\mathrm{U}_{\mathrm{O}_{1}}}-\frac{1}{\mathrm{U}_{\mathrm{O}_{2}}}\right)-\left(\frac{1}{\mathrm{~h}_{\mathrm{i}_{1}}}-\frac{1}{\mathrm{~h}_{\mathrm{i}_{2}}}\right) \frac{\mathrm{A}_{\mathrm{O}}}{\mathrm{A}_{\mathrm{i}}}\right] \\
& \frac{\delta \Delta \mathrm{h}}{\mathrm{h}_{\mathrm{O}_{1}}}=\mathrm{h}_{\mathrm{O}_{1}}\left(1+\frac{\Delta \mathrm{h}}{\mathrm{h}_{\mathrm{O}_{1}}}\right)^{2}\left[\left(\frac{\delta \mathrm{U}_{\mathrm{O}_{1}}}{\mathrm{U}_{\mathrm{O}_{1}^{2}}^{2}}\right)^{2}+\left(\frac{\delta \mathrm{U}_{\mathrm{O}_{2}}}{\mathrm{U}_{\mathrm{O}_{2}}^{2}}\right)^{2}\right. \\
& \left.+\left(\frac{A_{0}}{A_{i}} \frac{0.8}{h_{i_{1}}} \frac{\delta \stackrel{\operatorname{m}}{1}_{1}}{\stackrel{\operatorname{m}}{1}_{1}}\right)^{2}+\left(\frac{A_{0}}{A_{i}} \frac{0.8}{h_{i_{2}}} \frac{\delta \sin _{2}}{\operatorname{mig}_{2}}\right)^{2}\right]^{1 / 2}
\end{aligned}
$$

In determining $\delta \Delta h$, it was assumed that $h_{o_{1}}$ is known exactly; and Eq: A.13 then provides the uncertainty in the quantity $\left(h_{o_{2}}-h_{o_{1}}\right)$ relative to $\mathrm{h}_{\mathrm{O}_{1}}$.

The uncertainty in $\Delta h$ was estimated for the enhanced and unenhanced bundles, yielding: 


$$
\begin{array}{ll}
\frac{\delta \Delta h}{h_{\mathrm{O}_{1}}} \simeq \pm 20 \% & \text { (unenhanced) } \\
\frac{\delta \Delta h}{h_{\mathrm{O}_{1}}} \simeq \pm 50 \% & \text { (enhanced) }
\end{array}
$$

For these calculations it was assumed that $h_{\mathrm{O}_{1}}=1000$ and $4500 \mathrm{Btu} /$ $\mathrm{hr} \cdot \mathrm{ft}{ }^{2}{ }^{\circ} \mathrm{F}$ for the unenhanced and enhanced bundles, respectively. Also, some "typical" absolute magnitude for $\Delta \mathrm{h}$ was assumed in each case. Note that $\delta \Delta h / h_{o_{1}}$ is considerably less for the unenhanced portion.

- Exit quality

$$
x_{e}=\frac{\dot{m}_{v}}{\dot{m}_{v}+\dot{m}_{e}}
$$

Since $x_{e}=1$, it is more meaningful to consider the error in $1-x_{e}$ :

$$
\begin{aligned}
& 1-x_{e}=\frac{\dot{m}_{1}}{\dot{m}_{v}+\dot{m}_{1}} \\
& \frac{\delta\left(1-x_{e}\right)}{\left(1-x_{e}\right)}=x_{e}\left[\left(\frac{\delta \dot{m}_{1}}{\dot{\mathrm{m}}_{1}}\right)^{2}+\left(\frac{\delta \dot{\mathrm{m}}_{\mathrm{v}}}{\dot{\mathrm{m}}_{\mathrm{v}}}\right)^{2}\right]^{1 / 2}
\end{aligned}
$$

From Eq. A.14 the error is estimated to be about \pm 0.02 .

- Reflux Ratio

$$
\begin{aligned}
& \sigma=\frac{\dot{\mathrm{m}}_{\mathrm{f}}-\dot{\mathrm{m}}_{\mathrm{v}}}{\dot{\mathrm{m}}_{\mathrm{v}}} \\
& \frac{\delta \sigma}{\sigma}=\frac{\sigma+1}{\sigma}\left[\left(\frac{\delta \dot{\mathrm{m}}_{\mathrm{f}}}{\dot{\mathrm{m}}_{\mathrm{f}}}\right)^{2}+\left(\frac{\delta \dot{\mathrm{m}}_{\mathrm{v}}}{\dot{\mathrm{m}}_{\mathrm{v}}}\right)^{2}\right]^{1 / 2}
\end{aligned}
$$

The error in reflux ratio depends on the absolute value of o. For a typical reflux ratio of $\sigma=1.5$, the fractional error is $\frac{\delta \sigma}{\sigma}=0.02$. 
THIS PAGE WAS INTENTIONALLY LEFT BLANK 


\section{APPENDIX B}

DATA REDUCTION:

'EVAPORATOR AND CONDENSER PERFORMANCE 
- Overall Thermal Hydraulic Performance of Evaporator and Condenser

- Pressure Drop Between Water Boxes

For evaporator, $\Delta \mathrm{P}_{\mathrm{e}}$

For condenser, $\Delta P_{c}$

$$
\Delta P_{e}=P_{e i}-P_{e o}, p s i
$$

$P_{e i}=$ average of four pressure transducers at inlet water box of evaporator [PE7(4), 5-20 psig, \pm 0.05 psig]

$P_{\text {eo }}=$ average of four pressure transducers at outlet water box of evaporator [PE8(4), 5-20 psig, \pm 0.05 psig]

$\Delta P_{e} \simeq 3.0$ psi; accuracy $\simeq \pm 2.0 \%$

$\Delta P_{c}=P_{c i}-P_{c o}, p s i$

$P_{c i}=$ average of four pressure transducers at inlet water box of condenser [PE13(4), 5-20 psig, \pm 0.05 psig]

$\mathrm{P}_{\mathrm{co}}=$ average of four pressure transducers at outlet water box of condenser [PE12(4),5-20 psig, \pm 0.05 psig]

$\Delta \mathrm{P}_{\mathrm{c}} \simeq 3.3 \mathrm{psi} ;$ accuracy $\simeq \pm 2.0 \%$

- Overall Heat Transfer Coefficient and Heat Duty

For Evaporator; Ueo, Uéo, Uep, Uea, $\mathrm{U}_{e o}, \mathrm{Q}_{\mathrm{ep}}, \mathrm{Q}_{\mathrm{ea}}$

For Condenser, $\mathrm{U}_{\mathrm{co}}, \mathrm{U}_{\mathrm{co}}^{\prime}, \mathrm{Q}_{\mathrm{co}}$

$\mathrm{U}_{\text {eo }}=\frac{\mathrm{Q}_{\mathrm{eo}}}{\mathrm{A}_{\text {eo }} \Delta \mathrm{T}_{1 \mathrm{meo}}}, \mathrm{U}_{\mathrm{e}_{\mathrm{o}}}^{\prime}=\frac{\mathrm{Q}_{\mathrm{e}}^{\prime}}{\mathrm{A}_{\text {eo }} \Delta \mathrm{T}_{1 \mathrm{meo}}}, \frac{\mathrm{Btu}}{\mathrm{hr} \cdot \mathrm{ft}^{2} \cdot{ }^{\circ} \mathrm{F}}$

where $Q_{e}^{\prime}=$ see Eq. $1.11, B t u / h r$

$$
Q_{e o}=\dot{\mathrm{m}}_{\mathrm{e}} \mathrm{C}_{\mathrm{p}}\left(\mathrm{T}_{\mathrm{ei}}-\mathrm{T}_{\mathrm{eo}}\right), \mathrm{Btu} / \mathrm{hr}
$$

$A_{e o}=$ total heat transfer area based on tube outside diameter [Geometry Section, $\mathrm{ft}^{2}$ ]

$$
\Delta \mathrm{T}_{\text {lmeo }}=\frac{\left(\mathrm{T}_{e j}-\mathrm{T}_{\mathrm{eo}}\right)}{\ln \frac{\left(\mathrm{T}_{\mathrm{ei}}-\mathrm{T}_{\mathrm{e}}^{\prime}\right)}{\left(\mathrm{T}_{e o^{-}} \mathrm{T}_{\mathrm{e}}^{\prime}\right)}} ;{ }^{\circ} \mathrm{F}
$$




$$
\begin{aligned}
& \dot{\mathrm{m}}_{\mathrm{e}}=\text { flowrate from sonic flow meter at discharge of } \\
& \text { warm water pump [FT101, } 36 \times 10^{6}-48.5 \times 10^{6} 1 \mathrm{~b} / \mathrm{hr} \text {, } \\
& \pm 0.5 \% \text { of reading] } \\
& \mathrm{C}_{\mathrm{P}}=\text { heat capacity of warm sea water at temperature }= \\
& \left(\mathrm{T}_{e i}+\mathrm{T}_{\mathrm{eo}}\right) / 2 \text { [from Property Section, Btu/1b. }{ }^{\circ} \mathrm{F} \text { ] } \\
& \mathrm{T}_{e i}=\text { average of four RTDs at inlet water box of evaporator } \\
& {\left[\operatorname{TE} 8(4), 65-90^{\circ} \mathrm{F} ; \pm 0.125^{\circ} \mathrm{F}\right. \text { ] }} \\
& \mathbf{T}_{\text {eo }}=\text { average of } 14 \text { RTDs at outlet water box of evaporator } \\
& {\left[\operatorname{TE} 9(14), 65-90^{\circ} \mathrm{F}, \pm 0.125^{\circ} \mathrm{F}\right. \text { ] }}
\end{aligned}
$$

The ammonia saturation temperature in the evaporator is obtained differently depending on test conditions:

(1). If in sprayed-bundle mode and no superheat, i.e:,

$$
\begin{aligned}
\Delta \mathrm{T}_{\mathrm{e}}^{\prime} & <0.2^{\circ} \mathrm{F} \text { (see Eq. 3.1) } \\
\mathrm{T}_{\mathbf{e}}^{\prime}= & \begin{array}{l}
\text { average of } 10 \text { RTDs measuring } \mathrm{NH}_{3} \text { temperature in } \\
\text { evaporator }\left[\mathrm{TE} 7(10), 65-80^{\circ} \mathrm{F}, \pm 0.125^{\circ} \mathrm{F}\right]
\end{array}
\end{aligned}
$$

(2) If in flooded-bundle"mode or superheated, i.e.,

$$
\begin{aligned}
\Delta \mathrm{T}_{\mathrm{e}}^{\prime}> & 0.2^{\circ} \mathrm{F} \text { (see Eq. 3.1), } \\
\mathrm{T}_{\mathrm{e}}^{\prime}= & \mathrm{NH}_{3} \text { saturation temperature based on pressure measure- } \\
& \text { ment [PE1, 110-140 psig, } \pm 0.25 \mathrm{psig} \text { and from Property } \\
& \text { Section] }
\end{aligned}
$$

$\mathrm{U}_{\mathrm{eo}} \approx 360 \mathrm{Btu} / \mathrm{hr} \cdot \mathrm{ft}^{2} \cdot{ }^{\circ} \mathrm{F} ;$ accuracy $\simeq \pm 6.0 \%$

$\mathrm{U}_{\mathrm{eo}}^{\prime}=360 \mathrm{Btu} / \mathrm{hr} \cdot \mathrm{ft}^{2} \cdot{ }^{\circ} \mathrm{F} ;$ accuracy $\simeq \pm 3.0 \%$

$Q_{e o} \simeq 1.4 \times 10^{8} \mathrm{Btu} / \mathrm{hr} ;$ accuracy $\simeq \pm 5.0 \%$

$\mathrm{U}_{\text {ep }}=\frac{\mathrm{Q}_{\text {ep }}}{\mathrm{A}_{\text {ep }} \Delta \mathrm{T}_{1 \mathrm{mep}}}, \mathrm{Btu} / \mathrm{hr} \cdot \mathrm{ft}^{2} \cdot{ }^{\circ} \mathrm{F}$

where $Q_{e p}=0.5 \dot{m}_{e} C_{p}\left(T_{e i}-T_{e p}\right), B t u / h r$

$$
A_{e p}=0.5 A_{e o}, \mathrm{ft}^{2} \text {. }
$$

$$
\cdot \Delta T_{\text {lmep }}=\frac{\left(T_{e j}-T_{e p}\right)}{\ln \left(\frac{T_{e i}-T_{e}^{\dagger}}{T_{e p}-T_{e}^{\prime}}\right)},{ }^{\circ} F
$$




$$
\begin{aligned}
& \begin{aligned}
C_{p}= & \text { heat capacity of warm water at temp }=\left(T_{e i}+T_{e p}\right) / 2 \\
& {\left[\text { from Property Section, Btu } / 1 b \cdot{ }^{\circ} \mathrm{F}\right] }
\end{aligned} \\
& \mathrm{T}_{\text {ep }}=\text { average of upper seven RTDs at out let water box of } \\
& \text { evaporator }\left[\operatorname{TE} 9(7), 65-90^{\circ} \mathrm{F}, \pm 0.125^{\circ} \mathrm{F}\right] \\
& \mathrm{U}_{\mathrm{ea}}=\frac{\mathrm{Q}_{\mathrm{ea}}}{\mathrm{A}_{\mathrm{ea}} \Delta \mathrm{T}_{\mathrm{l}_{\mathrm{mea}}}}, \mathrm{Btu} / \mathrm{hr} \cdot \mathrm{ft}^{2 .{ }^{\circ} \mathrm{F}} \\
& \text { where } Q_{e a}=0.5 \dot{\mathrm{m}}_{\mathrm{e}} \mathrm{C}_{\mathrm{p}}\left(\mathrm{T}_{\mathrm{ei}}-\mathrm{T}_{\mathrm{ea}}\right), \mathrm{Btu} / \mathrm{hr} \\
& \mathrm{A}_{\mathrm{ea}}=0.5 \mathrm{~A}_{\mathrm{eo}}, \mathrm{ft}^{2} \\
& \Delta \mathrm{T}_{1 \mathrm{mea}}=\frac{\left(\mathrm{T}_{\mathrm{ei}}-\mathrm{T}_{\mathrm{ea}}\right)}{\ln \left(\frac{\mathrm{T}_{\mathrm{ei}}-\mathrm{T}_{\mathrm{e}}^{\prime}}{\mathrm{T}_{\mathrm{ea}}-\mathrm{T}_{\mathrm{e}}^{\prime}}\right)},{ }^{\circ} \mathrm{F} \\
& c_{p}=\text { heat capacity of warm sea water at temp }=\left(T_{e i}+T_{e a}\right) / 2 \\
& \text { [from Property Section, Btu/1b }{ }^{\circ} \mathrm{F} \text { ] } \\
& \mathrm{T}_{\mathrm{ea}}=\text { average of lower seven RTDs at out let water box of } \\
& \text { evaporator }\left[\operatorname{TE} 9(7), 65-90^{\circ} \mathrm{F}, \pm 0.125^{\circ} \mathrm{F}\right] \\
& U_{c o}=\frac{Q_{c o}}{A_{c o} \Delta T_{1 m c o}}, U_{c o}^{\prime}=\frac{Q_{c}^{\prime}}{A_{c o} \Delta T_{1 m c o}}, \frac{B_{t u}}{h r \cdot \mathrm{ft}^{2} \cdot{ }^{\circ} \mathrm{F}}
\end{aligned}
$$

where $Q_{c}^{\prime}=$ see $\mathrm{Eq} \cdot 1.13, \mathrm{Btu} / \mathrm{hr}$

$$
\begin{aligned}
& Q_{c o}=\dot{m}_{c} C_{p}\left(T_{c o}-T_{c i}\right), B t u / h r \\
& A_{c o}=\text { total heat transfer area based on tube outside } \\
& \text { diameter [Geometry Section, } \mathrm{ft}^{2} \text { ] } \\
& \Delta \mathrm{T}_{1 \mathrm{mco}}=\frac{\left(\mathrm{T}_{c i}-\mathrm{T}_{\mathrm{co}}\right)}{\ln \left(\frac{\mathrm{T}_{\mathrm{ci}}-\mathrm{T}_{\mathrm{c}}^{1}}{\mathrm{~T}_{\mathrm{co}}-\mathrm{T}_{\mathrm{c}}^{1}}\right)},{ }^{\circ} \mathrm{F}
\end{aligned}
$$




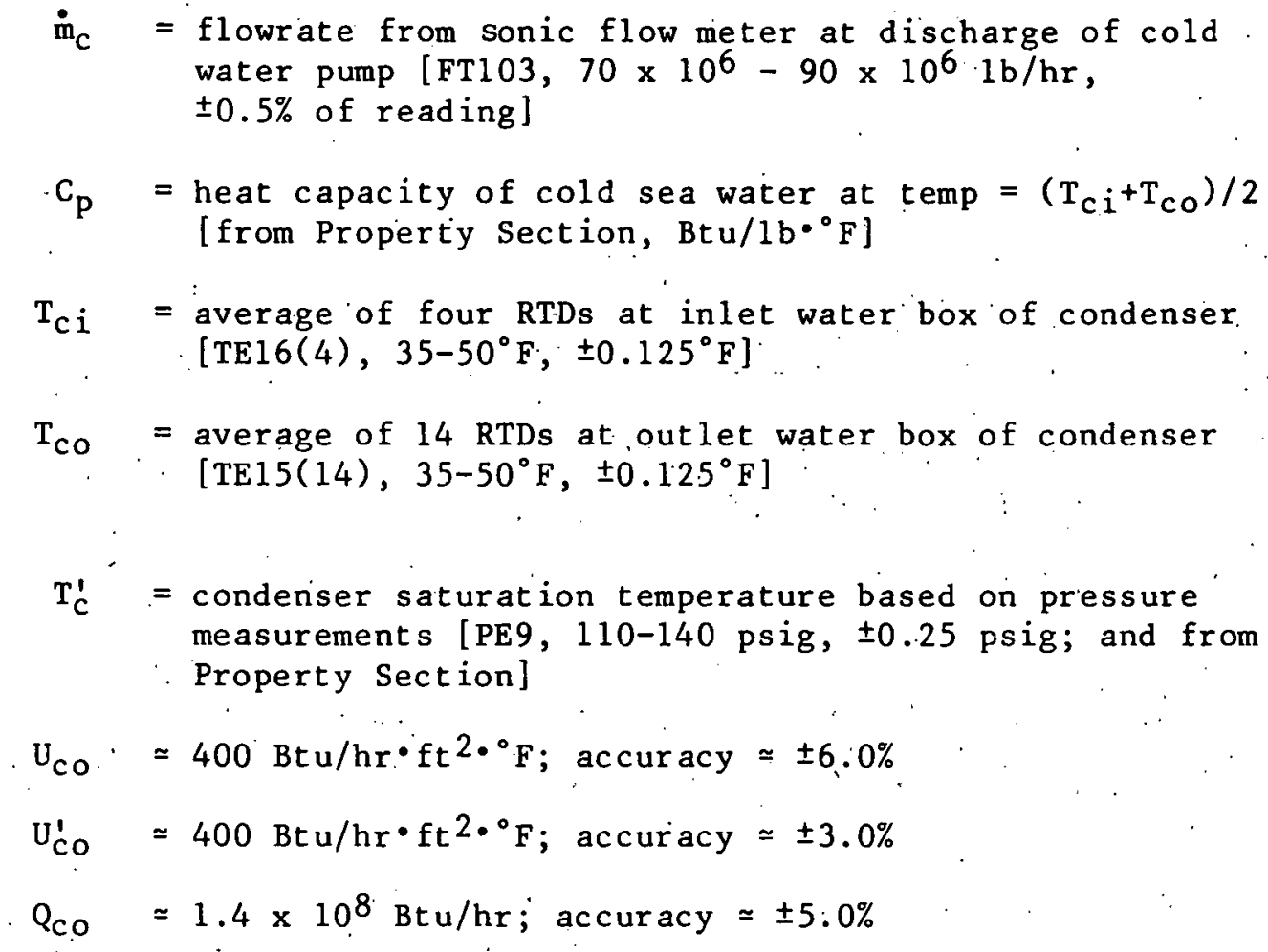

- Exit Quality and Entrainment

$\mathrm{x}_{e}, \dot{\mathrm{m}}_{\mathrm{ent}}$

$x_{e}=\frac{\dot{m}_{d v}}{\dot{m}_{d v}^{\prime}+\dot{m}_{d}^{\prime} l}$

$\dot{\mathrm{m}}_{\mathrm{d} \mathrm{v}}^{\prime}=$ vapor $\mathrm{NH}_{3}$ flow rate in demister from Venturi flow meter $\left[\right.$ FT106, $220 \times 10^{3}-305 \times 10^{3} 1 \mathrm{~b} / \mathrm{hr}, \pm 0.25 \%$ ]

$\dot{\mathrm{m}}_{\mathrm{d} 1}=1$ iquid $\mathrm{NH}_{3}$ flow rate in demister from one flow meter [FT4, 0-6 Gpm, $\pm 1.0 \%$ ]

$$
\dot{\mathrm{m}}_{\mathrm{ent}}=\dot{\mathrm{m}}_{\mathrm{d} \mathrm{l}} ; \mathrm{lb} / \mathrm{hr}
$$


Ammonia-Side Pressure Drop and Heat Balance

For evaporator, $\Delta \mathrm{P}_{\mathrm{p}}^{\prime}, \Delta \mathrm{P}_{\mathrm{a}}^{\prime}, \mathrm{Q}_{\mathrm{e}}^{\prime}$

For condenser, $\Delta \mathrm{P}_{\mathrm{c}}^{\prime}, \mathrm{Q}_{\mathrm{c}}^{\prime}$

$\Delta \mathrm{P}_{\mathrm{P}}^{\prime}=$ pressure difference from top to middle [DPE3,

0-5 in. $\mathrm{H}_{2} \mathrm{O}, \pm 0.01$ in. $\mathrm{H}_{2} \mathrm{O}$ ]

$\Delta \mathrm{P}_{\mathrm{a}}^{\prime}=$ Pressure difference from middle to bottom [DPE4, $0-5$ in. $\mathrm{H}_{2} \mathrm{O}, \pm 0.01$ in. $\left.\mathrm{H}_{2} \mathrm{O}\right]$

$Q_{e}^{\prime}=\dot{m}_{f}^{\prime} C_{p l}^{\prime}\left(T_{e}^{\prime}-T_{f i}^{\prime}\right)+\dot{m}_{d v}^{\prime}\left(h h_{g}+C_{p v}^{\prime} \Delta T_{e}^{\prime}\right), B t u / h r$

where $\dot{\mathrm{m}}_{\mathrm{f}}^{\prime}=1$ iquid $\mathrm{NH}_{3}$ feed rate from the sum of three flow meters [FT1, 1000-4000 gpm, $\pm 1.0 \%$; FT2, 0-2000 gpm, $\pm 1.0 \%$;

FT3, $0-200 \mathrm{gpm}, \pm 1.0 \%]$

$\begin{aligned} C_{p 1}^{\prime}= & \text { heat capacity of } 1 \text { iquid ammonia at temp }=\left(T_{e}^{\prime}+T_{f i}^{\prime}\right) \\ & {\left[\text { from Property Section, Btu/1 } b^{\circ \circ} \mathrm{F}\right] }\end{aligned}$

$\mathrm{T}_{\mathrm{f}}^{\prime}=1$ iquid $\mathrm{NH}_{3}$ inlet temp from one, two, or three. RTDs [TE2, TE3, TE4, 40-80 $\mathrm{F}, \pm 0.125^{\circ} \mathrm{F}$ ]

$\dot{\mathrm{m}}_{\mathrm{dv}}^{\prime}=$ vapor $\mathrm{NH}_{3}$ flow rate in demister from Venturi flow meter [FT106, $220 \times 10^{3}-305 \times 10^{3} 1 \mathrm{~b} / \mathrm{hr}, \pm 0.25 \%$ ]

$h_{f g}^{\prime}=$ heat of evaporation of $\mathrm{NH}_{3}$ at $\mathrm{T}_{e}^{\prime}$ [from Property Section, Btu/1b]

$\Delta \mathrm{T}_{\mathrm{e}}^{\prime}=$ superheat, see $\mathrm{Eq} \cdot 3.1$ $\begin{aligned} C_{p v}^{\prime}= & \text { heat capacity of ammonia vapor at temp }=T_{e}^{\prime}+\frac{\Delta T_{e}^{\prime}}{2} .\end{aligned}$

$Q_{e}^{\prime}:=1.4 \times 10^{8} \mathrm{Btu} / \mathrm{hr} ;$ accuracy $= \pm 1.0 \%$

$\Delta \mathrm{P}_{\mathrm{C}}^{\prime}=$ average of two differential pressure transducers measuring pressure difference from top to bottom [DPE10 and DPE11, 0-5 in. $\mathrm{H}_{2} \mathrm{O}, \pm 0.01$ in. $\mathrm{H}_{2} \mathrm{O}$ ]

$Q_{c}^{\prime}=\dot{m}_{c}^{\prime}\left[C_{p v}^{\prime}\left(T_{c i}^{\prime}-T_{c}^{\prime}\right)+h_{f g}^{\prime}+C_{p 1}^{\prime}\left(T_{c}^{\prime}-T_{c o}^{\prime}\right)\right], B t u / h r$ 


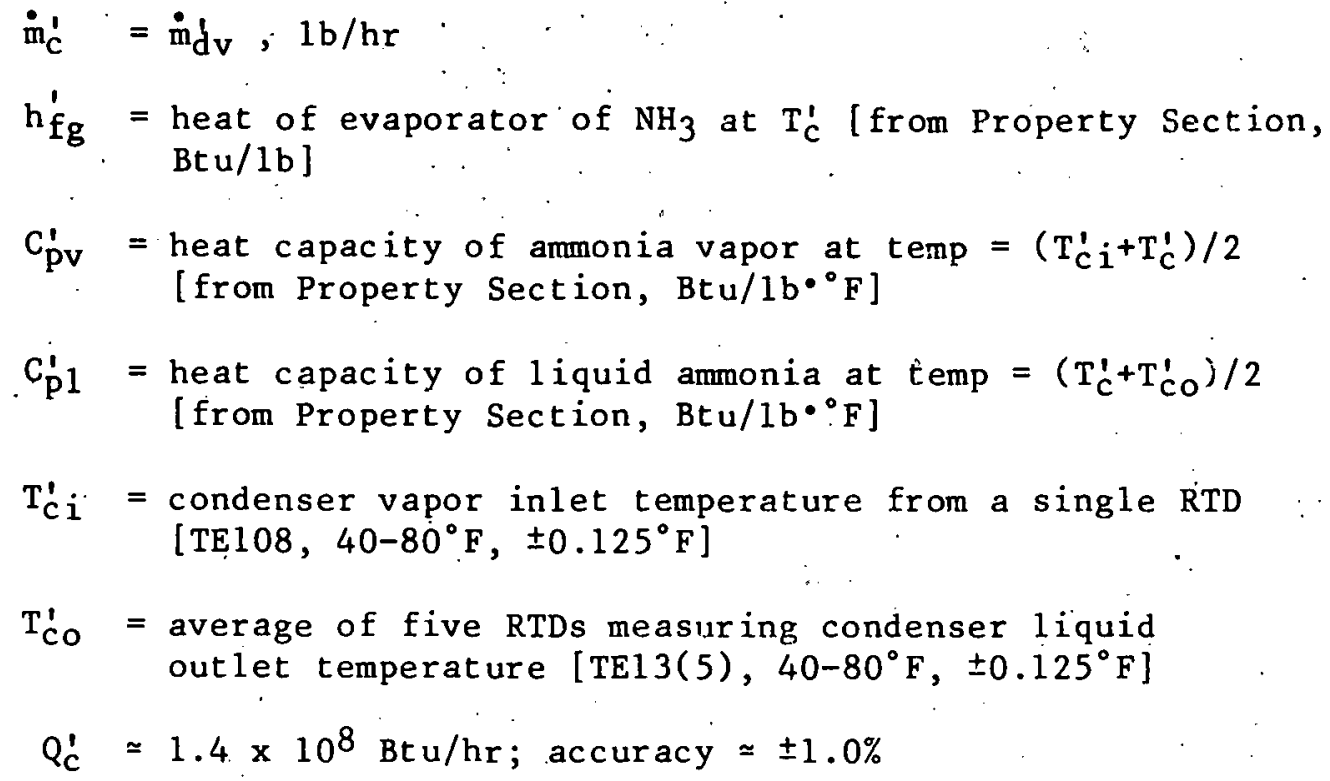

- Local Thermal Hydrauli.c Performance of Evaporator and Condenser Overall Heat Transfer Coefficient for Individual Instrumented Tubes

$$
\text { clean uncleaned cleaned }
$$

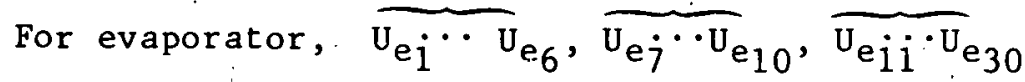

For condenser, $\quad \mathrm{u}_{\mathrm{c}_{\mathrm{i}}} \cdots \mathrm{U}_{\mathrm{c}_{6}}, \mathrm{u}_{\mathrm{c}_{7}} \cdot \mathrm{u}_{\mathrm{c}_{10}}, \mathrm{U}_{\mathrm{c}_{\mathrm{ii}}} \cdot \mathrm{U}_{\mathrm{c}_{30}}$

$$
\mathrm{U}_{e j}=\frac{Q_{e j}}{A_{e} \Delta T_{1 m e j}} \quad j=1, \ldots, 30 \quad B t u / h r \cdot f t{ }^{2 \cdot \circ F}
$$

$$
\begin{aligned}
& \text { where } Q_{e j}=\dot{m}_{e j} C_{p}\left(T_{e m}-T_{e j}\right), B t u / h r \\
& A_{e}=\text { total heat transfer area based on the } \\
& \text { outside surface of one evaporator tube } \\
& \text { [Geometry Section, } \mathrm{ft}^{2} \text { ] } \\
& \Delta T_{1 m e j}=\frac{\left(T_{e m}-T_{e j}\right)}{\ln \left(\frac{T_{e m}-T_{e}}{T_{e j}-T_{e}^{\prime}}\right)},{ }^{\circ} F \\
& \dot{\mathrm{m}}_{\mathrm{e}} \mathrm{j}=\text { flowrate from orifice flow meters [for six clean tubes, } \\
& \text { FT31, 0-15 gpm. } \pm 1.0 \% \text {; others, FT } 21,0-15 \mathrm{gpm}, \pm 1.0 \%] \\
& c_{p}=\text { heat capacity of fresh water }(j=1 \text { to } 6) \text { and sea } \\
& \text { water }(j=7 \text { to } 30) \text { at temp }=\left(T_{e m}+T_{e j}\right) / 2 \\
& \text { [from Property Section, Btu/1b }{ }^{\circ} \mathrm{F} \text { ] }
\end{aligned}
$$


$\begin{aligned} \mathrm{T}_{\mathrm{ej}}= & \mathrm{RTD} \text { reading at outlet of each instrumented tube } \\ & {\left[\mathrm{TE} 10(6) \text { and } \operatorname{TE} 11(24), 65-90^{\circ} \mathrm{F}, \pm 0.125^{\circ} \mathrm{F}\right] } \\ \mathrm{T}_{\mathrm{em}}= & \text { same as } \mathrm{T}_{\mathrm{ei}} \text { except for clean tubes } 1 \text { to } 6 \text {, where a } \\ & \left.\text { single RTD reading is used [TE } 12,65-90^{\circ} \mathrm{F}, \pm 0.125^{\circ} \mathrm{F}\right]\end{aligned}$

$U_{c j}=\frac{Q_{c j}}{A_{c} \Delta T_{1 m c j}}, j=1, \ldots, 30 \quad B t / h r \cdot f t^{2} \cdot{ }^{\circ} F$

where $Q_{c j}=\dot{m}_{c j} C_{p}\left(T_{c j}-T_{c m}\right), B t u / h r$

$A_{c}=$ total heat transfer area based on the outside surface of one single tube [Geometry Section, $\mathrm{ft}^{2}$ ]

$\Delta T_{1 m c j}=\frac{\left(T_{c m^{m}}-T_{c j}\right)}{\ln \left(\frac{T_{c m}-T_{c}^{\prime}}{T_{c j}-T_{c}^{\prime}}\right)}, \quad \circ$

$\begin{aligned} & \dot{\mathrm{m}}_{\mathrm{c}}= \text { flow rate from orifice, flow meters [ for } 6 \text { clean } \\ & \text { tubes, FT } 51,9-15 \mathrm{gpm}, \pm 1.0 \% \text {; others, FT41, 9-15 }\end{aligned}$ gpm, $\pm 1.0 \%]$

$c_{p}=$ heat capacity of fresh water $(j=1$ to 6$)$ and sea water $(j=7$ to 30$)$ at temp $=\left(T_{c m}+T_{c j}\right) / 2$

[from Property Section; Btu/lb ${ }^{\circ} \mathrm{F}$ ]

$T_{c j}=$ RTD reading at outlet of each instrumented tube $\left[\operatorname{TE} 17(6) \& \operatorname{TE} 18(24), 35-50^{\circ} \mathrm{F}, \pm 0.125^{\circ} \mathrm{F}\right]$

$\mathrm{T}_{\mathrm{cm}}=\mathrm{same}$ as $\mathrm{T}_{\mathrm{c} i}$ except for clean tubes 1 to 6 , where a single RTD reading is used [TE19, $\left.32-52^{\circ} \mathrm{F}, \pm 0.125^{\circ} \mathrm{F}\right]$

Water-Side Heat Transfer Coefficient for Individual Instrumented Tubes

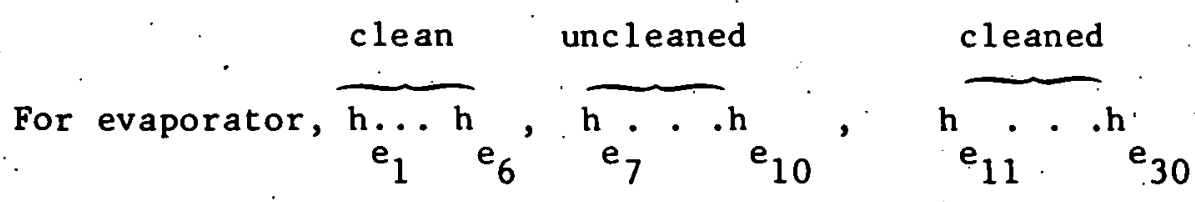

For condenser, $h_{\dot{c}_{1}}: h_{c_{6}}, h_{\dot{c}_{7}} \cdot h_{c_{10}}, \cdot h_{c_{11}} \cdot{ }^{\prime h} h_{c_{30}}$

$h_{e j}=0.023 \frac{k}{d_{e i}}\left(\frac{4 \dot{m}_{e j}}{\pi d_{e i} \mu_{1}}\right)^{0.8}{ }_{P_{r}} \quad 0.4 \quad j=1, \ldots, 30$. 
where $k$ = heat conductivity of fresh water $(j=1$ to 6$)$ and sea water at temp $=\left(\mathrm{T}_{e m}+\mathrm{T}_{\mathrm{ej}}\right) / 2$ [From Property Section, Btu/hr$\cdot \mathrm{ft} \cdot{ }^{\circ} \mathrm{F}$ ]

$\mathrm{d}_{\mathrm{e} i}=$ evaporator tube inside diameter [from Geometry Section, ft]

$\mu_{1}=$ dynamic viscosity of fresh water $(j=1$ to 6$)$ and sea water at temp $=\left(T_{e m}+T_{e j}\right) / 2$ [from Property Section, Btu/hr.ft]

$P_{r}=\operatorname{Prandt} 1$ number of fresh water $(j=1$ to 6$)$ and sea water at temp $=\left(\mathrm{T}_{\mathrm{em}}+\mathrm{T}_{\mathrm{ej}}\right) / 2 \cdot[$ from Property Section]

$h_{c j}=0.023 \frac{k}{d_{c i}}\left(\frac{4 \dot{m}_{c j}}{\pi d_{c i}{ }^{\mu} l}\right)^{0.8} P_{r} 0.4 j=1, \ldots, 30$

where $k=$ heat conductivity of fresh water $(j=1$ to 6$)$ and sea water at temp $=\left(\mathrm{T}_{\mathrm{cm}}+\mathrm{T}_{\mathrm{cj}}\right) / 2$ [from Property Section, Btu/hr.ft $\left.{ }^{\circ} \mathrm{F}\right]$

$d_{c i}=$ condenser tube inside diameter [from Property Section, $f t]$

$\mu_{1}=$ dynamic viscosity of fresh water $(j=1$ to 6$)$ and sea water at temp $=\left(\mathrm{T}_{\mathrm{cm}}+\mathrm{T}_{\mathrm{cj}}\right) / 2$ [from Property Section, Btu/hr$\cdot f t]$

$P_{r}=\operatorname{Prandt} 1$ number of fresh water $(j=1$ to 6$)$ and sea water at temp $=\left(\mathrm{T}_{\mathrm{cm}}+\mathrm{T}_{\mathrm{cj}}\right) / 2$ [from Property Section]

"Zonal" Variation of Overall Heat Transfer Coefficient Based on Outlet Water Box Temperature Rake

For evaporator, $\mathrm{U}_{\mathrm{e}_{31}}, \ldots, \mathrm{U}_{\mathrm{e}_{44}}$

For condenser, $\mathrm{U}_{\mathrm{c}_{31}}, \ldots, \mathrm{U}_{\mathrm{c}_{44}}$

$\mathrm{U}_{\mathrm{ek}}=\frac{\mathrm{Q}_{\mathrm{ek}}}{\mathrm{A}_{\mathrm{e}} \Delta \mathrm{T}_{1 \mathrm{mek}}} \quad \mathrm{k}=31, \ldots, 44, \mathrm{Btu} / \mathrm{hr} \cdot \mathrm{ft}^{2} .^{\circ} \mathrm{F}$

where $Q_{e k}=\frac{1}{N_{e}} \dot{\mathrm{m}}_{e} C_{p}\left(T_{e i}-T_{e k}\right)$, Btu/hr 


$$
\Delta \mathrm{T}_{1 \mathrm{mek}}=\frac{\left(\mathrm{T}_{\mathrm{ej}}-\mathrm{T}_{\mathrm{ek}}\right)}{\ln \left(\frac{\mathrm{T}_{\mathrm{ei}}-\mathrm{Te}_{\mathrm{e}}}{\mathrm{T}_{\mathrm{ek}}-\mathrm{T}_{\mathrm{e}}^{\prime}}\right)},{ }^{\circ} \dot{\mathrm{F}}
$$

$$
\begin{aligned}
& \mathrm{N}_{\mathbf{e}}=\begin{array}{l}
\text { total number of tubes in evaporator [from Geometry } \\
\text { Section] }
\end{array} \\
& C_{p}=\text { heat capacity. of warm sea water at temp }=\left(T_{e i}+T_{e k}\right) / 2 \\
& \text { [from Property Section, Btu/1b. }{ }^{\circ} \mathrm{F} \text { ] } \\
& 65-90^{\circ} \mathrm{F}, \pm 0.125^{\circ} \mathrm{F} \text { ] } \\
& \mathrm{U}_{\mathrm{ck}}=\frac{\mathrm{Q}_{\mathrm{ck}}}{\mathrm{A}_{\mathrm{c}} \Delta \mathrm{T}_{1 \mathrm{mck}}} \quad \mathrm{k}=31, \ldots, 44, \mathrm{Btu} / \mathrm{hr} \cdot \mathrm{ft}^{2} \cdot{ }^{\circ} \mathrm{F} \\
& \text { where } Q_{c k}=\frac{1}{\mathrm{~N}_{\mathrm{c}}} \quad \dot{\mathrm{m}}_{\mathrm{c}} \mathrm{C}_{\mathrm{p}}\left(\mathrm{T}_{\mathrm{ck}}-\mathrm{T}_{\mathrm{ci}}\right), \mathrm{Btu} / \mathrm{hr} \\
& \Delta T_{1 \mathrm{mck}}=\frac{\left(\mathrm{T}_{c j}-\mathrm{T}_{\mathrm{ck}}\right)}{\ln \left(\frac{\mathrm{T}_{\mathrm{ci}}-\mathrm{T}_{\mathrm{c}}^{\mathrm{c}}}{\mathrm{T}_{\mathrm{ck}}-\mathrm{T}_{\mathrm{c}}^{\mathrm{c}}}\right)},{ }^{\circ} \mathrm{F}
\end{aligned}
$$$$
\mathrm{T}_{\text {ek }}=\text { Individual outlet water box temperature } \operatorname{RTD}[\operatorname{TE} 9(14) \text {, }
$$

$N_{c}=$ total number of tubes in condenser [from Geometry Section ]

$$
\begin{aligned}
C_{p}= & \text { heat capacity of cold sea water at temp }=\left(T_{c i}+T_{c k}\right) / 2 \\
& {\left[\text { from Property Section, } B t u / 1 b \cdot{ }^{\circ}\right. \text { F] }}
\end{aligned}
$$

$\mathrm{T}_{\mathrm{ck}}=$ Individual out let water box temperature RTD [TE15(14), $\left.35-50^{\circ} \mathrm{F}, \pm 0.125^{\circ} \mathrm{F}\right]$

\section{Local Shel1-side Temperature and Pressure Measurements}

For evaporator, $T_{e j}^{\prime}, j=1, \ldots, 10,{ }^{\circ} F$

$$
\mathrm{P}_{e}^{\prime} \text {, one reading, psia }
$$

For condenser, $\mathrm{T}_{\mathrm{c} j}^{\prime}, \mathrm{j}=1, \ldots, 5,{ }^{\circ} \mathrm{F}$

$\mathrm{P}_{\mathrm{C}}^{\prime}$, one reading, psia 
$\mathrm{T}_{\mathrm{e} j}^{\prime}=$ Individual $\mathrm{RTD}$ reading measuring $\mathrm{NH}_{3}$ temperature in evaporator $\left[\operatorname{TE} 7(10), 65-90^{\circ} \mathrm{F}, - \pm 0.125^{\circ} \mathrm{F}\right]$
$\mathrm{P}_{\mathrm{e}}^{\prime}=$ One pressure transducer reading measuring $\mathrm{NH}_{3}$ pressure in evaporator [PE], 110-140 psig, \pm 0.25 psig]

$\mathrm{T}_{\mathrm{c}}^{\prime} \mathrm{j}=$ Individual $\mathrm{RTD}$ reading measuring $\mathrm{NH}_{3}$ temperature in condenser $\left[\mathrm{TE} 14(5), 40-80^{\circ} \mathrm{F}, \pm 0.125^{\circ} \mathrm{F}\right]$

$\mathrm{P}_{c}^{\prime}=$ One pressure transducer reading measuring $\mathrm{NH}_{3}$ pressure in condenser [PE9, 58-75 psig, \pm 0.25 psig]

\section{Zone-by-Zone Condensate Measurements}

Temperature, T'ck, $k=6, \ldots, 10,{ }^{\circ} \mathrm{F}$

$\mathrm{T}_{c k}^{\prime}=$ Individual $\mathrm{RTD}$ reading measuring condensate temperature at five different drain pipes [TE13(5), 4.0-80 $\mathrm{F}, \pm 0.125^{\circ} \mathrm{F}$, not connected to data acquisition system]

Condensate Flowrates, $\dot{\mathrm{m}}_{\mathrm{ck}}^{\prime}, \mathrm{k}=6, \ldots, 10 ; 1 \mathrm{~b} / \mathrm{hr}$

$\dot{\mathrm{m}}_{\mathrm{ck}}^{\prime}=$ : Individual flow meter reading measuring condensate flow rate at five different drain pipes [FT13(5), 0-250 gpm, $\pm 1.0 \%]$

- Evaporator Reflux Tests

- Top Nozzle $\mathrm{NH}_{3}$ Feed Rate and Inlet Temperature

$$
\dot{\mathrm{m}} \mathfrak{f}_{\mathrm{p}}, \mathrm{T}_{\mathfrak{\mathrm { p }}}
$$

m. $\mathfrak{f}_{\mathrm{p}}=$ liquid $\mathrm{NH}_{3}$ feed rate from the sum of two flow meters [FT $1,1000-4000 . \mathrm{gpm}, \pm 1.0 \%$; FT $2,0-2000 \mathrm{gpm}, \pm 1.0 \%$ ]

$\mathrm{T}_{\mathrm{f}_{\mathrm{p}}}^{\prime}=1$ iquid $\mathrm{NH}_{3}$ inlet temperature from one or two RTDs [TE2, $\mathrm{TE} 3,40-80^{\circ} \mathrm{F}, \pm 0.125^{\circ} \mathrm{F}$ ] 
140

- Mid-Plane $\mathrm{NH}_{3}$ Feed Rate and Inlet Temperature

$\dot{m}_{\mathfrak{k}}, \mathrm{T} \mathfrak{\text { fa }}$

$\dot{\mathrm{m}}_{\mathrm{fa}}=1$ liquid $\mathrm{NH}_{3}$ feed rate from one flow meter [FT3, 0-200 gpa, $\pm 1.0 \%$ ] .

T fa $=1 . i q u i d \mathrm{NH}_{3}$ inlet temperature from one RTD . [T EL, $40-80^{\circ} \mathrm{F}, \pm 0.125^{\circ} \mathrm{F}$ ]

- Exit Vapor Superheat

$$
\begin{aligned}
& \Delta \mathrm{T}_{\mathrm{e}}^{\prime}=\mathrm{T}_{\text {eos }}^{\prime}-\mathrm{T}_{\mathrm{e}}^{\prime},{ }^{\circ} \mathrm{F} \\
\mathrm{T}_{\text {eeo }}^{\prime}= & \text { exit } \mathrm{NH}_{3} \text { temperature based on average of } \\
& \text { two RTDS }\left[\mathrm{TE} 6(2), 65-80^{\circ} \mathrm{F}, \pm 0.125^{\circ} \mathrm{F}\right] \\
\mathrm{T}_{e s}^{\prime}= & \text { saturation } \mathrm{NH}_{3} \cdot \text { temperature based on evaporator } \\
& \begin{array}{l}
\text { pressure }[\mathrm{PE} 1,110-140 \text { prig, } \pm 0.25 \text { pig and from } \\
\text { Property Section] }
\end{array}
\end{aligned}
$$

- Reflux Ratio

$$
\begin{aligned}
& \sigma=\frac{\left(\dot{m}_{p}+\dot{m}_{f_{a}}-\dot{m}_{d v}\right)}{\dot{m}_{d v}^{\prime} v} \\
& \sigma \simeq 0-4 ; \text { accuracy } \simeq \pm 2.0 \%
\end{aligned}
$$




\section{HEAT EXCHANGER GEOMETRY}

A eo Total evaporator heat transfer area based on tube outside diameter, $\mathrm{ft}^{2}$

$A_{\text {co }}$. Total condenser heat transfer area based on tube outside.. diameter, $\mathrm{ft}^{2}$

$\mathrm{N}_{e}$ Number of tubes in evaporator

$\mathrm{N}_{\mathrm{c}}$ Number of tubes in condenser

$A_{e}$ Total heat transfer area based on the outside surface of one evaporator tube; $\mathrm{ft}^{2}$

A Total heat transfer area based on the outside surface of one condenser tube, $\mathrm{ft}^{2}$

$\mathrm{d}_{\mathrm{e}} \mathrm{i}$ Inside diameter of evaporator tube, $\mathrm{ft}$

$\mathrm{d}_{c i}$ Inside diameter of condenser tube, $\mathrm{ft}$ 
PHYSICAL PROPERTIES

PROPERTIES OF SEA-WATER

From Saline Water conversion, Engineering Data Book, Second Edition, prepared by the M.W. Kellogg. Company for the Office of Saline Water, U.S. Department of the Interior, 1971 .

A11 at $3.5 \%$ Salt Concentration

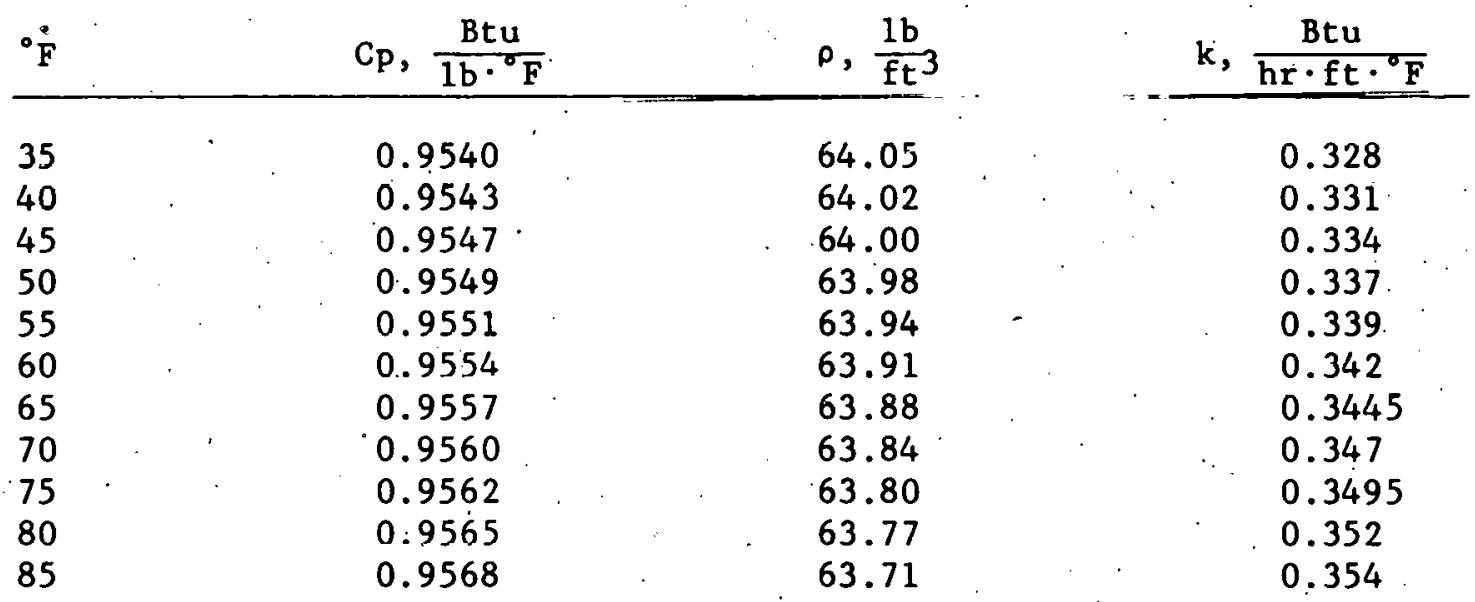

From Tables of Coefficients for A.T.T.C. Model - Ship Correlation and Kinematic Viscosity and Density of Fresh and Salt Water, Technical and Research Bulletin No. 1-25, Society of Naval Architects and Marine Engineers, New York, 1964.

Al1 at $3.5 \%$ Salt Concentration

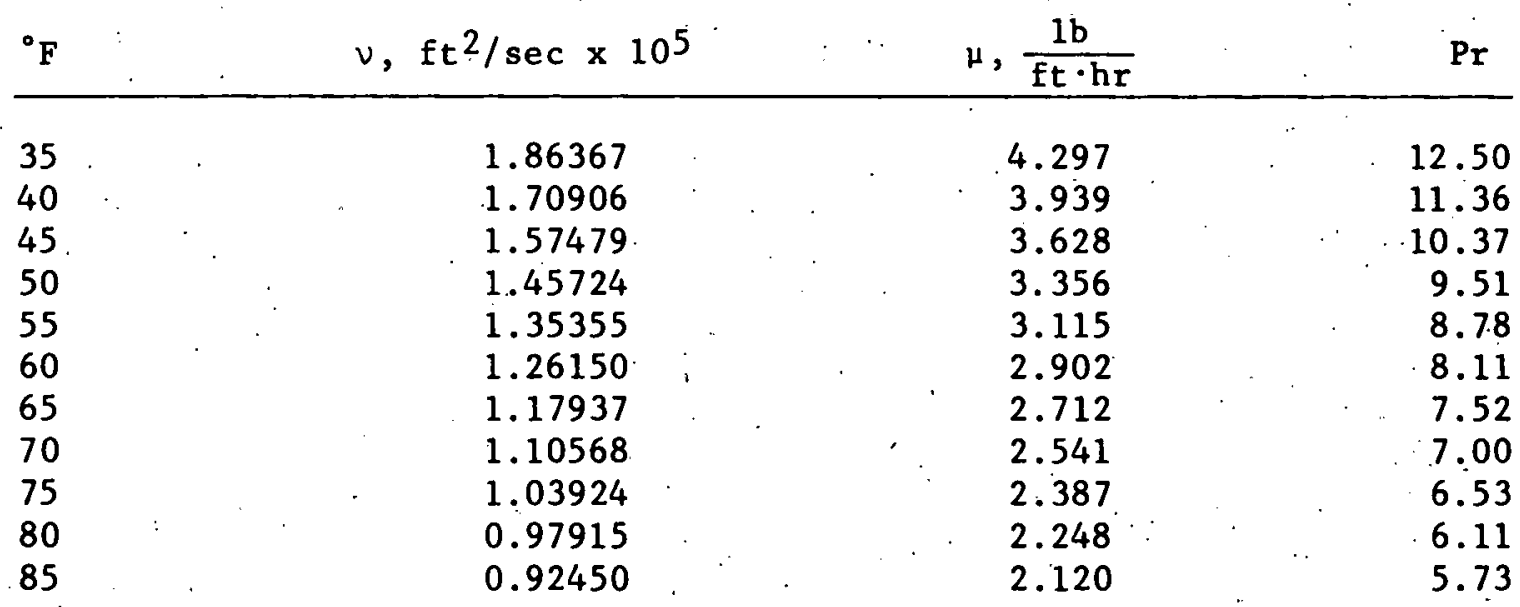




\section{PROPERTIES OF FRESH WATER}

From Frank Kreith, Principles of Heat Transfer, Table A-3. International Text Book Company, Scranton, PA, 1958.

\begin{tabular}{|c|c|c|c|c|c|c|}
\hline${ }^{\circ} \mathrm{F}$ & $C P ., \frac{B t u}{1 b \cdot{ }^{\circ} F}$ & $\therefore \quad \rho, \frac{1 b}{\mathrm{ft}^{3}}$ & $\kappa$, & $\frac{\mathrm{Btu}}{\mathrm{hr} \cdot \mathrm{ft} \cdot{ }^{\circ} \mathrm{F}}$ & $\mu, \frac{1 \mathrm{~b} \cdot}{\mathrm{hr} \cdot \mathrm{ft}}$ & $\operatorname{Pr}$ \\
\hline 32 & 1.010 & 62.4 & & 0.319 & 4.32 & 13.7 \\
\hline 40 & 1.000 & 62.4 & & 0.325 & 3.74 & 11.6 \\
\hline 50 & 1.000 & 62.4 & & 0.332 & 3.17 & 9.55 \\
\hline 60 & 0.999 & 62.3 & & 0.340 & 2.74 & 8.03 \\
\hline 70 & 0.998 & 62.3 & & 0.347 & 2.37 & 6.82 \\
\hline 80 & 0.998 & 62.2 & & 0.353 & 2.08 & 5.89 \\
\hline 90 & 0.997 & 62.1 & & 0.359 & 1.85 & 5.13 \\
\hline 100 & 0.998 & 62.0 & & 0.364 & 1.65 & 4.52 \\
\hline
\end{tabular}

$$
\begin{aligned}
& \text { PROPERTIES OF AMMONIA } \\
& \begin{aligned}
\mathrm{C}_{\mathrm{p} 1}^{\prime}= & \text { Specific heat of liquid ammonia as a function of temperature, } \\
& \mathrm{Btu} / 1 \mathrm{~b} \cdot{ }^{\circ} \mathrm{F}
\end{aligned} \\
& =6.2837 \times 10^{-2}+6.2936 \times 10^{-3}\left(t^{\prime}\right)-1.4071 \times 10^{-5}\left(t^{\prime}\right)^{2} \\
& +1.1296 \times 10^{-8}\left(t^{\prime}\right)^{3}
\end{aligned}
$$

where

$$
\begin{aligned}
& t^{\prime}=T^{\prime}+459.67,{ }^{\circ} \mathrm{R} \\
& T^{\prime}=1 \text { iquid ammonia temperature, }{ }^{\circ} \mathrm{F}
\end{aligned}
$$

For example:

$\begin{array}{cc}\mathrm{T}^{\prime}\left({ }^{\circ} \mathrm{F}\right) & \mathrm{C}_{\mathrm{P} 1}^{\prime}\left(\mathrm{Btu} / 1 \mathrm{~b} \cdot{ }^{\circ} \mathrm{F}\right) \\ 30 & 1.097 \\ 40 & 1.104 \\ 50 & 1.111 \\ 60 & 1.119 \\ 70 & 1.127 \\ 80 & \\ 90 & 1.137 \\ & 1.147\end{array}$


PROPERTIES OF AMMONIA (Cont'd)

$\mathrm{C}_{\mathrm{pv}}^{\prime}=$ Specific heat of saturated ammoria vapor as a function of temperature; $\mathrm{Btu} / 1 \mathrm{~b} \cdot{ }^{\circ} \mathrm{F}$

$\begin{array}{rc}\mathrm{T}^{\prime}\left({ }^{\circ} \mathrm{F}\right) & \mathrm{C}_{\mathrm{pv}}^{\prime}\left(\mathrm{Btu} / 1 \mathrm{~b} \cdot{ }^{\circ} \mathrm{F}\right) \\ 20 & 0.620 \\ 40 & 0.655 \\ 60 & 0.698 \\ 80 & 0.750 \\ 100 & 0.8114\end{array}$

ASHRAE Handbook of Fundamentals, Chapter 14, p. 268, Table 15.

$$
\begin{aligned}
h_{f g}^{\prime}= & \text { Latent heat of ammonia as a function of temperature, } \\
& B t u / 1 b \\
= & 560.96+0.78079\left(t^{\prime}\right)-1.6628 \times 10^{-3}\left(t^{\prime}\right)^{2}
\end{aligned}
$$

where

$$
\begin{aligned}
& \mathrm{t}^{\prime}=\mathrm{T}^{\prime}+459.67,{ }^{\circ} \mathrm{R} \\
& \mathrm{T}^{\prime}=\text { ammonia temperature, }{ }^{\circ} \mathrm{F}
\end{aligned}
$$

For example:

$$
\begin{aligned}
& \mathrm{T}^{\prime}\left({ }^{\circ} \mathrm{F}\right) . \quad \mathrm{h}_{\mathrm{fg}}^{\prime}(\mathrm{Btu} / 1 \mathrm{~b}) . \\
& 30 \quad 544.6 \\
& 40 \quad 535.9 \\
& 50 \quad 527.0 \\
& 60 \div \quad 517.7 \\
& 70 \quad 508.0 \\
& 80 \quad 498.0 \\
& 90 \quad 487.7 \\
& \mathrm{~T}_{\text {sat }}^{\prime}=\text { Saturation temperature as a function of pressure, }{ }^{\circ} \mathrm{F} \\
& \begin{array}{lc}
T^{\prime} & \begin{array}{c}
\text { Absolute } \\
\text { sat }
\end{array} \\
\left({ }^{\circ} \mathrm{F}\right) & \begin{array}{c}
\text { Pressure } \\
\text { (psia) }
\end{array} \\
35 & 66.26 \\
40 & 73.32 \\
45 & 80.96 \\
50 & 89.19 \\
55 & 98.06 \\
60 & 107.6 \\
65 & 117.8 \\
70 & 128.8 \\
75 & 140.5 \\
80 & 153.0
\end{array}
\end{aligned}
$$




\section{EVAPORATOR SENSOR LOCATIONS}

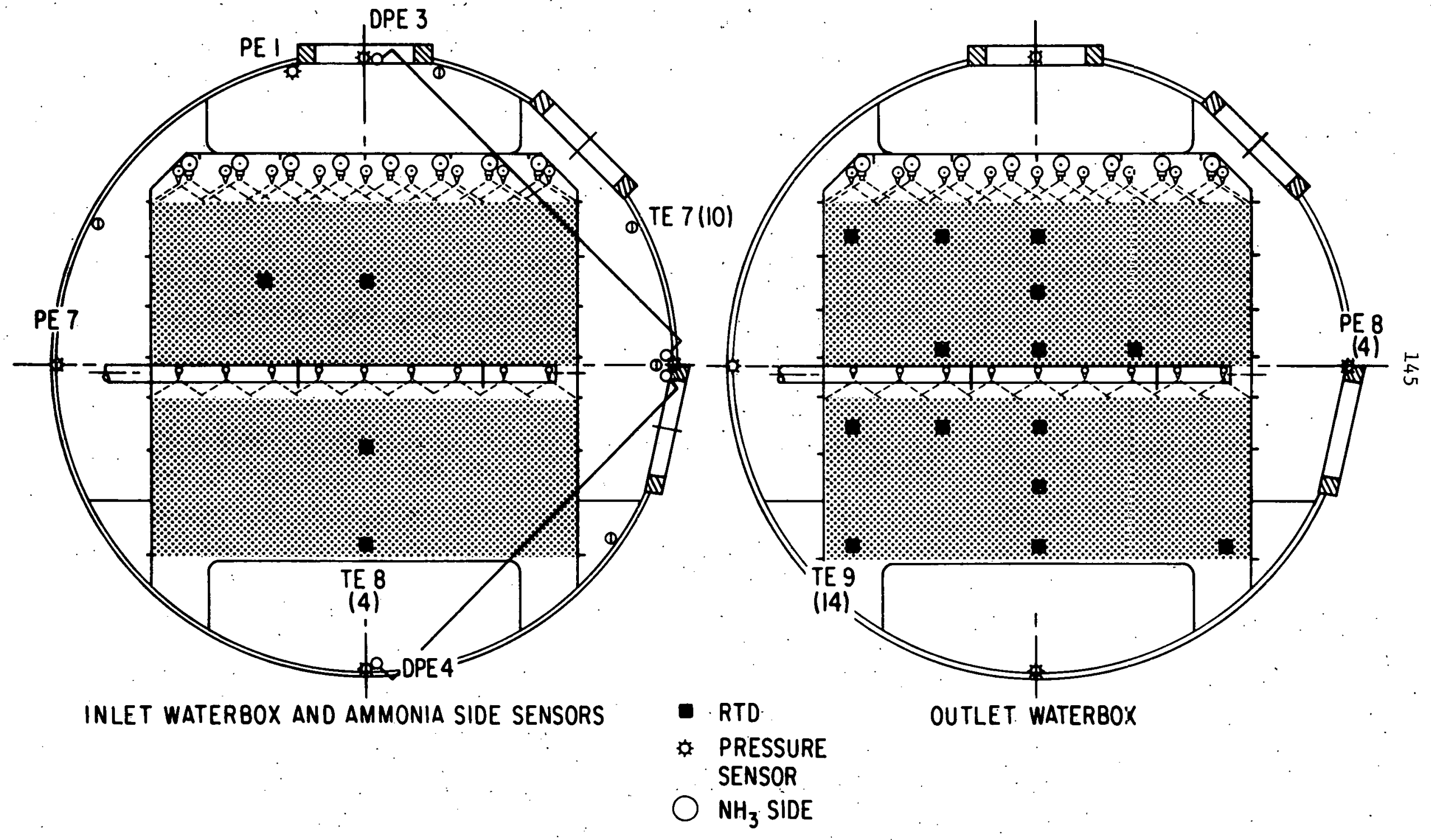




\section{EVAPORATOR AMMONIA SIDE INSTRUMENTATION}

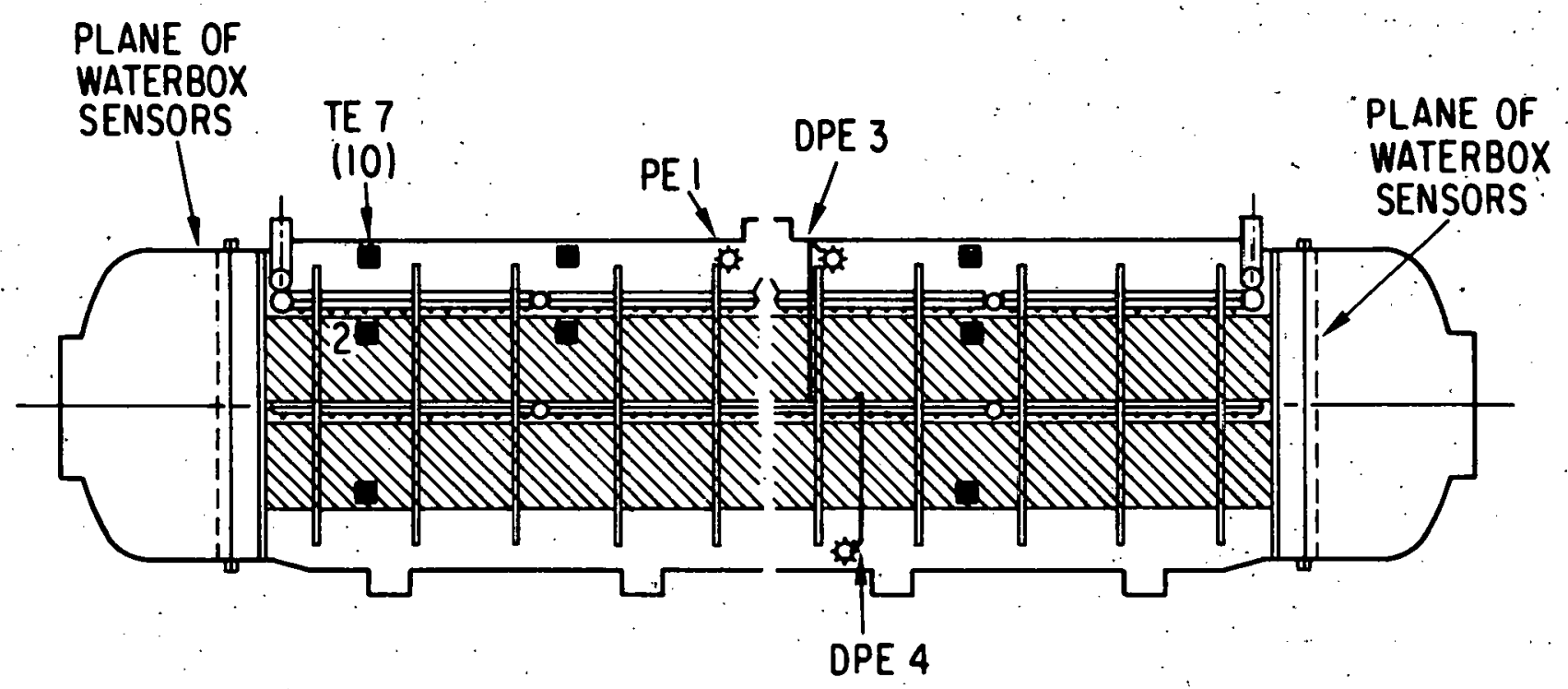

- RTD

* PRESSURE SENSOR 


\section{CONDENSER SENSOR LOCATIONS}

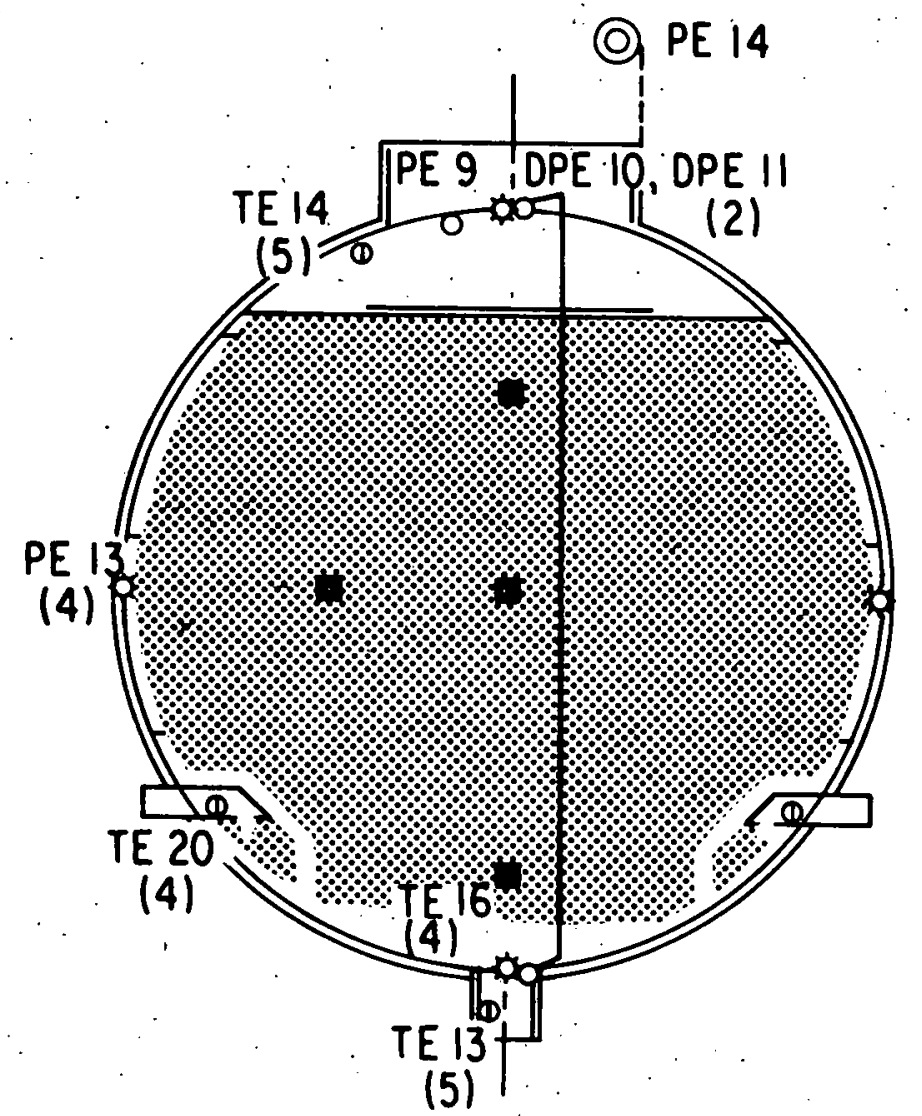

INLET WATERBOX AND AMMONIA SIDE SENSORS

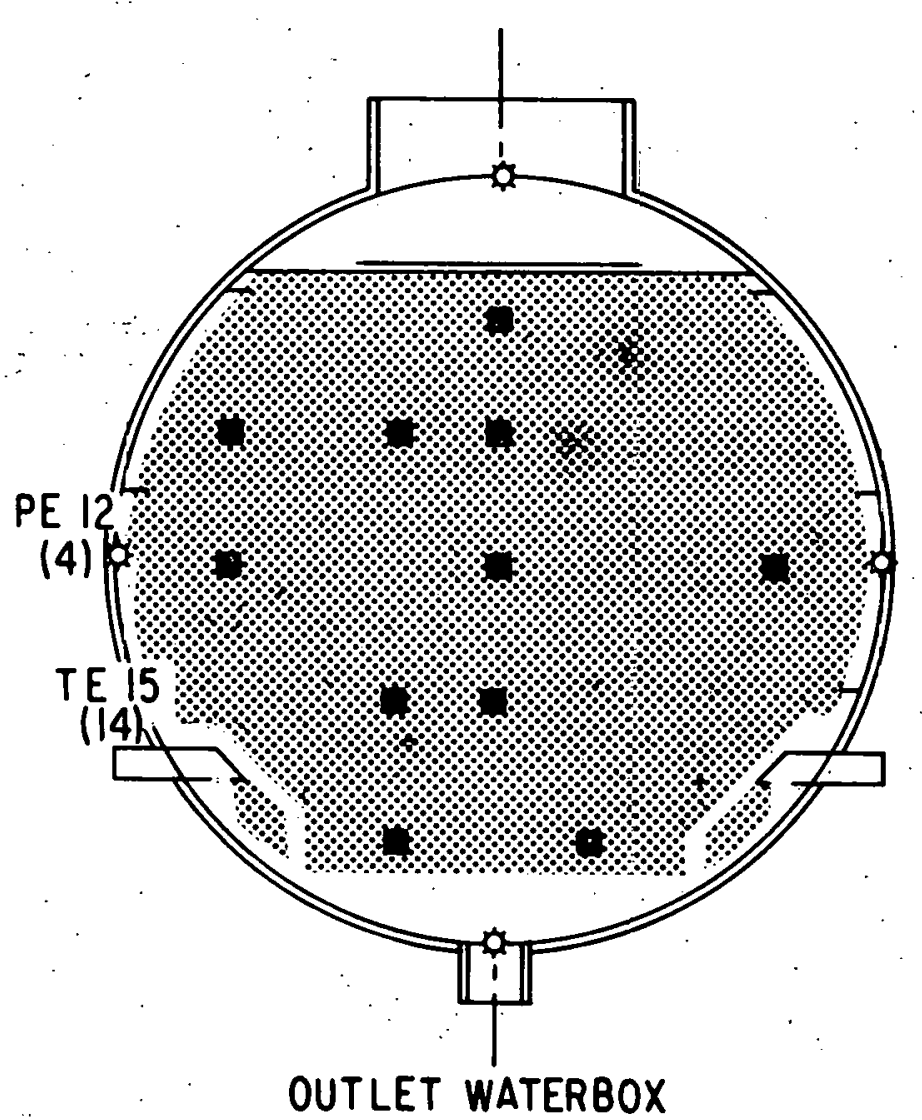

- RTD

* PRESSURE SENSOR

O. $\mathrm{NH}_{3}$ SIDE 


\section{CONDENSER AMMONIA SIDE INSTRUMENTATION}

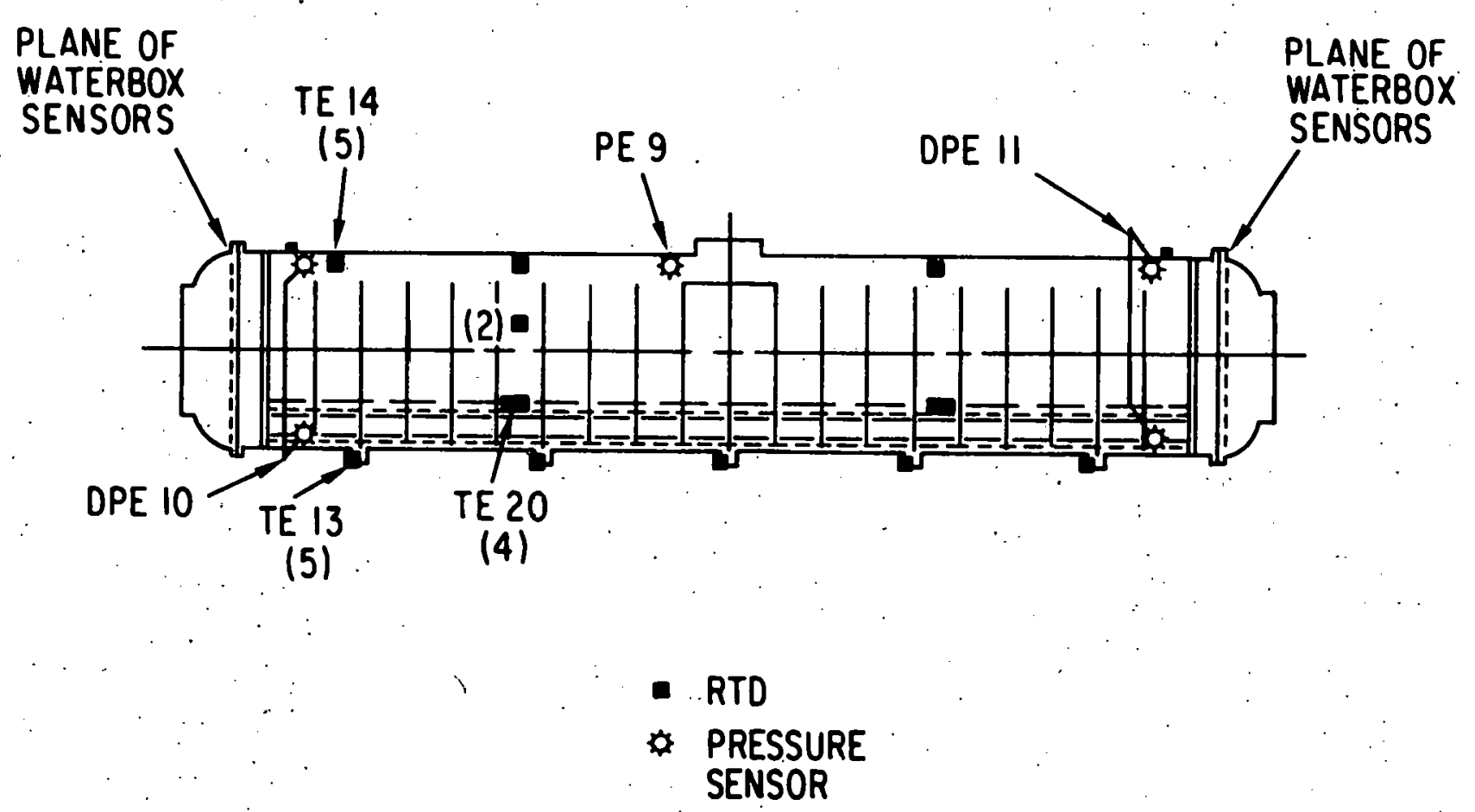

PRESSURE SENSOR 


\section{DEMISTER}
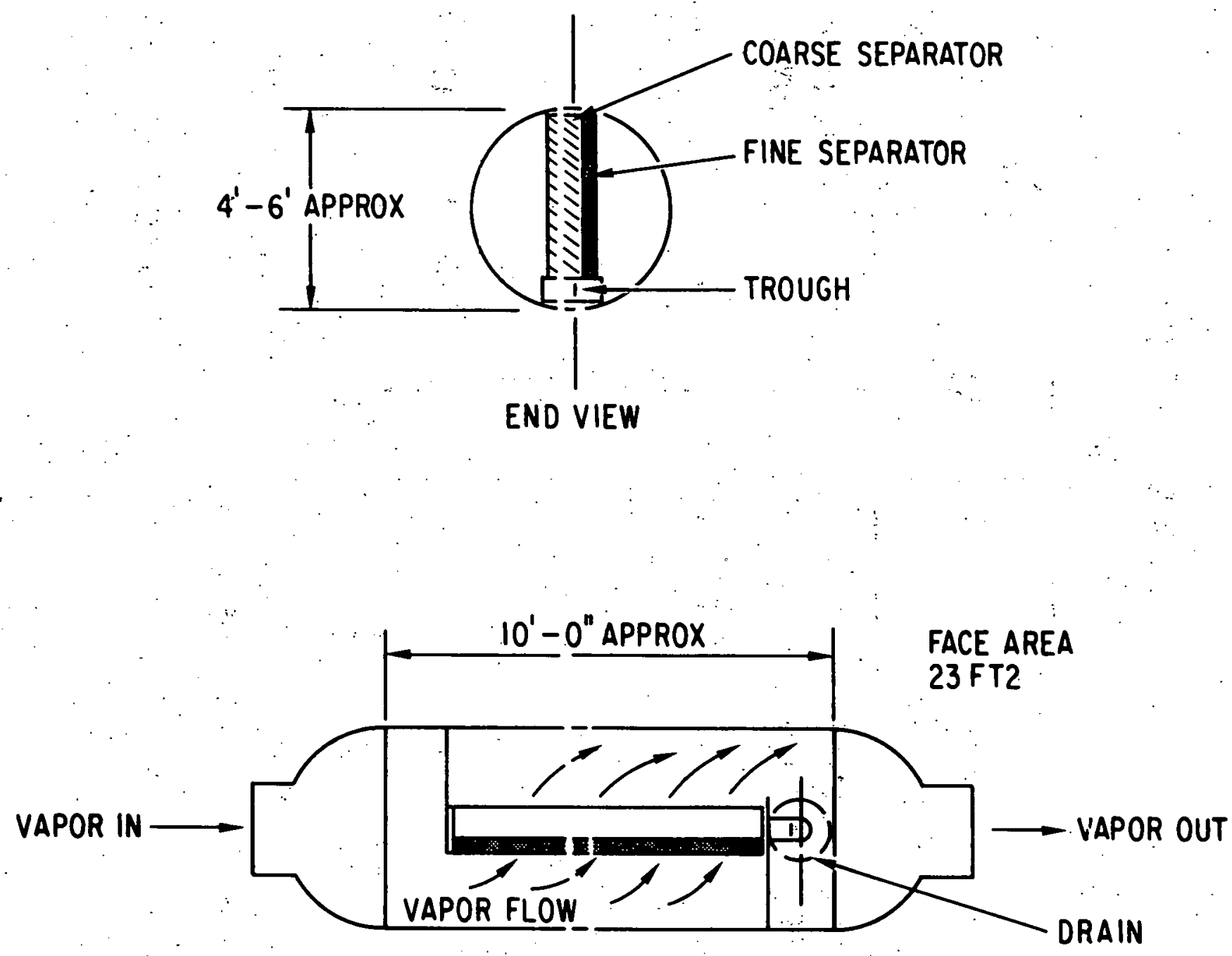

TOP VIEW 


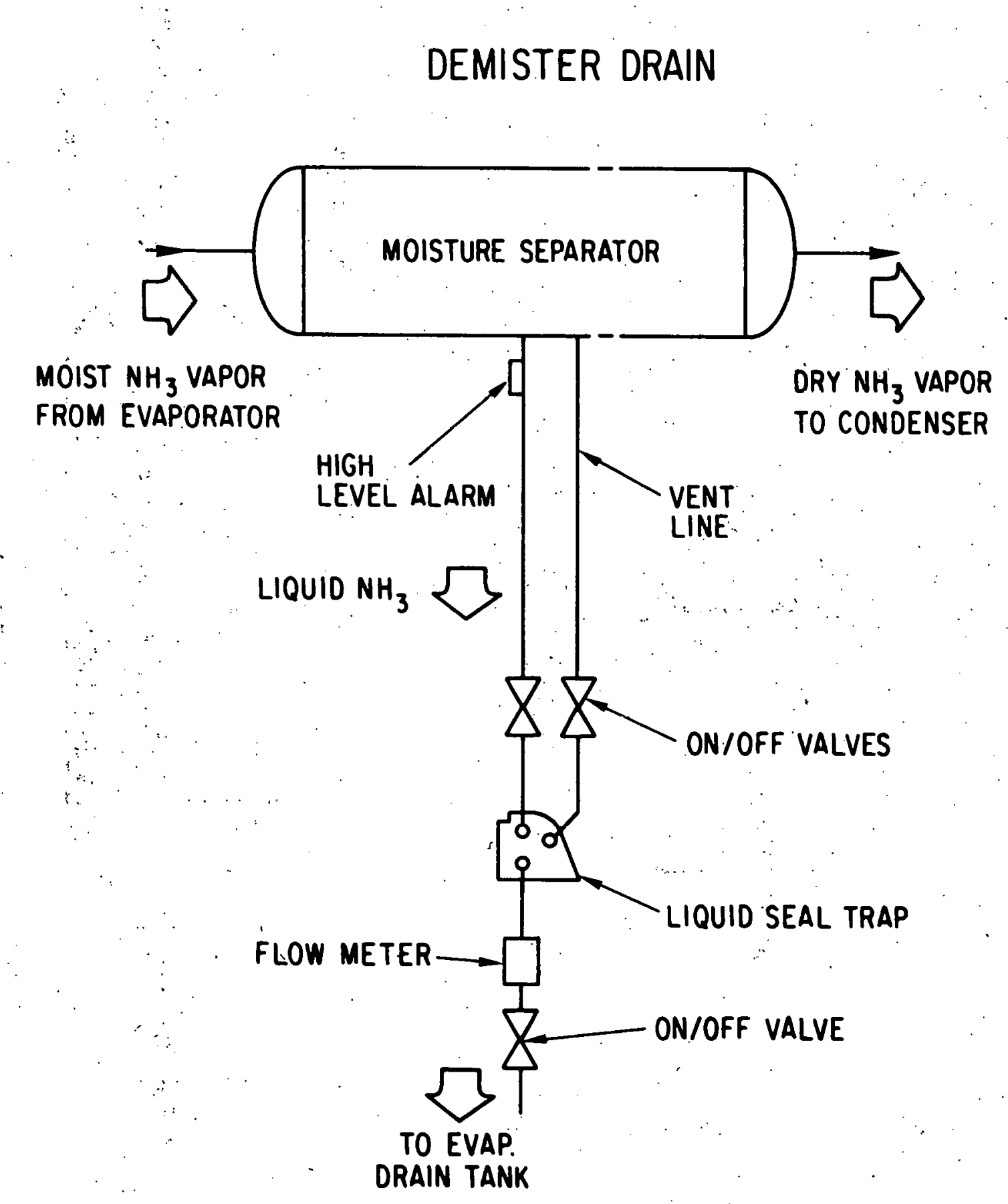




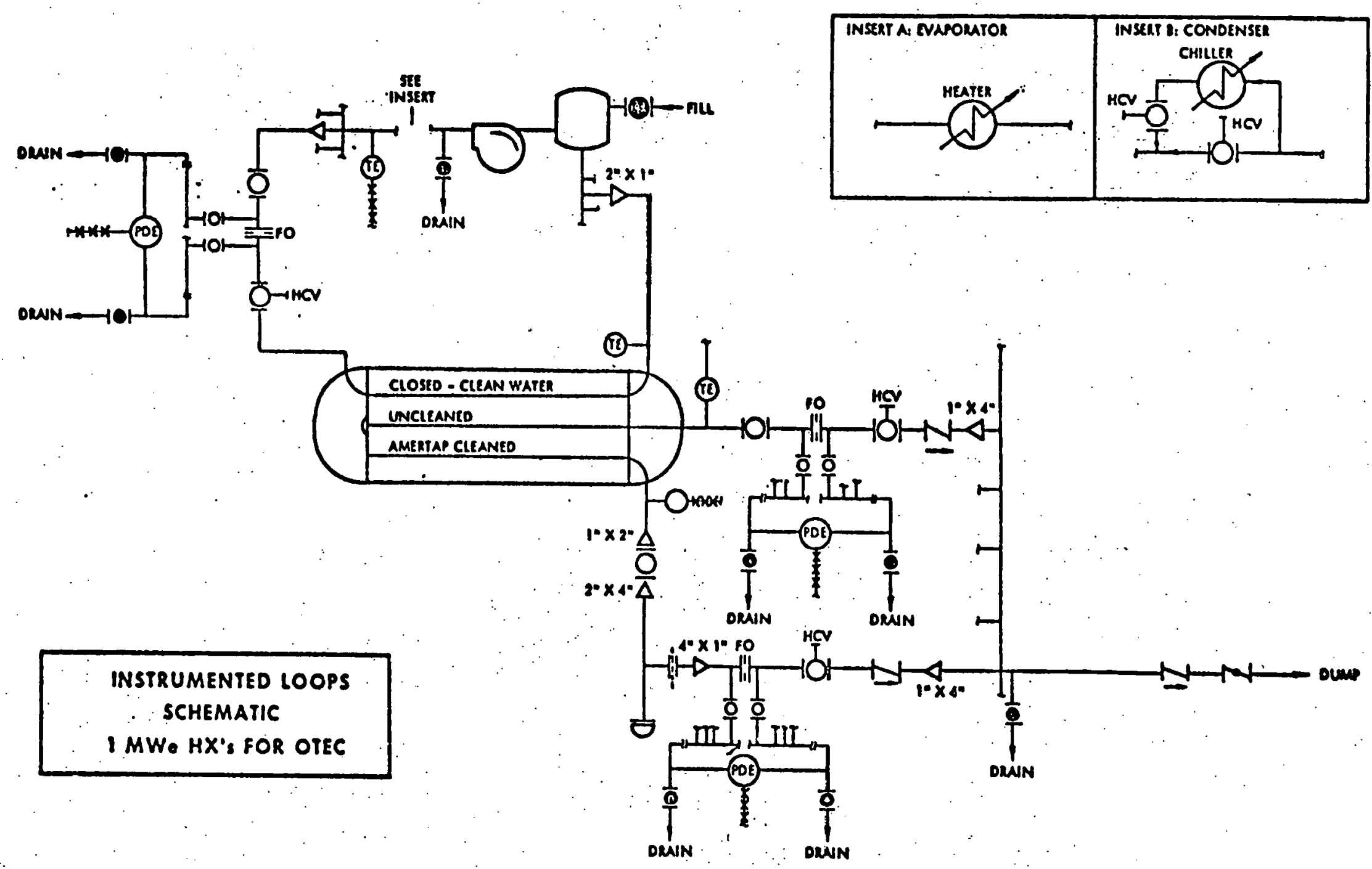

Instrumented Loops Schematic I MHe HX's for OTEC 
Internal:

H. Abelson

E. Beckjord

F.C. Bennett

P.H. Benson

C. Brzegowy

T.R. Bump

P.S. Chopra

J.M. Clinch

R. Combs

E.J. Croke

J.B. Darby

F.H. Davis

S. Davis

J.D. Ditmars
J.E. Draley

J.J. Dzinge 1

B. Frost

A.P. Gavin

D.L. Hillis

P. Howard

D. Hulet

W. Kann

A.B. Krisciunas

T. Kuzay

L.G. Lewis

J.J. Lorenz

K.S. Macal

W.E. Massey
D. McCown

E.G. Pewitt

G.F. Popper

J.J. Roberts.

G.S. Rosenberg

N.F. Sather (133)

H. Stevens

A. Thomas

D.T. Yung

R.S. Zeno

R.A. Zussman

ANL Contract File

ANL Libraries (5)

TIS Files (6)

\section{External:}

DOE-TIC, for distribution per UC-64 (386)

Manager, Chicago Operations and Regional office, DOE

Chief, Office of Patent Counsel, DOE-CORO

President, Argonne Universities Association

Energy and Environmental Systems Division Review Committee:

W.C. Ackermann, U. Illinois

E.E. Angino, U. Kans as

B.A. Egan, Environmental Research and Technology, Inc.

R.E. Gordon, U. Notre Dame

W.W. Hogan, Harvard U.

W.N: Poundstone, Consolidation Coal Co.

L.H. Roddis, Jr., Charleston, S.C.

G.A. Rohlich, U. Texas at Aust in

R.A. Schmidt, Booz, Allen, \& Hamilton

J.J. Stukel, U. Illinois

Components Technology Division Review Committee:

D. Berg, Carnegie-Mellon U.

F.W. Buckman, Consumers Power Co.

P.F. Cunniff, U.: Maryland

C.H. Kruger, Jr., Stanford U.

M.A. Schultz, Pennsylvania State U.

A. Sesonske, Purdue U.

Y.C.L.S. Wu, U. Tennessee Space Inst.

Alfa-Laval Thermal, Inc."

J. Conneli

J.E. Yaffo

J.H. Anderson, Sea Solar Power, Inc.

K.J. Bel1, Oklahoma State U.

A. Bergles, Iowa State U.

Carnegie-Mellon U.

J. Fetkovich

R. Rothfus

A. Westerberg

R.S. Dalrymple, Reynolds Metals 
G.J. Danek, Consultant, Annapolis, Md.

Department of Energy

C. Castellano

R. Cohen

S. Gronich (12)

M. Katz

E.H. Kinelski

L. Lewis

B. Miller

W. Richards

P. Ritrcoven

DOE/CORO

F. Herbaty (12)

J. Horowitz

R. Mayes

DOE/SAN

J. Hartman

D.E. Neely

R. Salazar

Dow Chemical Co.

W.D. Grimes

C.F. Schrieber

R. Dunne, Decision Planning Corp.

EG\&G

L. Hall

D. Fry

Electrotechnical Laboratory, Japan

T. Homma

T. Kajikawa

Energy Technology and Engineering Center

P. Archbold

R. Glumace

A. Klein

D. Polino

F. Poucher (12)

K. Robinson

E.N. Ganic, U. Illinois

General Electric Co.

R. Hindle

M.G. Olmsted

P.B. Pribis

J.H. Gibbons, U.S. Congress, Office of Technology Assessment

L.W. Hallanger, Research Corp., U. Hawaii

G.K. Hart, DSS Engineers, Inc.

R.N. Hazelwood, Global Marine

J. Hirshman, New York Institute of Technology

International Nickel Company

T.S. Lee

R. Lewis

Johns Hopkins U./Applied Physics Laboratory

R. Cusick

J. Funk

J. George *

$\mathrm{J}$ : Keirsey 

R. Makof ski

D. Richards

H. Kamogowa, Toshiba Corp., Japan

D.E. Kash, USGS, Reston, Va.

J. Knudsen, Oregon State U.

Lawrence Berkeley Laboratory

\section{P. Wilde}

V. Harms

A. Lavi, ERDI, Inc.

F.L. La Que, Verona, N.J.

B. Little, Naval Oceanic Research and Development Activity (NORDA)

Lockheed Missiles and Space Co.

R. Conti

R. Fuller

M. Leitner

$B$. Messinger

F. Naef

W.L. Owens

L. Trimble

D. Lott, Naval Coastal Systems Center (NCSC)

P. Marto, Naval Post Graduate School

J. Maurer, Allegheny Ludlum

R.A. Meyer, OTEC Liaison.

R. Mitchell, Harvard U.

J. Morse, U. Miami

R.S.C. Munier, Tracor Marine NOAA

T. McGuinness

R. Scotti

Oak Ridge National Laboratory

R. Lyon

J. Michel

R. Murphy

T.B. O'Neill, Civil Engineering Laboratory

Rand Corp.

C. Gazley

R. Pei

K. Read, U.S. Naval Academy

Rockwel1 International

\section{M.T. Constant ine}

W.R. Wagner

D. Wright

A. Rosenbiad, Rosenblad Corp.

C.M. Sabin, Geoscience, Ltd.

M.D. Sands, Interstate Electronics Corp.

J. Sangiovani, United Technologies Research Center

D. Sasscer, U. Puerto Rico

R. Scott, Gibbs \& Cox

Solar Energy Research Institute (SERI)

P. Davidoff

F. Kreith

D. Johnson

- T. Penny

D. Petty

S. Pohlman

B. Shelpuk 
F. Spiehler, NOAA Data Buoy office (NDBO)

T..J. Summerson, Kaiser Aluminum

R.B. Teel, Teel \& Associates

L.A. Toth, Alexander Systems Co.

Trane Co.

D. Ashworth

H. Foust

TRW

J. Denton

R. Douglass

J. Kaellis

E. Snyder

A. Sprouse

H. Uehara, Saga U., Japan

Union Carbide Corp.

A. Czikk

H. 'Fricke

P. O'Neill

U. Hawai i

R. Berger

$\mathrm{J}$. Larson-Basse

B. Liebert

E.K. Noda

J. Shupe

$P$. Yuen

U. Massachusetts

W. Heronemus

J. McGowan

VSE

J. Saldky

J. Obradovich

E.T. Wanderer, Alcoa Aluminum

R. Webb, Pennsylvania State U.

Westinghouse Electric Corp.

E. Barsness

J. Gertz

T.E. Little

P. Ritland

D.C. White, Florida State U.

H. White, National Energy Laboratory of Hawaii (NELH)

R.E. Williams :III, PRC Energy Analys is Co.

J.F. Yampolsky, General Atomic Co. 